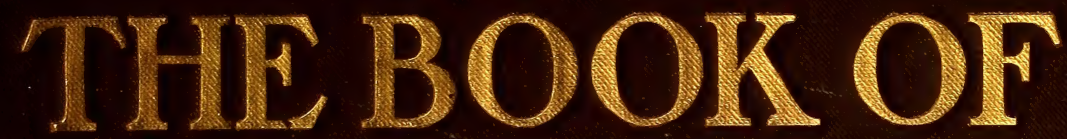

A L F A L F

F.D.COBURN 
๘ 







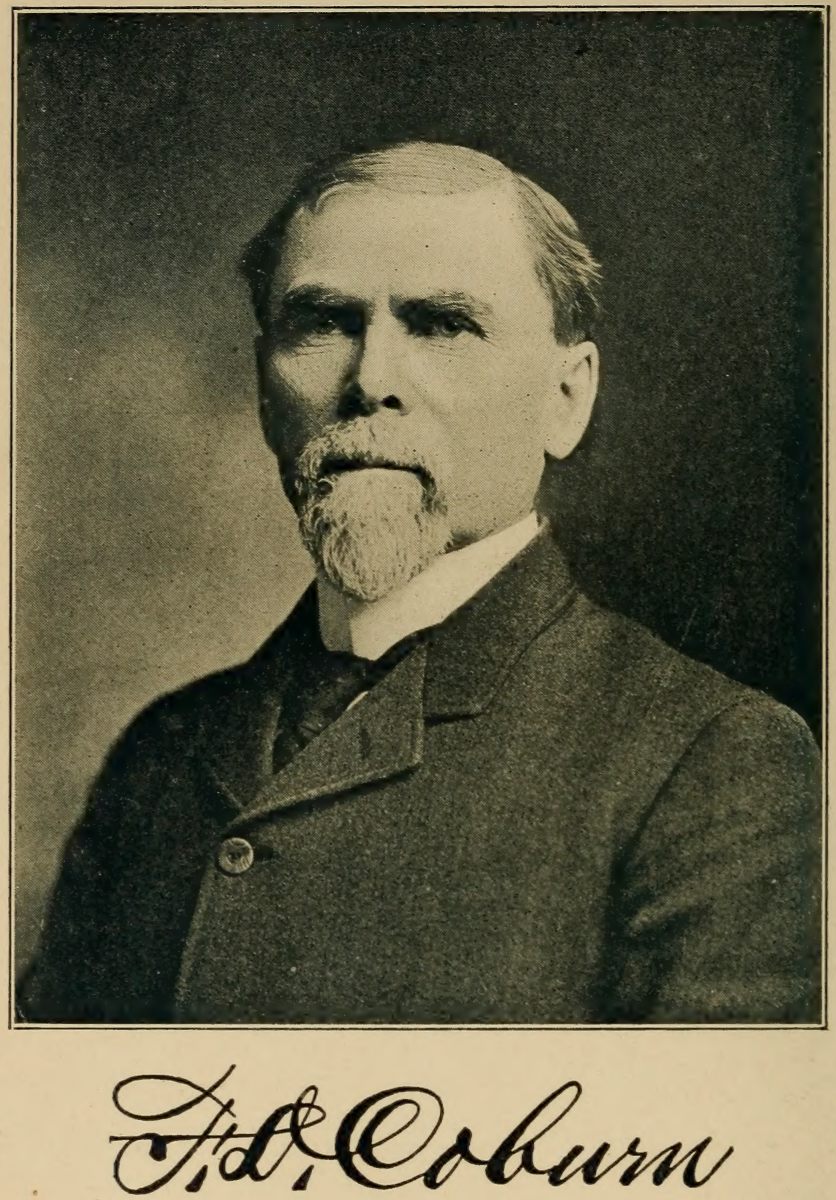

It is the pleasure of the publishers to present to those who are interested in alfalfa, the man who declined an appointment as United States Senator, that he might continue to direct the affairs of the Kansas State Board of Agriculture in general and of farmers in particular.Orange Judd Company. 


\section{The Book of Alfalfa \\ HISTORY, CULTIVATION AND MERITS. \\ ITS USES AS A FORAGE \\ AND FERTILIZER.}

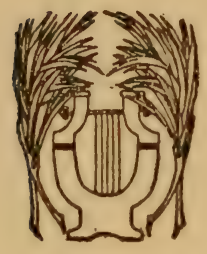

**** Spanish clover, such as has

Usurped the Occident and dwells

On Sacramento's sundown hills,

And all the verdant valley fills

With fragrance sweet and delicate

As wooing breath of woman is.

- Joaquin Miller.

\section{By F. D. COBURN}

Secretary Kansas Department of Agriculture.

Illustrated

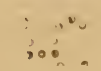

1907

ORANGE JUDD COMPANT

New York 

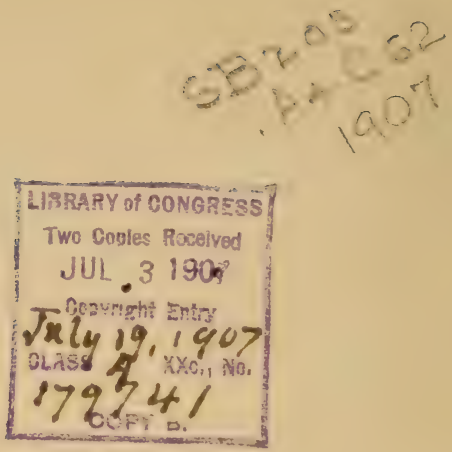

Copyright, 1906 by Orange Judd Company

New Revised Edition Copyrighted 1907 by Orange JudD Company

All Rights Reserved

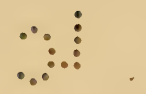


THERE ARE SOME SILENT SUBSOILERS THAT DO THEIR WORK WITH EASE, AND IN THEIR WAY, MORE EFFECTUALLY THAN ANY TEAM OR PLOW EVER HITCHED. THE CLOVER PLANT IS RIGHTEOUSLY FAMED AS ONE OF THESE, BUT ALFALFA IS ITS SUPERIOR. ITS ROOTS WORK' SUNDAY AS WELL 'AS SATURDAY, NIGHT AND DAY; THEY STRIKE 5, 10, 15 OR 20 FEET DEEP, MAKING INNUMERABLE PERFORATIONS, WHILE STORING UP NITROGEN, AND WHEN THESE ROOTS DECAY THEY LEAVE NOT ONLY A GENEROUS SUPPLY OF FERTILITY FOR ANY DESIRED CROP, BUT MILLIONS OF OPENINGS INTO WHICH THE AIR AND RAIN OF HEAVEN FIND THEIR WAY, AND HELP TO CONSTITUTE AN UNFAILING RESERVOIR OF WEALTH, UPON WHICH THE HUSBANDMAN CAN DRAW WITH LITTLE FEAR OF PROTEST OR OVERDRAFTS.
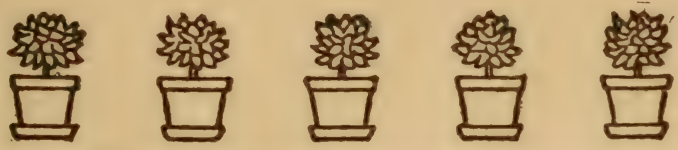

"Its long, branching roots penetrate far down, push and crowd the earth this way and that, and thus constitute a gigantic subsoiler. These become an immense magazine of fertility. As soon as cut, they begin to decay and liberate the vast reservoir of fertilizing matter below the plow, to be drawn upon by other crops for years to come" 


\section{The Author's Foreword}

This volume, however strong its statements in favor of alfalfa may appear to those unacquainted with that plant's productivity and beneficence, is by no means presented as an argument that everyone should raise alfalfa. It is intended rather as a conservative setting forth of what others have found alfalfa to be and do under wide variations of soil, climate, condition and locality; of its characteristics and uses; the most approved methods of its raising and utilization, and the estimates of it by those who have known it most intimately and longest as a farm forage crop and a restorer, and renovator of the soil.

The author believes in alfalfa; he believes in it for the big farmer as a profit-bringer in the form of hay, or condensed into beef, pork, mutton, or products of the cow ; but he has a still more abiding faith in it as a mainstay of the small farmer; for feed for all his live stock and for maintaining the fertility of the soil.

To avoid the appearance of both special pleading and exaggeration the statements have been guarded, and many of a laudatory nature, which fully authenticated facts seemed to justify, have been omitted, as neither the author nor the publishers have desire or willingness to extol unduly a commodity so little needing it as that of which the volume treats. Alfalfa's strongest commendations are invariably from those who know it best; none are incredulous who know it well, and none have grown it but wished their acreage increased.

F. D. COBURN.

Topeka, Kansas.

I906 


\title{
Introductory
}

BY

\section{Former Governor W. D. Hoard, of Wisconsin}

\author{
Editor Hoard's Dairyman
}

I am exceedingly gratified by the preparation and publication of a new and larger work devoted to the subject of Alfalfa The earlier effort by Mr. Coburn upon the same subject was in many respects a classic, and I am sure farmers everywhere will now hail with joy the advent of a kindred work by him, still more complete.

It is strange, this late awakening all over the Union and in Canada to the feeding value and possibilities of this marvelous plant. Again, it is wonderful to me that within a few years farmers everywhere are being compelled to revise their judgment as to their chances of success with it. A large correspondence on this subject comes to me from every state in the Union and the provinces of Canada, and success is being had in the growing of alfalfa where not more than three years ago it was deemed impossible to make it live. Of course the question of growing alfalfa contains a thousand or more chances for good or poor judgment. Men who are not too conceited, too ignorant or too stubborn to learn by reading other men's experience will go ahead rapidly and soon make a success of it.

I believe this alfalfa movement is the most important agricultural event of the century. For the production of 
beef, mutton and milk, the combination of corn ensilage and rightly cured alfalfa hay, furnishes almost a perfect ration, requiring but a small addition of grain feed. Both of these can be cheaply and easily produced on nearly every farm in the land. In my herd of nearly fifty registered and grade Guernsey cows these feeds constitute the sheet anchor of my dairy work.

No one more literally abets the growth of two blades of grass where one grew before than he who effectively urges the cultivation of alfalfa upon those who are strangers to it, and no one is more truly working for the benefit of agriculture, the basis of all prosperity, than he who proclaims its excelience as the foremosi forage.

Hoard's Dairyman will do al' in its power to enhance the circulation and reafing of such a book as Mr. Coburn has made.

\section{W. D. HOARD.}

Fort Atkinson, Wisconsin.

I906

\section{Publisher's Announcement}

All the plates of the "Book of Alfalfa" were destroyed in the disastrous fire that consumed our mechan1cal department January 28, 1907. We have taken advantage of this emergency and present the present volume in a new and revised edition, with the additional material furnished by the author.

ORANGE JUDD COMPANY. 


\section{Table of Contents}

The Ange

Introductory . . . . . . v v

CHAPTER I

History, Description, Varieties and Habits . . I

CHAPTER II

Universality of Alfalfa $\cdot$ CHAPTER III
CHAC

Yields, and Comparisons with other Crops . . 20

CHAPTER IV

Seed and Seed Selection .

CHAPTER V

Soil and Seeding

CHAPTER VI

Cultivation

CHAPTER VII

Harvesting . . . . $\quad$ • 79

CHAPTER VIII

Storing

CHAPTER IX

Pasturing and Soiling . . . . 107

CHAPTER X

Alfalfa as a Feed Stuff . . . . . 125

CHAPTER XI

Alfalfa in Beef-Making . . . . ${ }_{13} 8$

CHAPTER XII

Alfalfa and the Dairy . . . . . 143 
Alfalfa for Swine .

CHAPTER XIV

Alfalfa for Horses and Mules .

CHAPTER XV

Alfalfa and Sheep Raising

CHAPTER XVI

Alfalfa and Bees.

CHAPTER XVII

Alfalfa and Poultry

CHAPTER XVIII

Alfalfa Food Preparations

CHAPTER XIX

Alfalfa for Town and City

CHAPTER XX

Alfalfa in Crop Rotation

CHAPTER XXI

Nitro-Culture

CHAPTER XXII

Alfalfa as a Commercial Factor . . . 204

CHAPTER XXIII

The Enemies of Alfalfa.

CHAPTER XXIV

Difficulties and Discouragements

CHAPTER XXV

Miscellaneous

180 


\section{List of Illustrations}

F. D. Coburn . . . . . . . Frontispiece

A Typical Alfalfa Plant . . . . . . I

Typical Stems and Foliage of the Alfalfa Plant I

Crown of 'Plant Shown in the Preceding Illus-

tration . . . . . . . . . . . 6

An Eight-year-old Alfalfa Plant . . . . 6

Alfalfa Blossoms Enlarged . . . . . . 7

Intergrading Types of Seed Between Alfalfa

and Sweet Clover . . . . . . . 12

Seeds of the Weed Known as Buckhorn . . . I3

Alfalfa Seeds Magnified Five Diameters . . . I3

Sweet Clover-Alfalfa-Yellow Trefoil . . . 26 .

Three Distinctive Types of Alfalfa Seed Mag-

nified Twelve Times . . . . . . . 27

Yellow Trefoil Pods . . . . . . . . $3^{2}$

Alfalfa Seed Pods . . . . . . . . . 32

Bur Clover Seed Pods . . . . . . . . . 33

Sweet Clover Pods . . . . . . . . . . . 33

Three General Types of Alfalfa Seed . . . . 44

Dodder Seed Magnified . . . . . . . . 45

Alfalfa Seed Magnified . . . . . . . . 45

Dodder Plant on an Alfalfa Stem . . . . 46.

Alfalfa and Dodder Seed. (Actual Size) . . 47

Dodder (Cuscuta arvenis) . . . . . . . 47

Dodder (Cuscuta epithymum) . . . . . . 47 
Bur Clover Seed Pod Yellow Trefoil Seed Pod . . . . . . 66 Alfalfa Seed Pod . . . . . . . . 67 Spotted Clover Seed Pod . . . . . . . 67 Gathering Alfalfa Hay into Windrows with a Side-delivery Horserake 78 Cutting a Fine Field of Alfalfa

Alfalfa Harvesting Scene in Yellowstone County, Montana

Gathering an Alfalfa Crop in Page County,

Iowa

A Derrick Stacker

Mast and Boom Stacker, with Six-tined Jackson

Fork

Box Rack for Feeding Alfalfa to Sheep . . . 106

Lattice Rack for Feeding Alfalfa to Cattle . . 106

Box Rack for Feeding Alfalfa to Cattle . . . 107

Lattice Rack for Feeding Alfalfa to Sheep . . IO7

Alfalfa Field in New Jersey . . . . . . I24

A Second Cutting of Alfalfa (July 28) in Shawnee County, Eastern Kansas

Steers Eating Chopped Alfalfa and Corn Meal Mixed

Dorset Ewe Lambs in Alfalfa in Ohio

Showing Advantage of Early Fall Sowing . . I 54

Five-year-old Alfalfa . . . . . . . . 155

Alfalfa One Year Old, Showing Effects of Inoculation . . . . . . . . . . I70.

A Good Type of a Four-year-old Alfalfa Plant . I7I 
Alfalfa Plant and Roots Showing Bacteria Nodules . . . . . . . . . . 196 Tubercles on Clover Roots . . . . . . 197 Nodules on Small Rootlets . . . . . . . 206 Roots Showing Normal Nodules . . . . 207 And There's Still More to Follow . . . . . 220 Dead Prairie Dogs . . . . . . . . . $22 \mathrm{I}$ Pot Culture Experiments at University of Illinois . . . . . . . . . 230 Six Months' Growth of Alfalfa Foliage . . . $23 I$ Putting up Alfalfa Hay . . . . . . . 256

The Hay-loader Picks the Crop up Clean and Quickly . . . . . . . . . . . 256 A Cable Derrick, Provided with a Grapple Fork . 257 A 400-ton Rack of Alfalfa . . . . . . 257 Sweet Clover . . . . . . . . . . 288 Yellow Trefoil . . . . . . . . . . $\quad 289$ 



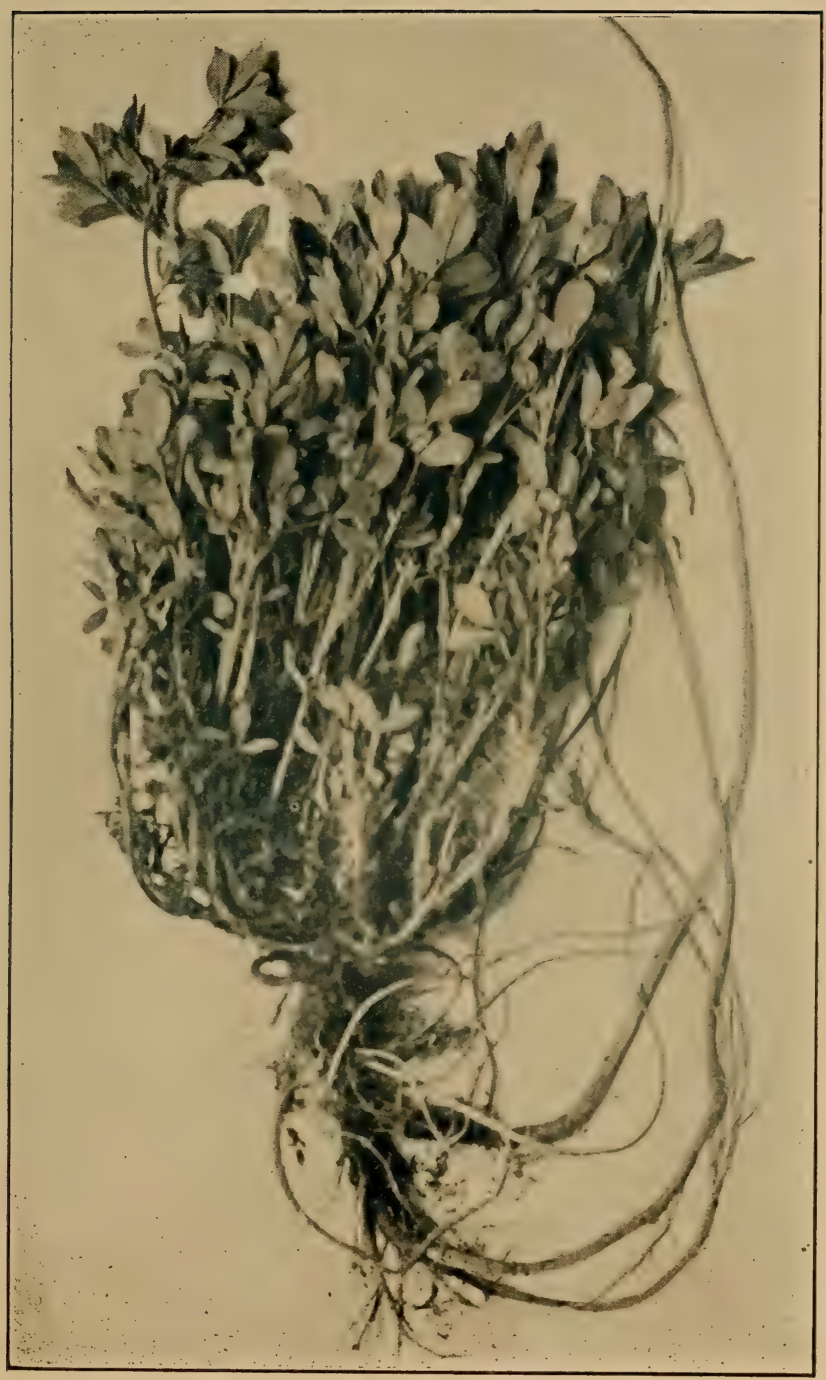

A Typical Alfalfa Plant

as it appears before the blossoms are developed. From Michigan Experiment Station Bulletin No. 225. 


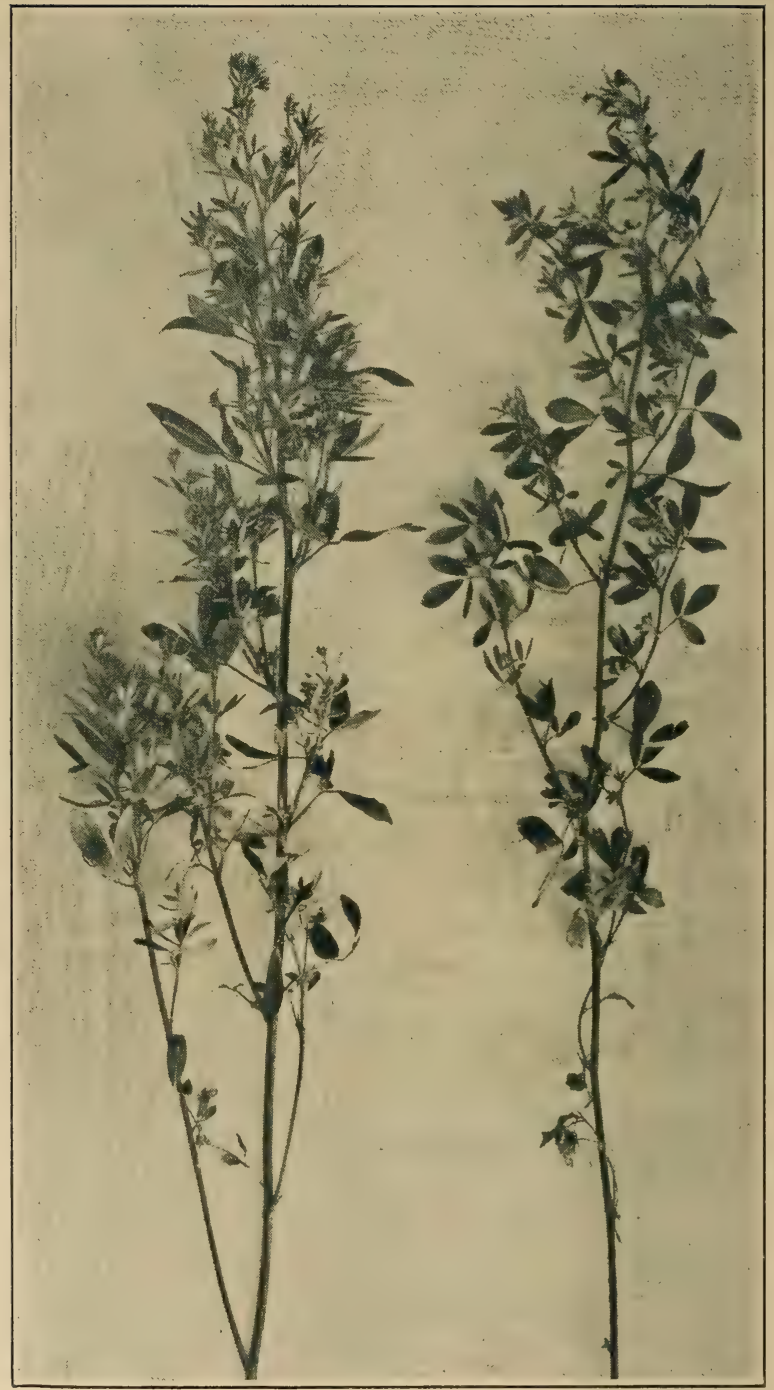

Typical Stems and Foliage of the Alfalfa Plant

when beginning to blossom the most suitable for hay. Grown in Shawnee county, Kansas, on unirrigated upland prairie with a "gumbo" or hardpan subsoil.

From the season's third cutting, August 20; height 24 and 26 inches. 


\title{
$A L F A L F A$ \\ (Medicago sativa, Linn.)
}

\author{
CHAPTER I.
}

\section{History, Description, Varieties and Habits}

\section{HAS ALWAYS BEEN KNOWN}

There appears no record of a time when alfalfa was not in some portions of the world esteemed one of $\mathrm{Na}$ ture's most generous benefactions to husbandry and an important feature of a profitable agriculture. Its beginning seems to have been contemporary with that of man, and, as with man, its first habitat was central Asia, where the progenitors of our race knew its capabilities in sustaining all herbivorous animal life, and where, possibly, it too afforded the herbage which sustained Nebuchadnezzar in his humiliating exile, and eventually restored him to sanity and manhood.

It was carried by the Persians into Greece with the invasion by Xerxes in 490 B. C., utilized by the Romans in their conquest of Greece, and carried to Rome in 146 B. C. Pliny and other writers praise it as a forage plant and it has been in cultivation in parts of Italy continuously from its introduction. Some writers are disposed to aver that it was brought to Spain and France by the Roman soldiery under Casar and early thereafter, but 
more probably it was not introduced into those counties until several centuries later. It is known to have been cultivated in Northern Africa about the time it was first brought to Italy; and the name "alfalfa" being Arabic the inference might be reasonable that it was introduced into Spain by the Moors from Northern Africa at the time of their conquest of Spain about 7 I I A. D., but this is of small consequence to the twentieth century. From Spain it crossed to France, and later to Belgium and England. It was highly spoken of by an English writer of the fifteenth century.

\section{AMERICA INDEBTED TO SPAIN}

But in those ages Europe was not so much interested in agriculture as in war. Land tenures were not well fixed and ownerships were uncertain. Spain, however, was to perform at least two important services for half the world, if none for herself. She was to reveal to civilization a new continent, and give to it the most valuable forage plant ever known. And so, in I519, Cortes, the Spaniard, and his remorseless brigands carried murder, rapine and havoc to Mexico, but gave alfalfa. Less than a score years later Spain also wrote in Peru and Chili some of the bloodiest pages of human history, but left alfalfa there, where it has since luxuriantly flourished. If it was brought to the Atlantic coast of the United States in that century, it was not adopted by the Indian inhabitants, who were not an agricultural people, nor by the early European settlers.

It was not until about I853 or 1854 that it was introduced into northern California, the legends say from Chili, but it had been grown by the Spaniards and 
Indians in southern California for probably a hundred years, having had a gradual migration from Mexico. Strange to relate, while it is even now on the Atlantic coast discussed as a new plant, there is good evidence that it has been in cultivation on a small scale in the Carolinas, New York and Pennsylvania for probably one hundred and fifty years. Certainly there are small fields in those states that have been producing for over sixty years, and there are to be found articles and letters written far earlier showing that it was then known and had been proven. One Spurrier, in a book dedicated to Thomas Jefferson, and written in I793, spoke highly of alfalfa, called "lucerne;" told how it should be cultivated, and that three crops of valuable hay could be cut annually. In the "Transactions of the Society for the Promotion of Agriculture," published at Albany in I80I, it was favorably mentioned, and in the "Farmers' Assistant," printed in Albany in I8I5, alfalfa was praised and the statement made of its yielding 6 to 9 tons of hay per acre "uncler the best cultivation and plentiful manuring." Yet its cultivation did not spread. The inertia of farmers, or perhaps their indifference to new ideas, in the early days must have been marvelous. According to Spurrier the difficulties were not considered greater than now ; he said one planting would survive many years and the yield was three times as great as that of any other forage plant. The seed was no doubt introduced there from England or France; it was probably scarce, and difficult to secure from growings in this country. 


\section{THE NAME AND ITS ORIGIN}

The name "Alfalfa" is from an Arabic word meaning "the best fodder," which honor it can certainly still claim Many writers have assumed that the name "Lucerne" which it bears in France and England, was from the name of the Swiss canton, Lucerne. This is a mistake as it was not known there until long after it was cultivated in France and England. The name is probably from the Spanish word "Userdas" which the French changed to "La-cuzerdo" and later to "Luzerne," still later to "Lizerne" and then to "Lucerne."

Among other names by which alfalfa is known are the following: Lucerne; French Lucerne; French Clover, in part; Mexican Clover, in part; Lucerne Clover; Lucerne Medicago; Alfalfa Clover; Chilian Clover; Brazilian Clover; Syrian Clover; Sainfoin, erroneously; Spanish Trefoil; Purple Medick; Manured Medick; Cultivated Medicago; Medick. Persian, Isfist; Greek, Medicai; Latin, Medica, Herba Medica; Italian, Herba Spagna; Spanish, Melga or Meilga, also (from the Arabic), Alfalfa, Alfasafat; French, La Lucerne; German, Lucerne, Common Fodder, Snail Clover, Blue Snail Clover, Branching Clover, Stem Clover, Monthly Clover, Horned Clover, in part, Perennial Clover, Blue Perennial Clover, Burgundy Clover, Welsh Clover, Sicilian Clover.

Alfalfa belongs to the botanical family Leguminosae, or the legumes, of which there are thousands of species, and is thus related to all clovers, peas, vetches and beans. Its botanical name is Medicago sativa. There are some fifty species of the genus Medicago that are known, but 
alfalfa and one or two others are all that are of practical value as fodders. It is a true perennial plant, smooth, upright, branching, ordinarily growing from one to four feet high, yet in some instances much higher, owing to conditions of soil, climate and cultivation. Its leaves are three parted, each leaflet being broadest about the middle, rounded in outline and slightly toothed toward the apex. The purple pea-like flowers instead of being in a head, as in red clover, are in long, loose clusters or racemes. These are scattered along the plant's stems and branches, instead of being especially borne, as in red clover, on the extremities of the branches. The matured seed-pods are spirally twisted through two or three complete curves, and each pod contains several seeds. The seeds are kidney-shaped, and average about one-twelfth of an inch long by half as thick. They are about onehalf larger than seeds of red clover, and in color are at their best an olive green or a bright egg-yellow, instead of a reddish or mustard yellow, or faded brown. The ends of the seeds are slightly compressed where they are crowded together in the pod.

Alfalfa is very long-lived; fields in Mexico, it is claimed, have been continuously productive without replanting for over two hundred years, and others in France are known to have flourished for more than a century. Its usual life in the United States is probably from ten to twenty-five years, although there is a field in New York that has been mown successively for over sixty years. It is not unlikely that under its normal conditions and with normal care it would well-nigh be, as it is called, everlasting. 


\section{ITS WONDERFUL ROOT SYSTEM}

In its root growth it is probably the greatest wonder among plants. While it usually grows no higher than four or five feet (although it has been known to reach more than ten feet; an unirrigated stalk is on exhibition at the office of the Kansas Board of Agriculture, measuring nearly seven feet) and its normal height is about three feet, its roots go down ten, twenty, or more feet, and one case in Nevada is reported by Charles W. Irish, chief of Irrigation Inquiry United States Department of Agriculture, where the roots were found penetrating through crevices in the roof of a tunnel one hundred and twenty-nine feet below the surface of an alfalfa field. Prof. W. P. Headden of Colorado found roots nine feet long from alfalfa only nine months old, and another reports roots seventeen inches long of but four weeks' growth, the plants being but six inches high. It usually has a slender taproot, with many branches tending downward, yet with considerable lateral growth. As the taproot is piercing the earth it is also sending out new fibrous roots, while the upper ones, decaying, are leaving humus and providing innumerable openings for air, the rains, and fertilizing elements from the surface soil. The mechanical effect of this root-growth and decay in the soil constitutes one of the greatest virtues of the plant, and by its roots alfalfa becomes, self-acting, by far the most efficient, deep reaching subsoiler and renovator known to agriculture.

\section{VARIETIES AND PECULIARTTIES}

There are several other varieties of alfalfa besides Medicago sativa, the most common being the Interme- 


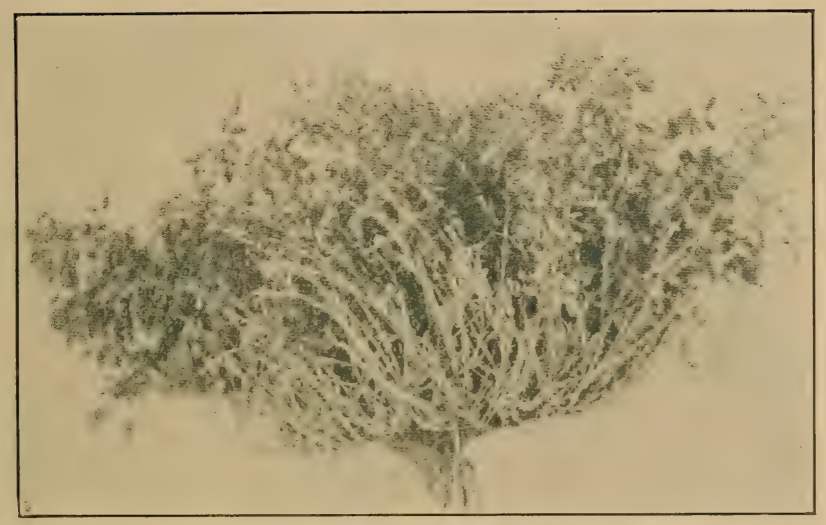

An Eight-year-old Alfalfa Plant

with 312 stems growing from one root Grown at Manhattan, Kan., on high upland prairie having a stiff, hardpan subsoil. Depth to water 180 feet. Height of growth, May 6, ten inches.

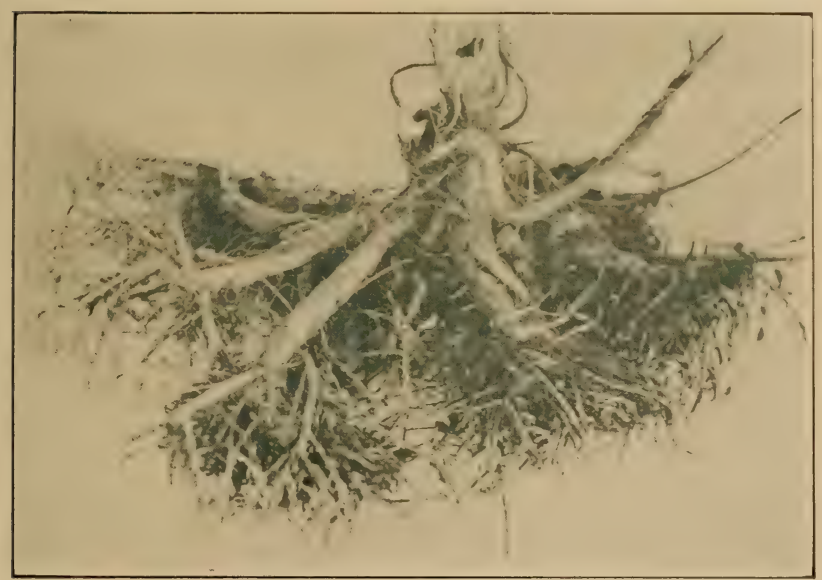

Crown of Plant Shown in the Preceding Illustration

Stalks removed to show branching crown 


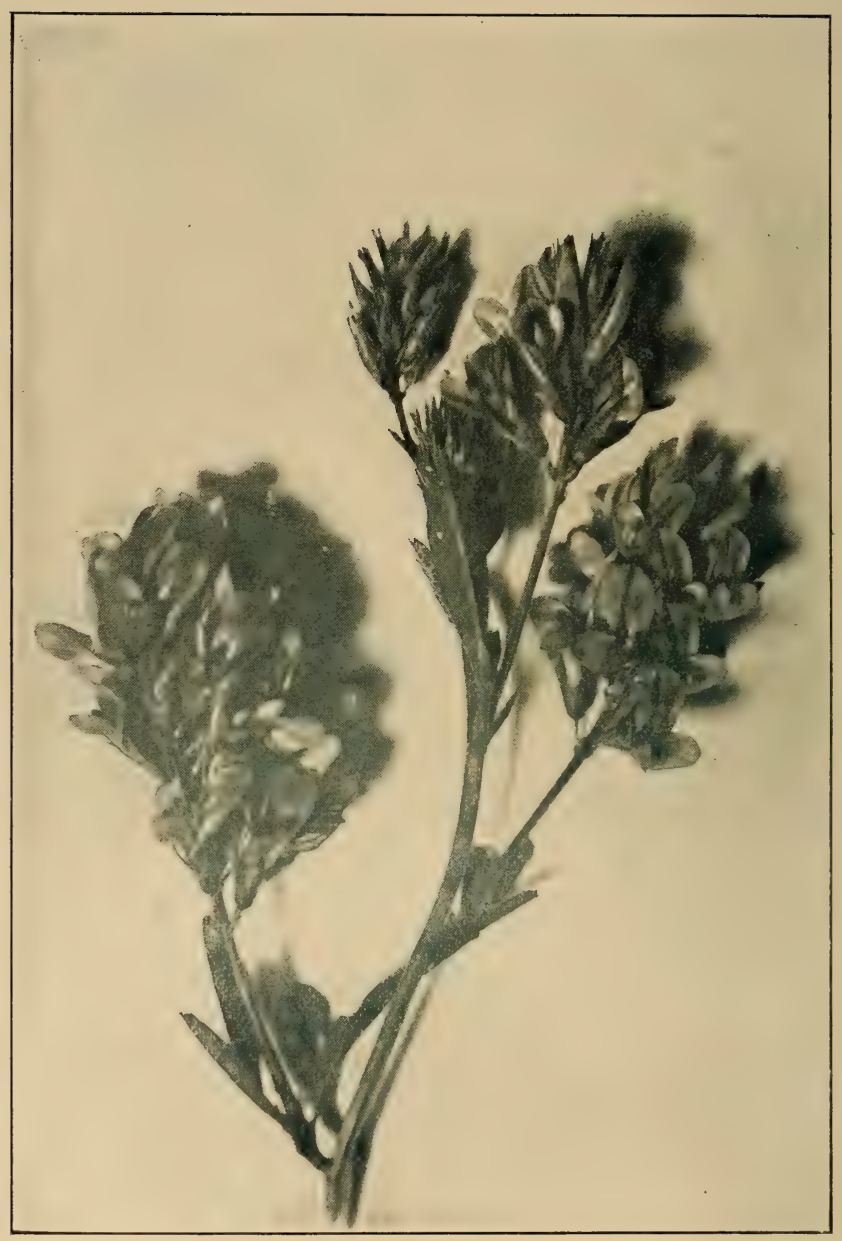

Alfalfa Blossoms Enlarged 
diate Lucerne or Medicago media, the Yellow Lucerne or Medicago foliata and Turkestan alfalfa or Medicago sativa Turkestanica. None of these have such unqualified value as the ordinary alfalfa; in fact the first two are properly regarded as weeds when found with Medicago sativa. In 1898 when there had been reported many failures in the alfalfa districts of the extreme North and the extreme Southwest, the United States Department of Agriculture sent Prof. N. E. Hansen of South Dakota to Russia, especially the cold, arid and semi-arid portions of northern Turkestan, to discover if possible a more hardy strain of alfalfa than that grown in America. He brought back from there several hundred bushels of seed which was distributed to government stations and individual experimenters in fortyseven states and territories. The reports of its behavior varied greatly, some growers being enthusiastically in its favor, while most reported results below or not above the average from other sorts, and some practically a failure. It would appear from the consensus of opinion at this time that the Turkestan alfalfa has not demonstrated in America any such superiority as to justify its general adoption, even in the dry and warm regions of the Southwest, in our colder states, or in Canada.

Among other claims for Turkestan alfalfa by the government officials in charge of its introduction and exploitation have been that "its seed will germinate much quicker and the plants start into growth earlier under the same conditions than common alfalfa. The plants are more leafy, grow more rapidly, and have a stronger, more vigorous root system. Another advan- 
tage which the Turkestan variety has is that the stems are more slender and less woody, the plants making a more nutritious hay of finer quality. That it will withstand drought under the same conditions better than ordinary alfalfa seems certain from the reports of the experimenters. In the West and Northwest, at least, it seems to be more productive, both with and without irrigation."

At the North Dakota station Turkestan alfalfa sown in I9OI yielded in the three years following (1902-3-4) at the average rate of slightly more than two tons per acre annually.

Acclimation of alfalfa is a slow process, and numerous close observers think there are too many radical differences in climate and possibly of soil between Turkestan and New Mexico, or North Dakota, to admit of this variety's becoming a preeminently valuable acquisition to America. It is thought more reasonable to let the American-grown alfalfa gradually accustom itself, as it will, to any particular region, sowing seed from nearly the same latitude and grown under as nearly as possible the conditions it will encounter in its new environment.

In 1903 the Department of Agriculture began experimenting on a small scale at stations in Arizona, California and the warm regions with alfalfa seed procured by Mr. D. G. Fairchild, from Arabia. The officials in charge observe that the plants from this seed appear to make a much quicker growth after cutting, and as a result of this one more crop in a season than is obtained from other alfalfa may be possible. It differs from other strains in having larger leaflets and in being much 
more hairy. "It is thought very probable that by careful selection hardiness can be bred into Arabian alfalfa so that it will grow much farther north than it does at present."

\section{AN OPINION FROM HEADQUARTERS}

As a latter day opinion or estimate of alfalfa from an official who is presumed to speak as an authority, without bias and knowing his subject, the words of W. J. Spillman, agrostologist of the United States Department of Agriculture, should carry weight. In an address before the eleventh annual convention of the National Hay Association, at St. Louis, in I904, Professor Spillman said:

"Alfalfa is the oldest plant known to man; it is the most valuable forage plant ever discovered. It has not been appreciated in the eastern part of the United States unitil the last five years. We are now growing it successfully in every state in the Union, and I believe it is safe to: say in every agricultural county in the United States it is being grown with success. Two weeks ago I secured a picture of a field of alfalfa in South Carolina that was sowed over sixty-nine years ago. It was still in pretty good condition. I know of another field in New York State sowed forty-five years ago, and one in Minnesota that was sowed thirty-three years ago. All over the West there are thousands of fields of alfalfa that were sowed twenty-five years ago that are still yielding large crops. In Wisconsin alfalfa yields three crops of hay a year, and in Texas, four and five large crops. In southern California, below sea-level, where they 
never have any frost, they cut alfalfa eleven times a year, and in Texas, south of the Rio Grande, they cut it nine times a year.

"Alfalfa does not exhaust the soil. Nitrogen is the soil's most important element, and the one most liable to give out; the one the farmer is called upon to supply first. Alfalfa does not ask the farmer for nitrogen at all, because it can get its nitrogen out of the atmosphere. Four-fifths of the atmosphere consists of nitrogen. Ordinarily, plants cannot make use of that nitrogen at all; the roots of the alfalfa will leave in the soil eight or ten times as much nitrogen as was there before. The farmer who plants alfalfa, clover or peas does not have to get nitrogen from the fertilizer factories. I know one farmer who for the past eight years has made an average of eight and one-half tons per acre of alfalfa on irrigated land in the state of Washington. I have heard of other men that produced twelve tons an acre in southern Texas on irrigated land. It would hardly be possible to produce that much on land that is not irrigated, because rain does not come to order.

"I have lived ten years in a country where the horses, cattle, sheep, hogs and chickens eat alfalfa hay, or green alfalfa, the year round. It is the richest hay food known. Eleven pounds of it is worth as much for feeding purposes as ten pounds of bran."

A most pleasing word-picture of alfalfa is that by Geo. L. Clothier, M. S., who has studied his subject closely in the field, the feed lot and the laboratory, and he paints it thus: 
"The cultivation and feeding of alfalfa mark the highest development of our modern agriculture. Alfalfa is one of nature's choicest gifts to man. It is the preserver and the conserver of the homestead. It is peculiarly adapted to a country with a republican government, for it smiles alike on the rich and the poor. It does not fail from old age. It loves the sunshine, converting the sunbeams into gold coin in the pockets of the thrifty husbandman. It is the greatest mortgage lifter yet discovered.

"The alfalfa plant furnishes the protein to construct and repair the brains of statesmen. It builds up the muscles and bones of the war-horse, and gives his rider sinews of iron. Alfalfa makes the hens cackle and the turkeys gobble. It induces the pigs to squeal and grunt with satisfaction. It causes the contented cow to give pailsful of creamy milk, and the Shorthorn and whitefaced steers to bawl for the feed rack. Alfalfa softens the disposition of the colt and hardens his bones and muscles. It fattens lambs as no other feed, and promotes a wool clip that is a veritable golden fleece. It compels skim-milk calves to make gains of two pounds per day. It helps the farmer to produce pork at a cent and a half a pound and beef at two cents.

"Alfalfa transforms the upland farm from a sometime waste of gullied clay banks into an undulating meadow fecund with plant-food. It drills for water, working 365 days in the year without any recompense from man. The labor it performs in penetrating the subsoil is enormous. No other agricultural plant leaves the soil in such good physical condition as alfalfa. It 
prospects beneath the surface of the earth and brings her hidden treasures to the light of day. It takes the earth, air, moisture and sunshine, and transmutes them into nourishing feed stuffs and into tints of green and purple, and into nectar and sweet perfumes, alluring the busy bees to visits of reciprocity, whereon they caress the alfalfa blossoms, which, in their turn, pour out secretions of nectar fit for Jupiter to sip. It forms a partnership with the micro-organisms of the earth by which it is enabled to enrich the soil upon which it feeds. It brings gold into the farmer's purse by processes more mysterious than the alchemy of old. The farmer with a fifty-acre meadow of alfalfa will have steady, enjoyable employment from June to October; for as soon as he has finished gathering the hay at one end of the field it will be again ready for the mower at the other. The homes surrounded by fields of alfalfa have an esthetic advantage unknown to those where the plant is not grown. The alfalfa meadow is clothed with purple and green and exhales fragrant, balmy odors throughout the growing season to be wafted by the breezes into the adjacent farmhouses." 


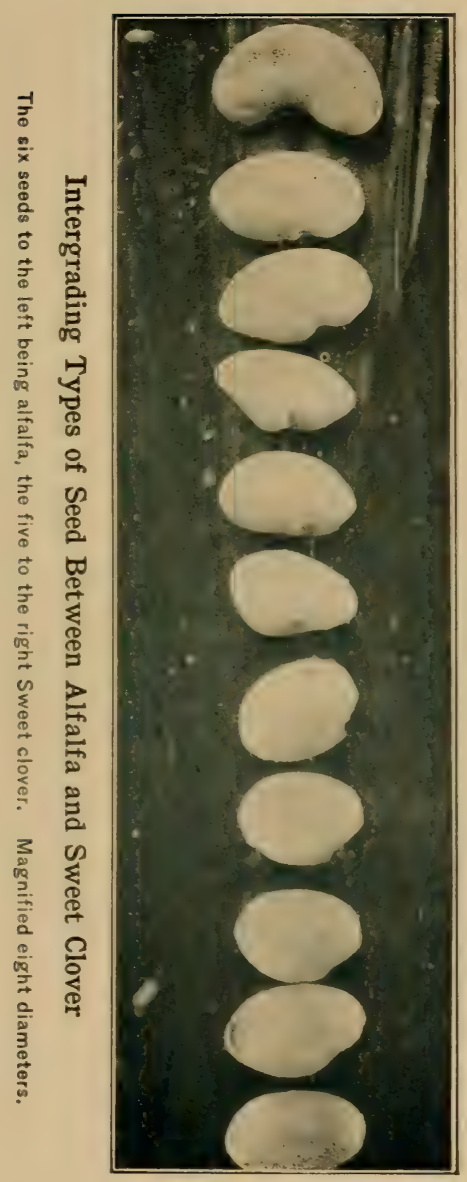




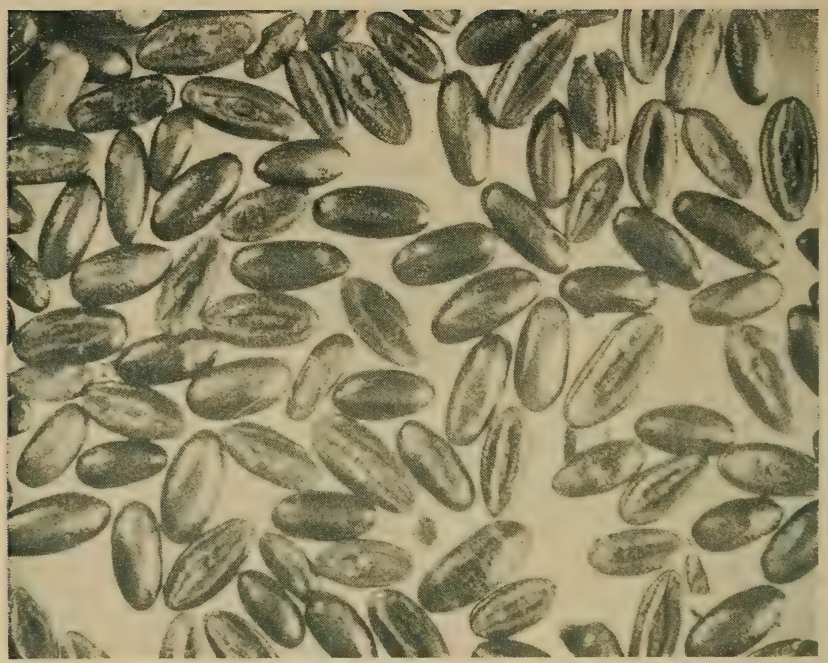

Seeds of the Weed Known as Buck-horn,

Ribbed plantain, English plantain, or Rib-grass, (Plantago lanceolata). Very commonly present in alfalfa seed, especially that of European origin. A bad weed. Magnification five diameters.

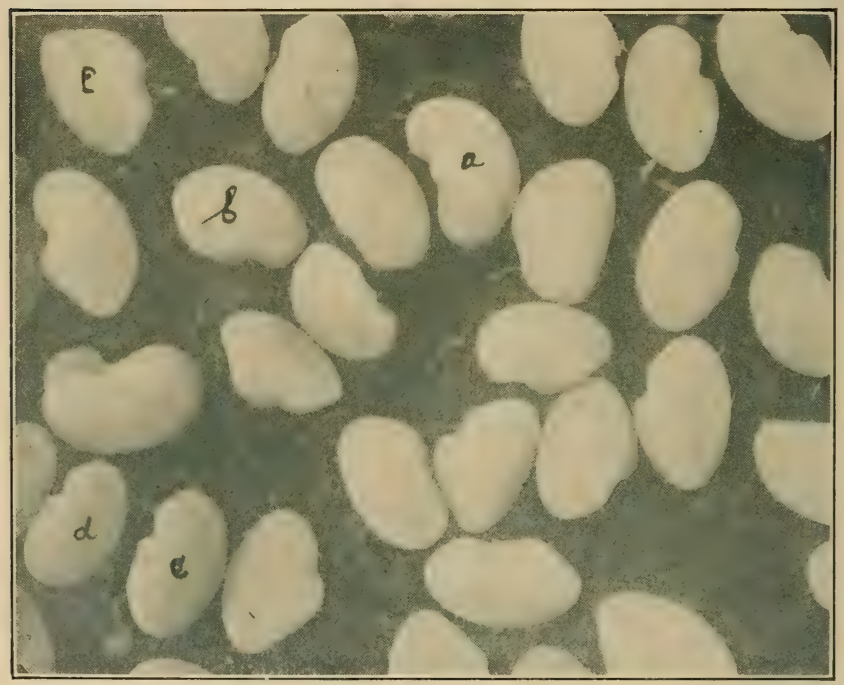

\section{Alfalfa Seeds Magnified Five Diameters}

Note the characteristic angular point at one end, typical of alfalfa. The kidney. shaped type, as in " $a$ " is also characteristic. The rounded type " $b$ " is rare, and resembles Sweet clover. Seeds marked "c" and " $d$ " resemble Yellow trefoil in the projecting "beak." 


\section{CHAPTER II.}

\section{Universality of Alfalfa}

\section{ITS WIDE DISTRIBUTION}

As the history of alfalfa is traced in the preceding chapter the conclusion is reached that its distribution is not to be circumscribed by any hard and fast lines of climate and soil. It is grown profitably in every country of Europe, in central Asia, its original home, in Australia, the islands of the sea, and in almost every state and territory of the United States, and in Canada. Only two states, Maine and New Hampshire, and only one territory, Alaska, are left wholly in the experimental column. Everywhere else there have been such results as to prove that it ought to become, in greater or less degree, a staple crop on practically every farm, dependent only upon more energy, faith and skill on the part of the farmer, and a natural acclimation. There are several other states such as Vermont, Massachusetts, Connecticut, Rhode Island, Michigan, Kentucky, Tennessee, Arkansas and North Dakota where the experiment station experts are not fully ready to recommend it as a regular crop for every farm, yet, in each of these there are enterprising farmers who have for years found profit in its raising. The station authorities in Vermont say that success with alfalfa there "depends first on the man, and second on the soil." 
W. R. Dodson, botanist of the Louisiana station, says it is his firm conviction that nothing will contribute so much as alfalfa toward making the southern farm selfsupplied with feed for work animals, for the production of dairy products, and home raised meat. "I doubt," he also says, "if alfalfa does better anywhere outside the irrigated regions of the West than it does in the alluvial lands of Louisiana. We have had as high as eight cuttings in one year, with a total tonnage larger than is had in Kansas or Nebraska, and our annual rainfall is sixtyfive inches, or more."

From Ontario, Canada, comes a report of a yield of four tons to the acre in three cuttings, on a clay hillside; at far-off Medicine Hat, Northwest Territory, it makes a growth pronounced "phenomenal," and at the experimental farm at Brandon, Manitoba, three cuttings per year are harvested. On a gravelly hill in the District of Columbia, a field was sown in April, I900. Two crops were cut from it that summer, three in I9OI, and the first cutting in 1902 yielded three tons per acre. In southern Minnesota, some thrifty Germans, not knowing that "alfalfa will not grow in Minnesota," have been raising it since 1872 , while others were declaring it impossible. A half-score of men in the sagebrush wilds of Nevada decided to try it, and in 1872 they had 625 prosperous acres, without plowing and without irrigation. J. H. Grisdale, agriculturist of the Central experimental farm at Ottawa, (Bul. No. 46) says, "it is grown in Canada more or less extensively from the Atlantic to the Pacific. It is the staple forage plant for winter in the dryer part of British Columbia, and it has been grown in 
Southern Alberta for many years. It is not much known in Manitoba, but is possible of easy propagation in almost all parts of Ontario. It is, and has been grown long and successfully in Quebec, and is not unknown in Nova Scotia and New Brunswick." In Cape Colony, South Africa, "lucerne can be cut from four to six times in summer and from once to twice in winter, and is the greatest forage plant in the world." In Igor the British consul at Buenos Ayres reported alfalfa as covering "an enormous area in Argentina, and every year becoming more important."

\section{NOT PARTICULAR AS TO SOIL}

While experts have been declaring that alfalfa would only grow in certain soils and in certain climates it has proven adaptability to nearly all climates and almost all soils. It produces with a rainfall as scant as 14 inches, and in the Gulf states flourishes with 65 inches. It gives crops at an elevation of 8000 feet above sea level, and in southern California it grows below sea level to a height of six feet or over, with nine cuttings a year, aggregating ten to twelve tons. An authenticated photograph in possession of the writer, reproduced opposite page 23I, shows a wonderful alfalfa plant raised in the (irrigated) desert of southern California, sixty feet below sea level, that measured considerably more than ten feet in height. Satisfactory crops are raised, but on limited areas as yet, in Vermont and Florida. New York has grown it for over one hundred years in her clay and gravel; Nebraska grows it in her western sand hills without plowing, as does Nevada on her sagebrush 
desert. The depleted cotton soils of Alabama and rich corn lands of Illinois and Missouri each respond generously with profitable yields to the enterprising farmer, while its accumulated nitrogen and the sub-soiling it effects are making the rich land more valuable and giving back to the crop-worn the priceless elements of which it has been in successive generations despoiled by a conscienceless husbandry.

Its introduction into Maryland was largely through the perseverance of Prof. W. T. L. Taliaferro of the agricultural college, who says: "The future for alfalfa for southern Maryland is bright, indeed, and with its general introduction will come a new era of prosperity for the 'lower counties.' Live stock farming will take the place of tobacco farming. The fertilizing elements of the soil will be concentrated at home instead of being shipped abroad. Larger crops will be raised. Soil improvement will take the place of soil exhaustion; wornout farms will be restored to their original fertility."

\section{THE ORACLES REFUTED}

One by one the oracular statements of so-called experts have been shown at fault. One said, "it will grow wherever corn will grow;" and as promptly men from New York and Louisiana rise and say that they are growing it where corn will not grow. Another declares, "it will not grow over a hardpan or gumbo subsoil;" at once a New York man reports a good field of alfalfa with roots fifteen feet long that pass through six inches of hardpan which was so hard that it had to be broken with a pick axe in following the root. A Kansas man writes that he has eighty acres that has stood five years 
and promises to continue indefinitely, yielding $4 \mathrm{I}-2$ tons from three cuttings a year, and the whole of it on gumbo soil where corn raising was a failure. Another declares, "it must have a rich, sandy loam," and forthwith from the deserts of Nevada, the sand hills of Nebraska and the thin, worn, clay soils of the South come reports of satisfactory yields. Such results are significant, indicating better returns than any other crop brings from these varied soils, and that few farmers are justified in postponing the addition of alfalfa to their agriculture because of supposed hindrance of soil and climate.

\section{A NEW YORI EXAMPLE}

As citing an example, and suggestive of the fact that alfalfa not only grows but flourishes in the eastern states where the claim has been made that it would not grow, the following by the editor of the Rural New-Yorker, in his journal of September 3, I904, is forcibly to the point:

"A farmer visiting the New York state fair this year will do well to take time to look at some of the alfalfa fields near Syracuse. Whether it means that the soil in this locality is well suited to alfalfa, or that farmers have learned how to grow it, it is a fact that the crop makes a wonderful showing there. You find it everywhere-in great billowy fields of green, along the roadsides-even in vacant city lots. The crop crowds in whether the seed is sown by hand, dropped from a passing load or scattered by the wind. The majority of the farms show great fields of it, and the character of farming is slowly changing as more and more alfalfa is cut. On fruit farms or small private places the crop is changing meth- 
ods and habits. A few acres in alfalfa provides all the roughness needed for stock on these small places, and gives extra room for fruit or similar crops. In fact, the most interesting thing about these alfalfa fields is the way they are changing the entire conditions of the country. It is similar to what happens when a new industry is established in a town or city.

"The Grange meeting at a Mr. Worker's farm, was held in a great barn. He had delayed the alfalfa cutting so that the barn might be empty. Some other farmers nearby had already cut. I had a chance to see alfalfa growing under what seemed to me about the toughest chance you can give a plant. The city of Syracuse is buying gravel from his field, to use on the street. The workmen are digging right into the hill, and it requires hard labor to pick up this tough, hard soil. As they dig they follow the roots of the alfalfa down. Some of the roots are quite as large as my thumb, and I am sure that many of them had gone down twenty feet at least into this tough soil. These big roots make plowing an alfalfa sod anything but fun. This is one of the few objections to the crop. I had supposed that the plant does its best where it can work down into an open or gravel subsoil. I have been told by one who is called an 'expert' that alfalfa cannot thrive on a hardpan subsoil, yet here it was going down into the toughest soil I ever saw, and covering the surface with a perfect mat of green stalks. Mr. Worker goes so far as to say that the tougher the subsoil the better the alfalfa goes through it, provided water does not stand about the roots. That is one point upon which all agree-the alfalfa cannot stand 
wet feet. It must have water enough; that is why its roots go down so far, but it will not thrive in wet fields where water does not run easily away.

"On other farms I saw the alfalfa growing at the top of steep clay hills, which were formerly almost useless for farm purposes unless stuffed with stable manure. Now that alfalfa has been started these hill-tops have become about the most profitable fields on the farm. At another place I saw a fair crop of alfalfa growing in a thin streak of soil over a rocky ledge. There were not eighteen inches of soil covering the solid rock, yet the alfalfa was thriving. I have been told that this is the condition under which alfalfa will not grow, yet here it was giving more forage than any red clover we can grow. I have said that the spreading of these alfalfa fields is changing the character of farming in central New York. It is not easy to realize just what this means without visiting this favored section. This new forage plant brings fertility and feed to the farm. It is just like having a fertilizer factory and a feed store drop out of the skies upon the farm, to get this alfalfa well started. Of course as the farmer learns what the crop will do he uses it more and more to feed both stock and the farm. It would not be a very bright farmer who would continue to grow wheat or some other annual crop which brings him \$25 per acre when a permanent crop like alfalfa will guarantee $\$ 60$. Some farmers are quicker to see this than others, but in the end the majority of them see it and then we see a change. These alfalfa farmers are giving a great object lesson, and their farms are more interesting than any exhibit at the state fair." 


\section{Yields, and Comparisons With Other Crops}

\section{COMPARED WITH CLOVER}

Many things are understood best through contrasts with others better known. In every part of the country certain crops are considered standard, and all others are judged by comparison with these. For example, red clover in most parts of the United States is ranked as the richest and best yielding forage, and the fertilizer and renovator par excellence.

The Massachusetts experiment station after a series of tests reports that roo pounds of clover contain 47.49 pounds of digestible food and 6.95 pounds of proteids, while Ioo pounds of alfalfa contain 54.43 pounds of digestible food and II.22 pounds of proteids.

The New Jersey station reports that the average yield per annum of green clover to the acre is 14,000 pounds, and of green alfalfa 36,500 pounds; the protein in the clover is 616 pounds and in the alfalfa, 22I 4 pounds; one ton of alfalfa has 265 pounds of protein, and clover only 246 pounds. But alfalfa will produce three, four, or more cuttings each year, while clover will produce but one or at most two. Further, clover will ordinarily survive but two years, while alfalfa will last from ten to one 
hundred, thus saving many plowings and seedings. It is also estimated that the stubble and root-growth of alfalfa are worth at least four times as much for humus as are those of clover, while the mechanical and other beneficent effects of the long alfalfa roots far excel those of clover. The alfalfa field is green for pasturage a month earlier in the spring than clover and may be mowed a month earlier. It starts a vigorous growth at once after cutting, covering the ground with its luxuriant foliage before the second growth of clover has made any substantial progress.

The Wisconsin experiment station says that "one acre of alfalfa yields as much protein as three acres of clover, as much as nine acres of timothy and twelve times as much as an acre of brome grass."

\section{COMPARISONS WITH SEVERAL GRASSES}

\begin{tabular}{|c|c|c|c|}
\hline Plat No. & Variety Grown & Hay lbs. & Yield per acre, lbs. \\
\hline $\begin{array}{r}5 \\
6 \\
7 \\
8 \\
9 \\
10 \\
11 \\
12 \uparrow\end{array}$ & 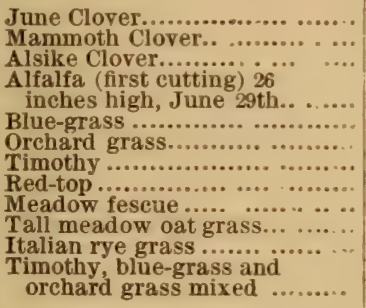 & $\begin{array}{l}473 \\
475 \\
413 \\
816 \\
575 \\
478 \\
560 \\
470 \\
375 \\
600 \\
\cdots \\
203\end{array}$ & $\begin{array}{l}2,365 \\
2,375 \\
2,065 \\
4,080 \\
2,875 \\
2,390 \\
2,800 \\
2,350 \\
1,875 \\
3,000 \\
\cdots \\
1,015\end{array}$ \\
\hline
\end{tabular}

*The alfalfa plat yielded a second cutting 26 inches high on August 2nd, and a third 24 inches high September 1st; there was also a six-inch after-growth estimated at 180 pounds. The total alfalfa yield was equivalent, "approximately to $61-2$ tons of good dry forage." None of the other clovers or grasses gave more than one cutting.

Tobbed somewhat of both plant food and moisture by an adjacent row of grown cottonwood trees. 
The Nebraska experiment station has made very careful tests of the comparative yields of various grasses, clovers and mixtures. These were on plats of one-fifth of an acre. The foregoing table shows the yields the second year from planting, which owing to the very dry spring was a quite unfavorable season.

\section{COMPARED WITH CORN}

The Colorado station reports a comparison with corn as follows:

\begin{tabular}{|c|c|c|}
\hline \multicolumn{3}{|c|}{ Yield per acre of Corn and Alfalfa } \\
\hline & Corn, lbs. & Alfalfa, lbs. \\
\hline 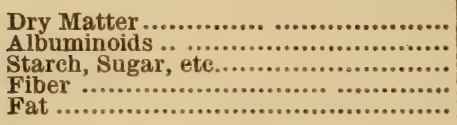 & $\begin{array}{r}3,605 \\
296 \\
2,186 \\
1,060 \\
63\end{array}$ & $\begin{array}{r}5,611 \\
1,198 \\
3,114 \\
1,198 \\
101\end{array}$ \\
\hline
\end{tabular}

INDIVIDUAL INSTANCES OF CASH RETURNS

A Lincoln county, Kansas, farmer writes that from five acres of alfalfa he received in one season $\$$ Ioo for hay, \$150 for seed and $\$ 20$ for straw.

A farmer near Atwood, Rawlins county, Kansas, cut two crops for hay and threshed the third crop for seed; realizing I3 bushels per acre, which sold at $\$ 5$ per bushel.

A Harlan county, Nebraska, farmer reports an income of $\$ 774$ in one year from seed and hay from six acres.

Scott Bros., of Pottawatomie county, Kansas, report to the author as follows concerning their returns from a twelve-acre field in one year: 
2 hay crops, 30 tons at $\$ 12 \ldots \ldots \ldots \ldots \ldots . \$ 360$

I0 5 bushels of seed at $\$ 6 \ldots \ldots \ldots \ldots \ldots \ldots 66_{30}$

Straw ........................... 50

Fourth cutting, I2 tons at $\$ 12 \ldots \ldots \ldots \ldots$ I44

Total, one year's return........ $\overline{\$ \mathrm{r}, \mathrm{I} 84}$

A Buffalo county, Nebraska, farmer sold from a year's growth on 22 acres, hay worth $\$ 328$. 12, seed $\$ 1000$, and straw \$I 50 .

A Montgomery county, Kansas, farmer reports to the author a return of \$Io6 per acre in one year from hay, seed and straw.

Another report was sent in 1904 from southern Kansas, of five cuttings, making 8 I-2 tons per acre, which sold at $\$ 5$ per ton in the field.

\section{SOME REPORTS OF YIELDS}

A farmer of Harvey county, Kansas, reported in 1903 two hay crops and one seed crop, the hay, seed and straw returning more than $\$ 50$ per acre from a field that two years before had failed to yield enough corn to justify its gathering.

Sixteen acres in Reno county, Kansas, are reported to have pastured in 1904 four hundred pigs and yielded one cutting of hay of over 16 tons.

An alfalfa field of eleven acres in Washington, on the bank of the Columbia river, under irrigation, produced in I90I over Ioo tons of hay.

Former Governor W. D. Hoard, of Wisconsin, reports from three-fifths of an acre on his farm in the southern part of the state, four cuttings in one season, yielding 5.7 tons of hay. 
Alva Langston, of Henry county, Indiana, sowed five acres of alfalfa May 2oth, and harvested nearly I I $/ 2$ tons of hay per acre August 25th following, and about the same quantity September 2oth to 25 th. This was on upland, thirty or more years in cultivation. The alfalfa was clipped twice before the cutting for hay.

In 1902 F. S. Kirk of Garfield county, Oklahoma, sowed a field near a creek, but about 25 feet above water, with thirty to thirty-five pounds of alfalfa seed per acre, broadcast. The soil, which he calls "high bottom," was a dark brown and contained considerable sand. For two years no attention was given the alfalfa except harvesting from it three crops the second year and four the third year. In 1905 he harvested from ten acres nine cuttings, estimated to weigh fully one and one-half tons each, per acre. The longest time between any two cuttings was twenty-two days, and the shortest fourteen days. During the season of 1904 seven cuttings were made and the field was gone over with a disk harrow early each time after removing the hay from the field. It was possible to cut another growth of 8 to 12 inches, had he not preferred to use it as pasturage for stock.

Mr. Kirk does not irrigate and maintains that in his part of the country "the best irrigation for alfalfa is with a disk harrow." He also insists that "alfalfa can be entirely killed by disking in the dark of the moon," especially if the weather that follows is hot and dry. He pastures his alfalfa with cattle and horses in fall and spring, and disks in the spring as soon as the stock is removed. 


\section{SOME MONEY COMPARISONS}

A good acre corn crop in Ohio is forty bushels, worth not to exceed $\$ 20$, after all the labor of cultivating and husking; the stover, if properly cared for, ought to be worth $\$ 5$, making a total of $\$ 25$. An Ohio farmer reports a yield of $4 \frac{1}{2}$ tons of alfalfa hay per acre, worth for feed as compared with the price of bran about $\$ 12$ per ton, or a total value of $\$ 54$, from only one plowing in six years (as long as he let it stand) and with less labor in harvesting than for husking corn and caring for the stover.

A good Kansas or Nebraska corn yield (far above the state average) is 50 bushels per acre, worth ordinarily about $\$ 17$, with stover worth $\$ 3$. The farmer should obtain from his alfalfa at least four to five tons, worth to him for feed for cattle, hogs or sheep from \$1o to \$I 2 per ton-practically two or three times his income from an acre of corn, while the cost of production is much less.

The average year's corn or wheat crop is worth only about \$IO per acre, while the average alfalfa crop is worth on the market from $\$ 15$ to $\$ 35$, or more, per acre, owing to the market appreciation of the crop, and from $\$ 35$ to $\$ 60$ as feed for stock.

Many thousands of acres in western Kansas and Nebraska are now returning from their alfalfa fields an income of from $\$$ I 5 to $\$ 25$ per acre where but a few years earlier the land was deemed worthless for agriculture. Hundreds of acres in western New York that 
were returning only a small income above cost of labor and fertilization are now supporting great money making dairies from alfalfa. Cotton land in the South rents for $\$ 5$ per acre, while alfalfa fields bring a yearly rental of three times that amount. 


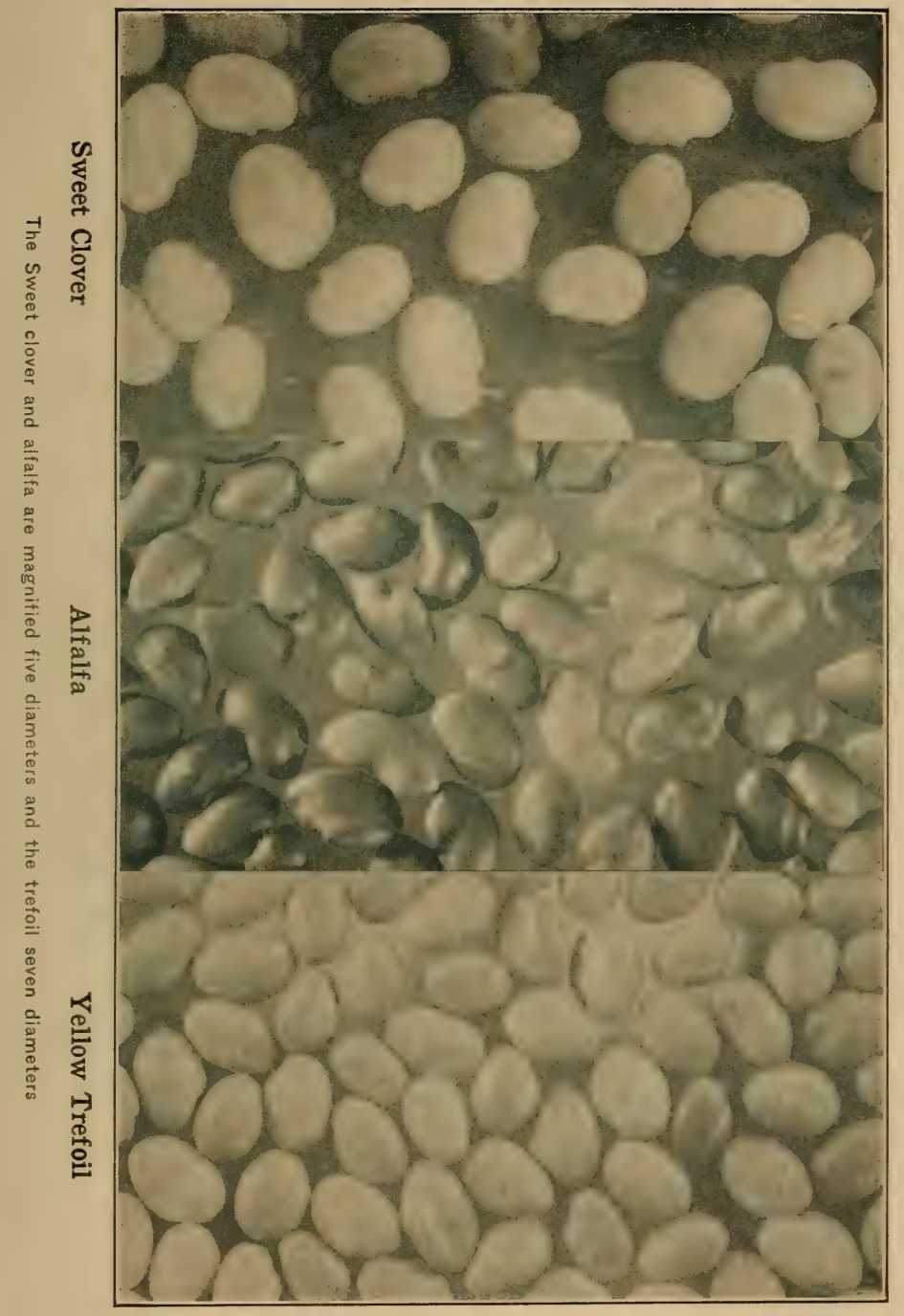




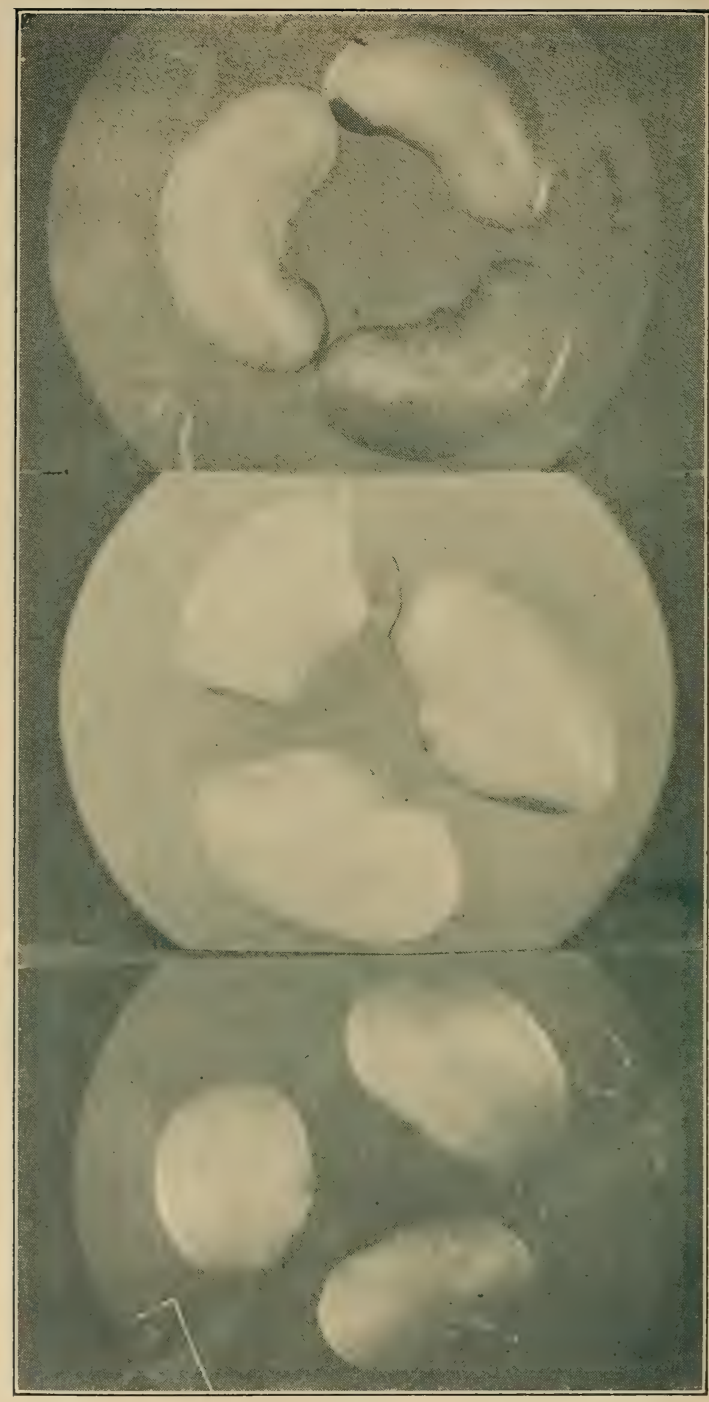

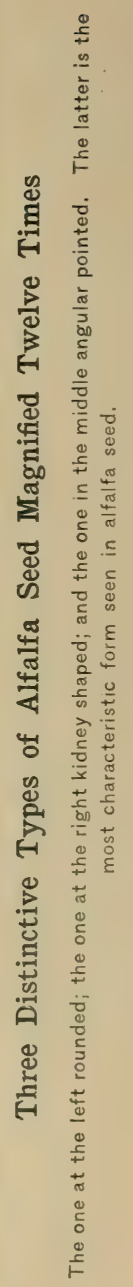




\section{CHAPTER IV.}

\section{Seed and Seed Selection}

\section{NO SUCCESS WITHOUT GOOD SEED}

It is a time-worn but no less true saying that good seed is essential to good agriculture. No matter how well the farmer prepares his land, no matter how much time, labor and money he spends on it, if much or all of his seed fails to grow, he will either have a poor crop or be obliged to reseed, thus losing time and labor. Many causes may contribute to prevent a good stand, but if he can eliminate any one of these, he is by so much the gainer. Poor seed is a primary and great cause of a poor stand.

The farmer obtains his seed from one of two sources; he raises it or buys it. If the former, there should be less danger, as the chief source of poor seed is careless handling in harvesting and storing. If the seed becomes damp, mold will damage much of it, or it will sprout, then dry out, and the germ be killed. If seed is bought of strangers or from a distance, the chances of poor quality increase many fold. If all seed were bought of reliable dealers, there would be less cause for complaint, but farmers too often buy where they can buy cheapest. They pay for trash that is either full of harmful weed seeds or has a liberal admixture of old and dead seeds left over from previous seasons. 
Before seed is purchased it should be tested for purity and germination. The adage that a dollar saved is a dollar earned well applies here; it is an easy matter to waste a dollar on seed, and when profit depends on avoidance of useless expenditure the use of inferior seed points its own moral.

\section{IMPORTANCE OF SIMILAR CONDITIONS}

The farmer who has brought himself to the point of introducing alfalfa upon his farm should be extremely careful in the selection of seed. In the first place it is important that he should sow such as is produced in about the same latitude as his farm and from a region of about the same rainfall, thus keeping in a line of acclimation, and with the habits and habitat, as it were, of what he is seeking to raise. Next, he should not sow seed raised under irrigation if he is in a non-irrigation region. A Michigan farmer, for example, should sow seed grown as near to his latitude as possible, say, from Wisconsin, Minnesota or the Dakotas, or not south of Nebraska or Kansas. It is questionable, at present, whether it is wise or profitable to attempt raising alfalfa seed in the more humid districts of the eastern and southern parts of the United States. It may be economy to leave the raising of seed to those regions with the least summer rainfall, keeping always in mind the securing of seed grown under conditions nearly like those to which the seed is to be introduced.

Speaking of the alleged different varieties of alfalfa, the seed of which is urged upon buyers by seedsmen, the editor of the Oklahoma Farm Journal pertinently says: 
"We see occasional references to 'dry land' alfalfa and statements that it's a kind that just longs for the hilltops so that it may turn off big crops of rich hay from land too dry and hard to yield good sorghum. Don't forget that the one thing to look for when purchasing alfalfa seed is good seed, that will grow. It's hard to find and the price is usually high. When you buy it, buy subject to test and send a fair sample of about an ounce to your experiment station, where it will be tested without charge. At the present time there is but one variety of alfalfa that Oklahoma farmers should buy, and that is good alfalfa seed. There is no 'dry land' variety of alfalfa, and the much boomed Turkestan variety isn't as good for sowing in Oklahoma as Oklahoma or Kansas grown seed. Rich soil, thorough preparation, good seed well sowed, cutting at the right time, harrowing when weeds and grass bother, all these are requisite to success with this most valuable crop, and it pays for all the bother."

Seed from Nebraska and northwestern Kansas has been generally successful through Iowa and Illinois, and is probably adapted to Ohio and southern Pennsylvania. Utah seed produces good crops in Minnesota, the extremes of cold and heat in Utah having developed a strain that does well in cold climates. The writer would use Utah grown seed for New York, northern New Jersey and northern Pennsylvania, and seed from Wyoming or Montana for New England. On the sandy land of southern New Jersey, in Delaware and Maryland, the seed grown in southern Colorado and southern Kansas ought to do well. 
Prof. H. M. Cottrell, formerly agriculturist of the Kansas experiment station, says: "One year I sowed 20 acres to alfalfa-I9 acres with Utah grown seed and one acre with imported seed; both showed a germination of over 98 per cent, and the growth was good from both lots all through the season, with no difference that could be detected. The next spring there was a good stand all over the I9 acres seeded with Utah seed, and not a single live plant on the acre seeded with the imported seed. I have seen several trials with imported seed, and never yet saw a good crop harvested from it. Usually after passing through the first winter there is from one-fourth to one-half a stand from such seed; the plants make a weak growth and, if allowed to remain, most of them die out in two or three years. Descriptions of the puny growth in reports of failures of this crop, given by eastern growers, make one think that probably imported seed had been sown. No intelligent farmer would take corn grown in the warm soil and climate and long season of southern Kansas and expect to grow a good crop in New York on heavy soil with short seasons. It is even more difficult to succeed with so great a change in growing alfalfa, as it would have to withstand the long severe winter, as well as the change in summer conditions. No one should sow alfalfa seed without knowing where and under what conditions it was grown."

New seed, other conditions being right, is always preferable, although that kept for several years, properly cared for, may have retained most of its germinability. Such tests as have been made appeared to show a loss in well stored seed of only about one and one-half per 
cent of germinability in five years. W. P. Headden (Colorado Bul. No. 35) after various experiments declares, "the results are positive in showing that the age of seed up to six years does not affect its germinating power." It is usually handled and stored by seedsmen in the ordinary seamless cotton sacks holding from ${ }^{5}{ }^{\circ}$ to I6o pounds, and quoted and sold by the pound or hundred-pounds instead of by the bushel. The legal weight of a bushel of recleaned alfalfa seed is sixty pounds.

Although the seed is handled in sacks for convenience, seedsmen say there is no good reason why it might not be safely stored in bulk in bins without any deterioration from heating, or otherwise. There might, however, be some degree of danger from weevils or other insect pests in warm weather. Exposed to too much light, seed will lose its bright yellow color and change to a brownish cast. When stored, dealers say, it does not go through a "sweating" process as do the seeds of some other forage plants and grasses.

\section{IMPORTS AND EXPORTS OF SEED}

In years of large production in America and a shortage in other countries, considerable American seed goes abroad to Italy, France, Germany and Australia. The largest portion is consigned to Germany because extensive seed houses at Hamburg act as distributers to all portions of the world, from which they receive demands.

In recent years the United States has been a buyer rather than a seller, and imports have been as follows: 


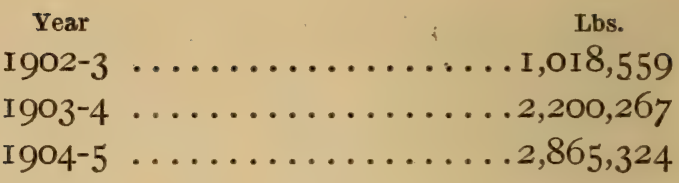

According to the government authorities the bulk of the imported seed comes from Germany and France. That having the best reputation in Europe comes from Provence, (southeastern) France. A small quantity comes from Italy, but it is not generally considered to be of as good quality as that grown farther north. Seedsmen complain that many consignments of the foreign seed contain large quantities of Yellow trefoil and Bur clover.

It is a fallacy popular among farmers and country seed dealers that great quantities of alfalfa seed are exported to be used for dyeing purposes. There is no foundation in fact for such a belief, and the exportations made, like the importations, are for seeding purposes exclusively.

\section{IMPURITIES AND ADULTERATIONS}

A foremost source of danger and loss, aside from infertile seed, is impurities and adulterants in the alfalfa seed planted. Growers often are careless and do not examine their alfalfa before or at the time of harvesting, and do not reclean their seed after threshing, thus sending out among innocent purchasers seed mixed with those of weeds, inferior grasses and forage plants, and with various trash which adds bulk and weight but has no value. The commonest seed adulterants or impurities are those of Sweet clover (Melilotus alba) (Illus. 


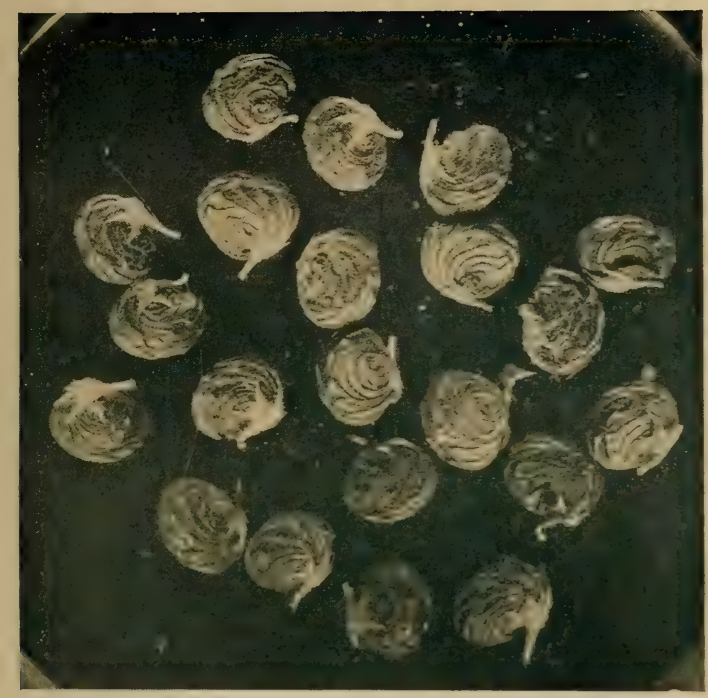

\section{Yellow Trefoil Pods}

The pods of Yellow trefoil are shaped as here shown and contain but a single seed. Magnified four diameters

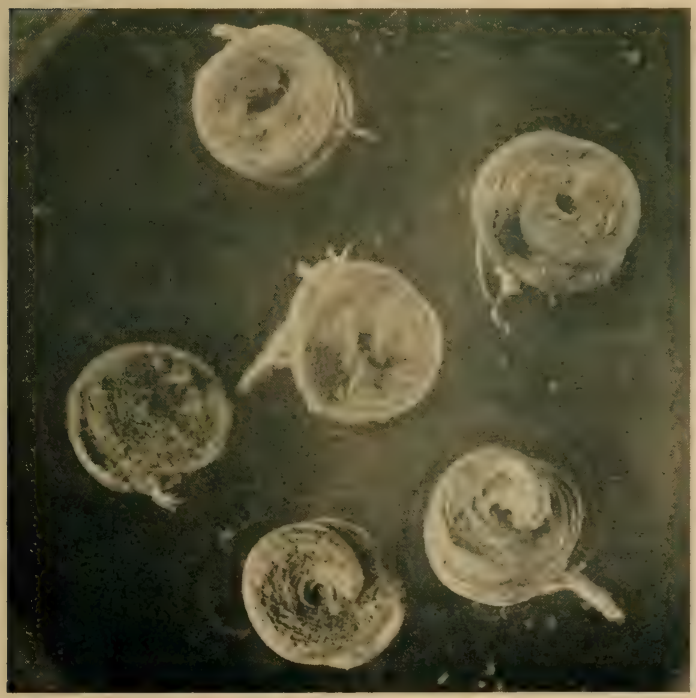

\section{Alfalfa Seed Pods}

Alfalfa has a spiral pod of two or three turns, often containing five or six seeds. Magnified four diameters. 


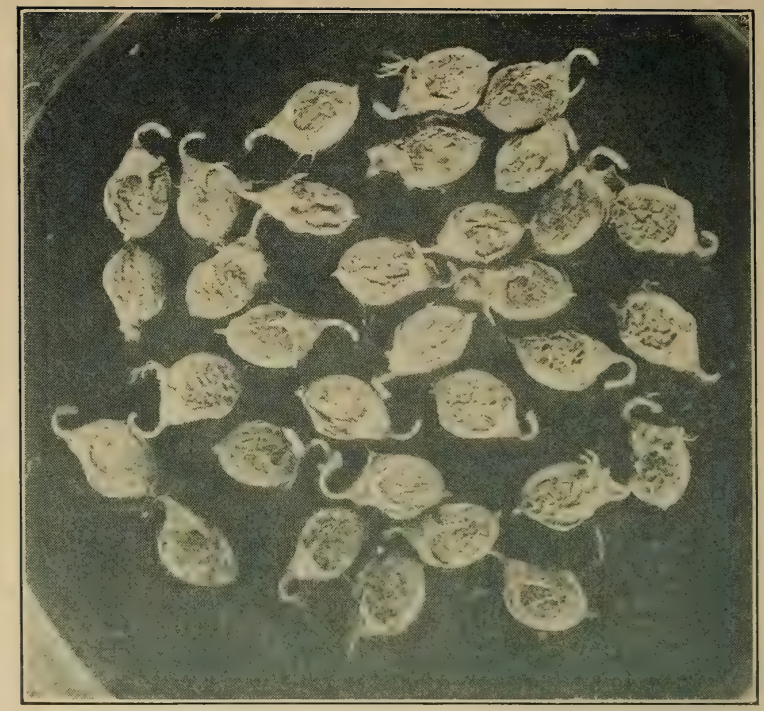

Sweet Clover Pods

Magnified four diameters

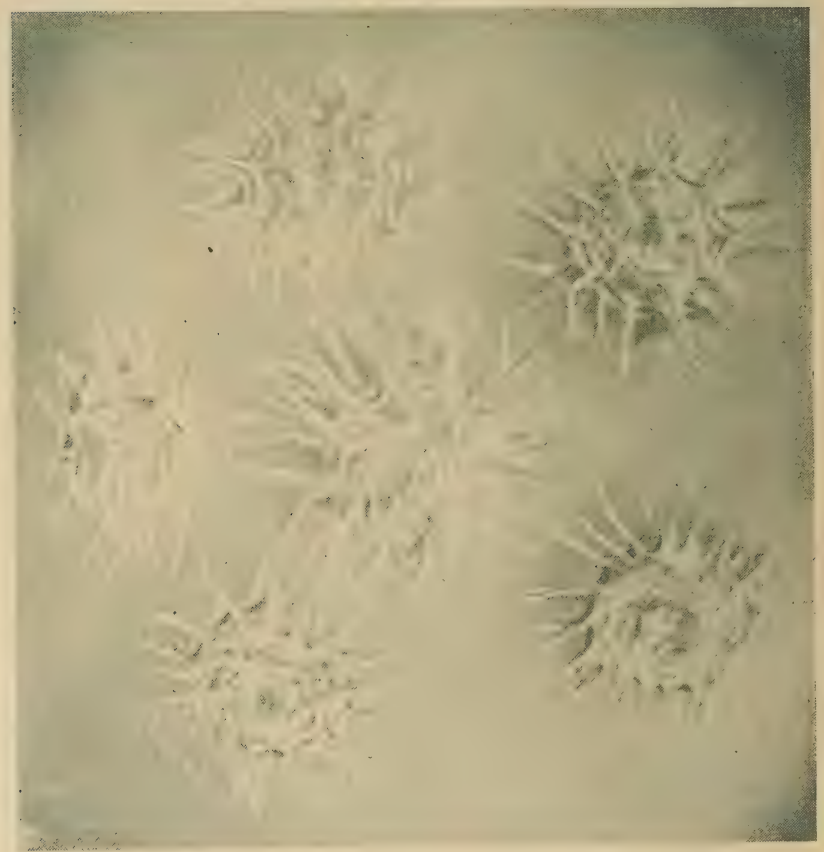

Bur Clover Seed Pors

The seeds are inclosed in a coiled pod which is covered with bristly projections as shown above. Magnified four diameters. 
opp. p. 26), Bur clover (Medicago denticulata), Spotted clover (Medicago Arabica) (p. 67), Yellow trefoil or Hop clover (Medicago lupulina) (p. 26), and the Dodders (Cuscuta epithymum and Cuscuta arvensis), (pp. 45 and 47 ).

That an extraordinary proportion of the alfalfa seed in the markets, wheresoever from, is adulterated to an amazing extent with seeds of undesirable plants or loaded with worthless, if not actually harmful impurities, is being demonstrated by the United States Department of Agriculture. In a circular pertaining to this work is given the following, showing the adulterants found in samples bought in the open markets of the cities named:

Seeds used as adulterants.

\begin{tabular}{|c|c|c|c|c|}
\hline City where bought & $\begin{array}{l}\text { Sweet } \\
\text { clover }\end{array}$ & Bur clover & $\begin{array}{c}\text { Yellow } \\
\text { trefoil }\end{array}$ & $\begin{array}{c}\text { Total } \\
\text { adulterant£ }\end{array}$ \\
\hline & Per Cent & Per Cent & Per Cent & Per Cent \\
\hline Providence, R. I.................. & ...... & 3.47 & 32.86 & 36.33 \\
\hline 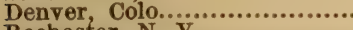 & ...... & 16.86 & 0 & 16.86 \\
\hline 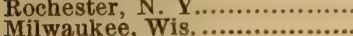 & $\cdots \cdots$ & $\begin{array}{l}5.02 \\
5.74\end{array}$ & 39.48 & $\begin{array}{r}44.50 \\
5.74\end{array}$ \\
\hline 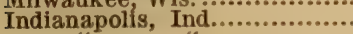 & $\cdots \cdots$ & $\begin{array}{l}0.74 \\
4.27\end{array}$ & $\ddot{38} .43$ & $\begin{array}{r}5.74 \\
42.70\end{array}$ \\
\hline 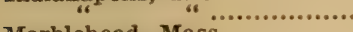 & ....... & 3.90 & 39.53 & 43.43 \\
\hline Marblehead, Mass................. & ....... & 3.00 & & 3.00 \\
\hline Petersburg, Va..................... & ....... & & 1.25 & 1.25 \\
\hline Cedar Rapids, Iowa............... & ...... & 5.49 & & 5.49 \\
\hline Indianapolis, Ind.................. & $\ldots . .$. & 3.37 & 38.54 & 41.91 \\
\hline Pittsfield, Mass................... & 9.52 & & ....... & 9.52 \\
\hline Atlanta, Ga.......................... & ....... & 10.04 & $\cdots \cdots$ & 10.04 \\
\hline Salem, Ill.............................. & ....... & ....... & 6.98 & 6.98 \\
\hline St. Paul, Minn......................... & ....... & & 31.77 & 31.77 \\
\hline Louisville, Ky........................ & ....... & 16.53 & & 16.53 \\
\hline New Haven, Conn................... & ....... & 5.88 & 39.85 & 45.73 \\
\hline Independence, Iowa.............. & ....... & 12.69 & ....... & 12.69 \\
\hline New Orleans, La................. & ....... & 2.57 & .63 & 3.20 \\
\hline 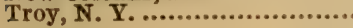 & $\ldots . .$. & 6.23 & 31.26 & 37.49 \\
\hline
\end{tabular}

In Farmers' Bulletin No. 194 of the United States Department of Agriculture is given the table on page 34 
to snow the result of analyses of alfalfa seed imported within a period of six months.

Bearing also upon the adulterations, impurities and defectiver found in alfalfa seed sold in the markets, extracts from reports of tests made at the Wooster, Ohio station (Bul. No. I42) are exceedingly interesting. In

\begin{tabular}{|c|c|c|c|c|c|c|c|}
\hline $\begin{array}{l}\text { Laboratory } \\
\text { test No. }\end{array}$ & $\begin{array}{c}\text { Alfalfa } \\
\text { seed }\end{array}$ & $\begin{array}{c}\text { Broken } \\
\text { seed } \\
\text { and } \\
\text { dirt }\end{array}$ & $\begin{array}{l}\text { Weed } \\
\text { seeds }\end{array}$ & $\begin{array}{l}\text { Number } \\
\text { of weed } \\
\text { seeds in } \\
1 \text { pound }\end{array}$ & $\begin{array}{l}\text { Number } \\
\text { of dodder } \\
\text { seeds in } \\
1 \text { pound }\end{array}$ & $\begin{array}{c}\text { Alfalfa } \\
\text { seed } \\
\text { that'll } \\
\text { grow }\end{array}$ & $\underset{\text { imported }}{\text { Amount }}$ \\
\hline & Per Ct. & Per Ct. & Per Ct. & & & Per Ct. & Pounds \\
\hline 21000 : & $93^{\circ} .38$ & 5.8 & 0.82 & 2,160 & ....... & 63.73 & 4,000 \\
\hline 21001 .. & 92.1 & 7.34 & .56 & 900 & & 59.17 & 30,800 \\
\hline $21002 \ldots \ldots \ldots \ldots$ & 82.28 & 15.92 & 1.8 & 3,060 & $\ldots$. & 66.64 & 5,500 \\
\hline $21003 \ldots$. & 84.72 & 11.58 & 3.7 & 3,420 & & 57.39 & 32,877 \\
\hline $21004 \ldots \ldots \ldots \ldots \ldots$ & 89.16 & 8.78 & 2.06 & 2,700 & 90 & 62.18 & 14,700 \\
\hline $21005 \ldots \ldots \ldots$ & 74.06 & 21.38 & 4.56 & 15,928 & 2,520 & 53.87 & 7,613 \\
\hline $21006 \ldots \ldots \ldots \ldots \ldots$ & 58.74 & 34.46 & 6.8 & 32,420 & 5,490 & 28.78 & 33,075 \\
\hline $21007 \ldots \ldots \ldots \ldots \ldots$ & 86.12 & 11.34 & 2.54 & 8,964 & 270 & 61.36 & 8,779 \\
\hline $21008 \ldots \ldots \ldots \ldots$ & 73.02 & 22.32 & 4.66 & 12,829 & 90 & 49.65 & 32,963 \\
\hline 21009 .............. & 96.82 & 2.72 & .46 & 990 & ...... & 85.2 & 33,000 \\
\hline $21010 \ldots \ldots \ldots \ldots \ldots$ & 86.2 & 12.1 & 1.7 & 3,060 & ....... & 55.59 & 30,800 \\
\hline $21011 \ldots \ldots \ldots \ldots \ldots$ & 96.96 & 2.16 & .88 & 1,710 & ....... & 87.26 & 5,500 \\
\hline 21012 ............... & 88.84 & 3.98 & 7.18 & 17,299 & ....... & 43.2 & 33,000 \\
\hline $21013 \ldots \ldots \ldots \ldots$ & 96.24 & 2.66 & 1.1 & 3,510 & ....... & 77.47 & 21,340 \\
\hline $21014 \ldots \ldots \ldots \ldots \ldots$ & 91.06 & 5.44 & 3.5 & 7,650 & ........ & 62.14 & 8,778 \\
\hline $21015 \ldots \ldots \ldots \ldots \ldots$ & 93.44 & 2.7 & 3.86 & 8,526 & ........ & 77.08 & 33,000 \\
\hline $21016 \ldots \ldots \ldots \ldots$ & 77.78 & 16.04 & 6.18 & 16,435 & 360 & 47.83 & 33,000 \\
\hline $21017 \ldots \ldots \ldots \ldots$ & 81.52 & 12.18 & 6.3 & 21,848 & 720 & 7.13 & 16,280 \\
\hline $21018 \ldots \ldots \ldots \ldots \ldots$ & 69.48 & 23.78 & 6.74 & 23,082 & 810 & 5.21 & 38,172 \\
\hline $21019 \ldots \ldots \ldots \ldots$ & 96.5 & 3.04 & .46 & 1,080 & ....... & 88.53 & 44,000 \\
\hline $21020 \ldots \ldots \ldots \ldots \ldots$ & 96.4 & 2.82 & .78 & 1,260 & ....... & 91.82 & 44,000 \\
\hline 21021 ................ & 94.4 & 5.04 & .56 & 1,620 & & 90.15 & 72,600 \\
\hline $21022 \ldots \ldots \ldots \ldots \ldots$ & 24.5 & 70.96 & 4.54 & 21,070 & 4,950 & 6.34 & 12,540 \\
\hline $21023 \ldots \ldots \ldots \ldots$ & 94.14 & 1.8 & 4.06 & 3,780 & ....... & 73.43 & 234 \\
\hline $21024 \ldots \ldots \ldots \ldots \ldots$ & 94.58 & 3.44 & 1.98 & 3,060 & ....... & 51.78 & 5,500 \\
\hline $21031 \ldots \ldots \ldots \ldots$ & $=87.72$ & 11.02 & 1.26 & 4,140 & 90 & 81.14 & 143,000 \\
\hline 21032 .............. & 90.56 & 8.08 & 1.36 & 3,420 & $\ldots \ldots$ & 76.29 & 33,000 \\
\hline $21033 \ldots \ldots \ldots \ldots \ldots$ & 89.04 & 10.5 & .46 & 1,260 & 90 & 84.7 & 6,673 \\
\hline $21035 \ldots \ldots \ldots \ldots \ldots$ & 72.36 & 27.1 & .54 & 270 & ...... & 64.58 & 13,516 \\
\hline
\end{tabular}

fifteen samples bought, each of one dollar's worth, the quantity of pure germinable seed was found to range from 5.I to 9.3 pounds; the number of noxious seeds found in a dollar's worth of that bought as alfalfa seed ranged from 360 to 185,940 . Seven of the fifteen one-dollar samples each carried more than 23,000 noxious seeds. 
Seed bought at $\$ 7.80$ per bushel showed as low as 61.2 per cent that was germinable, of which the actual cost was \$12.74 per bushel. None of the fifteen samples had less than 77 per cent of germinable seed. One pound sample contained 2I,728 noxious seeds, of which I8, I 44 were lamb's-quarter or pigweeds; the same pound also had 3 I 26 seeds of dodder. Another pound carried 6420 seeds of crab grass, and one had 3325 seeds of foxtail.

The station authorities recommend that no alfalfa seed be sown until carefully screened through a screen fine enough to remove dodder seeds. Wire sieves or screens with twenty meshes to the inch are found to serve the purpose.

\section{ADULTERANTS DESCRIBED AND ILUSTRATED}

As a further and more thorough discussion of the frequent adulterants, Prof. H. F. Roberts, botanist of the Kansas experiment station, has kindly prepared, with illustrations, for this volume the quoted statements which follow here:

"The immense and steadily increasing value of alfalfa as a forage crop in the United States, and the high price of the seed, make the securing of sound, pure seed a matter of supreme importance to farmers, and render it equally important for them to be able to recognize, by sight, the presence in alfalfa seed of the adulterants and seeds of certain weeds most commonly known to occur. There is conclusive evidence that an amount of adulteration and substitution is actually practiced with alfalfa seed. It is usually charged that this is done abroad, especially, as is alleged, in Germany. 
"The writer has been informed that, to a limited extent, the practice exists in America. The chief adulterant used is the seed of the Yellow trefoil, or, as it is sometimes called, Hop clover or Black medick. (See illustrations opposite pages 26 and 32.) About fifty species of plants are known as 'medicks' or, scientifically, Medicago; but it so happens that the only perennial species among them is alfalfa, which goes under the botanical name of Medicago sativa, (p. I). Other species such as Yellow trefoil (Medicago lupulina) ( $\mathrm{p}$. 38 ) and Bur clover (Medicago denticulata, ) while they possess some forage value and are useful to a limited extent, lack, for the most part, the lush, abundant growth of alfalfa itself, and are notably inferior through the fact of their annual habit. It is because of its perennial nature, therefore, as well as on account of its rank, succulent growth, that no species of annual leguminous plant can hope to compete with alfalfa for a moment in importance. This means, then, that any substitute for alfalfa seed, or adulteration of it with the seed of another related species, such as Yellow trefoil or Bur clover, is distinctly a fraud of serious character, despite the fact that the adulterants are plants that make fair pasturage and have some forage value. They are merely annuals, ending their life with the season, whereas a field of alfalfa should live twenty years or more, under right conditions.

\section{THE CHIEF ADULTERANT}

"At present, as stated, Yellow trefoil is the chief adulterant used in American alfalfa seed. A number of cases, 
indeed, of complete or almost complete substitution of Yellow trefoil for alfalfa seed have come to the writer's attention within the past year. It is important, therefore, for farmers to know the characteristic marks of distinction between the seed of alfalfa and of its chief adulterants. What are the chief characteristics of alfalfa seed? Facing page I3 are samples of pure alfalfa seed, photographed under a magnification of five diameters. It will be noted that seeds of three general types exist: ( I ) A kidney-shaped type, marked ' $a$ ' in the illustration; (2) a type in which one end terminates in an acute wedge, marked 'e'; and (3) a type that is round or nearly so, marked 'b'. These types clearly illustrated, arranged for comparison in parallel rows are shown opposite page 44 . See also page 27 . It should be noticed that type 2 is the most characteristic and frequent, and that the perfectly round type is extremely rare. This angular slant toward one tip of the seed is found nowhere among any of the adulterants. Neither does the kidney shape of seed occur, except in Bur clover; and, in that case, the difference in the size of the seeds of the two species is sufficient to distinguish them, in most instances.

"It is when we consider the round or roundish type of alfalfa seed that there is difficulty in distinguishing from alfalfa the seeds of Yellow trefoil and of Sweet clover (illus. opp. p. 26), which latter frequently occurs as a weed seed, and possibly in some cases in sufficient quantity to be suspected as an adulterant. By comparison of the seeds of alfalfa with the two adulterants just mentioned, (p. 26) the resemblances and differences of the three species will become evident. In general the 
seeds of Yellow trefoil are shorter and rounder than those of alfalfa, the largest seeds of trefoil measuring 0.0629 inch wide by 0.0897 inch long; whereas the largest alfalfa seeds measure 0.0653 inch wide by 0. I I 53 inch long; so that the largest alfalfa seeds are a trifle wider and more than a third again as long as the largest trefoil

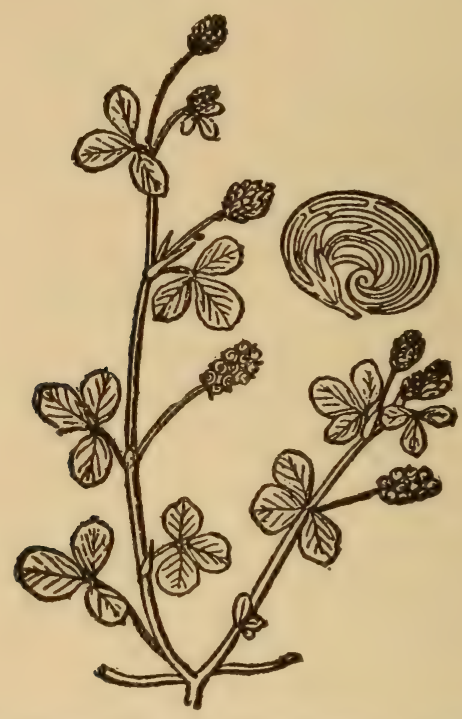

Yellow Trefoil: Black Medic: Hop Clover (Medicago lupulina,

seeds. The smallest seeds of Yellow trefoil are usually plumper and shorter than those of alfalfa (0.05 I inch wide by 0.029 I inch long, as compared with 0.0496 inch wide by $0.075^{\mathrm{I}}$ inch long in alfalfa) ; nevertheless, among both the small and the large seeds, so far as the criterion of size goes, individuals occur that equally well belong to either species, and the average differences in size are 
not so great as the differences found on comparing the largest and the smallest seeds of the two species, the average for the trefoil being 0.0574 inch by 0.0799 inch, and for alfalfa 0.0582 inch by 0.0944 inch. So it will be seen at once that while trefoil seeds as a rule are smaller, shorter and rounder than those of alfalfa, the rule is transgressed by many individuals. We must, therefore, turn to the form and general outline of the seed. A farmer can detect at once an attempt to substitute wholly Yellow trefoil for alfalfa seed by the fact that in no case will the kidney-shaped or the regular-pointed types of seed be found in trefoil, whereas these always occur in alfalfa. (Illustrated opp p. 26.)

"In the more common cases, where adulteration rather than complete substitution is practiced, detection is more difficult-is practically impossible, in fact, without the aid of a lens or magnifying glass having a power of about fifteen diameters. There are many seeds of trefoil which can scarcely be distinguished from certain rounded seeds of alfalfa. Generally, however, the trefoil seed has a little projection or "beak" on the middle line of the seed, just back of the scar marking where the seed was attached to the pod. This is rarely found in alfalfa.

"Bur clover as an adulterant is probably not so frequently used as Yellow trefoil, since the larger size of its seed renders detection easy. Were it not for this fact, Bur clover would be a most effective adulterant, because its seeds resemble those of alfalfa more closely than do those of Yellow trefoil. There are, of course, smaller seeds of Bur clover and larger seeds of alfalfa that approximate each other in size, but the average Bur clover 
seeds measure 0.0604 inch by 0.1188 inch, as compared with an average for alfalfa of only 0.0582 inch by 0.0944 inch.

"So far as the plants of Yellow trefoil and Bur clover are concerned, they are easily distinguishable from alfalfa. Both are of lower growth, as a rule, than alfalfa. Both have wider leaflets, which, in Bur clover, are like broad, inverted wedges. The flowers of these plants are yellow, and are borne in scanty clusters. The pods are wholly unlike those of alfalfa. Alfalfa has a spiral pod of two or three turns (p. 32), containing as many as five or six seeds. Yellow trefoil has a straight pod (p. 32 ), containing but one seed. Bur clover has a coiled pod (p. 33), but covered with bristly projections that give the plant its name. Where adulteration or substitution is practiced, some of the pods are very apt to occur in the bulk seed, and they can then easily be identified and distinguished from those of alfalfa.

"Seed of Sweet clover seems to occur frequently in western-grown alfalfa seed (p. 26). Sweet clover (illustrated in this book) grows to a height frequently of from four to six feet, bearing small, white flowers on slender spikes three or four inches long. Unfortunately, and unlike Yellow trefoil and Bur clover, Sweet clover is generally rejected by stock. 'On this account, it is a plant of no generally established value for hay or as pasture, although, in some instances, it is successfully used. The seeds of Sweet clover are of a golden yellow when ripe; those of alfalfa, trefoil and Bur clover being greenish yellow. The seed coat of Sweet clover seed is covered with minute elevations, while alfalfa seed is smooth. The seeds 
of Sweet clover (p. 26) are rounder and plumper than those of alfalfa, and have a very pronounced groove between the main body of the seed and the ridge which marks the location of the rootlet of the young plant within. It is this ridge that in alfalfa seeds runs off, as a rule, in a marked slant, but which in both trefoil and Sweet clover, especially in the latter, forms a well-rounded curve to the tip of the seed. No pointed or kidney-shaped seeds are ever seen in Sweet clover. (See illus. opp. p. 26.).

\section{A COMMON WEED IN IMPORTED ALFALFA SEED}

"It remains to mention the most common weed found in imported alfalfa seed-the English or Ribbed plantain, or, as it is more generally called in the West, Buckhorn or Rib grass. It is a difficult weed to eradicate, lots of seed containing any noticeable percentage of it should be rejected. (See illus. opp. p. I3.)

"The farmer is often to blame for the poor seed of which he makes complaint. Prime alfalfa seed is expensive, and a cheap grade will inevitably be poor in quality, containing much dead seed, rubbish, and the seeds of many kinds of weeds. Where 'cheap' alfalfa seed is demanded it will always be sold, and buyers need not be surprised by its quality. On the other hand, there is no excuse or palliation for the offense of selling, under the name and at the price of standard alfalfa seed, seed of substituted species. It is the duty of seed dealers to ascertain beforehand the character and genuineness of seed that they sell under any given name, and this applies to the retailers as well as to the wholesale dealers. On the 
other hand, farmers cannot expect to obtain the best seed unless they are willing to pay the price it brings."

\section{DODDER SEED}

Dodder seeds are somewhat smaller than alfalfa seeds (pp. 45 and 47), but are not separated from them except by careful recleaning; consequently, they are often sown along with the alfalfa seed, especially in that which has been imported. If a field is badly infested, it should be plowed up and devoted to some other crop for a few years. Prof. F. H. Hillman of Nevada (Bul. No. 47) says there are several kinds that infest alfalfa, but two kinds are especially common and destructive in this country. Cuscuta epithymum is the commoner. "The seeds of this (p. 47) are very small, and are almost sure to escape detection on casual examination of the samples; yet, once recognized under the lens, their presence may be easily discovered. They are so much smaller than alfalfa seeds that the use of a sieve of twenty meshes per inch separates them from the latter when only free dodder seeds are present. Not only are various other small weed seeds disposed of in the process, but little if any alfalfa seed worth buying is lost. The few ripened flowers of dodder retaining matured seeds, which sometimes pass the thresher uninjured, may be removed by proper fanning. It is safe to say that no purchaser of alfalfa seed can afford to neglect sifting his seed carefully with a twenty-mesh sieve, which is the mesh the writer recommends for the separation of this kind of dodder from alfalfa seed. 
"Cuscuta arvensis is another dodder as destructive when once established. Its seeds (p. 47) seem to be less common, however. They are larger than the preceding, many of them being practically the same size as the smaller, more rounded alfalfa seeds, which they often strikingly resemble. Thus they are hard to detect, and cannot be removed without the loss of much small alfalfa seed. This should be the more dreaded of the two dodders, because alfalfa seed infested with seeds of Cuscuta epithymum can be made practically free from them with comparatively little loss and expense. Not so, however, with seed containing Cuscuta arvensis, which should not be purchased at any price. Dodder seeds can scarcely be regarded as an adulterant, yet as an impurity they are very common and most objectionable." (See illustrations opp. pp. 45, 46 and 47.) 


\section{Soil and Seeding}

\section{VARIATE, YET UNIFORM}

In this double title we have a case of the widest variations and the most positive and rigid uniformity. Alfalfa may be grown in almost every possible kind of soil and under almost all soil conditions (save two), but omitting these the seeding, including the tilth of the ground, is based, so far as any future success is concerned, on perfect cultivation. The dictum, "Alfalfa must have a dry, warm, sandy loam, very rich" has become obsolete, as already pointed out.

There are just two soil conditions that seem absolutely against the growth of alfalfa. The first is a soil constantly wet. The common remark, "Alfalfa will not stand 'wet feet'," seems to be the expression of a law. It does not do well where the water is nearer to the surface than six feet, or where in winter water will stand on the ground for over forty-eight hours. This invariably smothers the plants; in fact it usually kills any crop. If water flows over the field for some such time, due to a freshet, the alfalfa is often found uninjured if too much soil has not been deposited on and around the plants. Even in such instances fields have been saved by a disking once or twice, but it is wholly unwise to sow on 


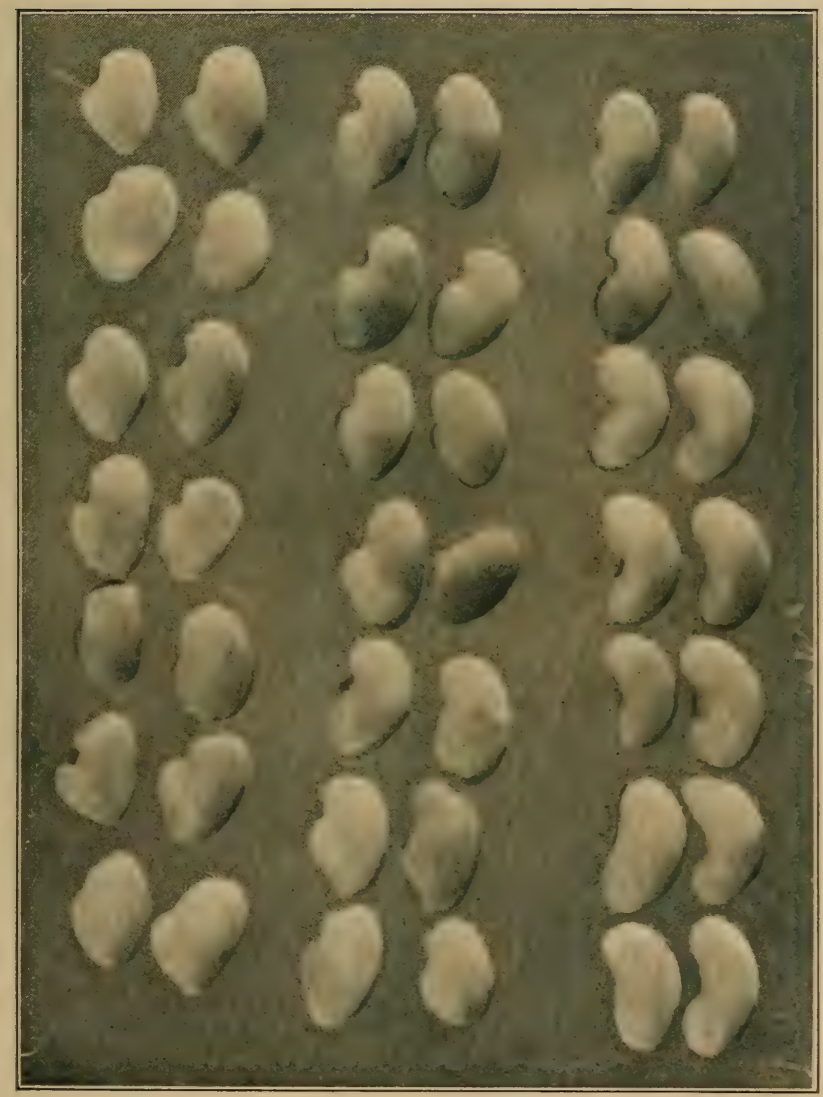

Three General Types of Alfalfa Seed

The right-hand column, kidney-shaped, a characteristic form, but not so common as the type in the central column. The left-hand column approaches more nearly the rounded type of Sweet clover. Magnification five diameters. 


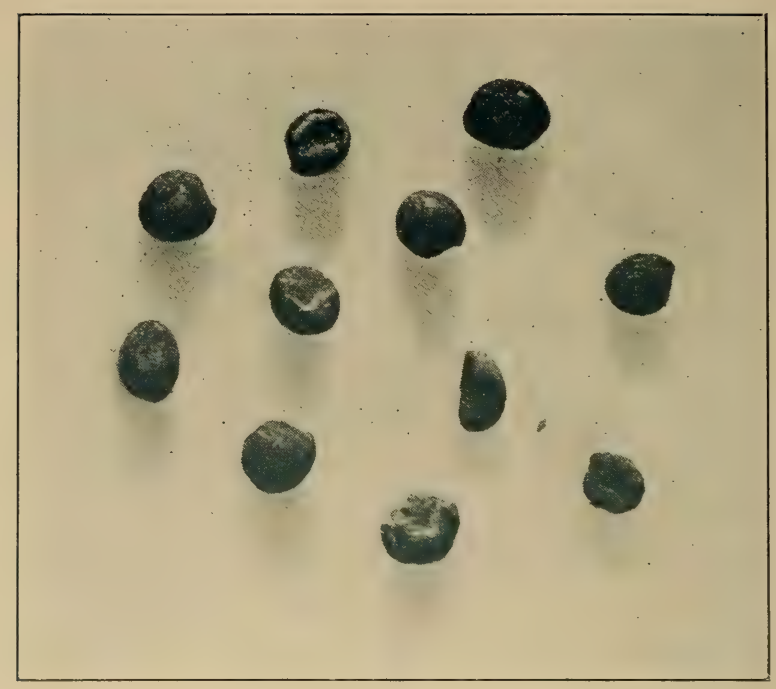

Dodder Seed Magnified

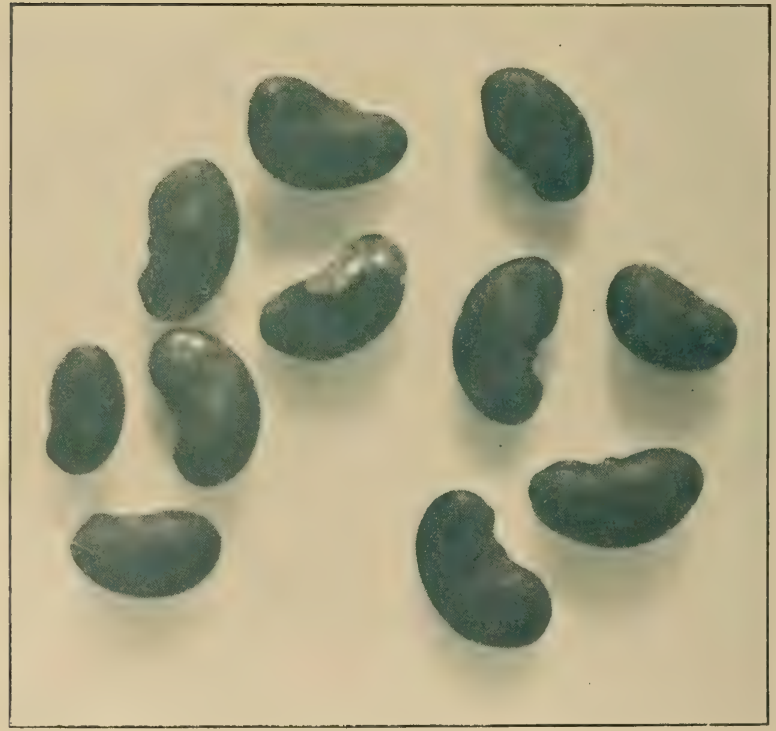

Alfalfa Seed Magnified 
a field subject to overflow, or one where water rises to the surface in winter or spring; likewise on a field so flat that water will not run off in time of a heavy rain or promptly drain out through the sub-surface. The time is rapidly coming everywhere when the intelligent farmer will not try to raise any crop on such a field, undrained. The alfalfa roots will find their way to moisture if given the right surface conditions. There are profitable alfalfa meadows in parts of Kansas where it is eighty feet to water, but there has not yet been found one that is prosperous where water comes close to the surface, or where it stands on the ground in winter.

The other kind of soil where alfalfa refuses to grow is that in which there is too much acidity. This is often the case where corn and wheat have been raised for many years, thus robbing the soil of much lime; a condition that may be remedied by an application of lime to the land just before sowing the alfalfa, harrowing it in beforehand or, if the seed is to be broadcasted, the lime may be applied just before sowing, when once harrowing will suffice for both, or it may be sown with a drill- 500 to 1000 pounds per acre.

A simple test for acidity is to make a deep cut in the ground with a knife, pressing the earth slightly apart; then push a piece of litmus paper into the opening and press the earth together. Leave the paper there for a few hours. If upon examination the litmus paper has a pink appearance it is proof of acidity, and this, as already said, may best be remedied with lime. 


\section{SOIL PREPARATION}

With the only two negative points considered, the more important conditions upon which success will depend may be discussed. One chief essential is the advance preparation. Many of the most successful growers begin their preparations two or three years before they sow the seed. There must be, by rights, the most perfect physical condition of the soil. It should have been plowed deep for at least two years, and in most fields in the central and northern states a two- or threeinch subsoiling along with a seven- or eight-inch plowing will be very helpful.

If corn is to precede a spring sowing, the ground should have a liberal dressing of stable manure plowed under for humus, to encourage earthworms and to introduce the particular bacteria so essential to alfalfa's welfare or at least furnish favorable conditions for bacteria, and the harrow should follow the plow each day. The soil's condition should be like that for a garden. Care should be taken never to work with the ground when too wet, as such working almost inevitably results in clods and baked soil. The corn should be cultivated often, and a liberal sowing of cowpeas just before the last cultivation, which should be shallow, has been found quite helpful. This crop will repress and take the place of weeds, furnish a rich food for fattening pigs or lambs after the corn is cut, add fertility to the soil, and also introduce bacteria similar to the bacteria for the alfalfa. The cowpea, being a legume, prepares the way for alfalfa, its near relative. 


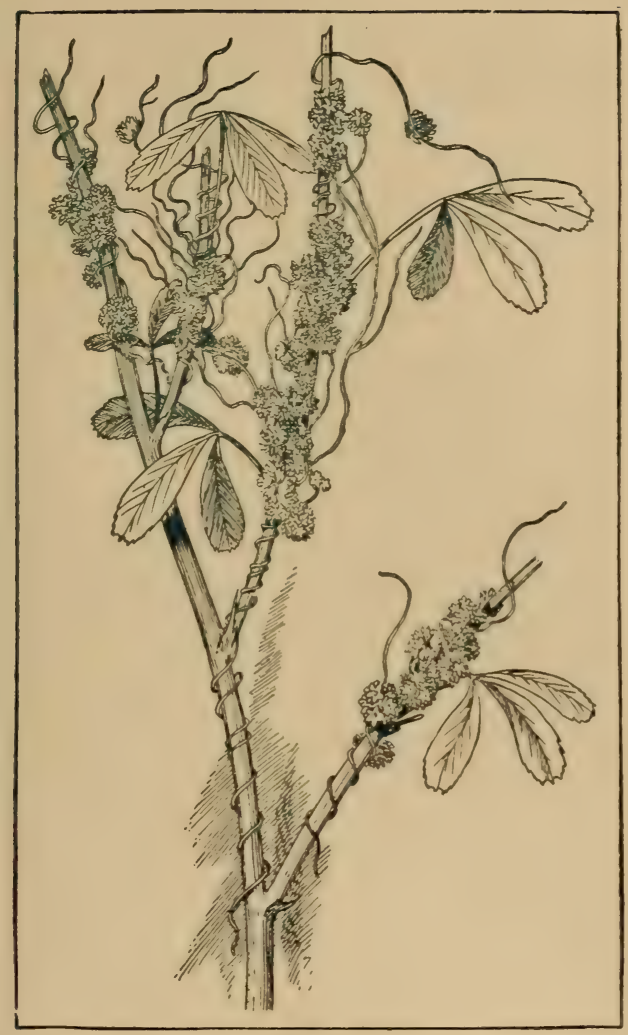

Dodder Plant on an Alfalfa Stem 


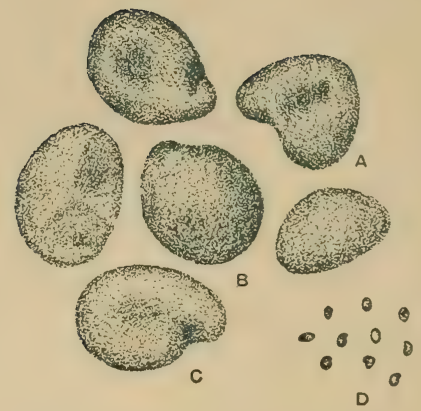

Dodder, Cuscuta arvensis

(a) A group of seeds (enlarged), showing the prevailing forms; ( $a$, b, and c) individual seeds having somewhat the form of clover seeds; (d) a group showing the natural size.

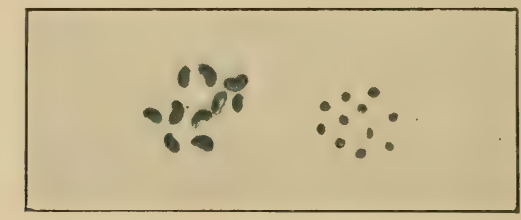

\section{Alfalfa and Dodder Seed. Actual Size}

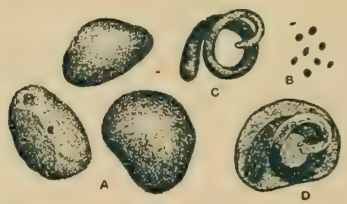

\section{Dodder, Cuscuta epithymum}

(a) A group of seeds, showing comparative forms and relative size (enlarged); (b) a group showing the natural size; (c) the embryo removed from the seed, showing the form it usually assumes; (d) a section of a seed, showing the manner in which the embryo lies imbedded in the endosperm. 


\section{KEEP DOWN THE WEEDS}

It is always timely to emphasize the very great importance of keeping down weeds in the cornfield where alfalfa is to be sowed the next spring. If corn is husked from the fields, the stalks should not be pastured except when the ground is fully frozen. Later they should be thoroughly broken, raked and burned, to leave the land in the best condition for spring work. If the corn is cut and fodder hauled off, the stubs should be broken in cold weather by a pole or other drag, and raked and burned as recommended for the stalks. This adapts the ground for disking and harrowing early in March. Then every ten days the field should be disked or harrowed to conserve moisture, to start weeds and then kill them, and to bring the ground into the desirable tilth. Ordinarily, in the central states, sowing may be done early in April, while in the South this may be done by the middle of March, and in Wisconsin and Canada by the last of April or early May, although the dates are variable. Many report seeding in Kansas the middle of May, obtaining a clipping in July and a hay crop in September. Others report sowing in March and cutting a hay crop in June. Some Wisconsin reports say that the first of June is early enough, while others in that state and in Minnesota prefer to sow two or three weeks earlier, and still others in Wisconsin sow in April. The important things to keep in mind are to have the soil right and the weeds disposed of, and to sow when the weather and moisture and conditions are right. Alfalfa is a child of the sun; permanent shade from any source is its enemy, and when young it is not a good fighter against adversaries of any sort. More 
failures are due to weeds than to any other one cause, and unfortunately all the weeds do not grow on the land of the farmer who is shiftless or neglectful. The latter is so benevolent as to permit his weeds to scatter their seeds to the fields of his neighbors.

If a spring sowing is to be made on wheat ground, the land will be helped by a liberal dressing of manure immediately after the harvest, and by plowing and harrowing at once; then sowing about the last of August to rye or wheat for fall and winter pasturage, and to prevent the soil from leaching or washing. In the spring the land should be disked and harrowed for alfalfa, keeping in mind the point emphasized in the preceding paragraph. Instead of the rye or wheat, cowpeas may be sowed after the wheat harvest; thus both fertility and bacteria will be added to the soil, and the farmer have a valuable pasture crop for pigs or lambs. If the season is extremely favorable, a hay crop may be cut in early October.

If potatoes are to precede a spring sowing of alfalfa, more than usual care should be taken to keep the field clean of weeds. Some farmers do well by sowing millet with the last cultivation of potatoes, leaving the potatoes in the ground until after the millet is harvested, and when the crop is dug the land is free from weeds. Then it may be harrowed or disked and seeded to rye for winter pasture. Some plow the potato ground in the fall and sow to wheat or rye. Certainly if weeds are present the ground should be plowed as soon as the potatoes are dug. The idea is to secure a fine seed bed and have the ground free from weeds, the great curse of the American farm. All things considered there is probably 
no crop which leaves the soil in finer physical condition for alfalfa-sowing than millet, and none that is more unsatisfactory for a like purpose than sorghum or Kafir corn that was planted in hills or rows.

A clover sod for a spring sowing should be plowed in September or October, disked or harrowed, and not infrequently a light sowing of rye for winter pasture is feasible. In early spring use disk and tooth harrows on the land. It is excellent if a liberal application of rotted stable manure is plowed under with the clover sod. Usually it is better to follow clover with a corn or potato crop before seeding to alfalfa.

\section{FALL SOWING}

Fall sowing presents fewer difficulties than spring sowing. Corn is not the preceding crop and hence the weed problem is not so formidable. Usually a fall suwing follows millet or oats, cowpeas or potatoes. Almost any crop except the sorghums may be grown to precede alfalfa for a fall sowing; these should not be as they consume too much moisture. If possible, put on a dressing of stable manure the preceding winter; plow deep in the spring and work to a fine tilth for the summer crop. South of the latitude of 40 degrees cowpeas is one of the best preparatory crops. They are legumes, and the bacteria that live on their roots are similar to those upon the alfalfa roots; they are also nitrogen-gatherers, taking nitrogen from the air as does the alfalfa, and thus they prepare the soil for alfalfa. Besides, cowpeas are a valuable forage, the hay being worth almost as much, pound for pound, as that of 
alfalfa. When cut off they leave the ground ready for disking and other preparation. Millet is also excellent for this purpose, leaving the soil unusually friable. Potatoes make a satisfactory preparatory crop, but the danger from them too often is neglect to keep the weeds down. As soon as the land is free, it should be disked and harrowed, and this repeated about every ten days until the time for sowing.

\section{RECENT PLOWING NOT DESIRABLE}

It is seen that plowing for alfalfa just preceding the seeding is not recommended. Plowing leaves the subsurface too loose, thus depriving the roots of a sufficiently firm footing and making a full sowing more liable to harm from freezing and thawing, and the spring sowing to harm from a dry summer. The necessity of the most perfect surface conditions cannot be to often emphasized, and this too includes considerable compactness rather than a too light or ashy condition. There must be no clods, no stiff and stubborn humps.

If alfalfa is to follow clover, and to be seeded in the fall, the sod should be broken early after the clover is harvested and each day's plowing harrowed that day; then the field disked and cross-disked and harrowed again. After that it should be disked, lapping half, every ten or fifteen days until time for seeding. Alfalfa may follow timothy if the sod is not too old and stubborn, and it may be treated the same as clover sod.

\section{INTRODUCE BACTERIA BY PREPARATORY SOWING}

Another form of preparation followed by many successful growers, men who do not complain about alfalfa 
not doing well "here," is the sowing of a few pounds of alfalfa seed on the field two or three years before it is intended to sow for a permanent crop. Mr. Joseph E. Wing, of central western Ohio, a widely known farmer, stockman, and writer on matters agricultural, uses alfalfa in a regular rotation, and two years before he is ready to sow it on a given field as a main crop, sows clover and timothy along with two or three pounds of alfalfa seed, for a pasture crop. Thus the bacteria are introduced, and when the pasture is plowed for the full sowing of alfalfa, the disking and harrowing that follow distribute the bacteria throughout the soil, and the probabilities of a good stand are greatly enhanced. He sometimes sows two or three pounds of alfalfa seed to the acre with a wheat crop two years before he is to sow the field entirely to alfalfa. Another, in a state where the experiment station director still declares alfalfa-raising to be doubtful, writes that he has not had a failure in a decade, and his plan is to precede alfalfa with winter wheat, sowing a little alfalfa seed with the wheat, probably three pounds to the acre, and the next fall after giving the land a thorough preparation he sows fifteen pounds of alfalfa seed to the acre. Another reports pleasing results in two different fields by sowing in the spring five pounds of alfalfa seed with clover; in two years the alfalfa stood thick on the ground, having crowded out the clover. If these plans introduce the bacteria into the soil, it may be wondered why it would not be equally helpful to sow two or three pounds of alfalfa seed per acre with the oats or millet in the spring, preparatory to the thorough seeding to alfalfa in the fall. 
Another man, whose profit in raising alfalfa has been marker, reports that his soil is very waxy and hard to deal with. He has met this trouble by listing his ground in the fall and leaving it thus open for hard freezing throughout the winter. He then disks and cross-disks in the spring, putting the soil in fine tilth, and sowing millet as a preparatory crop. He has occasionally sowed alfalfa in the spring, following the fall listing and later freezing of his ground.

\section{ALL CROPS DEMAND CONDTTIONS}

Alfalfa, like corn and cotton, demands certain conditions of the soil and certain constituents in that soil. Every crop demands its certain foods. All crops except alfalfa and the other legumes obtain practically all their food, including nitrogen, from the soil. The latter crops use nitrogen but get it from the air. Alfalfa takes nitrogen from the soil only during the first few months of its growth, and thereafter not only takes its own necessary supply from the air, but a large surplus which it stores in the soil, available for whatever crop may follow. Other crops take much nitrogen from the soil, but contribute nothing to its enrichmen ${ }^{2}$

\section{SPRING OR FALL SOWING-WHICH?}

This has been a much argued question with experimenters. Possibly it will be found to be of minor importance in itself, depending more upon other conditions than the season. From the northern tier of states many reports favor spring sowing, yet from each come letters in favor of fall sowing. Several experiment stations in the South are in favor of spring sowing, yet report sat- 
isfactory results from fall seeding. It seems pretty well established, however, that fall sowing is safer in the central latitude states, say including Ohio, Nebraska, Missouri, Kansas, Colorado and Utah, and states within the same parallels.

In other states prevailing opinions favor spring sowing. Nevertheless, when all conditions are understood, fall sowing seems likely to become the established practice throughout the United States. This is in line with the system for the more staple crops and common rotation; it gives opportunity to bring the ground into better condition; the preparation and sowing come at the most convenient season, and one of relatively greater leisure; there is less interruption by unfavorable weather; the soil, responding more readily to surface cultivation, permits the work to be done with less danger of surface water retarding normal root development, and the annual weeds being dead they cannot interfere with the first growth of the alfalfa. Sown in the fall, with time to secure some growth for winter protection, alfalfa will be ready to respond to the first call of spring, and for the mower early in June. Moreover, if it fails from freezing or other cause, little crop-time is lost. The farmer has but to disk and harrow in April or early May, and sow half as much seed as he sowed in the fall, and he will have prospect of a cutting in eighty or ninety days, at an expenditure of but few pounds of seed and a little labor.

\section{DISADVANTAGES OF SPRING SOWING}

Ordinarily, if a farmer sows in the spring, he has his old enemy, the weeds, to contend with. If the season be 
damp and cloudy, the alfalfa may not grow fast, but weeds will. Therefore, June may see him mowing to retard a rampant growth of weeds instead of gathering a profitable cutting of prime hay. It is not improbable that he may be doing the same in July or in September, thus losing a whole season. Again, the spring preparation comes when the farmer needs to be working his corn and potato land; hence he is likely to slight or neglect the careful preparation of the alfaifa ground and so do a poor job, with, in such cases, the usual result of a "poor stand." Then too, the frequent rains interfere with regular disking and harrowing and the weeds may obtain a start the farmer cannot check. In most cases fall sowing means three cuttings the following year. In many instances spring sowing means no crop the first season, although better farming will gain a September crop, while the best farming, with no weeds, may give two if not three crops; not heavy ones, perhaps, but of no inconsiderable value.

Commenting on spring sowing in the more northern states, Henry Wallace, editor of Wallaces' Farmer, says :

"Our own experience in growing alfalfa both in $\mathrm{Ne}$ braska and Iowa has taught us that it is a waste of time and labor to sow in the spring. If sown in the spring without a nurse crop, it will have to be mowed twice, probably three times, to keep down the weeds, and even then it will not be in as good condition as if a crop of early corn or even oats was taken off, and the ground put in fine condition and seeded in August.

"In I904 we sowed in the spring 250 acres of alfalfa on our Nebraska farm, and some twenty or thirty acres 
of it was washed in ridges by a very heavy rain immediately after. We reseeded the vacant spaces in the fall and later could see no difference between the fall sowing and the spring sowing. We did the same thing on one of our Iowa farms, sowing in the spring and mowing three times. Another piece was sowed in August. The August sowing was much better than the spring sowing. It should be said, however, that the land was richer and the difference was therefore not all due to the time of sowing. So long as Kansas farmers continued to sow their alfalfa in the spring they had but partial success, owing to the fact that Crab grass and other grasses will come up in the early fall and smother out the spring sowing. By using some other crop the first part of the season, then putting the land in fine condition in the month of August or even by September Ist, an alfalfa crop can be started which will have a strong enough growth to smother out the weeds the next spring.

"We don't know that we would insist on this so strongly for northern Iowa and Minnesota, but certainly from the latitude of the Northwestern railroad in Iowa, south, and corresponding latitude in other states, we would abandon spring sowing and sow alfalfa on well prepared ground in August. We would not, however, plow the ground for this fall sowing, but put the soil in first-class condition for a spring crop, then use a disk and harrow for the fall preparation."

\section{SEEDING BY DRILL OR BROADCAST?}

Here too, there is a variety of opinions, all based on experience. Those who object most to drills may have 
used poor implements, with feeding gears not well regulated, or possibly they have not known how to use the drills. Many who object to the broadcast method have had little training or skill in it. It is reasonable to suppose, however, that given soil in fine tilth, and a good drill rightly adjusted, there will be a more even, and hence a more economical distribution and a better and more uniform covering of the seed. It is also claimed that drilling secures a more uniform distribution of soil moisture. The general opinion is that by sowing with a drill, properly regulated, one can safely use five pounds less of seed per acre. Some alfalfa raisers use a wheelbarrow seeder; others use a kind of swing seeder strapped to the sower's body; still others, who have had training in the old-fashioned method of broadcasting, declare it the best, but the experiment stations of practically all the states, and most up-to-date farmers, favor the use of the press drill. A very common method when using the drill is to mix an equal quantity of wheat bran, corn meal, or alfalfa meal with the seed, as aids to an even distribution and a not too excessive seeding. At the Kansas agricultural college farm, success has followed broadcasting; and when the drill has been used no particular advantage from cross-drilling was discovered.

\section{HOW MUCH SEED TO THE ACRE?}

Reports of seed sown, varying from six to sixty pounds to the acre, indicate much ignorance of the nature of the alfalfa plant; or a great recklessness and extravagance. Twenty pounds to the acre, if all seeds 
germinated, would mean $2,500,000$ to $3,000,000$ plants, whereas a stand of 500,000 is ample. Most of the experiment stations favor twenty to thirty pounds to the acre, although several experts at these stations insist that fifteen pounds of clean, germinable seed to the acre is as much as should be sowed. Even if these all grew it would give nearly 44 plants to the foot square of land, or four to five times as many as would thrive after two years old. Of course the quantity may depend upon a variety of circumstances, such as the vitality of the seed, condition of the surface soil, condition of the subsoil as to moisture, the method of sowing, weather conditions at the time of sowing or immediately after, also the natural fertility of the soil and the bacterial life present, or at least the conditions for propagating or sustaining bacterial life. With land prepared by sowing a few pounds of seed six months or a year preceding, with a heavy application of stable manure plowed under six months before, perfect soil preparation, normal moisture, and clean seed, testing ninety per cent germinable, there should be no need for more than ten pounds to the acre. Disking that the field should have later will split the crowns and many new stalks will be sent up; so that in a few years a square foot of surface will not accommodate more than six to ten robust, vigorous plants, and having these the ideal stand has pretty nearly been attained. One plant has been known to send out as many as 360 branches from its single main root, resembling in form a spreading bush. A successful farmer in Geary county, Kansas, who has been raising alfalfa for twenty vears. seldom sows more than six 
pounds of seed to the acre and never more than ten. A prominent Ohio farmer usually sows but ten, and never over twelve or fifteen pounds to the acre, although he has always introduced alfalfa bacteria into the soil one or two years before ready to give it a full seeding. Of strictly good seed, well cleaned, twelve pounds would likely be too much rather than too little, other conditions being right.

\section{WITH OR WITHOUT A NURSE CROP?}

The practice of sowing a nurse crop with alfalfa was inaugurated when the nature of the plant was not as well understood as now. It was also somewhat on the theory too that " a half-loaf is better than no bread." It began when there was a good deal of doubt about "getting a stand," and the farmer thought no doubt that a crop of oats or barley would pay for the plowing even if the alfalfa failed. While the practice is continued by many, the prevalent later method is to provide no nurse crop. Few who have abandoned the nurse crop have returned to it. The alfalfa plant does not need protection from the sun, nor is it bettered by dividing any of the soil moisture or fertility with those of another crop. On the other hand, if alfalfa is sowed in the spring, it is important that it obtain an early start in order that its roots can quickly work their way down into the moisture of the subsoil, against the dry days of July and August. When a nurse crop of any vigor is removed the alfalfa plants are likely to be found weak, spindling and with little root growth; the nurse crop also has taken up some of the soil nitrogen needed by the young alfalfa; or if 
the nurse crop is heavy and has lodged, there will be left bare spots, where the alfalfa has been smothered out.

Cutting the nurse crop is likely to be attended with no little damage to the tender alfalfa plants by trampling their crowns into the ground, or by breaking them off. Practically all the experiment stations favor sowing alone. With few exceptions the second and third years have brought heavier yields where no nurse crop was used. The theory that the nurse crop will prevent the weeds choking the alfalfa is apparently, as a rule, not well founded. In the first place alfalfa should not be sown on foul land, and in the second place proper disking and harrowing, at near intervals for four or six weeks before sowing, will disturb or kill far more weeds than can any nurse crop. Besides, the oats or barley sown as a nurse will when cut leave weeds in good growth, or dormant and ready to spring up as fast or faster than the alfalfa. No nurse crop is ever used with fall sowing. When ground has been thoroughly prepared for the preceding crop, and then properly cared for, and made ready for the alfalfa by the preliminary weed destruction, it will be found advisable to sow alfalfa alone, even in the spring.

\section{INOCULATING THE SOIL}

It has been found where alfalfa shows thrifty vigor. is making a good stand, and is at least two years old, that on the roots are little nodules or wart-like protuberances. On fields where the alfalfa is unthrifty or failing to make a good stand, examination will probably fail to discover any of these nodules. Scientists tell us 
that these nodules are the homes of bacteria, microscopic vegetable organisms obtaining their sustenance from the nitrogen of the air and the starch of the plant; that they collect much more nitrogen than they need, the over-supply being taken up by the alfalfa, which, after these nodules are formed and occupied, takes no more nitrogen from the soil, but annually stores about its roots more from the air, thus adding to the nitrogen supply in the soil instead of taking from it as do all other farm crops except the legumes. Each legume-clover, alfalfa, cowpeas, etc.- has a distinct species of bacteria, or at least bacteria with a distinct development, excepting, as has been found, that Sweet clover (Melilotus alba) and Bur clover (Medicago denticulata) develop the same species as does alfalfa.

\section{BUYING INFECTED SOIL,}

Several methods of preparing land for alfalfa by introducing its peculiar bacteria have been suggested, and practiced to some extent. Many farmers and experimenters have used with success infected soil upon their lands; soil from established alfalfa fields, or that from along the roads or creeks where the Sweet clover or Bur clover has been growing. This soil is spread upon the field or sown with alfalfa just before the seeding. If the drill is to be used the inoculated soil is spread on and harrowed in. If the seed is to be broadcasted, the infected soil may be harrowed in with the seed. It is better, however, to harrow this infected soil in thoroughly before seeding. Experiment stations recommend an application of two hundred pounds of such soil to 
every acre, but good results have been secured from half that quantity. This will depend very much upon the nature of the soil, and the subsoil especially. Many fields seem to have these bacteria waiting for the coming of alfalfa. Land that has been well manured and contains abundant humus, and land that is light and friable will usually respond to the bacterial life attached to the alfalfa seed. Most farmers who have established fields will sell soil to their neighbors, which should be from the top six or eight inches, and include roots, stubble and earth. Both Sweet clover and Bur clover are found in almost every neighborhood in the northern states, while the latter is very general in the South.

Some alfalfa raisers make a business of selling and shipping inoculated soil. Probably any experiment station will ship small quantities to farmers within its state, at about the cost of digging, sacking and delivering at the railroad station. Therefore, if a farmer desires to use it, little labor or expense is attached to doing so. There is reason, however, to doubt the need of this method in any of the western or central western states where the suggestions mentioned in the first part of the chapter are closely followed. No doubt there are advantages in using it in most states east of the Mississippi river, in order to hasten the development of the bacteria and to make a good stand more certain. Preparation one or two years in advance as already described, by a light sowing of alfalfa seed for introducing its peculiar bacteria, is less expensive, and requires less labor and carries no risk of introducing the seeds of other clovers or weeds. Most farms have enough weed seeds already. 


\section{DANGERS OF INOCULATION BY SOIL TRANSFER}

Touching upon the dangers possibly resulting from inoculation by soil transfer a bulletin from the United States Department of Agriculture has this to suggest:

"Satisfactory inoculations have been obtained by transferring soil from old fields on which the legume has been grown, but experience has shown that there are dangers incident to such methods of soil transfer which it is wise to avoid.

"The source of supply of such soil should be definitely known, and in no case should soil be used from fields which have previously borne any crop affected with a fungous disease, a bacterial disease, or with nematodes. Where a rotation of crops is practiced, it is often difficult to make sure of this factor, so that the method of soil transfer is, under average circumstances, open to suspicion, if not to positive objection. Numerous animal and plant parasite live in the soil for years, and are already established in so many localities that it is manifestly unwise to ship soil indiscriminateıy from one portion of the country to another.

"The bacterial diseases of the tomato, potato, and egg plant, and the club-root, brown rot, and wilt disease of the cabbage, all more or less widely distributed, are readily transmitted in the soil; while in the South and West there are the wilt diseases of cotton, melons, sweet potatoes, cowpeas, and flax, and various nematoid and rootrot diseases which might easily become a serious menace over areas much larger than they now occupy if deliberately spread by the careless use of soil for inoculation purposes. There are several insects and fungous 
diseases of clover to be avoided, and various diseases of beans and peas. There is also a disease of alfalfa, the 'leaf spot,' which is causing damage in some regions. These are only a few of many diseases liable to be transmitted in soils. The farmer should therefore be on his guard. The danger from such sources is by no means imaginary. The Department of Agriculture has had specific cases of such accidental distribution reported, and if the business of selling soil for inoculation is made to flourish by farmers purchasing without question 'alfalfa soil,' 'cowpea soil,' etc., there is every reason to believe that experience will demonstrate the folly of such haphazard methods.

"Of scarcely less importance is the danger of disseminating noxious weeds and insect pests through this plan of inoculation by means of soils. Even though weeds may not have been serious in the field, the great number of dormant seeds, requiring but a slight change in surroundings to produce germination, is always a menace. The enormous damage to crops caused by introduced insects and weeds should convey a warning and lead to caution. It is not the part of good judgment to view the risk as a slight one."

\section{OTHER METHODS OF INOCULATION}

There are two or three better ways of inoculating land than by using a neighbor's soil. Some alfalfa raisers recommend the sowing of alfalfa meal with the seed. Another plan which appears reasonable and practicable is for the farmer who wishes to introduce alfalfa to buy alfalfa hay the year before and feed it to his live stock; 
then haul the manure to the fields and plow it under for the crop to precede alfalfa. It is claimed by those who have done this that a satisfactory stand is well-nigh certain, other conditions being met. It can be said, however, that some high authorities on this crop, men who have experimented on many different kinds of soil and who have succeeded under varying conditions, declare that neither soil nor seed inoculation is necessary. It is altogether probable that if a field has been well farmed for a few years previous to the alfalfa-sowing, with unusually good cultivation the preceding year, a heavy application of stable manure plowed under at least five months before, then given the proper preparation and seeding, using seed raised in about the same latitude and under similar conditions in which the new crop must grow, and with seed testing ninety per cent germinable, there should be little anxiety about the need of inoculation. Of course old, worn-out land may require more fertilizers, restoring to the soil not only necessary nitrogen that has been exhausted by other crops, but also the potash and phosphorus. In eastern states it has been found advantageous also to apply a very light top-dressing of stable manure just before sowing the seed. If lime is deficient, that must be applied. An examination of any particular soil will usually be made without charge by the state chemists, and the farmer may thus approximately ascertain just what the soil will need for alfalfa, corn, or any other crop he may desire to raise.

\section{KEEP ON TRYING}

It is important to say to the eastern farmers, especially, that there is little difference between successful 
alfalfa-growing and the successful growing of other crops. Poor farming never brings big crops, nor will poor land produce as big yields as the more fertile. Failure to restore to the soil the necessary elements of which it has been robbed means the same in New York, Kansas, Virginia, or anywhere else. Every farm plant, to prosper, must find in the soil, readily available, the elements needed for its development. If a farmer finds the soil lacking in elements needed for certain crops, he should either apply the deficiency or not attempt their raising. This is true of corn or wheat, cotton, or tobacco, no less than alfalfa.

Alfalfa needs especially nitrogen, potash and phosphorus. The average virgin soil in the United States contains enough of these to last several hundred years. If there had been at all times an intelligent rotation of crops, these chemical elements would be found in just as large proportions in the soil that has been farmed a hundred years as in the soil never cultivated. Hence, if after trying alfalfa a man meets with failure, he should not stop, and say, "Alfalfa won't grow 'here'," but try it again immediately. If he discovers a seeming failure in March or April, he should disk and harrow and as early as possible sow about ten pounds of seed to the acre; in many instances he will have to clip his alfalfa in about six or eight weeks and can mow a crop of hay in September, or possibly two hay crops in the season. There have been various cases reported where three hay crops were secured the first season after such cultivation, when the fields had been pronounced a failure in March. Alfalfa may be sown on such ground as late as the first 
of June if the weeds have been thoroughly subdued. Or, if it has been sown in the spring and the weeds seem to be overtopping it in July, mow close to the ground, rake into windrows and burn. Then disk and harrow thoroughly and sow again. In all probability there will be something of a crop to mow early in September, with a considerable autumn growth to follow. If it is not desired to sow alfalfa in midsummer, disk this ground and sow to rye or oats for pasture; then late in August disk and put in readiness for September sowing. The failure may have been because the soil had not enough bacteria, or favorable environment for the bacteria. Some of the seed sowed at first undoubtedly germinated and some bacteria were developed; enough certainly to prepare the soil for the second sowing. It is unwise after such a failure to go to another field or to wait for another year. It is wiser to meet the conditions at once, and vigorously persevere.

In reference to the application of lime, mentioned on a preceding page, it should be noted that the later experiments seem to indicate that it is better to apply smaller quantities at shorter intervals than larger quantities at longer intervals; also that air-slacked lime is less caustic than the quicklime, and not so liable, when recently applied, to harm the young plants which may come in contact with it, hence more of the former may be used and with greater safety. Ordinarily quicklime is considered the most beneficial. 


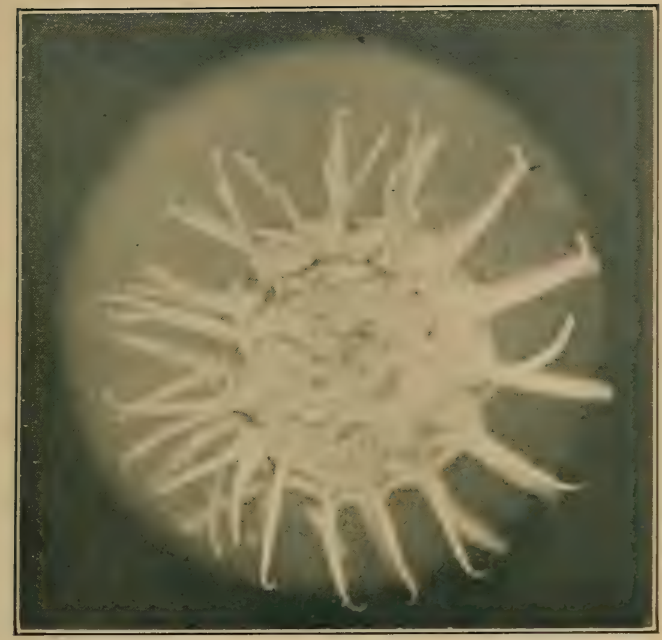

\section{Bur Clover Pod}

Magnified six diameters

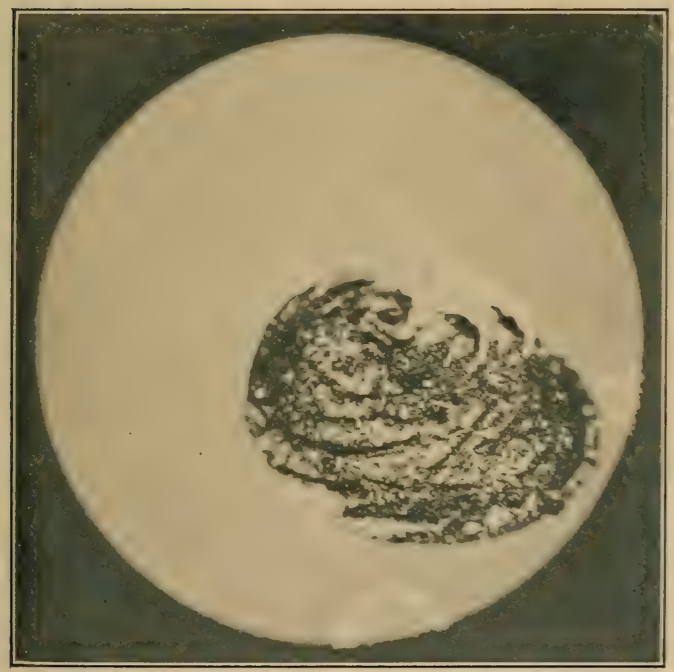

Yellow Trefoil Seed Pod

Magnified twelve diameters 


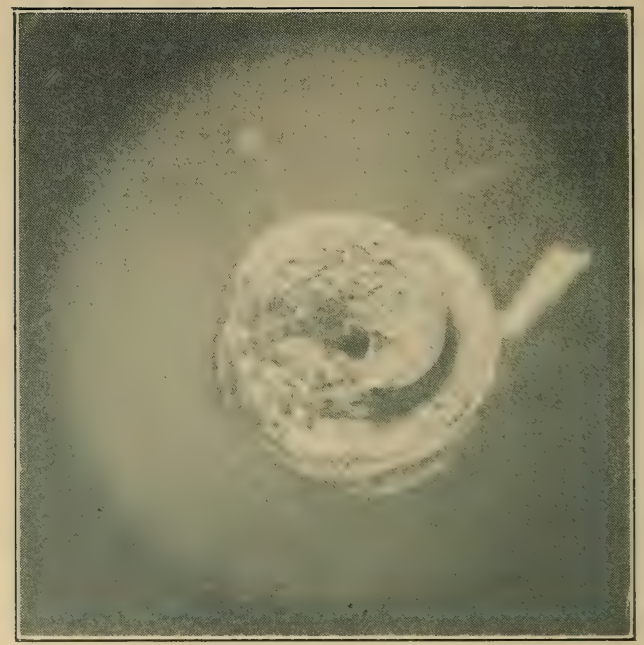

Alfalfa Seed Pod

- Magnified six diameters

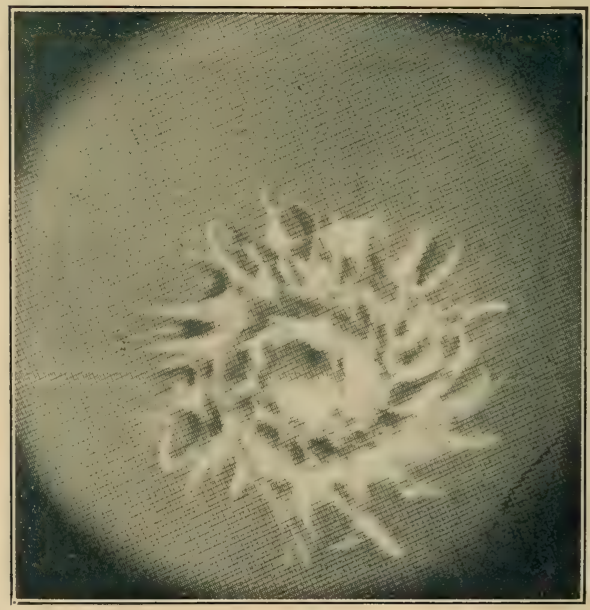

Spotted Clover Pod

Magnified six diameters 


\section{Cultivation}

\section{CLIPPING IS AN INVIGORANT}

Strange as this title may seem it suggests a very important means of securing a satisfactory stand. In fact in some parts of the South, where the land has become very foul, it is occasionally recommended to sow the alfalfa in rows, eighteen inches apart, for regular cultivation the first season. After the second year the crowns will have sent up so many stems that the surface of the ground will be well occupied. Spurrier, in his work referred to in Chapter I, recommended drilling in rows and cultivating the first year. But it is better to get rid of the weeds before trying alfalfa. The cultivation here recommended is clipping, manuring, disking and harrowing. Frequently when alfalfa is sowed in the spring it comes up weak and spindling. In such case clip it just before ready to bloom, having the mower sickle set rather high. If the growth is not very heavy, leave this cutting on the ground; if quite heavy, remove it. The field may need to be clipped again cluring the summer, but the farmer can feel reasonably assured that he will have a good stand the following spring. If the leaves turn yellow, mowing is the remedy. If there is any sign of the "spotted leaf" disease, the mower should be used 
forthwith. Of course if alfalfa comes up strong, vigorous, and free from weeds, it should stand until blossoming is well begun and then be mown for hay.

It should not be supposed that the purpose in clipping and allowing the clippings to remain on the ground is primarily to make a mulch. It is to retard the weeds, and as no other way equally convenient and economical has presented itself, the young growths are mown and left on the ground.

In many parts of the country Crab grass (Panicum sanguinale) is the plant or weed that most persistently interferes with the prosperity of alfalfa during its first year, and frequent mowing is the remedy most recommended and resorted to, but there are growers who maintain that such treatment is not best. An extensive and very successful grower in southern Kansas tells the author repeated experience has demonstrated to his satisfaction that the advice to mow alfalfa frequently during the first summer may under some circumstances be quite wrong. If the season happens to be wet, and there is a rank growth of Crab grass, frequent mowing causes the Crab grass to set in a close sod and smother out the alfalfa. He says: "My practice has been, under these conditions, to let the Crab grass grow with the alfalfa until matured, before mowing. The young alfalfa will usually keep its head out sufficiently to breathe, and will survive until the Crab grass is matured and all is cut. If allowed to mature, the Crab grass will not start a second time, and the alfalfa immediately springs up and occupies the ground. Where the Crab grass is very rank it may sometimes be blown down in spots and smother out some 
alfalfa, but even under these conditions one will have a much better stand than is possible by repeated mowings. This is not mere theory, but has been proven correct by frequent experience and close observation of the other method during the same seasons." Something similar may be said of Witch-grass (Panicum capillare), which, however, is less obnoxious than the Crab grass, because of not having the habit of rooting at the joints.

In many parts of the country Crab grass (Panicum sanguinale) is the plant or weed that most persistently as to make burning in the spring seem the most feasible means of getting rid of them, and fire is resorted to. Prof. A. M. Ten Eyck says he has seen this done a number of times without injury to the alfalfa crowns. He, however, recommends disking after burning, to loosen the exposed soil and leave the surface generally in a better condition. Sowing additional seed on the ground before such disking may do much to improve and thicken the stand.

The editor of the Nebraska Farmer has been collecting information on alfalfa culture from every section of the United States for the past ten years, and as a result of this work unhesitatingly advances the opinion that "ninetenths of the failures with alfalfa have been due to failure or neglect to cut it as should have been done when young. This is the law of alfalfa culture; it must be cut down. And the man who has not the courage, morally and physically, to use a mowing machine persistently had best pass by alfalfa culture. It takes moral courage to cut baby alfalfa ; but it must be cut down to save it." 


\section{MANURING}

A light top-dressing of manure after sowing, or, in case of fall sowing, any time during the winter, helps to conserve moisture as well as to give the growing plants some nitrogenous food. Applying a top-dressing of stable manure at least every second or third winter is certain to prove profitable. If it contains coarse straw or other litter, this should be raked and hauled off later, but before the alfalfa grows too high, especially if the hay is intended for the city market. Many successful growers in Kansas, who claim to cut from five to seven tons of alfalfa hay per acre in a season apply a top-dressing of manure every winter. The highest yields reported from eastern states are where this practice is followed. Some experiment station men believe that where this is not done the crop will after eight or ten years tend to impoverish the land instead of further improving it.

\section{DISKING}

The foremost method of cultivation is with the disk harrow, one of the most excellent farm implements ever invented. Alfalfa sown in the fall is almost invariably helped by disking the following spring, with the disks set quite straight, so as not to cut the crowns but to split them. It is usually well to follow this disking with a tooth harrow, with its teeth set straight. Occasionally in a dry summer the disk may be used to great advantage after the second, and possibly the third, cutting also. Many disk their alfalfa field every spring, and some after each cutting, others do so only once in every two or three years, owing to weather conditions and the conditions of the alfalfa. In some instances the common harrow is used instead of a disk. 
The disking has several beneficial effects. It splits and spreads the crowns, causing more and consequently finer stems to spring up, affording hay of the most delightful quality, easily cured; it loosens the soil about the crowns, conserves moisture and destroys the weeds. There need be no fear of killing the plants if the disks and the harrow-teeth are set straight and weighted or otherwise adjusted to give direct and steady forward movement. As an implement for the cultivation and invigoration of an alfalfa field the disk harrow has no equal, and its frequent use is by those who know it best deemed quite indispensable.

\section{RESEEDING}

If it is a question of reseeding the whole field, the problem is simple. In that case disk and harrow the ground and sow half as much seed as was sowed at first. But to restore bare spots is more difficult; the young plants from the reseeding in these spots will be shaded by the larger growth about them, and such reseeding seldom gives the desired results. There is no doubt that very many fields are given up as failures and inferior crops planted in them, when a thorough disking would have renewed the growth, saved a crop, and, what is more important, a stand of alfalfa. Many reports have come to the writer of fields that had little sign of life the first of March, yet when thoroughly disked, cross-disked and harrowed, surprised the neighborhood by showing in two weeks a strong growth.

Some wishing to be on the safe side, have sown a little seed after this heavy disking and harrowing, but many of them have reported an entire loss of the seed, 
as the plants from the previous sowing came up so thick as to choke out those from the later seeding. In some states a common plan of thickening a stand is to let the third crop ripen seed, and then about the last of September disk and harrow the seed into the ground where it grew. This frequently saves the stand and adds many years to its life. But where a field begins to fail after a third year it is usually better to plow it up and raise one or two crops of corn, a crop of oats or of millet, and then reseed.

\section{ALFALFA UNDER IRRIGATION}

The greatest yields of alfalfa are produced by irrigation. Reported yields of six or more cuttings, aggregating eight to twelve tons per acre each year, are almost invariably, yet not always, from districts where irrigation is practiced. It is claimed by experiment station experts from the irrigation states that the tendency is to use too much water; too much at a time and too often. The general recommendation is to irrigate thoroughly before the ground is plowed or disked, and not again till the alfalfa is about four inches high. Then again a week before each cutting. It has been found that old alfalfa fields do not need as much water as new fields, the alfalfa roots seeming to find moisture and bring it to the surface.

It is insisted that the surface must be perfectly smooth to keep water from settling into low places and smothering the plants. Some farmers do not irrigate for the second crop if as much as two inches of rain falls after the first mowing. Others claim that old fields do not need flooding for the second crop even if there has been no rainfall after the first cutting. 
Wilcox in his "Irrigation Farming"* says: "The critical time with alfalfa is the first six weeks of its growth. Flooding during this period is quite certain to give the plants a backset from which they seldom fully recover before the second, and sometimes not before the third year, and it is not often in the arid states that rain falls with sufficient frequency to dispense with the necessity for irrigating the plants while small. By soaking the earth from thirty-six to forty-eight hours before seeding, however, the plants will make vigorous growth until they are ten to twelve inches high, after which they may be irrigated with safety.

"When alfalfa has become established, a single copious irrigation after each cutting will ordinarily be found sufficient. Irrigation before cutting is undesirable, because it leaves the earth so soft as to interfere with the movement of machinery and loads. It also makes the stalks more sappy, and, while they will retain the leaves better, there is more difficulty to be experienced in the curing at harvest time; and taken all in all, we much prefer to irrigate after each cutting. In Colorado we cut alfalfa three times and often four times in a season, hence the stand gets as many irrigations. Some people irrigate very early in springtime, before the crowns have awakened from their hibernal rest, but this practice is not right. The chill of the water in very early spring is not conducive to quick growth and may often retard the plants in getting an early start. We do not irrigate prior to the first cutting unless the season is particularly dry and the plants seem to actually demand water. We * "Irrigation Farming," by Lute Wilcox: 314 pp. Orange Judd Company.
New York. 
irrigate late in the fall and apply a top-dressing of light barnyard manure, which is found to be of great service in several ways."

\section{INFLUENCE OF IRRIGATION UPON COMPOSITION}

I find no report of experiments published by any station in which the influence of irrigation upon alfalfa hay is made a special study, but Bulletin No. 80 of the Utah station contains a great deal of information along this line relative to grain crops, potatoes, and mixed grasses. In summing up the results of the experiments, the following conclusions are

"Heavy irrigations increase the percentage of weight of the heads of plants; light irrigations increase the relative weight of leaves.

"Irrigation modifies definitely the composition of plants and plant parts; the seeds are affected more than any other plant part.

"The percentage of protein in corn l.ernels was increased from I2.05 to I5.08, as the amount of irrigation decreased; in oat kernels from 14.07 to 20.79 ; in wheat kernels from 15.26 to 26.72 . In all these seeds the fat and nitrogen-free extracts were increased by liberal waterings.

"Increased irrigations increased the starch content and decreased the protein content of potatoes.

"The water in plants is somewhat dependent on the water in the soil.

"The proportion of ear corn to stover increased regularly with the increased application of water.

"The percentage of grain in the wheat crop increased with increased irrigations. 
"The yield of wheat increased up to thirty inches of water.

"Crops in an arid district require a greater number of pounds of water for one pound of dry matter than in humid climates."

The experiments cited do not include alfalfa, yet the results with other crops would indicate that the percentage of protein in alfalfa hay may be less where the crop is grown by irrigation than where it is grown by dryland farming. The composition of the hay, however, will depend upon the quantity of water supplied to the crop and not upon the method; that is, alfalfa which receives as much natural rainfall as other alfalfa would receive by irrigation, would be similarly affected in composition, and from the experiments with grains reported in the bulletin noted, it would appear that with the application of large quantities of water the percentage of protein is decreased; yet, the yield is increased, and although the feeding value of the crop may be a little less, the quantity may be greater, due to large applications of water.

\section{WIDE VARIATIONS IN CONTENT}

Professor Ten Eyck compiled from their station bulletins the following figures on the composition of alfalfa hay in four different states:

\begin{tabular}{|c|c|c|c|c|c|}
\hline & $\begin{array}{l}\text { Bulletin } \\
\text { Number }\end{array}$ & Protein & $\begin{array}{c}\text { Carbo- } \\
\text { hydrates }\end{array}$ & Fat & $\begin{array}{l}\text { Number of } \\
\text { Analyses }\end{array}$ \\
\hline & & Per Cent & Per Cent & Per Cent & \\
\hline 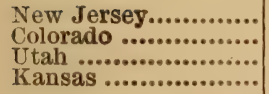 & $\begin{array}{r}148 \\
39 \\
61 \\
114\end{array}$ & $\begin{array}{r}15.84 \\
17.36 \\
9.22 \\
11.89\end{array}$ & $\begin{array}{l}38.97 \\
36.71 \\
43.25 \\
41.03\end{array}$ & $\begin{array}{r}3.82 \\
1.65 \\
.97 \\
.66\end{array}$ & $\begin{array}{r}2 \\
9 \\
29 \\
3\end{array}$ \\
\hline
\end{tabular}


On this showing he remarks:

"Although it was not definitely stated, I take it that the Colorado and Utah hay were grown by irrigation, while the New Jersey and Kansas hay received no irrigation. It will be observed that while the percentages of protein and fat in the Utah samples are low, the percentage of carbohydrates is high; yet the Colorado samples grown under irrigation show a larger percentage of protein and fat than the Kansas samples grown without irrigation. The crude protein often varies in quantity according to the stage of maturity of the alfalfa when it is cut for hay, as shown by experiments at the Kansas station, and described in Bulletin No. I I4.

"The general conclusion may be that the protein content of alfalfa hay will decrease to some extent, according as the supply of water furnished the crop is increased; that is, by supplying the right quantity of water, a better quality of hay may be grown by irrigation than is often grown in humid climates in soil which receives only the natural rainfall. From what I know of the Colorado and Utah stations, I would judge that the quantity of water supplied at the Utah station was much larger than that supplied at the Colorado station. At the Colorado station the supply of irrigation water is often limited, and hence, the larger percentage of protein and fat which appears in the samples of hay grown and analyzed at that station."

The annual report of the secretary of agriculture (I904) says that at the Utah station a series of co-operative experiments is in progress to determine the water necessary, and the most favorable method of application, 
to insure a maximum yield of alfalfa, and also experiments to determine the minimum application of water required to secure a crop. "It has been found that abundant irrigation throughout the season, $6 \mathrm{I}$ inches of water being applied, gave a yield of 6.2 tons per acre, while four irrigations in the early part of the season with only 25 inches gave five tons per acre, showing that beyond a certain supply the excess is wasted."

A. S. Hitchcock, in United States Farmers' Bulletin No. 2 I 5, speaking of the Utah experiment just mentioned, says that where the supply of water is limited a much less quantity than is ordinarily used will produce paying crops. The minimum quantity to produce a crop of alfalfa, and the time at which the water should be applied, depends upon the soil and climatic conditions. Below are results of experiments in 1903 , by the Utah station:

WATER REQUIRED BY ALFALFA; QUANTITY AND DATE OF APPLICATION

\begin{tabular}{|c|c|c|c|c|c|c|c|c|}
\hline \multicolumn{8}{|c|}{ Date of each irrigation and quantity of water applied } & \multirow{3}{*}{$\begin{array}{c}\begin{array}{c}\text { Total } \\
\text { Water } \\
\text { applied }\end{array} \\
\text { Acre in. }\end{array}$} \\
\hline \multicolumn{2}{|c|}{ First } & \multicolumn{2}{|c|}{ Second } & \multicolumn{2}{|c|}{ Third } & \multicolumn{2}{|c|}{ Fourth } & \\
\hline & Acrein. & & Acrein. & & Aerein. & & Acrein. & \\
\hline June 16 & 3.360 & July 29 & 3.359 & & & & & 6.719 \\
\hline June 29 & 5.970 & July 29 & 3.359 & Aug. 19 & 3.359 & & .......... & 12.688 \\
\hline June 16 & 5.070 & July 8 & 5.036 & Aug. 6 & 5.003 & ........... & $\ldots \ldots \ldots$ & 15.109 \\
\hline June 29 & 7.020 & July 8 & 5.036 & Aug. 19 & 5.002 & & $\ldots \ldots \ldots$ & 17.058 \\
\hline June 15 & 5.030 & July 3 & 5.100 & Aug. 1 & 5.036 & Aug. 24 & 5.002 & 20.168 \\
\hline June 20 & 6.774 & July 8 & 6.694 & Aug. 19 & 6.682 & ............ & .......... & 20.150 \\
\hline July 8 & 12.490 & Aug. 19 & 12.506 & & ........... & .......... & .......... & 25.002 \\
\hline June 20 & 8.303 & July 6 & 8.352 & Aug. 19 & 8.362 & .......... & .......... & 25.017 \\
\hline June 15 & 6.320 & July 6 & 6.248 & Aug. 1 & 6.248 & Aug. 29 & 6.250 & 25.066 \\
\hline June,16 & 6.250 & June 23 & 4.280 & June 30 & 5.705 & July 7 & a 5.230 & 61.465 \\
\hline June 23 & 6.250 & July 7 & 6.220 & Aug. 15 & 6.250 & Aug. 31 & 6.250 & 24.970 \\
\hline June 16 & 6.250 & July 7 & 6.220 & Aug. 6 & 6.750 & Aug. 31 & 6.250 & 25.470 \\
\hline June 23 & 6.610 & July 7 & 3.720 & Aug. 15 & 3.250 & Aug. 31 & 3.750 & $\mathbf{1 7 . 3 3 0}$ \\
\hline June 16 & 3.980 & July 7 & 3.720 & Aug. 6 & 3.750 & Aug. 31 & 3.750 & 15.200 \\
\hline
\end{tabular}

aThis plat was given 5 inches of water on each of the following dates: July 14, July 22, July 28, August 4, August 17, August 25, August 31, September 8. 
DATE OF HARVEST AND YIELD OF HAY

\begin{tabular}{|c|c|c|c|c|c|c|c|}
\hline \multicolumn{6}{|c|}{ Date of harvest and yield of hay at each cutting } & \multirow{2}{*}{$\begin{array}{c}\text { Total } \\
\text { yield of } \\
\text { plat }\end{array}$} & \multirow{2}{*}{$\begin{array}{l}\text { Calcu- } \\
\text { lated } \\
\text { yield } \\
\text { per acre }\end{array}$} \\
\hline \multicolumn{2}{|c|}{ First } & \multicolumn{2}{|c|}{ Second } & \multicolumn{2}{|c|}{ Third } & & \\
\hline & Pounds & & Pounds & & Pounds & Pounds & Tons \\
\hline June 26. & 264 & Aug. $12 \ldots$. & $501-2$ & & & 314 1-2 & 3.145 \\
\hline June 26. & 177 & Aug. $12 \ldots$ & 101 & & & 278 & 2.780 \\
\hline le 26 . & 261 & Aug. $12 \ldots$ & $681-2$ & & . & 329 1-2 & 3.295 \\
\hline ae $26 .$. & 204 & Aug. $12 \ldots$. & $1081-2$ & & & 312 1-2 & 3.125 \\
\hline e 26 . & 191 & Aug. $12 .$. & $851-2$ & .. $\quad$ - & ..... & $2761-2$ & 2.765 \\
\hline June 26 .. & 175 & Aug. $12 \ldots$. & 74 & . & & 249 & 2.49 \\
\hline June 26 .. & 93 & Aug. 12 .. & 62 & ... & ......... & 155 & 1.550 \\
\hline June 26 .. & 99 & Aug. $12 \ldots$ & 44 & ........ & ......... & 143 & 1.43 \\
\hline June 26 .. & 224 & Aug. 12 .. & 140 & & ........ & 364 & 3.640 \\
\hline June 18 .. & $1761-2$ & Aug. $10 \ldots$ & 1771.4 & Oct. 16... & $1201-2$ & $4741-4$ & 6.2 \\
\hline June 18.. & $1701-2$ & Aug. $10 \ldots$ & $136 »-2$ & Oct. 16... & $733-4$ & $3803-4$ & 5.0 \\
\hline June 18 .. & 147 & Aug. 10.. & 141 & Oct. 16... & & & 4.5 \\
\hline June 18.. & 105 & Aug. $10 \ldots$ & $1121-4$ & Oct. 16...... & 46 & $2631-4$ & 3.468 \\
\hline June $18 . .$. & $1121-2$ & Aug. $10 \ldots$ & 106 & Oct. 16....... & 35 & $2531-2$ & 3.340 \\
\hline
\end{tabular}

"It will be observed that the maximum crop was produced by applying plenty of water throughout the growing season. However, it is also to be noted that a much less quantity of water, when applied at intervals of three or four weeks, produced a fair crop. Fifteen and I7 inches of water applied in this way produced more than half as much as 6r inches applied at frequent intervals. Furthermore, three irrigations of 15 to 17 inches produced about the same results as the same amount applied at four irrigations. In applying irrigation water to fields it is necessary to saturate the soil to a reasonable depth. All the water that drains off beyond the amount required for use is lost to the crop. It is not necessary to apply water again until the crop has removed a large part of the available supply." 


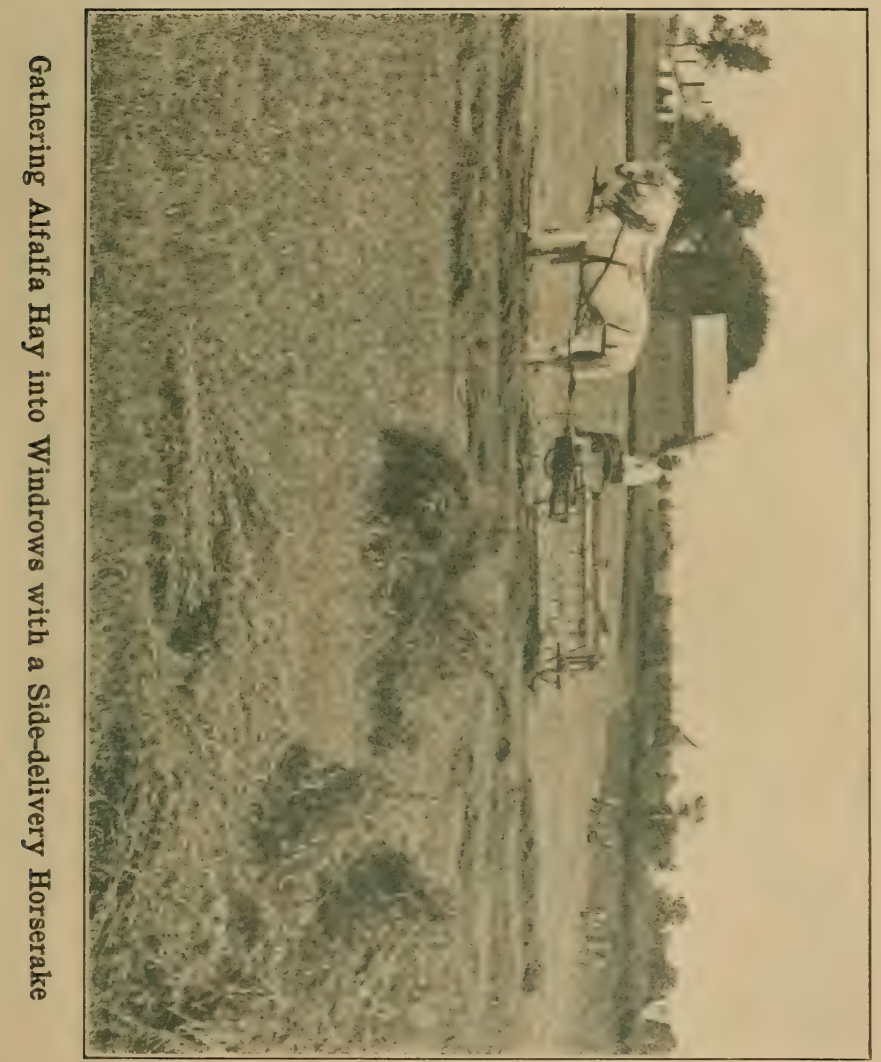




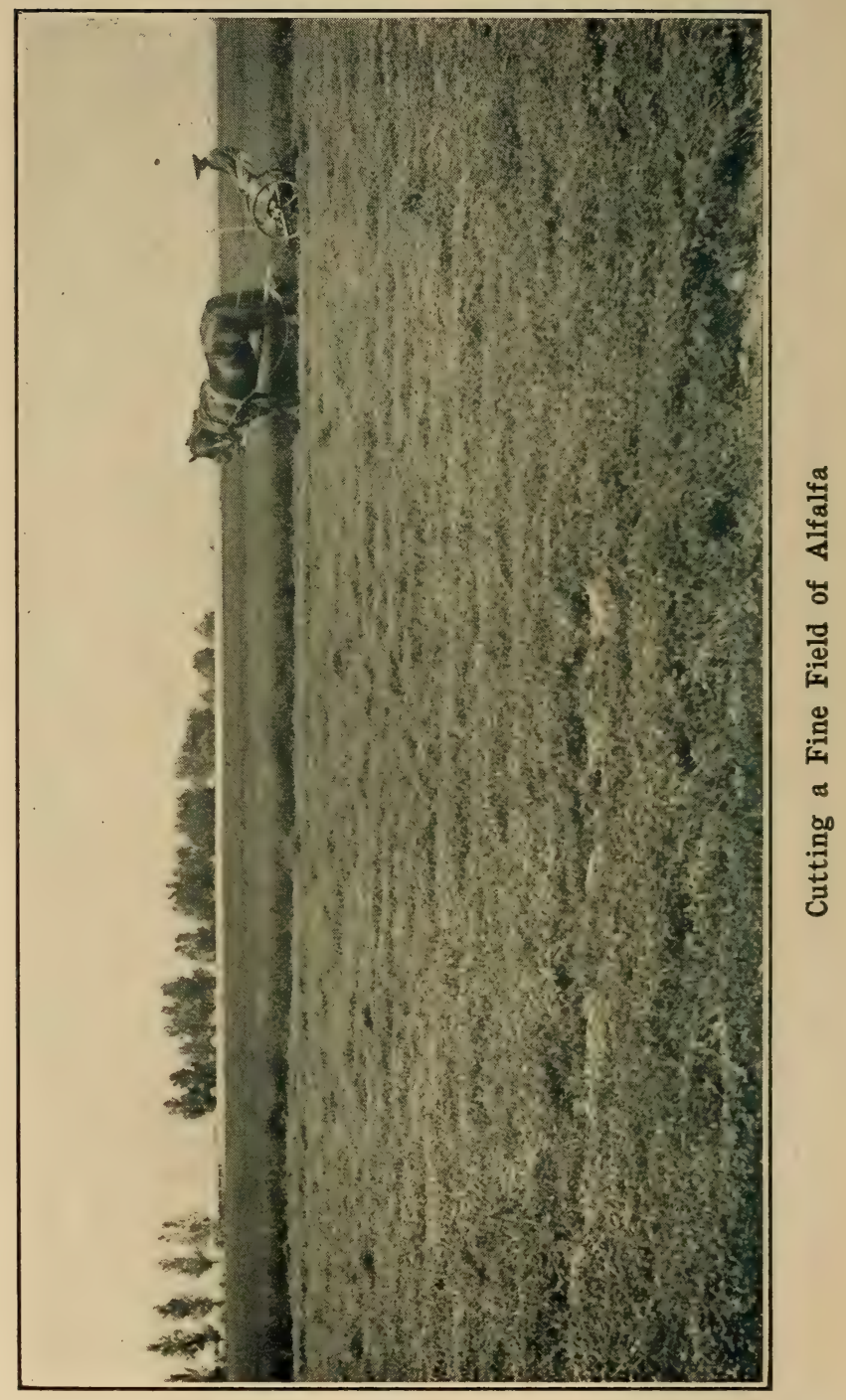




\section{Harvesting}

\section{CALLS FOR INTELIIGENCE AND PAINSTAKING}

Considerable space in this volume is devoted to the discussion of soil and seeding, but their importance cannot well be over-estimated. Really the whole subject of alfalfa might well be treated under the two heads, "Seeding" and "Harvesting," so very inclusive are these two phases of the subject. Without careful seeding one cannot have a crop to harvest, and without careful harvesting he might almost as well not have a crop. Both call for intelligence and painstaking farming, and much patience and hard work. But the rewards of these virtues and labors are heavy yields from the most valuable forage plant. If it is worth nine times as much as timothy, it can well demand a little more time and labor than the average crop.

\section{GREAT VALUE OF LEAVES}

The first point to accentuate as we approach the subject of harvesting is the preeminent value of the leaves. These contain from seventy-five to eighty per cent of the protein of the whole plant, that valuable compound that goes to produce milk and meat. It has been estimated that a ton of properly cured alfalfa leaves is equal in pro- 
tein to 2800 pounds of wheat bran; and when it is also estimated by careful observers that the loss of leaves in harvesting, even under favoring circumstances, ranges from fifteen to thirty or more per cent it is readily seen that the harvesting is an important part in alfalfa haymaking.

\section{WHEN TO CUT}

For the best hay the cutting should begin when the alfalfa is about one-tenth in bloom. Of course, if the acreage is small, calling for but one or two days' cutting, it might stand without particular harm until a fifth or fourth was in bloom. Cutting should be completed, if possible, by the time one-half is in bloom, as after that it is cut at a loss of leaves. As they have more experience the tendency among farmers is to cut alfalfa earlier than had before been believed at all desirable, and some experienced growers and feeders now insist upon cutting just before the blossoming stage is reached.

Experiments seem to show that horses like the hay that has been cut when at least half in bloom, or later, better than do other stock. For sake of the after effects on the plant, it is highly important that the first cutting be made in the early bloom, as, if it is delayed, the second crop starts more slowly and gives a lighter yield. Frequently a short delay in cutting the first crop means that the field will produce but two crops instead of three or four. So important is this that Prof. H. M. Cottrell declares that he has found it profitable to cut the first crop of a season in earliest bloom even if it were to be injured by being rained upon, or in fact entirely lost. 


\section{MOST PROTEIN IN EARLY CUTTINGS}

The Utah experiment station found by a feeding test that the early cut alfalfa was worth far more than any later cutting. It reported:

\begin{tabular}{|c|c|c|}
\hline Stage of Growth & Hay worth, per ton & Beef, lbs. produced \\
\hline 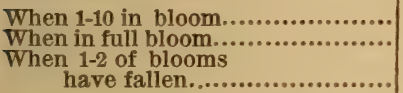 & $\begin{array}{r}\$ 5.35 \\
4.90 \\
4.35\end{array}$ & $\begin{array}{l}706 \\
562 \\
490\end{array}$ \\
\hline
\end{tabular}

The Kansas station found the protein content to be:

Stage of Growth Protein content When I-Io in bloom...... I8.5 per cent. When I-2 in bloom.....I7.2" " When in full bloom......14.4 " "

\section{CONSTANT WATCHFULNESS DEMANDED}

In humid regions, the alfalfa farmer at the time of the first cutting often finds himself in a trying position. The value of the leaves demands early cutting, and this may be just when it is likely to rain with great frequency. He knows that a wetting will injure his hay, and that this results in more or less loss of some of its most valuable parts from the hour of cutting until it is thoroughly cured. The Colorado station reports that alfalfa hay left out for fifteen days after cutting and rained on twice, lost 26. I per cent of its feeding value. Hay left out for seven days and having only one light rain, lost Io per cent. Another lot left out three days, without rain, lost 5 per cent. Wetting delays the curing, and by the washing the hay loses much sugar, dex- 
trin and other soluble matters, and also develops fungi. However, the only thing to do is to cut, exercising good judgment of course as to the amount each day.

\section{LOSSES IN CURING}

Headden found, at the Colorado station, that in an average alfalfa plant the stems amounted to forty to fifty per cent of the weight, while with very leafy, smallstemmed plants the leaves sometimes form more than sixty per cent of the entire weight. The leaves were readily lost if the hay was not handled carefully. He concluded that the minimum loss from the falling off of the leaves and stems in careful haymaking amounts to from fifteen to twenty per cent; and in cases where conditions have been unfavorable, as much as sixty or even sixtysix per cent of the entire dry crop is lost. Stated in another way, with the best of conditions, and with great care, for every I,700 pounds of hay taken off the field, at least 300 pounds of leaves and stems are left scattered on the ground, "and, in very bad cases, as much as I,200 pounds may be left for each 800 pounds taken." A study of these facts should induce the careful haymaker to use all possible skill in curing alfalfa, and they show that it will be profitable to expend more than the usual amount of labor in saving the leaves, considering that they are worth, pound for pound, nearly four times as much as the stems.

\section{HARVESTING IN HUMTD REGIONS}

Ordinarily, it is not well to cut alfalfa immediately after a heavy rain, because the wet ground will operate against proper curing. Begin cutting in the morning, 
when the dew is well off. If the weather is fair, the tedder ought to follow about two hours behind the mower. It is a mistake to think that the sun is the great curing agent. Too long exposure to the sun makes the curing all the more unsatisfactory, besides drying the leaves in such a way that they crumble and drop off.

Aslong as alfalfa remains "alive" water will be exhaled from the surface of the leaves and be pumped constantly from the stalks in a natural way much as though they were still standing. On the other hand, if newly cut alfalfa is spread too long in hot sunshine, the leaves are scorched to such an extent that transpiration of moisture from pores becomes impossible. Hence, that in the stalks can only escape by simple evaporation, which is very slow. By this means much undesirable, in fact harmful, moisture in the hay is brought to the barn or stack, although the leaves of the hay are dry and crisp.

As J. E. Wing has well said in his bulletin (Bul. No. I29 prepared for the Pennsylvania department of agriculture), "there is a principle to be observed in making alfalfa hay that applies to making hay from all clovers. If it can be so managed that the leaves are not at once burned and dried to powder, the moisture from the stems is the more easily removed. Leaves are natural evaporators of sap; stems are not. Therefore, while the leaf has yet pliancy and some semblance of its natural condition, it is most efficiently carrying away the sap of the stem, but when it is dried up it no longer aids in drying the plant at all. Therefore, the best hay in all respects is made partly in the shade, in loosely turned windrows, or in narrow cocks." 
Two or three hours behind the tedder start the rake and keep it going regardless of the noon hour, and unless the hay is very heavy it may be put into small cocks, this to be completed before the dew forms. In humid regions, hay is cured best and with greatest safety by the use of hay-caps, and these should be put on the cocks also before the dew forms, and removed each morning. The hay may be left in these cocks for four or five days, as found necessary, and then stacked or stored in the barn. This may not follow, however, unless the weather is favorable. Many prefer to leave the hay in the windrows until the second morning, turning them by hand or otherwise before noon and putting into cocks in the afternoon, letting these stand for two or three days. If it is left in the cocks over three days, they should be moved or the plants under them will be smothered. All agree that alfalfa should not lie in the swath over two or three hours. Most who have ever used a tedder like it if the alfalfa is less than half in bloom. If half or more in bloom, the tedder may cause the breaking off and loss of many leaves. Most experiment stations recommend that the hay be put into small cocks on the day of the cutting, if the weather is at all fair, not risking it in the windrows over night. It is a fact that cocked green alfalfa, even without caps, will shed much rain, while when fairly well-cured it will not do so.

A Colorado farmer reported that he started the mower one morning as soon as the dew was off, followed it with the tedder one hour later, and with the rake one hour behind the tedder; he kept a force of men only two hours behind the rake putting the alfalfa, yet quite green, into 
small cocks. These stood through two days of heavy rain. Later the cocks were opened and found to be unharmed, and after one day the hay was put into stacks in excellent condition. This was a somewhat unusual circumstance, surely, and might not often occur in a climate less dry than that in some parts of Colorado.

A grower in southern Kansas, however, who harvests about one thousand tons of alfalfa per year, and is working with it nearly every day from the second week in May until November Io, insists that alfalfa, under the same conditions of rainfall, is much easier to save in fair feeding condition than red clover. He finds the sidedelivery rake especially excellent for turning over the green or wet windrows to the sun and air with the least loss of leaves, and cured thus, after being wet, the natural color is better preserved. "That alfalfa hay has a higher feeding value than almost any other, even when saved under the most unfavorable circumstances, should be impressed upon the inexperienced."

\section{THE USE OF HAY-CAPS}

Any man who goes into the business of raising alfalfa anywhere in the rain belt cannot well afford to ignore hay-caps as a part of his equipment. Comparatively the cost is slight and the trouble of using them small considered in the light of their great utility, although the expense, and the use and care of them may at first blush appear to be quite formidable. American haymakers do not seem to appreciate the bad effect of dew upon the color and aroma of all kinds of hay. Prof. F. H. Storer in his "Agriculture" (Vol. III, p. 559) says: "One 
advantage gained by the use of hay-caps to protect the cocks during the night, is that they hold in the raked-up warmth, and keep the hay from cooling off. Thus it happens that the hay not only improves a little as to dryness during the night, but is all ready to dry rapidly when the cocks are again exposed to the air and sunshine, on being uncovered in the morning. All this as a normal and constant benefit, to say nothing of the advantages derived from the caps in case light rains, or even heavy rains, should fall before the cocks are again opened. The caps keep dew from settling upon the hay, moreover, and thus prevent the loss of aromatic matters that would result if the dew were to dry off from the hay."

"With regard to the exclusion of dew, it is not alone its power to carry off aroma that should be considered. When dew 'falls' it must tend to carry with it any particles of solid matter that may happen to be in the air from which it is deposited, and, in this way the spores of fungi, such as would cause the hay to mold, are put upon it. It can scarcely be questioned that many of the organisms deposited with the dew are likely to promote hurtful decomposition, especially in case the hay should remain or become damp, and the less of these organisms that infest the hay the better it will be."

When the farmer considers that a ton of well-cured alfalfa hay is worth about as much as a ton of wheat bran, he ought to see that it is profitable to protect it from the rain and the dew. He would scarcely hesitate to provide suitable covering if he had several tons of bran in the field exposed to the elements. Hay-caps will 
soon pay for themselves by the finer quality of the hay they assure, aside from the larger quantity of the best grade that their protection guarantees.

Storer further says, "there can be no question as to the very great merit of hay-caps when properly used. They are simply pieces of stout, cotton cloth of suitable size, say 40 to 45 inches square as a minimum, (6o inches square would be far better-Author) which are thrown over the cocks when rain is imminent, or at nightfall. These cloths may have wooden pegs or some sort of weight attached to each corner to hold them in place; the pegs can be driven into the ground or pushed under the hay, as seems most suitable to the size of the cock or conditions of the weather. The porosity of the cotton cloth hinders dampness from collecting beneath it at the top of the cock which it covers."

Curing alfalfa in dry regions where the problems and dangers of rainfall do not need any large consideration, is attended with few of the difficulties which confront the grower in a region of much humidity. In western Kansas and Nebraska, and in Texas and other states where summer rains are somewhat infrequent, the mowers start at the beginning and do not stop until the field or fields of alfalfa are all in the swath. The rakes follow close behind, frequently the side-delivery rake, and then the gathering implement, usually designated as a "go-devil," keep only about a half-day behind, dragging the cured hay to the stack or rick where the horsefork lifts and carries it to the center of the stack, to be distributed and placed by men with pitchforks. The market and feeding value of hay so cured and gathered, 
is deemed by some authorities as not the highest. Curing in the windrow alone is likely to be a mere drying (perhaps too rapid drying) of one side of the exposed portions. Alfalfa should cure successively in the swath, windrow, cock and stack or mow, to develop its greatest value. The man who has so many acres that he cannot cure it in this way might do better with fewer acres for hay, and pasture hogs on the remainder, or use the land for other crops. Still it is true that alfalfa even poorly cured has no inconsiderable feeding value. Many farmers in the West and Middle West claim to secure very good hay by early following the mower with the tedder, this with the rake, and then the "buncher," letting the hay remain in bunches over night and dragging it to the stack the next day. Others take from the windrow to wagons by a hay-loader, preferably one operated by a belt.

After all is said and done, and regardless of thrift and yield, it is unquestionable that the grower of alfalfa in humid regions meets with difficulties in the matter of satisfactory curing that in some years are almost or quite disheartening, and of a character to which his brother in arid territory is virtuaily a total stranger. Curing in the two regions presents different problems, with advantage all the time favoring the man in the country of little rainfall.

Second and later cuttings are not so much endangered by rains as is the first, and, hence, these are usually cured in better condition. Notwithstanding this, virtually all tests point out that the first cutting has more feeding value and is better relished by all kinds of stock. Most farm- 
ers are agreed that it pays to cut every time the alfalfa blooms, up to the last of September in the North, and possibly a month later in the more southern latitudes. A few have reported that they prefer to make but two cuttings a year, claiming to realize a greater feeding value by so doing; but it seems that the loss in leaves and protein, together with the fact that live stock has less relish for the more mature cuttings, makes frequent cutting by far the most profitable.

To sum up, the points to be emphasized in cutting alfalfa for hay, and its treatment immediately after, are:

Cut in early bloom.

Handle as little as possible.

Prevent its being wet after cutting.

Cure if possible partly in the swath, in the windrow, in the cock and in the stack or mor

Cut as often as it blooms, which will range from twice in New England to nine times a year in southern Oklahoma, southern California, Texas and Louisiana.

In a region of frequent rains protect with hay-caps.

\section{HARVESTING FOR SEED}

The first cutting should not be used for seed for three reasons: First, if that cutting is delayed until the seed has ripened, the second and third cuttings will be very light, and in the extreme northern alfalfa territory there may not be even a second. A stronger reason is that at the time of the first cutting, favorable weather is likely to be much less certain and rains will interfere with the stacking of the seed crop, which, to insure its best value, must be put in the stack or mow without wetting. 
Another is that the seed pods at that season are not usually so well filled and the proportion of fertile seeds is less because the bees and other insects have not so early in the season had time and opportunity to aid in the pollenation.

Cutting should be done when the greater proportion of the seeds are hard, but not sufficiently ripe to shell. At this stage a majority of the pods are turned a darkbrown color and the seeds are fully developed. Frequently the cutting can be raked into windrows after two hours if the weather is drying, and in two or three hours more put into cocks and let stand for twenty-four to forty-eight hours, as the weather may justify. It should, however, be well cured and thoroughly dry when put in the stack, or there is danger of heating, and stackheating seriously injures the vitality of the seed. It is not uncommon, if extremely ripe, to leave the cutting in the swath only an hour or a half-hour, then stack, and let stand for autumn or later threshing. If allowed to stand in the stack for about thirty days, the entire mass goes through a sweating and curing process which makes the threshing easier, while less of the seed is left in the straw than would be if it had not stack-cured. In western Kansas many seed raisers cut their seed crop with a selfbinder, put the sheaves in shocks the same day and thresh in about ten days, or put it into a stack to await a convenient threshing time. They claim to secure 20 per cent more of the seed in this way than if they cut with the ordinary mower. Others cut with a mower having a dropper attachment which leaves the alfalfa in small bunches at the will of the driver, in the center of the 
swath, and these are "straddled" by the team and the wheels of the mower in the subsequent rounds. These bunches are left for two or three days and then stacked. There is little, if any, danger from mold or spontaneous combustion in stacks of alfalfa cut for seed, but there is danger of the seed heating in the stack if stacked when damp. If bright, clean seed is expected, the stacks must be well topped with slough grass, or covered with tarpaulins or boards, or given other protection. It is better still to put the alfalfa intended for seed into a barn.

One Kansas farmer in the western part of the state reports that he used a self-binding harvester, shocked the sheaves like those of grain, let them stand ten days and then put in a mow, with no bad results.

\section{YIELDS OF SEED}

The yield of seed ranges all the way from two to thirteen bushels per acre, the normal yield in the seed regions being four to eight bushels. It is threshed with ordinary grain separators with seed attachments, although the clover-huller is usually preferred. No threshing machine cleans the seed satisfactorily or sufficiently, and a careful recleaning is necessary. Fanning mills or seed-cleaners are now made that will remove most weed seeds, seeds of dodder, and all light-weight and probably infertile alfalfa seeds. However, no raiser should by rights thresh, to say nothing of marketing, the seeds of the dodder or any other weed with his alfalfa; these should be cut out of the field with scythe, sickle or knife a month before the alfalfa is cut.

The threshed alfalfa straw is worth only about half as much as the hay, yet it makes excellent feed for horses, 
colts and calves. Or, if put into stacks of alfalfa of the third cutting, in alternate layers, it may be fed to any stock to good advantage, as it is relished quite as well as ordinary third cuttings, notwithstanding its lower feeding value.

\section{THE THIRD CUTTING FOR SEED}

Seed raisers in some instances, especially in Kansas, use the third cutting for seed, claiming that the pods are more uniformly filled and the seeds more generally fertile, due to the assistance of the bees in pollenation. They claim, too, that this cutting has fewer weeds and weed seeds than its predecessors; also that they are thus sure of two good hay crops, while often if they use the second crop for seed, the third crop is hardly worth more than the cutting. The only point left in favor of using the second cutting for seed, where the farmer is confident of a third, is that the protein value of the second is the lowest, and hence its hay can better be spared than that from any other cutting.

The raising of seed in the more humid eastern states should not, generally, be attempted, as it will not only interfere with obtaining full value in the hay crop, but the less fertile soil will not produce as vigorous seed as will the newer and richer lands west of the Missouri river. At present the best seed for general use is produced between that river and the Rocky mountains. Utah produces a hardy seed, but much if not most of it is raised under irrigation, and, hence, at least theoretically, not deemed best adapted for regions dependent entirely upon soil moisture from rains. 


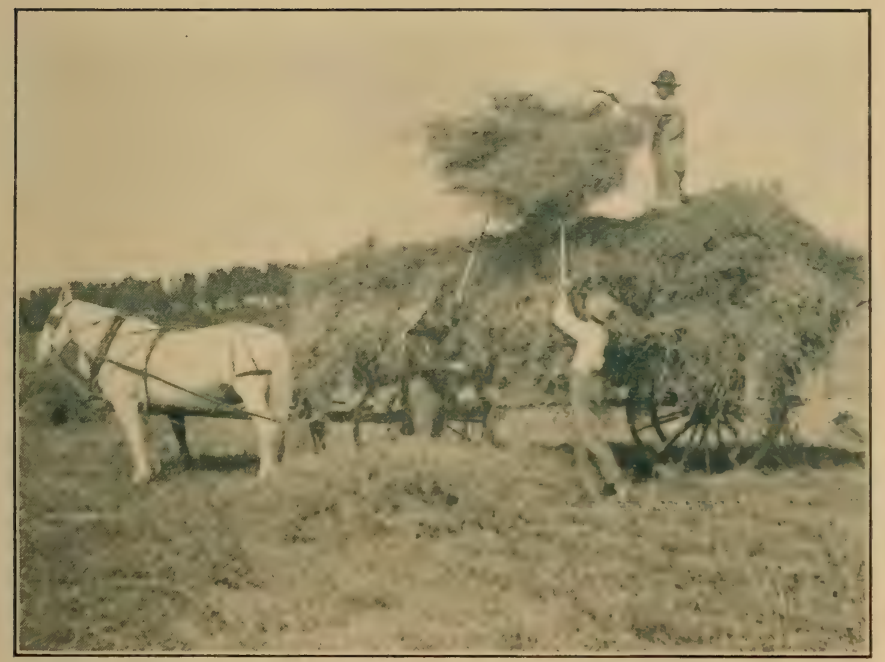

Gathering an Alfalfa Crop in Page County, Iowa Photograph by courtesy Henry Field

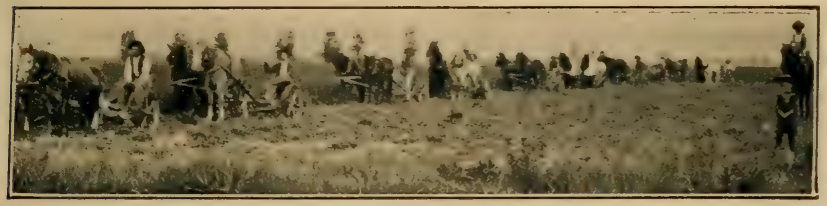

Alfalfa Harvesting Scene in Yellowstone County, Montana 


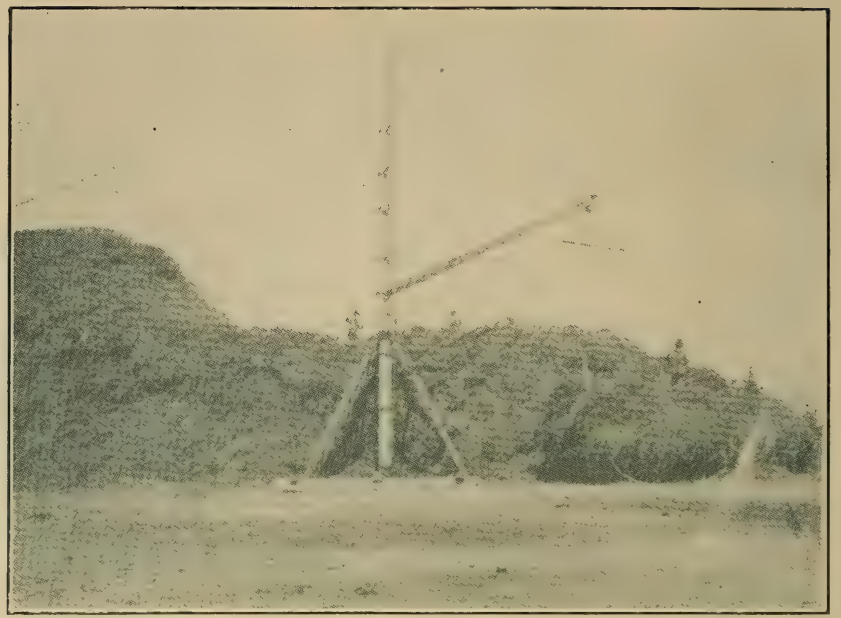

Mast and Boom Stacker, with Six-Tined Jackson Fork

The mast is held in place by guy ropes from the top. Leading to the right may be seen the rope to which is attached a team of horses. The base of the derrick is in the form of sled runners, so that the whole may be drawn along the stack by attaching a team.

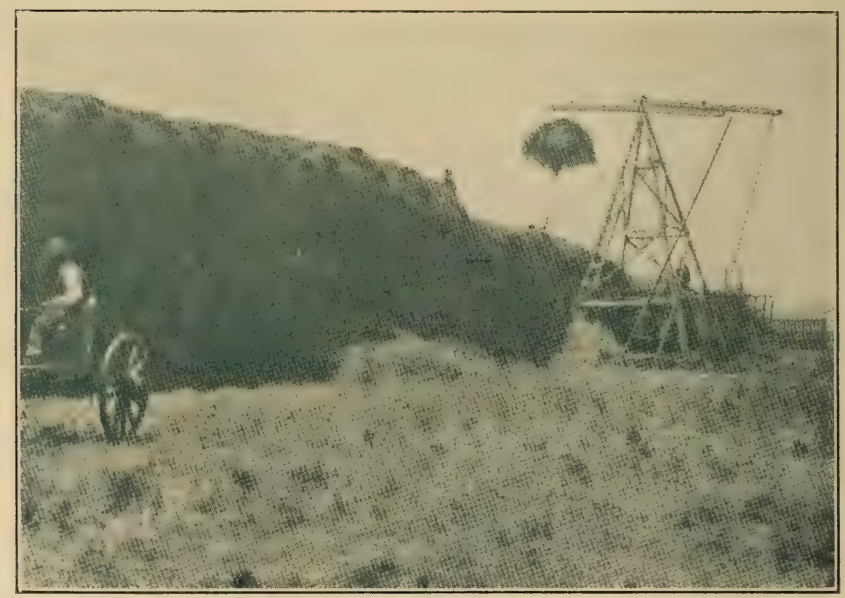

A Derrick Stacker

with six-tined Jackson or California fork. The derrick is substantial, and guy ropes are not necessary. Stakes driven into the ground around the base hold the derrick in place. 
CHAPTER VIII.

\section{Storing}

\section{CARE IN CURING}

After all possible care has been taken in seeding, cultivating and harvesting alfalfa, its feeding value may be greatly impaired or quite lost by ignorance or carelessness in storing; that is, by stacking or putting it into sheds or barns, or by baling it for market when in an unsuitable condition.

The only path to safety in stacking or storing in shed or mow is having the hay in proper condition for completing its own curing. The true medium for its curing is air, not sun; the sun has done possibly more than its share already. But good hay is not completely and properly cured in swath, windrow and cock. If cured in the windrow, the exposed parts are liable to be much injured by the sun. Therefore the principle stands, "Handle alfalfa green." It must be cut green, teddered, raked and cocked or bunched while comparatively green, and must not then be allowed to dry and parch to brittleness. True, it must not be put into a stack so long as it is possible to wring water out of the stalks. A constant study should be to find the best method of getting the hay into storage without loss of its natural color. The method that will safely store it greenest will be the best to follow. 
Handled green the leaves are saved, and these constitute from 50 to 75 per cent of the whole value.

\section{PUTTING INTO WINTER QUARTERS}

When (in regions of much humidity) the hay is safely in cock, covered with hay-caps, and has had a few days of curing, it is ready for permanent quarters. Remembering that the hay after its drying has begun should be handled as little as possible, the cocks have been made small enough so that two men may lift them bodily onto a wagon, if a wagon is used in the stacking. From the wagon, the hay is lifted by a hayfork to the stack. Or, more careful still, the farmer will use three slings to each wagon, which are lifted by a hook to the stack or mow. A sling is a heavy sheet the size of the wagon hayrack. One is spread on the bottom of the rack, another on top of the first one-third of the load, and the other on top of the second third. These slings are banded at the ends; the ends are drawn together and a third of the load lifted to the stack or mow, thus saving in some instances a third more leaves than any other method.

In arid and semi-arid territory, cocking and loading on or off wagons are dispensed with by dragging the rapidly dried hay directly to stacks built in the fields, where the lifting into place is done with great expedition by horse implements. A wheel-rake or "go-devil" is used to take at once several cocks, bunches or a part of a windrow to a nearby stack. Others use a rope to drag one or more large cocks to the stack; or, if the hay is to be taken from windrows, it may be put upon wagons with 
a loader. The loader is an excellent implement for handling timothy and clover, but is apt to shake off a good many leaves of alfalfa if the hay is very dry. The more common sling now on the market is made of ropes, four ropes the length of the hayrack and with ropes across like a rope ladder, and used to handle one-third or onefourth of a load. Others are made like the carriers of a threshing machine with slats and ropes.

\section{STORING IN THE BARN}

The barn is the best place for alfalfa if all conditions are right. Cases of spontaneous combustion in stack and mow make farmers fearful of using the barn, especially for the first cutting, which is always most difficult to cure. There are certain conditions that must be observed if this hay is to complete its curing properly and safely in the mow. The bottom of the mow should be elevated at least a foot from the ground, floored with poles or joists, and they should be about two-thirds covered with boards or other material in such a way as to provide numerous openings or air spaces of considerable size. If the mow already has a tight floor, a part of the flooring should be removed before the hay is put in. Then a box or barrel should be placed in the center of the space and lifted up as the filling proceeds. If the mow is over thirty feet long, a second barrel should be used; that is, an air shaft should be left in about each fifteen to twenty feet. A layer of dry hay or straw sandwiched in about every four of five feet, as the mow fills, can be used to much advantage. If the mow is large enough in length and width, an excellent, safe plan is to 
spread the first cutting over the entire bottom, filling up to a height of four or five feet. The second cutting may be placed over this, on top of a layer of straw, and the third cutting over this. There is virtually no danger from spontaneous combustion or from mold if this is done, and the hay will be as bright and green and almost as rich in protein in January as when harvested.

J. W. Berry of Jewell county, Kansas, member of the board of regents of the state agricultural college, uses this method and bales his hay in October for the city markets, finding it in perfect condition. He puts his hay into the mow green but not wet, direct from the cocks, or windrows the day it is cut, in layers about four feet deep, with the slightest possible loss of leaves, no bleaching and no injury by dew. In 1905 he cut his alfalfa four times and stored the fourth cutting on top of the three preceding. He says that having an open floor and plenty of air from the outside, the hay can be put in the barn as described; that it should not be tramped, and it will settle and cure perfectly. The bottom layer or first cutting may show some dust when taken out if handled loose, but the color will be good and it will bale in with the other cuttings and all grade well. Hay cured in this way in 1904 graded "choice" in the St. Louis market.

Spontaneous combustion does not occur very often, but it is a possibility, and it is well to bear in mind that hay may be put in the barn too green. Observation teaches that it never takes place unless the hay has been put in the barn while containing a large amount of moisture, and piled too deep. Alfalfa and other clover hays 
may safely be put in the barn when they contain not to exceed 30 per cent of water. If, however, they contain much more than this there is considerable danger, especially where large quantities are put together, as is the case in large, deep mows and sometimes in large stacks. A practical test which may be safely followed is to take a handful of hay, twist it as hard as possible, and if no juice can be wrung out of its stems, it is dry enough to be put in the mow. Bunches of wet hay mixed with dry hay have often caused combustion. Such should always be discarded. It is poor policy to haul clover hays into a barn after sundown, as at that time it absorbs moisture from the atmosphere very rapidly.

It is a good plan for the haymaker to go into his mow every morning while the hay is curing and observe the conditions, but he should not, however, become alarmed if he finds that the top of his hay is very damp. This will always be the case, even if it was comparatively dry when put in ; considerable heat develops during the night, which in turn evaporates moisture. The following morning, when the air is cool, a large percentage of this, especially if the mow is not well ventilated, is condensed and settles back on the hay. If the moisture, however, is excessive, it is a good plan to scatter a load of dry straw over the top. This will absorb the moisture in part, after which filling may be continued. In case a load has been put in the barn too wet, it should be spread to the outer edges, as there is much less danger of combustion at these places than in the center In fact, the greatest heat is always developed in the center, where the so-called craters form, and from which moisture and 
gases are given off as a result of heating and oxidation below.

From the fact that spontaneous combustion cannot take place until the water has all been evaporated, there is no danger until three to four weeks after the hay has been stored. During the first week or so, if the hay heats to such an extent that there is danger of combustion, it is well to open up the center as much as possible and allow some of the heat to escape. If, however, the heating has continued much longer, it is dangerous practice to open the hay at all, because all that is needed, after the water has been evaporated, is air, or oxygen to support combustion, and the mass will at once burst into flames. Sometimes combustion takes place without flames, in which case the center of the mow gradually chars, leaving the hay there as black as charcoal, and without value.

Professor Cottrell, discussing spontaneous combustion (Kansas Bul. No. I I4), says that all cases observed by him have occurred in hay of the season's first cuttingcut at a time when the growth was rank and the curing most difficult. A period of wet, muggy weather in July or August increases the danger, which in dry weather seems much less. On account of previous trouble from heating in the barn, he had four year prior to writing stacked the first cutting out of doors and put only the later cuttings in the barn.

\section{LOSSES FROM STACKING}

The Colorado station found that the loss in feeding value from the hour of cocking to the hour of taking from 
the stack was 12.4 per cent, while the loss in hay stored in the barn was about 2.5 per cent. If we add to this the stacked hay lost by exposure, it will easily reach more than 20 per cent under average conditions while in many cases it would reach 40 per cent. This certainly represents an enormous waste, and by preventing it a man with any considerable area of alfalfa could soon save enough to pay for a barn.

\section{THE HAY SHED}

After a barn the next best place for storing hay is a shed with an adjustable or lifting roof. The ground dimensions should be ample to allow the first cutting to cover its floor and not be over five or possibly six feet deep when first put in. The bottom of the mow should be raised at least one foot from the ground, and the floor should have at least a twelve-inch air space about every three feet. Poles or joists covered with dry straw or old hay make a good floor. Spread the hay over the entire floor surface, on a layer of straw or other dry material. Use barrels or boxes as recommended for ventilation in the barn, and lower the roof until the second cutting. For such a roof the covering should be of some such material as ruberoid, and the rafters need not be heavy, except about every sixteen feet. Strong iron clamps can be easily adjusted to the supports. When the second cutting is ready, raise the roof, which should be in sections, and put the second crop on top of the first. Follow this plan for all other cuttings. If a shed with a stationary roof is used, dry straw, or hay, or corn stover should be 
put on top of each cutting to protect the alfalfa from rain. Almost any kind of a shed or covered structure is preferable to a stack.

\section{CONDITIONS FOR STACKING}

If the hay is to be stacked, there are also special conditions that the experienced insist should be observed. This is not to say that alfalfa hay stacked under conditions quite different may not give fair results, and much depends on the locality and the climate. However, the result desired is palatable and nutritious hay and not such as is moldy, stack-burned or dusty. Stacking the hay directly on the ground is sure to mean a loss of some portion of it. Elevate the bottom of the stack with poles, timbers or other like material; put straw at the bottom and, preferably, build a rick rather than a round stack. Start the bottom sixteen or eighteen feet wide and build straight up instead of tapering or slanting the sides, as alfalfa hay will not shed rain or snow water. If there is much moisture and it is convenient to do so, use a layer of straw or dry hay of some kind every five or six feet. Keep the stack full in the middle, or a little higher than the sides, and well tramped all the time. When the stack has reached the.desired height, top it out with slough grass, or dry timothy or prairie hay, or very green alfalfa, or protect with tarpaulins or boards; the boards may be nailed and chained together, lapped and weighted at the corners, making a very satisfactory roof. If these directions are followed, the losses will be kept at a minimum. The Kansas experiment station authorities say that in an experiment made there an application of 
salt to the hay when being stored seemed to decrease, if anything, rather than increase its feeding value. Lime applied in stacking is claimed to have a beneficial effect in preventing mold.

The raised bottom and layers of straw are useful accessories for the stack, shed or mow, while the barrel or other ventilating contrivances should not be overlooked in either sheds or mows.

\section{STORING AS SHLAGE}

As land values increase and farmers and dairymen come to more fully appreciate the worth of green feed in winter, the silo grows in estimation. Eastern farmers who keep cows or young stock of any kind use the silo more or less, to conserve for winter the value of both green grass and corn. Alfalfa makes an excellent silage, but its peculiar quality of retaining its green food value, as hay, when properly cured, makes its ensiling much less a necessity. Alfalfa hay taken from the mow in February, green, appetizing and nutritious, falls little, if any, short of serving the purposes of silage.

\section{OFTEN PROFTTABLE TO ENSICE THE FIRST CUTTING}

However, it is not infrequently found that the first cutting of alfalfa may be ensiled directly from the field at a season when rains would prevent its proper curing for hay. If this is done, it is important that the rakes and wagons follow very closely after the mower, as even two hours of sun exposure in the swath lessens its value for silage. Men who have cut alfalfa during a light rain and 
raked and hauled it directly to the silo have reported satisfactory results. Others report having cut it in the late afternoon and, the next morning, after a heavy rain, raked and hauled it to the silo while dripping wet. Therefore the farmer in the eastern and southern states, in the Pacific Northwest, or even in the central states may, on occasion, plan for the ensiling of his first cutting, in the faith that it will come out in fine condition if his silo is properly constructed.

\section{SUGGESTIONS FOR SILONNG}

The Kansas and Colorado experiment stations recommend that alfalfa for silage should be cut into lengths of, say, two inches. Long alfalfa does not pack sufficiently close in the silo, and when so stored the loss is much more than if in short lengths. It should always be heavily weighted and great care taken to pack it well at the outer edges. Round silos are most approved because their contents are more readily compacted. The points urged by Professor Ten Eyck, of the Kansas experiment station, are, (a) getting the alfalfa to the silo quickly after mowing, allowing little, if any, curing; (b) cutting the alfalfa into short lengths rather than storing it whole; (c) packing it tightly, and weighting heavily when all in. He says, however, that if the weather will permit proper curing of the alfalfa, it will make more valuable winter feed as hay than as silage.

\section{BALING}

The increasing general demand for alfalfa hay in the city markets of the United States, away from the distinct alfalfa regions, has made finding a method of pre- 
paring it for economic shipment of much importance. The compressing of timothy and prairie hay has become so general that alfalfa raisers and shippers are also following this method. The problem of saving the leaves, and, at the same time, being able to market alfalfa green, has been hard to solve. Baling it uncured meant mold, and baling it when very dry meant loss of leaves and, hence, loss in feeding and selling value. The Kansas station a few years ago carried on a series of experiments extending over several years from which the conclusion was that the only safe procedure is to cure carefully in the field, put in the stack or mow, and bale after the final sweating - say thirty days. Most of the hay cured and baled in the field was moldy or brown. It is possible, however, that a more careful curing, the use of hay-caps, letting it stand for several days in cock, baling, and then storing in an open shed, the bales stacked on edge and separated about every third layer by poles, rails or rafters, might result in securing high-grade hay direct from the field without stacking. Seemingly it will never be safe, away from the semi-arid regions, to bale the first cutting from the field; but the secret may yet be found of so baling the second and third cuttings and obtaining prime hay. Its doing is not likely to prove satisfactory, however, except in the drier portions of the alfalfa district where large cocks of, say, 500 pounds may be made and left standing for several days before baling. But baling is not likely to be largely followed except in territory where extensive areas are devoted to alfalfa. When practically every farmer in the United States has his field of alfalfa as he now has of corn, cotton or clover, the 
greater part of the product will be fed on the farm and the surplus hauled direct to the local markets. Western Kansas and Nebraska alfalfa raisers are having this problem solved for them by the growing practice of stockmen shipping cattle and sheep from the mountain ranges to be fed or fattened where the hay is raised, and hauled directly from the stack to the feed lots.

\section{POOR STUFF}

Hay dealers report that much of the baled alfalfa shipped is poor stuff. They advise small bales, weighing about sixty to eighty pounds ; about 27 to 36 inches long, I4 or I 5 inches thick and I8 inches high when laid on edge. They also recommend that in loading a car the bales be placed on their edges instead of on the sides, as they are less liable to heat. The problem of the city hay dealer is to sell what he has received, with satisfaction to the purchaser and profit to himself and to his client. If he receives moldy, dead hay, with little protein value, he is not able to please his customer, not able to secure a good price, and hence, not able to please either shipper or buyer. The farmer who raises and ships hay and receives two dollars less per ton for it than his neighbor, should learn by such money losses the necessity of harvesting and storing his product properly.

A. S. Hitchcock says in Farmers' Bulletin No. 2 I 5, of the United States Department of Agriculture, that the baled hay for export to Alaska, Hawaii, and other transoceanic points is compressed by the process known as double compression, done with baling machines operated by electricity or hydraulic power. The hay obtained 
by loosening the ordinary bale is compressed into square or cylindrical packages of smaller and more compact form than the ordinary bale. The hydraulic presses used for making the round bales are similar to those used for the cylindrical bales of cotton. The measurements of the different types of double-compressed bales are about as follows: Square, I 5 by 18 by 38 inches, weight 160 pounds; square bale for Alaskan trade, I 4 by 18 by 26 inches, weight Ioo pounds; round bale, 2 feet in diameter, 24 inches long, weight I45 pounds, or 36 inches long, weight 260 pounds. The saving of space in transit may best be understood by comparing the weight and cubic contents of baled and compressed hay. The ordinary bale occupies I4O to I6o cubic feet per ton, and round bales 55 feet per ton. The most essential point in loading new hay into a car is to see that it is not loaded flat, that is, with the flat sides of the bale up. When loaded in this way, with the smooth sides of the bales together, no space is left for air and as a consequence the hay not infrequently heats. A properly loaded car has the edges or rough sides of the bales together. This allows air space between the bales and always prevents danger of heating.

A new machine is being introduced which makes (from the windrow if desired) a cylindrical bale, with a hollow space lengthwise through its middle. This open space must undoubtedly facilitate the curing of hay baled before sufficiently dry. The machine has a capacity of four to six tons per hour, makes a bale thirty-six inches long and twenty inches or less in diameter, as desired, bound with twine, and the hay can be eaten from the bale, with a 
minimum of waste, without untastening. This baler, if it justifies the claims of its inventors, should be very useful to those who grow alfalfa for marketing away from the farm.

\section{GRADING AND GRADES OF ALFALFA HAY}

On account of the increasing demands for alfalfa hay, and growth in the business of selling it in cities, dealers have found that the establishment of some uniform and generally accepted method of grading the different qualities was a business necessity. As a result of this its consideration was taken up by the National Hay Association's committee on grades and upon the committee's recommendation the association in I905 adopted the following classification :

Choice Alfalfa-Shall be reasonably fine, leafy alfalfa, of bright green color, properly cured, sound, sweet and well baled.

No. I Alfalfa-Shall be coarse alfalfa of bright, green color, or reasonably fine, leafy, of good color, and may contain five per cent of foreign grasses; must be well baled, sound and sweet.

No. 2 Alfalfa-Shall include alfalfa somewhat bleached, but of fair color, reasonably leafy, not more than one-eighth foreign grasses, sound and well baled.

No. 3 Alfalfa-Shall include bleached alfalfa, or alfalfa mixed with not to exceed one-fourth foreign grasses, but when mixed must be of fair color, sound and well baled.

No Grade Alfalfa-Shall include all alfalfa not good enough for other grades, caked, musty, grassy, or threshed. 


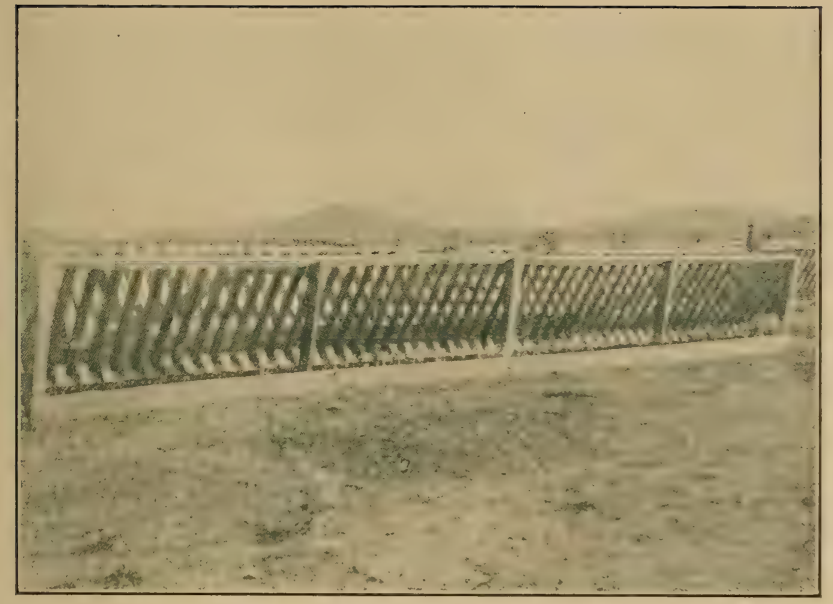

Lattice Rack for Feeding Alfalfa to Sheep

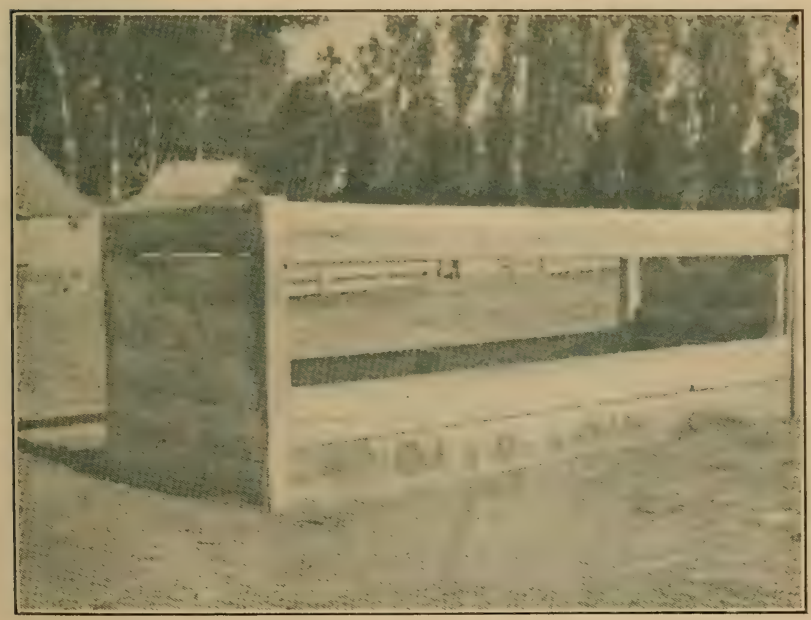

Box Rack for Feeding Alfalfa to Cattle 


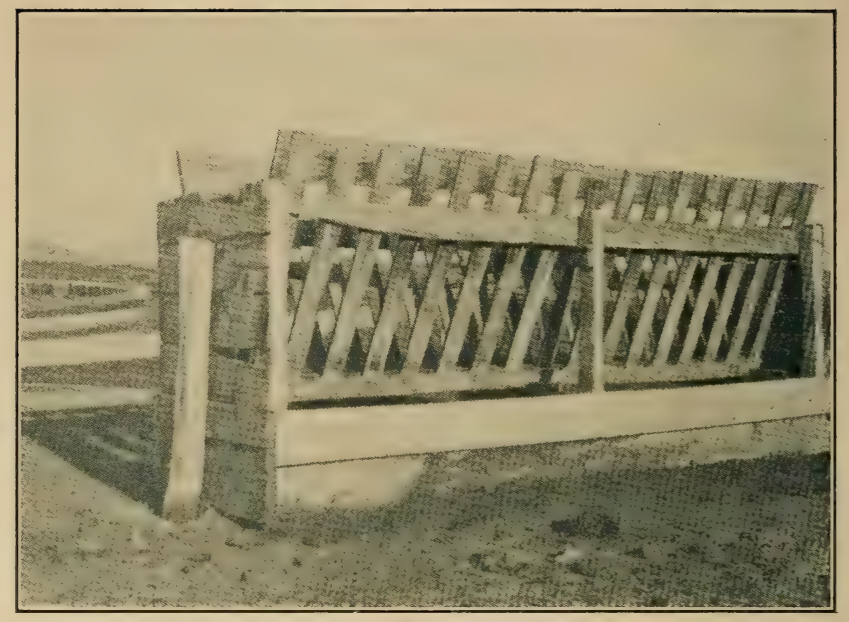

Lattice Rack for Feeding Alfalfa to Cattle

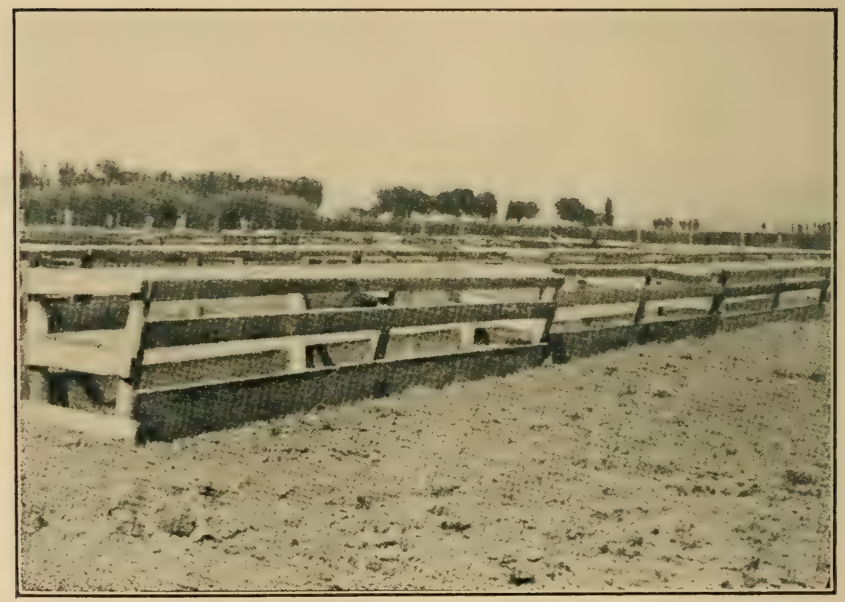

Box Rack for Feeding Alfalfa to Sheep 


\section{Pasturing and Soiling}

\section{PASTURING NOT ALWAYS ECONOMY}

Its perennial nature and the reports of its wonderfully productive and nutritive qualities might naturally lead the farmer, without better acquaintance, to suppose that with alfalfa he has perpetual pasture; that he will open the gate to his live stock in the spring, send for the butcher or buyer in October, and then winter in luxurious leisure. But he finds that the easiest is not always the most profitable way. Pasturing with any stock is an expensive and extravagant method of gathering a valuable crop from high-priced land. Where land is cheap and pasture is wild, stock are not expensive help in gathering a cheap crop; but it is easily demonstrated that when land values are high and a crop value is in a like altitude, man with machinery can do the harvesting more economically than can a cow, a steer or even a sheep.

\section{ALFALFA A TENDER PLANT}

In some respects alfalfa does not seem to be a natural pasture plant. The stems are delicate, it will not thrive in a hard, trampled soil, and the crowns when broken off will not revive; if some of the plants bloom and drop their flowers early in the season, they lose vigor and many of them die. These peculiarities would at least indicate 
that it should not be pastured at all until it has become established, has its crowns well spread, has abundant stem\$ and its roots have a strong start on their underground career. Not an animal should be turned on an alfalfa field until the second or third year if it is desired that the stand endure for several years, nor should it be pastured too early in the spring or too late in the fall. There should be something of a growth left for winter protection. Careful alfalfa raisers are known who pasture their older fields, but never put on a full quota of stock until they have cut over the field when the plants are first coming into bloom. They insist that this cutting invigorates and gives the plants new life. They then pasture quite closely until some time in September, after which there is time for some final growth for winter protection.

\section{A GOOD SWINE PASTURE}

A chief exception that most farmers insist on is that it is an excellent pasture for pigs and, if it is not stocked too heavily, its use for grazing young swine will not largely decrease the yield of hay. Its marked protein property seems to give to the pigs a superior growth of frame and flesh. Farmers claim that pigs a few weeks old turned into an alfalfa field derive almost their entire living from it and leave the sows two weeks earlier than other pigs, coming in September with a gain of from Ioo to I 25 pounds, while the field has yielded its three cuttings of hay. Of course, if too many pigs are grazed, the hay yield will be less. But even here the question of labor versus hay must be considered. 


\section{DANGERS TO CATTLE AND SHEEP}

The greatest objection to pasturing alfalfa is its bloating cattle and sheep. Hogs and horses do not suffer, although a Texas farmer writes that he lost some pigs from something similar to bloat that he attributed to the alfalfa. But this may be considered questionable, as thousands have regularly pastured hogs and horses on alfalfa with no symptoms of bloat. From hundreds of inquiries sent out by the experiment stations, it is determined that over ninety per cent of those who have pastured cattle or sheep on alfalfa have lost one or more animals by doing so, yet many report having pastured the same kind of stock on alfalfa for years, regularly every season, without loss. Careful investigations have been made with the purpose of finding out why some have been immune while others suffered. Since, in the cases of loss, only a small proportion of the animals pastured are affected, it may be inferred that much depends upon the nature and condition of the individual animal. Practically every western station has carefully experimented, following the directions of men who have been free from loss, yet it has cost each station valuable animals.

Horse stock of all ages find alfalfa pasturage conducive to growth, fattening, and their general health. If the foliage is short and scant, horses are severe on the fields used in winter because they are able to crop close, and not infrequently paw loose dirt away from the plants, biting off the crowns a fourth or even half inch below the surface of the ground. It is easy to understand the loss of the bud or growing point may be detrimental to the growth and usefulness of the plants, 
causing many to die, resulting in bare spots later to be overgrown by noxious weeds and grasses. After the damage is done there remains no remedy but to plow up the field and reseed, or to disk thoroughly and then reseed the bare spots. If the field has not deteriorated too much, the latter is much to be preferred. By diligence and careful treatment, or prompt action closely following any encroachments upon the life of the plants, the quality and yield may be maintained and the profits relatively enhanced. Alfalfa has wonderful recuperative powers, but continuous nipping of the crowns will do most serious harm and eventually decrease the yield not a little.

\section{EXPERIENCES WITH CATTLE}

One inan reports turning eighty steers into one alfalfa field where there was running water, and a second herd into another field without running water, but water ran through a wild grass meadow adjoining, into which this herd was driven every afternoon and turned back into the alfalfa the next morning. The first herd suffered no loss, while five valuable animals died in the second field on the second day, before they could be removed. When all were put into the first field there was no more bloat. Another reported turning cows into a small field where there was a trough full of water all the time. Here, as in the case of the steers, a full feed was given before the cows were turned on the alfalfa. Before noon one cow had to be relieved by a trocar, and another by being driven rapidly about the field. The wherefores of such occurrences present a problem yet to be solved. Certainly there is more danger in pasturing cows and sheep on alfalfa 
than most people care to risk. Aside from the financial loss, there is, also, the humane side of the question.

A very fair statement, representative of those made by parties who pasture cattle on alfalfa without losses from bloat, is the following, given to the author by Mr. S. C. Hanna, an extensive and reputable breeder of Shorthorns, in Elk county, (southern) Kansas, who says:

"I have been pasturing alfalfa successfully without bloating my cattle for a number of years; in fact, I have never lost an animal from alfalfa bloat. As I am raising high priced, pure bred Shorthorns and graze them on my meadows more or less at all times of year, I always sow a good mixture of English blue-grass (Festuca elatior) and orchard grass (Dactylis glomerata) with it, making alfalfa the base and principal seeding. I am very partial to orchard grass in this mixture because it makes considerable hay, and springs up so quickly after each mowing. In this section orchard grass is a stayer, and will hold its own against all comers.

"I always am cautious when we first turn the cattle on alfalfa, seeing to it that they have a good fill on something else beforehand, and hold them at first on some part of the field where the mixed grasses are the thickest, so they can graze there first. In twenty minutes they will be safe to go where they wish, and may be allowed to run at will thereafter. I find, however, that on the clear alfalfa meadows there is almost no danger from bloat after the plants have begun to bloom. I usually have some hay stacked in the pastures, that the cattle may run to. I have, however, pastured alfalfa in all stages where there would be perhaps twenty acres of alfalfa in one 
place, and some prairie grass and also tame grasses in the same enclosure, and had no bloat. This has been, too, sometimes in May and June, when showers were frequent and the alfalfa most succulent. It would seem that the cattle will take care of themselves if they have a good chance. I usually superintend these changes personally, and see that all conditions are right.

"I find we get almost as much hay from the mixed fields as from the exclusively alfalfa meadows, and the fall aftermath is much better. The theory that alfalfa will not flourish with the other grasses is wrong. My favorite meadows contain a mixture of this kind, including some red clover, and I have cut four good crops of hay from them this season, after pasturing moderately from March I 5 to May I. I always get the stock horses and mules on pasture by March I5, and the cattle about April I, and move them to wild grass prairie pasture about May I, except a few that we will keep on the meadows all season. These we change from one field to another when the alfalfa becomes tall enough to be trampled down or damaged.

"If my object was only to raise hay for market, I would sow the alfalfa alone and keep the stock off altogether, but for my purpose I prefer a mixture. By doing my way I never miss a good stand, and the mixture keeps down the foxtail and crab grass. I have been sowing this mixture for about fifteen years, and have over 300 acres."

Mr. J. F. Stodder of Cowley county, Kansas, a prominent breeder of pure bred cattle, makes this statement to the author, which is simply further testimony that a mix- 
ture of other grasses with alfalfa intended for grazing greatly diminishes, if it does not entirely eliminate, the risk and dangers of bloat:

"I have several fields of mixed grasses. These contain enough alfalfa so that we cut them for hay at regular times, and the proportion of grasses and alfalfa is largely in favor of the latter. In such fields as these I pasture cattle at will, and have never seen any evidence of bloat therefrom. But my experience with the straight alfalfa fields leads me to be very cautious. I find that I can pasture them at times without danger, and at other times a large proportion of the cattle will bloat. It is possible that I have made the statement that I never lost cattle by pasturing alfalfa, which is true, because we have always been lucky enough to discover the ailing animals in time to give them relief."

Mr. F. S. Kirk of Oklahoma, mentioned in Chapter III, pastures his cattle on alfalfa in fall and spring, but does not give them access to his meadows in the morning until the dew has dried off, and for only twenty or thirty minutes the first day or two; then for an hour or two for a few days, and after that they are left in the pastures until sundown.

\section{GENERALLY DANGEROUS TO SHEEP}

Experiments with sheep seem to be even more disastrous than with cattle. In an investigation conducted by the Colorado station, losses were reported by nearly every man who had pastured sheep on alfalfa. Some lost but one or two, while others lost forty or fifty. A few reported that each spring they lost a few sheep the first 
day they were on the pasture, and then no more, and that the losses of old sheep were of less importance than the growth of the lambs, these being seldom affected by bloat. Most, however, advised that the old should not be turned on alfalfa under any circumstances, but that lambs, if well fed in the morning, let on the alfalfa after the dew was off and then kept there night and day would do well, and the loss be smaller than that in a normal season from other causes. J. E. Wing states that his loss from pasturing lambs on alfalfa in Ohio is less than it formerly was from one or two parasitic diseases that never trouble alfalfa-pastured lambs. He gives his lambs a full feed in the morning, turns them on the alfalfa field about ten o'clock, and leaves them there continuously until September. He begins the pasturing just before the seasons first growth of the alfalfa blooms.

While by no means without risk, pasturing sheep on alfalfa is not always necessarily fatal and the following, related in the Breeder's Gazette by Mr. C. H. Williams of Powell county, Montana, is interesting:

"We have been pasturing sheep in large numbers on alfalfa for the past eight years. We have lost from bloat as many as 26 in one day from a flock of 1600 , but we seldom lose one now. We find they are much more apt to bloat on windy days; more especially if the wind blows from the south and is soft and balmy. This may seem strange, but we believe it a fact. We have in our employ a shepherd who has during the greater part of his life herded sheep on alfalfa in the vicinity of $\mathrm{Pau}$ and d'Oloron, France. The day we lost 26 ewes from bloat this man was several miles from the home ranch. When 
visited by the camptender he remarked: 'This will be a bad day for the old ewes on the alfalfa.' Why so? 'Because the wind is soft and warm,' said he. That afternoon we found 26 dead.

"Our French shepherd has a simple and never failing remedy for bloat from alfalfa or clover. It is simply a half-pint of sweet milk administered to the animal when found bloated. I saved a fine ram lamb the other day. He was fearfully bloated, unable to walk and scarcely able to breathe. I found an old can in the road, hastened to the pasture, milked a half pint of milk from a cow, set the lamb on his rump and poured the milk down his throat. In a half hour he was all right and following the flock. Milk from a ewe will answer just as well. IVe have adopted the following rules: Never allow the sheep to go on alfalfa pasture when very hungry; if possible get a little dry feed in their stomachs in the morning before going to the alfalfa; watch them closely on windy days, and have the herders carry a bottle of sweet milk."

\section{A POSSHBL EXpLanation}

The most of the losses reported were of animals which had been taken off the pasture at night and turned back the second morning when hungry and eager to graze. Yet there are reports of severe losses the first day, even after a full feed. Possibly it will be found that the animals that suffer from bloat are not in good physical condition, and are more nervous and greedy in their habit of eating than those not affected. It may be that an intelligent sorting of the animals to be turned on the pasture 
might save loss. It is also quite generally believed that alfalfa growing on uplands is less liable to cause bloat than that raised on bottom lands.

\section{RULES FOR PASTURING}

The most generally approved rules in regard to pasturing are :

At the beginning of the pasturing season give animals a heavy feeding in the morning before turning upon the alfalfa.

Have water in the pasture all the time.

Keep the animals in the pasture night and day, after they have become accustomed to it, until removed permanently.

Use upland in preference to bottom fields for pasture.

Watch the stock closely the first few days and remove permanently animals that show symptoms of bloat.

Sow blue-grass, brome grass, or meadow fescue with alfalfa in fields intended for permanent pasture.

The following valuable information upon bloat (tympanitis) and its treatment was prepared by Nelson S. Mayo, formerly professor of veterinary science at the Kansas agricultural college:

"Bloating, in all cases, is accumulation of gas in the stomach or intestines, or both, but more particularly in the paunch (rumen). This gas is produced by a fermentation, similar to that observed when cider is 'working' and the gas escapes in bubbles. There is usually a small quantity of gas given off from the food during normal, healthy digestion, but so small that it causes no trouble, and passes off readily through the intestines, though 
sometimes from the stomach, up the esophagus, and out of the nose or mouth-'belched up,' as it is commonly expressed. These gases which cause an animal to bloat are generated in considerable quantities if a large amount of juicy, green food is eaten. Alfalfa, clover and frozen roots are very liable to produce bloating.

"It is well known that only part of the animals in a herd pasturing upon clover or alfalfa bloat; so the blame cannot be laid entirely upon the food, but is probably the result of a slight derangement of the digestive organs, not ordinarily noticed, but easily aggravated by certain foods which ferment easily. Animals that are ailing are very liable to bloat when turned on alfalfa pastures. Alfalfa and clover are much more liable to produce bloating if wet with rain or dew, and especially hoar frost, and animals are more apt to bloat if turned into the pastures when very hungry, as they gorge themselves, and the food is not properly masticated. Hence, cattle should not be allowed to go hungry to the pastures.

"It is generally believed by those who have had considerable experience in pasturing clover or alfalfa, that cattle and sheep are less liable to bloat if they have free access to dry food, such as hay or straw. Common bloating, or hoove, occurs in animals having a compound stomach and that chew the cud-ruminants, as they are called. Of our common domestic animals, cattle and sheep belong to this order.

"One of the first symptoms noticed is that the animal stops feeding, and remains lagging behind or stands by itself. Rumination, or chewing of the cud, is suspended; the animal appears dull and listless, the back slightly 
arched; the whole abdomen or belly is distended with a prominent swelling on the left side just forward of the point of the hip. If the swelling is tapped lightly with the fingers there is a hollow, drum-like sound; hence the technical name, tympanitis.

"The rumen being distended with gas not only makes the animal appear much fuller than usual, but it presses forward on the diaphragm, or 'midriff,' and this presses against the lungs, and interferes seriously with the animal's breathing. The breath is short and rapid. The animal often grunts, or moans, with each breath. The animal's nose protrudes, and there is a driveling of saliva from the mouth. Sometimes there are quite severe colicky pains, shown by the animal's kicking at its belly and stepping about uneasily. Sometimes, also, the pressure is so great as to cause eversion or bulging out of the rectum. The symptoms of bloating are so prominent, especially when the history of the case is taken into account, as to make this disease very easy to recognize, even by an ordinary observer.

"When animals die from bloating, death usually takes place in the following manner: The diaphragm is pressed against the lungs so hard that the animal cannot breathe, and it dies of suffocation. Animals usually remain standing until near the end, when they gradually lose consciousness, stagger, and fall, and in falling rupture some of the vital organs.

"Treatment must depend somewhat upon the condition of the animal. If the animal is badly bloated, with labored breathing and staggering gait, energetic measures must be resorted to at once. The best and most 
satisfactory treatment for bad cases is tapping. This consists in making a hole through the skin and muscles, over the prominent swelling on the left side, into the rumen or 'paunch,' thus allowing the gas to escape at once, relieving the animal.

"The best method of tapping is by means of an instrument called a trocar and canmula. A trocar is a sharppointed instrument, five or six inches long, and about the size of a lead pencil, with a handle at one end. Over the point of the trocar slips a tube, called a cannula, not quite as long as the trocar, with a wide flange around the upper end of the tube, as shown in the illustration herewith.

\section{TROCAR AND CANNULA}

"To use a trocar and cannula, proceed as follows: Tie the animal so it cannot get away. With a sharp knife, make a small incision through the skin over the prominent part of the swelling on the left side. This incision

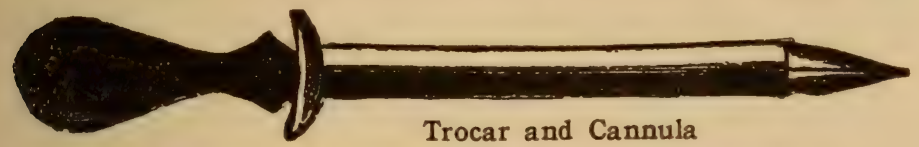

should be made about nalf way between the point of the hip and the last rib, and should be large enough to admit the trocar and cannula readily. The incision should be made quickly; then the animal will not notice it. After the incision is made the trocar and cannula are pushed quickly in and directed downward, inward, and forward; push the trocar in until the flange of the cannula rests against the skin. Withdraw the trocar and the gas will rush out; that is, it usually does so; occasionally, however, the end of the cannula is plugged up with green 
food. This can usually be remedied by pulling out the cannula part way, or pushing the trocar in again and withdrawing it. If this doesn't work, tap the stomach again in another place, using the same hole through the skin. The escape of gas is usually accompanied by a small quantity of green food.

"If a trocar and cannula are not available in an urgent case, a knife can be used very successfully-a good-sized pocket knife blade, pushed quickly through the skin and muscles, in the same manner as described for the trocar and cannula. Care must be taken that the sharp edge of the blade is not turned towards the animal's tail, as it sometimes jumps forward, and a much larger hole is cut than was originally intended.

"A careful and observing stockman of Colorado, who has had a large experience with alfalfa bloating, informs me that he prefers a moderately small, sharp butcher knife to either a trocar and cannula or a pocket knife. It gives relief quicker and with no bad effects. Sometimes, if the opcning through the skin is small, made by a small knife, a quill or small tube is fastened in to keep the incision open, so the gas can escape. It is usually necessary to keep the incision open for several hours. The only bad result of tapping is that occasionally green food gets outside of the rumen into the abdominal cavity in sufficient quantities to cause inflammation and death; but if the operation is intelligently performed, these bad results are extremely rare-probably not more than one case in Ioo. If the weather is warm, care should be taken that flies do not bother the wound in the skin. 
"If the case is not severe enough to warrant tapping, the following remedies will be found useful: A gag made by winding a good-sized rope back of the horns and through the mouth, or a bit, made of a piece of wood the size of a fork handle, can be tied in the animal's mouth. The bit should be smooth, to prevent injuring the mouth. Then a small handful of salt should be thrown well back on the roots of the tongue. This causes the animal to work its tongue, increases the flow of saliva, and thus favors the regurgitation, or gulping up, of the gas. The salt and saliva swallowed help to stop fermentation.

"Blankets wrung out of cold water and wrapped around the abdomen or belly, or cold water dashed on with a bucket, often give relief. Turpentine given as a drench, in milk sufficient that it will not irritate the animal, is good, two ounces of turpentine for adult cattle and one-half ounce for sheep being a dose. Hyposulphite of soda, dissolved in water and given as a drench, is good; one ounce for cattle and two drachms for sheep. This can be repeated every half hour for two or three doses. Aqua ammonia, two ounces for cattle and onehalf ounce for sheep, well diluted with water; carbolic acid, cattle 30 drops, sheep 8 to Io drops in sufficient water; common soda, in half-ounce doses for cattle and one-half drachm for sheep, can be given. In giving medicine as drenches, they should be well diluted with water or other substances until they will not burn when touched to the tongue. In giving drenches, be careful and not choke the animal. If the animal coughs or struggles violently, stop at once until it recovers somewhat. Give drenches slowly. 
"Drenches are mostly administered from along-necked, thick, glass bottle, or drenching horn. Take hold of the nose with the left hand, by putting the thumb and finger in the nostrils, while an assistant takes hold of the horns, and tips the head back. Standing on the right side of the animal, with the right hand put the neck of the bottle in the right corner of the mouth, and pour the medicine in slowly. After the bloating has been relieved, it is a good plan to give the animal a purgative-one pound of Epsom salts, with one-half pound common salt, for cattle; and for a sheep, six ounces of Epsom salts and three ounces of common salt, dissolved in plenty of warm water, and given as a drench. The animals should also be dieted until their digestive organs regain their normal condition. By dieting, I do not mean starving, but plenty of easily digested and nutritious food. An animal that bloats once is very liable to bloat again. By judicious handling and feeding, by watching animals closely, and treating them in time, few will be lost by alfalfa bloating."

\section{ALFALFA AS A SOILING CROP}

Alfalfa may be cut for soiling just when it contains the highest per cent of protein, while if pastured some is eaten before its best period, the most of it after that point is reached, and probably a large portion of the leaves is lost entirely. Cut for soiling and fed daily, when wilted, there is less danger from bloat, as in this way animals will eat stalks as well as leaves; the entire product is used and there is no loss from trampling the fields nor by plants being covered and smothered with animal droppings. 


\section{SOME COMPARISONS}

The Nebraska station reports that in an experiment there it required .7I of an acre to keep a cow for a given time by soiling, while by pasturing it required 3.63 acres; also that the cows kept on! pasture during the experiment actually consumed more grain than those that were soiled. This report further states that while the pastured cows gave more milk each day, the cost of production was greater. By another experiment with cows for a single year it was indicated (Bul. No. 69) "that about twice as much feed was secured from the land when the alfalfa was soiled as when it was pastured. The average daily production of milk and of butterfat was markedly greater when the crop was pastured than when soiled. In one test this amounted to one-third more, but in the other test the difference was not so great. The profits from soiling as compared with pasturing will depend largely on two factors-the price of labor and the value of the land."

A western Kansas farmer writes that one acre of alfalfa cut daily for soiling maintained as many cows as he was able to keep on a five-acre field used as pasture.

The Kansas station reported that in an experiment, lasting I44 days, the cows on alfalfa pasture returned an income, less cost of grain fed, of $\$ 4.23$, while cows soiled on alfalfa cut and fed green returned an income, less the grain fed, of \$18.08. This station also reported that a neighboring dairyman maintained ten milch cows for a whole summer, without any grain, on two acres of alfalfa, cut and fed to them fresh three times a day. 


\section{A METHOD FOR THE SMALC FARMER}

In the Central West where labor is scarce and land comparatively low in price, farmers are not likely to adopt the soiling system while such conditions exist; but east of the Mississippi river, and especially in New York, Pennsylvania and New England, where land is high and labor scarce, alfalfa offers great possibilities as a soiling crop. The small farmer who now cannot afford to raise many pigs, because he does not raise enough corn to fatten them, will find that by soiling alfalfa he can maintain from May to September from five acres as many as ten cows and fifty pigs; and that these pigs, with some grain from the first of August, while being fed green alfalfa, may by the middle of November be made ready for market. If he has another five acres of alfalfa for hay, it will yield enough in three cuttings to go far toward wintering his cows, a team of horses, and his sows. His ten acres will be growing richer every year, and at the end of five years be in prime condition to yield him big returns in corn, wheat, or potatoes and other vegetables. Alfalfa is distinctly a crop adapted to the small farmer, everywhere; there is, as a rule, little question that this method of utilizing it brings much greater returns per acre than if it were used as pasturage or hay.

Green alfalfa when pastured, (barring bloat), or cut and fed daily is peculiarly valuable for all such young stock as colts, lambs, calves and pigs. It tends to develop strength of bone and hastens the growth of muscle. 


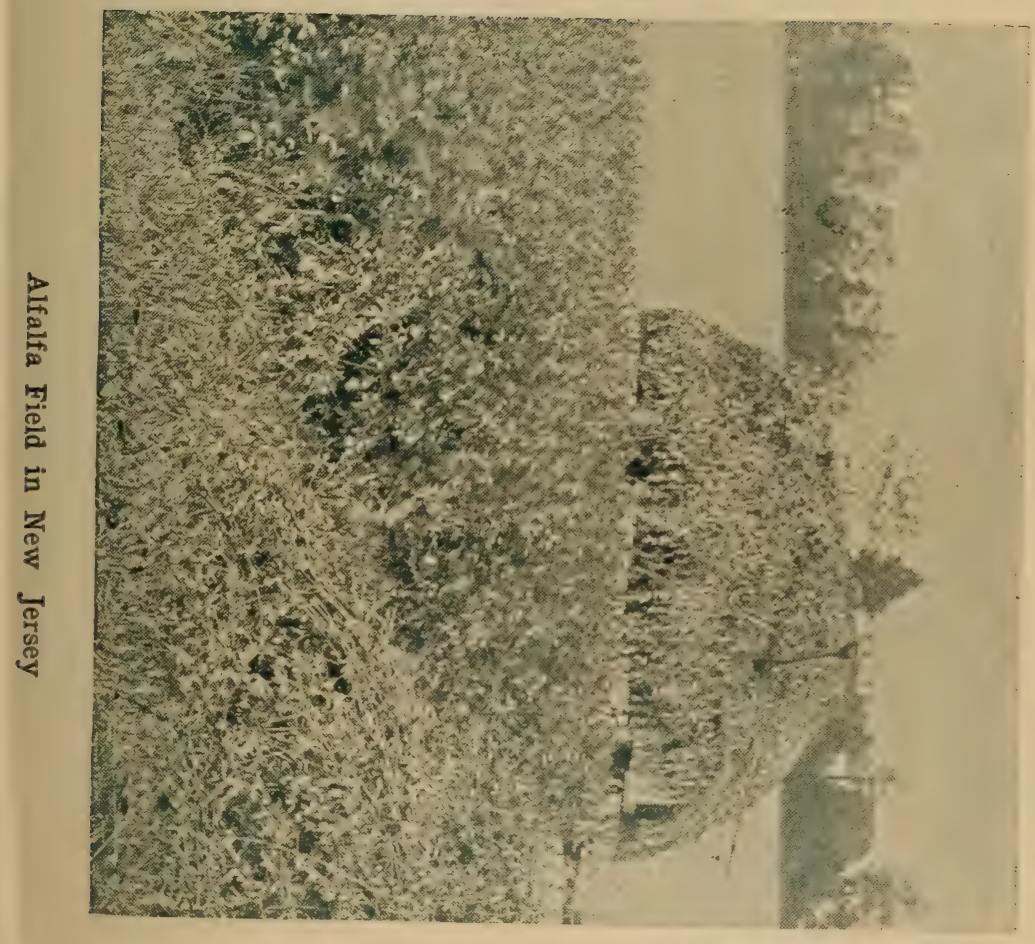




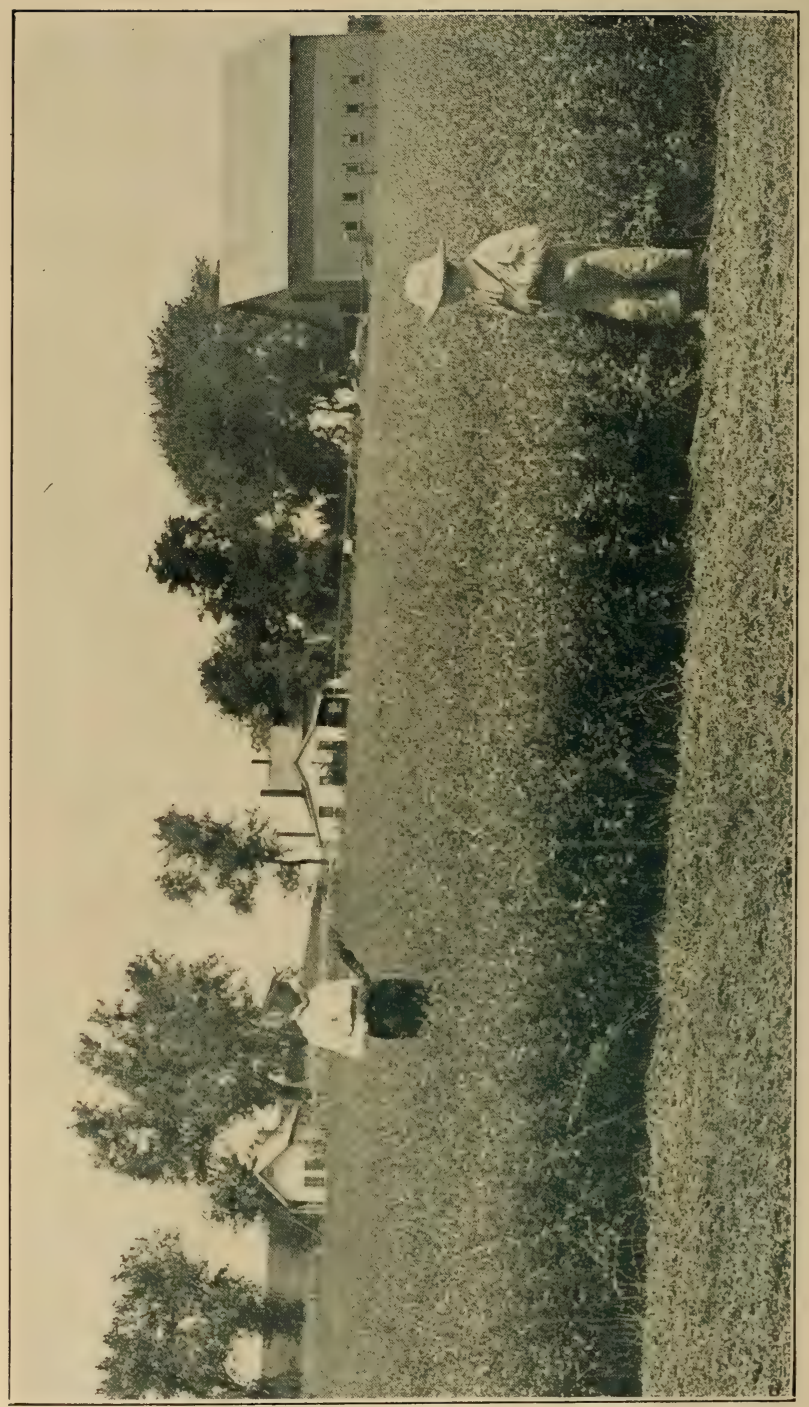

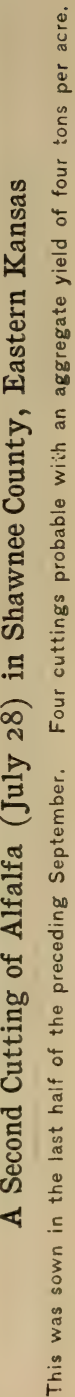


CHAPTER X.

\section{Alfalfa as a Feed Stuff}

\section{AS AN APPETIZER}

The feeding value of alfalfa is largely in its chemical sompound known as protein; its extreme digestibility is another desirable quality to be considered, and not least is its appetizing character. Not only do all animals like it, but when given in moderate quantities it seems to increase the general appetite for more fat-making feeds. Steers beginning to "fall off" on a heavy diet of corn will come to their appetites after being fed only a few pounds of alfalfa daily, and will eat and assimilate more corn than before.

Alfalfa alone is not a fat-making feed. Animals fed upon it grow in weight, but the weight is principally of bone, blood and muscle. It is without a sufficiency of fat and carbohydrates, and these should be added in such foods as corn, corn meal, Kafir corn, or Kafir corn meal; or to a limited degree even in corn stover, sorghum or millet. When alfalfa is fed alone all the protein cannot be digested, and, therefore, it is always economical to add some carbonaceous foods, if animals are fattening for market. 
For several years feeders have been deploring the fact that fattening mainly with corn was becoming less and less profitable. When they began to figure the exact cost of each pound of gain on a steer or hog, they saw clearly that corn alone made the pound of gain cost too much; sometimes as much as it was worth in the market, leaving neither profit nor interest on the investment. The problem then became how to produce the pound of meat more economically.

Such a condition has prompted the state stations to make tests to determine the feeding value of various articles, and especially the value o $i$ alfalfa as a balance to the more carbonaceous foods. The tables here appended are worth studying:

FOOD VALUE OF SEVERAL FODDER CROPS

(From New York experiment station Bul. No. I I8.)

\begin{tabular}{|c|c|c|c|c|}
\hline & $\begin{array}{l}\text { Yield per acre } \\
\text { of total crop }\end{array}$ & $\begin{array}{l}\text { Dry matter } \\
\text { per acre }\end{array}$ & $\begin{array}{l}\text { Total digesti- } \\
\text { ble matter } \\
\text { per acre }\end{array}$ & $\begin{array}{c}\text { Digestible } \\
\text { protein }\end{array}$ \\
\hline & Pounds & Pounds & Pounds & Pounds \\
\hline Alfalfa ............. & 34,100 & 8,000 & 5,280 & 875 \\
\hline Corn, entire plant... & 28,000 & 5,800 & 3,800 & 300 \\
\hline Red clover................ & 18,000 & 5,220 & 3,200 & 491 \\
\hline Oats and peas.............. & 13,000 & 3,120 & 2,521 & 350 \\
\hline Timothy ................... & 10,000 & 3,500 & 2,000 & 228 \\
\hline Rutabagas... & 31,700 & 3,400 & 3,000 & 279 \\
\hline Mangels...... & 25,000 & $\begin{array}{l}5,400 \\
3,500\end{array}$ & $\begin{array}{l}2,750 \\
2,750\end{array}$ & 232 \\
\hline Sugar beets... & 17,800 & 2,500 & 1,800 & 213 \\
\hline
\end{tabular}

ANALYSES OF FEEDSTUFFS

The following table gives the analyses of a number of feedstuffs, showing the percentage of digestible nutrients and fertilizing constituents in each: 
(From Texas experiment station Bul. No. 66)

\begin{tabular}{|c|c|c|c|c|c|c|c|}
\hline & \multirow{2}{*}{ 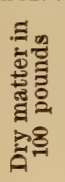 } & \multicolumn{3}{|c|}{$\begin{array}{l}\text { Digestible nutrients } \\
\text { in } 100 \text { pounds }\end{array}$} & \multicolumn{3}{|c|}{$\begin{array}{l}\text { Fertilizer constituents } \\
\text { in } 1000 \text { pounds }\end{array}$} \\
\hline & & $\frac{\Xi}{\frac{D}{0}}$ & 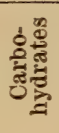 & 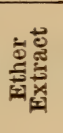 & 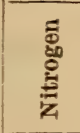 & $\begin{array}{l}\frac{0}{0} \\
\frac{2}{2} \text { 옹 } \\
\frac{8}{2}\end{array}$ & $\begin{array}{l}\text { 패 } \\
\text { హ్ } \\
\text { के } \\
\text { ค1 }\end{array}$ \\
\hline \multicolumn{8}{|l|}{ HAYS: } \\
\hline Alfalfa ............. & 91.6 & 11.0 & 39.6 & 1.2 & 21.9 & 5.1 & 16.8 \\
\hline Cowpea .................. & 89.3 & 10.8 & 38.6 & 1.1 & 19.5 & 5.2 & 14.7 \\
\hline oat hay ................. & 91.1 & 4.3 & 46.4 & 1.5 & $\ldots . .$. & & \\
\hline Fodder corn............. & 57.8 & 2.5 & & & 17.6 & 5.4 & 8.9 \\
\hline $\begin{array}{l}\text { Sorghum.................. } \\
\text { Cottonseed hulls ...... }\end{array}$ & $\begin{array}{l}82.04 \\
88.9\end{array}$ & $\begin{array}{r}2.4 \\
.3\end{array}$ & $\begin{array}{l}40.6 \\
33.1\end{array}$ & $\begin{array}{l}1.2 \\
1.7\end{array}$ & 6.9 & 2.5 & $\ddot{10.2}$ \\
\hline \multicolumn{8}{|l|}{ GREEN FEEDS: } \\
\hline Alfalfa $\ldots \ldots \ldots \ldots \ldots$ & 28.2 & 3.9 & 12.7 & .5 & 7.2 & 1.3 & 5.6 \\
\hline Cowpea .................. & 16.4 & 1.8 & 8.7 & .2 & 2.7 & 1.0 & 3.1 \\
\hline Oat fodder............... & 37.8 & 1.6 & 18.9 & 1.0 & 4.9 & 1.3 & 3.8 \\
\hline Corn silage........... & 20.9 & .9 & 11.3 & .7 & 2.8 & 1.1 & 3.7 \\
\hline Sorghum........ & 82.4 & 2.4 & 4.1 & 1.2 & & & \\
\hline Rape..................... & 14.0 & 1.5 & 8.1 & .2 & 4.5 & 1.5 & 3.6 \\
\hline \multicolumn{8}{|l|}{ GRAINS: } \\
\hline Wheat bran.............. & 88.1 & 12.2 & 39.2 & 2.7 & 26.7 & 28.9 & 16.1 \\
\hline Cottonseed meal ...... & 91.8 & 37.2 & 16.9 & 12.2 & 67.9 & 28.8 & 8.7 \\
\hline Corn ...................... & 89.1 & 7.9 & 66.7 & 4.3 & 18.2 & 7.0 & 4.0 \\
\hline Cowpea ................... & 85.2 & 18.3 & 54.2 & 1.1 & 33.3 & & \\
\hline Cotton seed .............. & 89.7 & 12.5 & 30.0 & 17.3 & 31.3 & 12.7 & 11.7 \\
\hline
\end{tabular}

From the above table we find that five tons of alfalfa hay contains I, IOO pounds of protein, equal to this food element in

Cotton seed meal....... 2,956 pounds

Linseed meal......... 3,754 pounds

Wheat bran......... 9,016 pounds

Cowpea hay........... I0, 185 pounds

Red clover hay......... 6,176 pounds

Timothy hay.........39,285 pounds

\section{RELATIVE VALUES OF DIFFERENT CUTTINGS}

The most interesting experiments comprehending tests of the comparative yield, composition and digestibility of early, medium and late cuttings of alfalfa, of the first, second and third crops; the relative feeding value 
of the various cuttings, and of the different crops, have been made at the Utah station, details of which are recorded in the station's bulletins Nos. 3I, 44 and 6r. These tests and investigations extended continuously through a period of five years, and following are the more important facts developed and the conclusions that may be legitimately drawn from them, as summarized (Bul. No. 6I) by Profs. Luther Foster and L. A. Merrill who supervised the work:

I. The largest annual yield of hay per acre is obtained by the method of early cutting and the lowest by the late, the average result standing as follows: early cutting, Ioo; medium, 92 ; and late, 85.

2. The early cut alfalfa contains the highest per cent of protein and fat, the most valuable food constituents, and the lowest per cent of crude fiber, the most indigestible portion. The former decrease constantly while the latter increases rapidly from early bloom to the full maturity of the plant.

3. The proportionate amount of leaves to stems is greater a: early bloom that at any subsequent time, and both leaves and stems contain a greater per cent of protein and a less per cent of crude fiber at this time than at any later period in the growth of the plant. The relative proportion of leaves to stems in the different cuttings is as tollows: early, 42 to 58 ; medium, 40 to 60 ; and late, 33 to 67 .

4. Alfalfa leaves as compared with stems are very much richer in protein, fat and nitrogen-free extract, and they contain a much smaller proportion of crude fiber. The per cent of the protein and fat grows constantly less, 
and that of the crude fiber greater, from the time of early bloom to maturity. The average composition of all cuttings and crops shows the leaves to contain I 50 per cent more protein than the stems, 300 per cent more fat, 35 per cent more nitrogen-free extract, and 256 per cent less crude fiber.

5. The more important nutrients, protein and fat, have the highest per cent of digestibility in the early cuttings and it grows less and less with the age of the plant.

6. In the feeding tests, the highest gains were made from the early cuttings and the lowest from the late, the results standing proportionately as follows : early cutting, Ioo; medium, 85 ; and late, 75 .

7. The variation in the amount of the different cuttings eaten per day was very slight, being the highest for the early cutting and the lowest for the late, but the quantity of dry matter and also of digestible matter required for a pound of gain was decidedly lowest for the early cutting and highest for the late, the relative amounts of dry matter standing as follows: early cutting, roo; medium, I3 I ; and late, I66.

8. The annual beef product per acre was largest from the early cuttings, not only in the general average but in each separate season's test, and that from the late cuttings was smallest, the proportional products standing as follows: early cutting, IOo; medium, $79 \frac{1}{2}$; and late, $691 / 2$.

9. Taking all points of comparison into consideration, both separately and collectively, including everything that pertains to the largest yield and the highest feeding value, the tests favor cutting alfalfa for cattle feeding when the first blooms appear. 


\section{CROP COMPARISONS}

IO. The first crop gave the largest yield in each of the five tests and in fourteen out of the fifteen cuttings, while the third crop gave the lowest for every test and in every cutting but one. The average acre yields for the five years, including all cuttings, stand in the following relation: first crop, IOO; second, 78 ; and third, 39; for the early cuttings alone, first crop, IOo; second, 83 ; and third, 66.

II. In the average composition of all cuttings for three years, the nutrients of the three crops vary but little. The second has slightly the highest per cent of protein and fiber; and the third the most fat and nitrogen-free extract.

I2. The third crop has the largest proportion of leaves to stems; but the per cent of protein in the leaves is highest in the second crop; and next highest in the first. The leaves of the first crop contain the most fat and of the second, the least.

I3. The third crop produced a higher average rate of gain in the feeding tests than the first or second and also higher than any of the separate cuttings. The amount eaten daily was also highest of all, but the dry matter and digestible matter for a pound of gain were the lowest. In a pound per pound comparison the gains stood as follows: first crop, IOo; second, 8I ; and third, I 26 ; dry matter for a pound of gain, first crop, IOO ; second, II 5 ; and third, 69.

I4. The beef product per acre, taking the average result of all cuttings for the five years, was very much the highest for the first crop and decidcdly the lowest for 
the third, standing as follows : first crop, Ioo ; second, 6r ; and third, 45. But taking the early cuttings alone they stand, first crop, Ioo; second, 80; and third, 69.

I5. Pound for pound, taken as a whole, the results show the highest feeding value for the third crop and the lowest for the second.

I6. The average annual beef product from early cut alfalfa was 705.6I pounds per acre; it required 9575 pounds of timothy to produce an equal weight; I I,967 pounds of red clover, and 10,083 pounds of shredded corn fodder.

Prof. John A. Widtsoe at the Utah station (Bul. No. 48) made a study of the nutrients of the alfalfa crop, and some of the facts gathered are given in the following table:

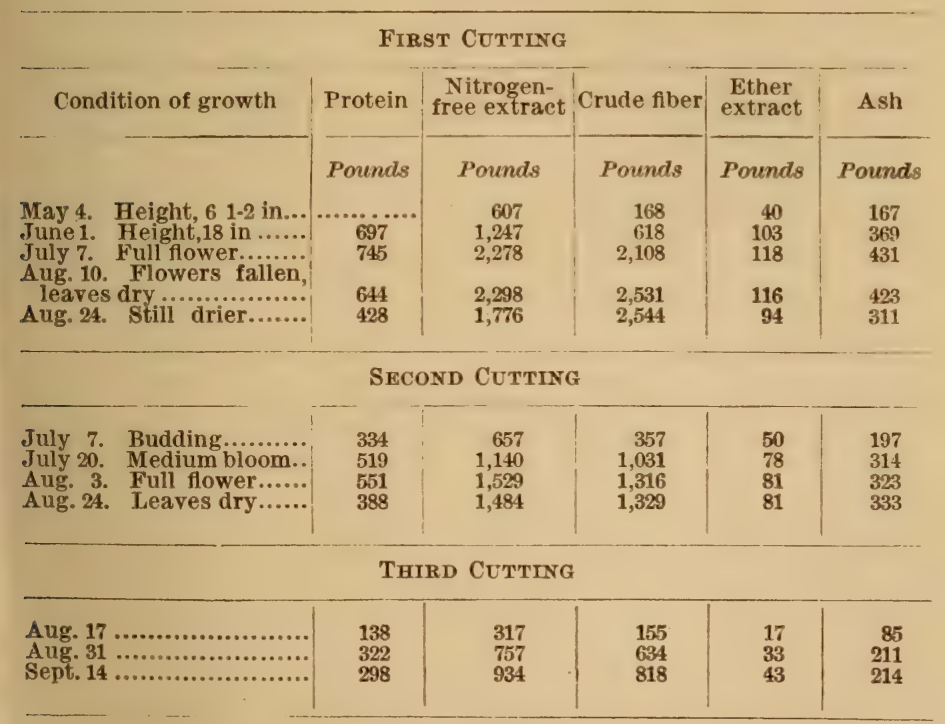




\section{COMPARATIVE CROP AND FEEDING VALUES}

The following is another table showing the average yield of alfalfa as compared with some of the more common fodder crops and hays, as found in New Jersey station Bulletin No. 148.

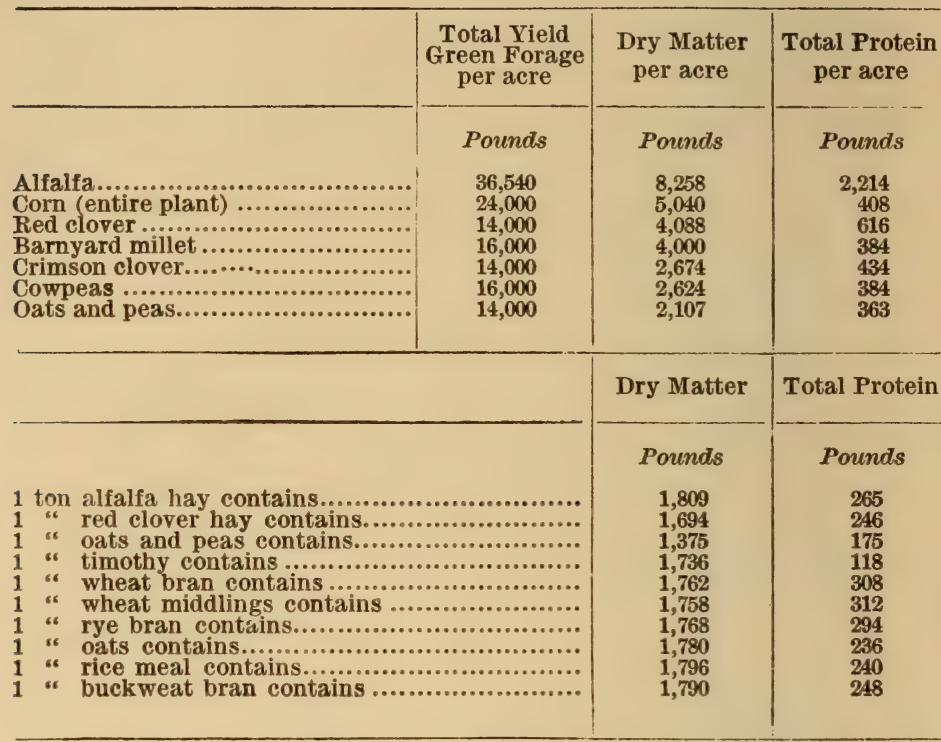

At the Colorado station (Bul. No. 26) Prof. W. W. Cooke compared an acre of dent (Golden Beauty) corn, planted May 16 and harvested September 21, with returns from an acre of alfalfa on an adjoining plat, three years seeded. The corn crop was a fair one, and including ears and stalks weighed I 5,500 pounds, containing 35.62 per cent or 5539 pounds of dry matter. The alfalfa yielded three cuttings of hay weighing respectively 4600 , 3350 and 3250 pounds, or 5.6 tons, containing 10,304 pounds of dry matter. But, as Professor Cooke says, this 
is not quite a fair comparison, for a pound of dry matter from the corn crop is more digestible and has a higher feeding value than an equal amount from the alfalfa. The corn crop contained 3605 pounds of digestible feeding material, while the alfalfa crop contained 56 I I pounds, or a little more than half as much again. The corn crop per acre in feeding value was equivalent to three and a half tons of alfalfa hay.

The total digestible nutrients of the two crops are presented in the following table:

\begin{tabular}{|c|c|c|c|c|}
\hline & \multicolumn{2}{|c|}{ TOTAL } & \multicolumn{2}{|c|}{ DIGESTIBLE } \\
\hline & Corn & Alfalfa & Corn & Alfalfa \\
\hline 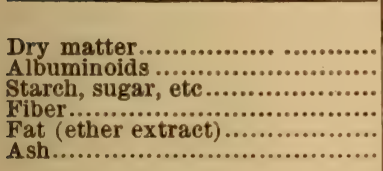 & $\begin{array}{c}\text { Pounds } \\
5,539 \\
405 \\
3,263 \\
1,472 \\
84 \\
315\end{array}$ & $\begin{array}{c}\text { Poninds } \\
10,304 \\
1,602 \\
4,782 \\
2,800 \\
246 \\
829\end{array}$ & 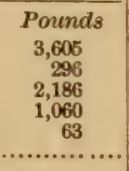 & $\begin{array}{c}\text { Pounds } \\
\mathbf{5 , 6 1 1} \\
\mathbf{1}, 198 \\
\mathbf{3}, 114 \\
\mathbf{1 , 1 9 8} \\
\mathbf{1 0 1} \\
\ldots \ldots . . . . . .\end{array}$ \\
\hline
\end{tabular}

\section{COMPARATIVE VALUES OF ALFALFA HAY AND OTHER} FEEDSTUFES FOR PROTEIN

\begin{tabular}{|c|c|c|c|}
\hline \multirow{2}{*}{ Feedstuff } & \multicolumn{3}{|c|}{$\begin{array}{l}\text { Value per ton when prairie hay } \\
\text { is worth per ton- }\end{array}$} \\
\hline & $\$ 2.00$ & $\$ 3.00$ & $\$ 4.00$ \\
\hline 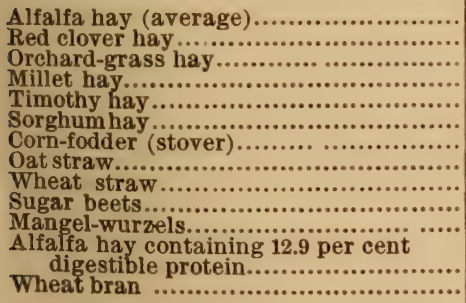 & $\begin{array}{r}\$ 6.05 \\
3.88 \\
2.74 \\
2.57 \\
1.65 \\
1.37 \\
1.14 \\
.91 \\
.45 \\
.62 \\
.57 \\
7.36 \\
7.02\end{array}$ & $\begin{array}{r}\$ 9.08 \\
5.82 \\
4.11 \\
3.85 \\
2.48 \\
2.05 \\
1.71 \\
1.37 \\
.68 \\
.94 \\
.85\end{array}$ & $\begin{array}{r}\$ 12.11 \\
7.77 \\
5.48 \\
5.14 \\
3.31 \\
2.74 \\
2.28 \\
1.82 \\
.91 \\
1.25 \\
1.14\end{array}$ \\
\hline
\end{tabular}


It is seen that the alfalfa yielded nearly twice as many pounds of dry matter as the corn, with the digestible nutrients far in the lead, and the protein of the alfalfa was three times that of the corn.

\section{THE BALANCED RATION}

No feeder can learn to use alfalfa, or in fact any forage or grain, in the most economical way until he understands somewhat the compounding of a balanced ration. All foodstuffs for either man or beast are, as already stated, made up of three classes of substances-namely, protein or proteids, carbohydrates and fats. The animal's digestive and assimilative organs are so constructed that it cannot use these three classes of substances interchangeably; in other words, an animal fed wholly upon any one of these three would be in process of gradual starvation. Given in the proportions needed to best supply the vital organs of the body, these substances become the sustenance for animal life and growth. The protein builds up the brain, nerves, muscles and other tissues in which the life force is active, and without protein there would be no life.

To balance a ration for domestic animals is to so adjust the quantity of digestible proteids, fats and carbohydrates it contains that the animal economy may use each without waste. The balanced ration means an economical ration, allowing the digestive organs to work at their highest efficiency; an unbalanced ration is one in which one of the three classes of food substances is in excess, or is deficient. Fed such a ration, the animal retaliates upon its owner by failure to digest the excess, 
which is worse than wasted; for the feeding of any class of substances in excess adds to the labor of the digestive organs and reduces their efficiency.

\section{MAKING A BALANCED RATION}

In Press Bulletin No. I2, from the Kansas station, the following is given to illustrate somewhat how a balanced ration would differ from others into which consideration of a proper balance had not entered:

"There are three important groups of substances in feeds-protein, carbohydrates, and fat. Protein includes all materials in feeds which contain nitrogen. It enters into the composition of milk, blood, muscle, hair and the brain and nerves; is necessary in the formation of these, and no other substance can take its place. Protein is also used in the body in producing heat, energy and fat. Carbohydrates include the fiber of feeds, the sugars, starch, and gums, and furnish heat, energy and fat in the body. Carbohydrates and fat can take each other's places, one pound of fat being worth 2.2 pounds of carbohydrates for production of heat in the body.

"Extended investigations have shown that to obtain the best results, feed should be given which will furnish these materials in the following proportions:

"Dairy cow-protein, $21 / 2$ pounds ; carbohydrates, $121 / 2$ pounds; fat, $1 / 2$ pound.

"Fattening steer-protein, $2 \frac{1}{2}$ to 3 pounds; carbohydrates, I5 pounds; fat, $I / 2$ to $3 / 4$ pound.

"Growing cattle-protein, 4 pounds; carbohydrates, I $3 \frac{T}{2}$ pounds; fat, 2 pounds.

"For a young animal (cattle) gradually decrease the proportion of protein until at the age of two years the pro- 
portions are similar to those for the fattening steer, but less in quantity. A pig two to three months old needs feeds containing seven and one-half pounds of protein to each thirty pounds of carbohydrates and fat, while a year-old pig needs seven and one-half pounds of protein to each forty-eight pounds of carbohydrates and fat. Feeds containing a greater proportion of protein than called for by these standards can be fed, because protein can take the place of the other materials. Carbohydrates and fat cannot take the place of protein, however, and no matter in how large quantities they may be fed, if protein is lacking, the growth or gain will be less.

"The weak point in feeding is that the average rations are greatly deficient in protein, and have too much carbohydrates and fat. Every feeder knows that good pasturage produces rapid growth, good gains, and abundant milk yields. It furnishes nutriment in the proportion of three pounds of protein, twelve pounds of carbohydrates, and one-half pound of fat. The proportions in some of our feeds in pounds per IOO pounds of feed, are as follows :

\begin{tabular}{|c|c|c|c|}
\hline & Protein & $\begin{array}{c}\text { Carbohy- } \\
\text { drates }\end{array}$ & Fat \\
\hline 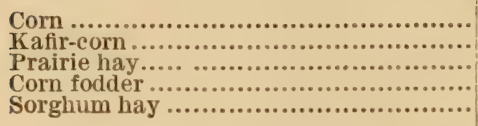 & $\begin{array}{l}7.8 \\
7.8 \\
3.5 \\
2.0 \\
2.4\end{array}$ & $\begin{array}{l}66.7 \\
57.1 \\
41.8 \\
33.2 \\
40.6\end{array}$ & $\begin{array}{l}1.6 \\
2.7 \\
1.4 \\
0.6 \\
1.2\end{array}$ \\
\hline
\end{tabular}

"It will be seen that none of these contain a sufficient proportion of protein to secure best results, and all combinations of these feeds will have the same defect. 
"Some feeds have too great a proportion of protein to be fed alone, as shown below, the figures indicating pounds per Ioo pounds of feed:

\begin{tabular}{|c|c|c|c|}
\hline & Protein & $\begin{array}{l}\text { Carbohy- } \\
\text { drates }\end{array}$ & Fat \\
\hline 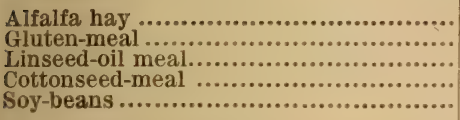 & $\begin{array}{l}10.6 \\
31.1 \\
28.8 \\
37.0 \\
39.6\end{array}$ & $\begin{array}{l}37.3 \\
43.9 \\
32.8 \\
16.5 \\
22.3\end{array}$ & $\begin{array}{r}1.4 \\
4.8 \\
7.1 \\
12.6 \\
14.4\end{array}$ \\
\hline
\end{tabular}

"Making a balanced ration is combining the feeds deficient in protein with those having an excess of it, to make a ration which will contain the right proportions for the animals fed."

\section{VARIATIONS IN ANALYSIS}

Variations in the foregoing tables would indicate that the analysis is likely to vary with the product of different soils and different cultivations. In spite of variations it may be readily seen that alfalfa with its high protein value makes a very effective and economical balance for corn for heavy feeding. When it is taken into consideration that this forage so rich in protein can be raised at home, and that its growing is at the same time enriching: the soil, the conclusion is easy that alfalfa hay may profitably constitute a part of all the fattening operations; it is also clear that the economical way to market alfalfa is through the farm's live stock. 


\section{CHAPTER XI.}

\section{Alfalfa in Beef-Making}

The cattle feeder is not much given to sentiment and cares less for the beauty of the purple flowers of the alfalfa than he does for the best method of converting those purple flowers and the accompanying foliage into marketable beef. An accepted but unwritten rule of cornfeeding is that 1000 pounds of grain with ordinary forage will produce Ioo pounds of gain, under normal conditions.

\section{SOME FEEDING TESTS}

The Kansas station in a careful feeding test of 153 days produced 100 pounds of gain with 718 pounds of grain by using alfalfa hay for roughness. This test also gave the following table of gain in values, from the use of different feeds in the same given time:

Corn and alfalfa hay........ \$109.74

Corn and prairie hay......... 56.96

Corn and sorghum hay...... 27.09

Corn and oat straw......... 43.28

Barley and alfalfa hay....... 57.16

The Utah station after a feeding test published the statement that to produce 705.6I pounds of beef it required :

Of alfalfa hay....... 7,182 pounds

Of timothy hay....... 9,575

Of red clover hay........ II 967 "

Of shredded corn fodder. . I0,083 “ “ 


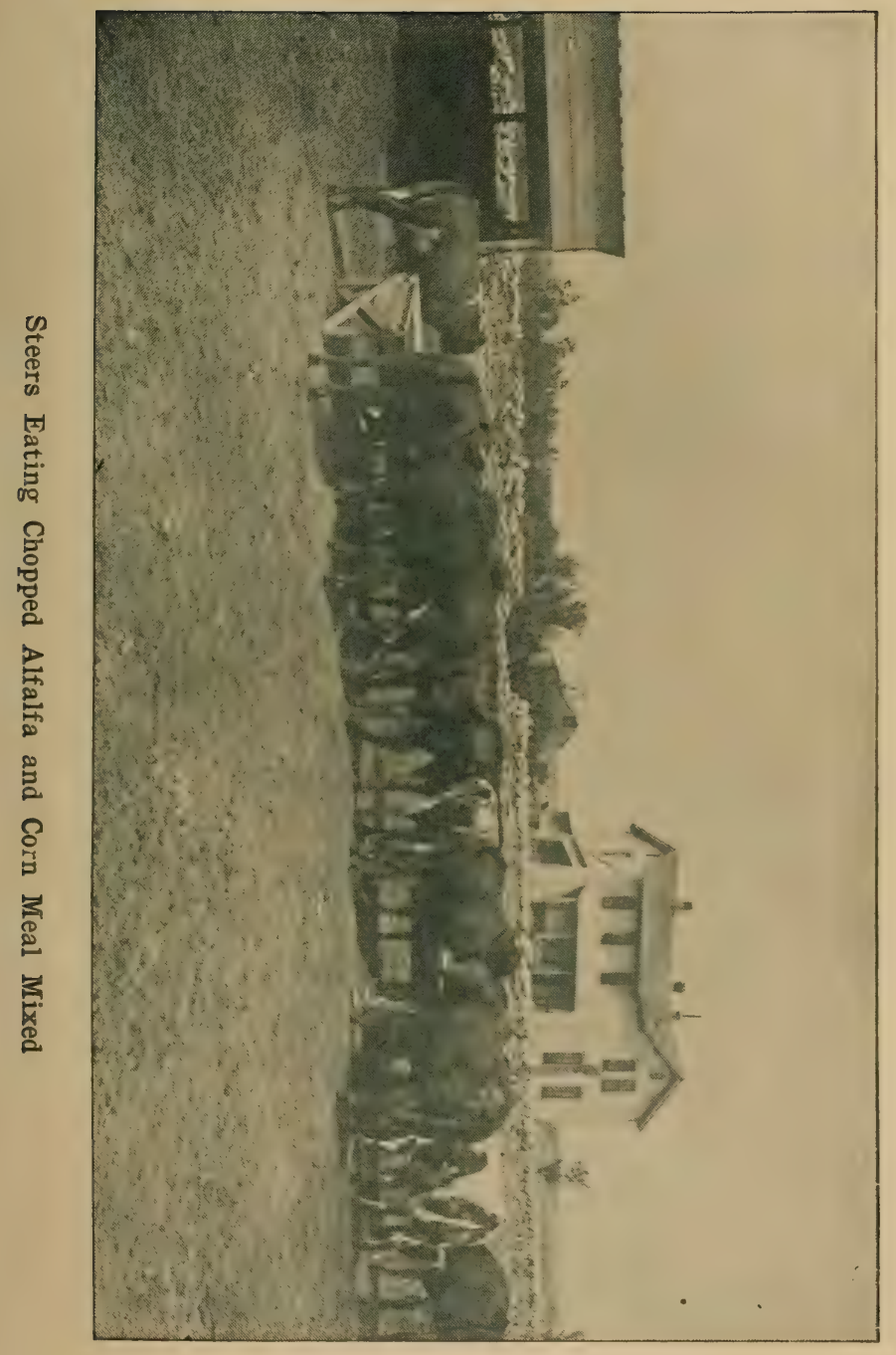




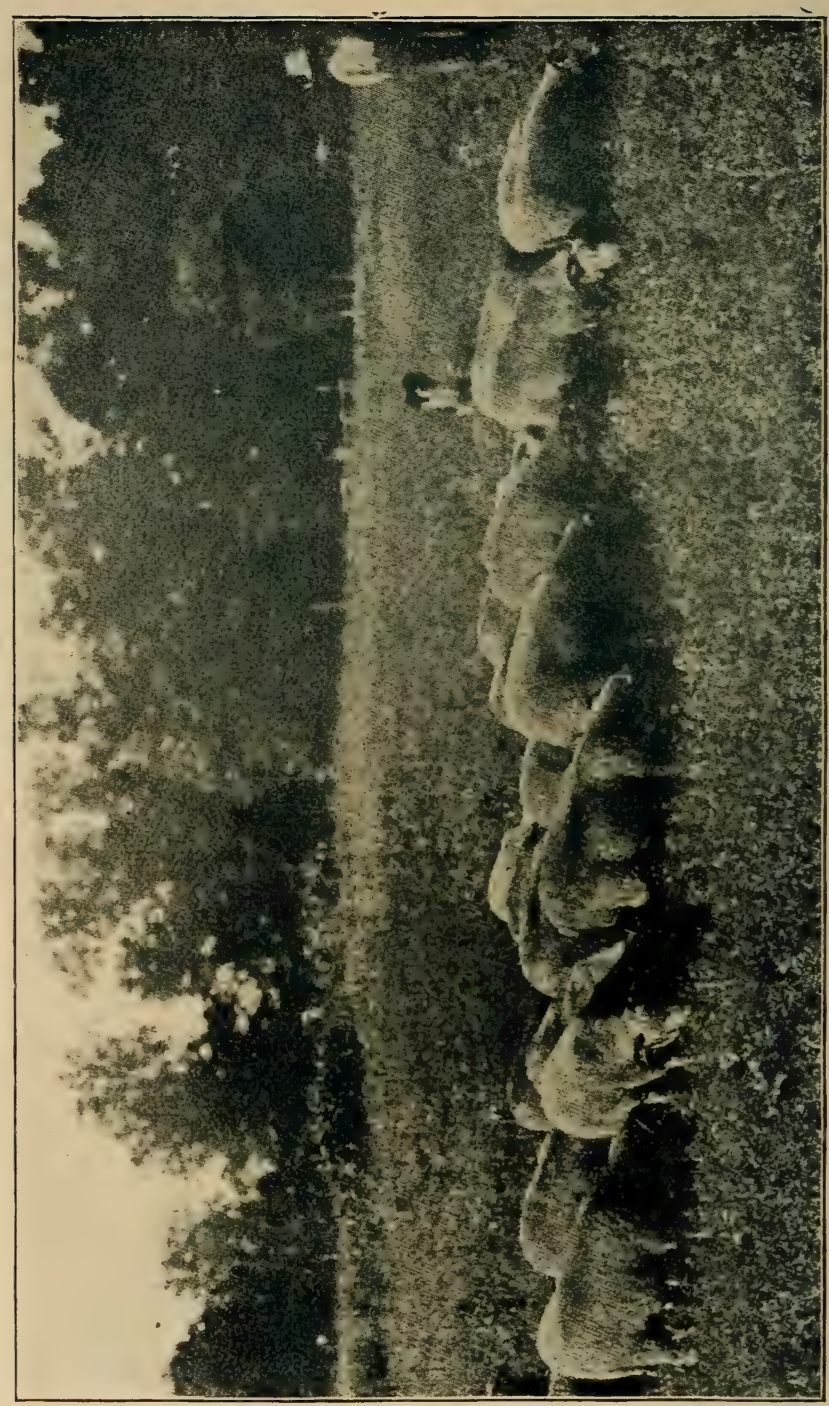

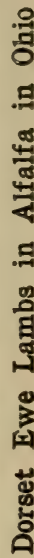


At this station steers made a most rapid gain when fed upon early cut alfalfa hay, either with or without an accompanying ration of grain. "By early cut hay was meant hay cut just before bloom. The gain upon this early cut alfalfa hay was one-third more than that upon hay cut when in full bloom or later."

The Utah station also reports a cattle feeding test (Bul. No. 6I) in which roo pounds of gain from feeding alfalfa hay cost $\$ 3.76$; from timothy, $\$ 4.71$, and from corn fodder, $\$ 6.2 \mathrm{I}$.

At the Nebraska station Prof. Howard R. Smith (Buls. 85 and 90 ) fed 50 yearling and 50 two-year-old grade steers in lots of ten for six months, each lot of each fifty having rations different from the others, and the table herewith shows the average cost per pound of gain made by each steer of each lot of yearlings:

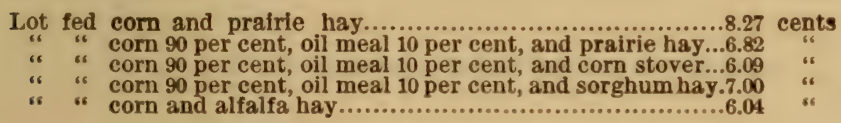

Below is shown the cost under similar conditions with the two-year-olds, (the cost of the corn and oil meal fed them having been slightly greater than that fed the yearlings) :

Lot fed corn and prairie hay $\ldots \ldots \ldots \ldots \ldots \ldots \ldots \ldots \ldots \ldots \ldots \ldots \ldots .23$ cents

"“ " corn 90 per cent, oil meal 10 per cent, and prairie hay ....8.27

“ “. corn 90 per cent, oil meal 10 per cent, and corn stover ...6.49

"s " corn 90 per cent, oil meal 10 per cent, and sorghum hay...7.87 ",

Among the deductions from these experiments, Professor Smith records the following, bearing upon the use of alfalfa : 
"Alfalfa is much superior to prairie hay when the grain consists of corn alone. It also proved to be a cheaper source of protein than oil meal. The returns on the cattle fed alfalfa hay, were the alfalfa figured at \$II.I4 per ton, would have been as great as the returns on prairie hay at $\$ 6$ per ton, with corn as the grain ration at 39 cents per bushel. In comparison with prairie hay at $\$ 6$ when oil meal worth $\$ 28$ per ton was a part of the grain ration, the alfalfa returned a value of $\$ 8.28$ per ton. (In these experiments the cost of all alfalfa hay and all prairie hay was figured at the one price of $\$ 6$ per ton.Author.)

"Bright, well-cured corn stover fed with an equal weight of alfalfa, the grain consisting of corn alone, gave slightly larger gains than corn and alfalfa, and proved the most economical ration in the experiment. The addition of corn stover may have improved, to some extent, the corn and alfalfa ration by furnishing greater variety, and by its tendency to check scours sometimes caused by alfalfa. The stover fed with alfalfa returned a value of $\$+57$ per ton in comparison with alfalfa at $\$ 6$ per ton as the sole roughness.

"By feeding alfalfa hay, which is a protein-rich roughness, extremely palatable and readily masticated, in place of prairie hay with corn alone, I4 per cent less grain was required for each pound of gain on two-year-olds and 27 per cent less on yearlings.

"Alfalfa hay, fed once per day in connection with corn and well-cured cornstalks, furnished sufficient protein for two-year-olds to make the three foods a combination 
producing heavy and very economical gains-more economical than any other ration in the experiment.

"Alfalfa is pronouncedly superior to prairie hay for beef production, and the more rapid the extension of the area of land devoted to the production of alfalfa, supplanting the less valuable and lower yielding native hay, the more rapid will be the production of wealth from our soil."

One authority who has made a study of such problems says, "steers can be fattened on one-third less corn with alfalfa for roughness than without."

W. H. Jordan, director of the New York (Geneva) experiment station says: "Probably no species of forage are known that are more economical sources of highclass cattle food than alfalfa and corn, and if in the realms of stock raising corn is king, alfalfa is queen."

\section{FEEDING TOO MUCH ALFALFA}

Many feeders make the mistake of feeding too much alfalfa hay to young steers grained heavily on corn. Careful tests seem to prove that cattle on a heavy feed of corn, corn meal, Kafir-corn or Kafir-corn meal gain as much with 15 or 20 pounds of alfalfa hay per day as by having 35 pounds, the very common quantity in feeding. It is also reported by experienced feeders that steers over three years old may be fattened on alfalfa with a moderate feed of corn, while for younger steers the heavy feed should be corn with I 5 to 25 pounds of alfalfa hay per day.

A Colorado feeder put a lot of steers nearly four years old on a daily ration of ten pounds of corn chop and 
fifteen pounds of alfalfa hay for Ioo days. The gain was surprising and the steers weighed on the Denver market about I430 pounds per head.

A feeder in Osborne county, Kansas, reported to the author the following: "Began feeding 22 two-year-old steers on February 3rd, averaging 94I pounds in weight. Gave them no feed but alfalfa hay until March 4 th. From March 4th until May Ist fed all the alfalfa they wanted and 243 bushels of corn chop, when they weighed out at an average gain of 259 pounds each in 86 days, or three pounds per day on a feed of I I bushels of corn chop and plenty of alfalfa hay per steer."

Western feeders generally claim to be able to put fat cattle on the market from 20 to 30 per cent cheaper with alfalfa as the balance than on corn alone, or with corn and bran or any purchased protein foods. The cheapest beef-making in the West is the raising of calves on alfalfa, and at 20 to 24 months fattening them by a heavy feeding of corn and alfalfa hay for Ioo days. Cattle carried to $I 000$ to 200 pounds on alfalfa, and then finished by strong feeding on corn with alfalfa hay for fifty to sixty days, make beef of a choice quality at a low cost. 


\section{Alfalfa and the Dairy}

\section{MAKING A MARGIN}

The most enthusiastic advocates of alfalfa are dairymen. The market price of milk is quite well fixed and the price of butterfat at the creameries remains, in the different seasons, pretty much the same year by year. Hence, the problem of increasing his financial returns must depend upon the dairyman's being able to increase the volume of his product or to decrease the cost, or both. If he is selling butterfat at a profit of five cents and he cannot force the price any higher, it is the sensible thing to decrease the cost per pound and thereby enlarge his profit.

The dairyman who buys all his feed has but little margin. To raise enough clover calls for considerable land. Alfalfa will yield a large bulk of excellent feed from a few acres of well treated land. For profit he must raise more feedstuff and buy less. The Kansas station reported that with common scrub cows fed on alfalfa hay and Kafir corn meal it was possible to produce butterfat at a cost of seven cents a pound.

\section{SOME MILKING TEST VALUATIONS}

The New Jersey station as a result of a very painstaking milking test reported: (I) In a ration where 
alfalfa hay was tested against wheat bran and dried brewers' grain the saving in the cost of milk was I2.7 cents per hundred, and 2.3 cents per pound of butter when alfalfa hay was used. This saving means a great deal when it is considered that the alfalfa is raised and not purchased. (2) That the milk value of one acre of alfalfa was $\$ 74$.

A Kansas dairyman is reported to have kept ten cows through one summer on the alfalfa cut daily from a patch containing four square rods less than two acres.

Some dairymen believe that there is a great saving in the alfalfa hay by cutting it into two-inch lengths, and feeding it dry. It is also believed that it will always be a matter of economy to feed with the alfalfa, green or as hay, a small ration of carbonaceous food, even cornstover serving such a purpose.

Former Governor Hoard, editor of Hoard's Dairyman, says that with alfalfa hay at \$Io and bran at \$20 per ton there is a saving, by using alfalfa, of $\$ 2.80$ for every Ioo pounds of butter made, and a saving of I 9.8 cents for every Ioo pounds of milk.

In a section of New York where alfalfa has been quite generally introduced, dairymen claim an increase in their profits of I 5 to 30 per cent by its use, besides the enrichment of their farms for other crops.

Prof. D. H. Otis, telling of experiments with the dairy herd at the Kansas agricultural college, states that, "it is usually recommended to feed a cow all the rough feed she will eat, and then balance up the ration with grain. The experience at the college indicates that much rough feed is wasted in careless feeding. The cow will eat the 
best first, and, if given too much, will pick the most desirable morsels, leaving what might be called passably good, which too frequently is treated as waste and thrown under foot. No more hay should be given an animal than it will eat up clean. This refers to first-class quality, however, as a cow could not be expected to eat poor hay clean.

"In feeding the rough feeds, the following table has been used by the college as a guide:

RoUGHNESS.-Value per ton when alfalfa is worth $\$ 1.00$ per ton

\begin{tabular}{|c|c|c|c|c|c|}
\hline FEED & $\begin{array}{c}\text { Total } \\
\text { nutrients }\end{array}$ & $\begin{array}{c}\text { Protein } \\
\text { nutrients }\end{array}$ & FEED & $\begin{array}{c}\text { Total } \\
\text { nutrients }\end{array}$ & $\begin{array}{c}\text { Protein } \\
\text { nutrient }\end{array}$ \\
\hline DRY ROUGHNES\& & . & & GREEN ROUGHNESS & & \\
\hline 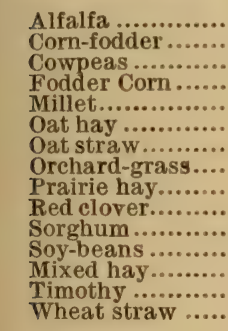 & $\begin{array}{r}\$ 1.00 \\
.32 \\
.97 \\
.40 \\
.64 \\
.59 \\
.33 \\
.60 \\
.51 \\
.70 \\
.43 \\
.98 \\
.67 \\
.47 \\
.25\end{array}$ & $\begin{array}{r}\$ 1.00 \\
.19 \\
1.02 \\
.24 \\
.42 \\
.41 \\
.15 \\
.45 \\
.33 \\
.64 \\
.23 \\
1.02 \\
.56 \\
.27 \\
.08\end{array}$ & 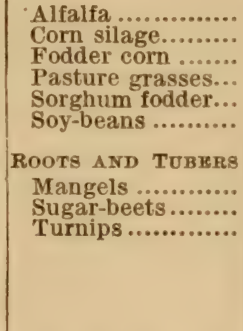 & $\begin{array}{r}\$ 0.34 \\
.13 \\
.14 \\
.23 \\
.12 \\
.28\end{array}$ & $\begin{array}{r}\$ 0.37 \\
.12 \\
.09 \\
.24 \\
.06 \\
.30\end{array}$ \\
\hline
\end{tabular}

"Students working with the dairy herd were anxious to have the cows make the best possible yields, and were tempted to give all the good alfalfa hay the cows would eat. When we discovered the alfalfa hay going too rapidly we looked for the cause and found that the dairy cows had consumed an average of forty-three pounds per head daily, besides fifteen pounds of Kafir corn fodder. The quantity of alfalfa was reduced to thirty-three pounds 
and the Kafir-corn fodder to three and one-half pounds daily per cow, and we found that the daily yield of milk was slightly increased. The quality of the hay was the same in both instances. In the latter case it was eaten up clean, while in the former considerable was hauled away and fed to dry cows. Later records show a still greater reduction in the allowance of alfalfa without decreasing the flow of milk. This experience shows some of the leaks that may take place in feeding roughness, especially when those feeds are appetizing, like alfalfa and red clover.

"For ease of calculation the roughness is figured on the basis of alfalfa hay selling for one dollar per ton. When alfalfa is worth six dollars per ton the other rough feeds are worth six times the amount indicated in the table; when alfalfa is worth eight dollars per ton the other feeds are worth eight times as much, and so on. Usually we find that we can give practically all the rough feed that the cows can eat, although, as indicated above, with a good quality of alfalfa or clover hay more may be eaten than will be consumed at a profit. At this writing alfalfa hay is selling in Manhattan at seven dollars per ton. This would make the feeding values of the other rough feeds worth seven times the amount indicated in the table. Red clover, for instance, would be worth seven times seventy cents or $\$ 4.90$ per ton; prairie hay would be worth $\$ 3.57$ per ton; and millet hay would be worth $\$ 4.48$ per ton. If the problem was to select the most economical roughness, we would select alfalfa at seven dollars per ton, in preference to red clover at six dollars per ton, or prairie hay at four dollars per ton, or millet 
at five dollars per ton. Knowing the cost of these different rough feeds and having this table before him, a feeder can tell which is the most economical feed to use. It will be noticed that the table is divided into two parts, the first part giving the value of the total nutrients, and the second one the value of the protein nutrients. It frequently happens that we have plenty of carbohydrates and fat, but that we are lacking in protein. In this case we would consult the 'protein nutrients' column in order to determine what feed to buy in order to furnish the protein most economically. If it be carbohydrates and fat as well as protein that is required, as was the condition in the dry year of I9or, then we should take the total nutrients' column. When it is possible to get a rough feed containing a large amount of protein, we find that in feeding a liberal allowance of roughness the grain can be reduced. Hence, the importance of providing roughness rich in protein, like alfalfa."

\section{SELLING FARM PRODUCTS THROUGH THE COW}

No other branch of agriculture presents more advantages than dairying-disposing of the products of the farm as milk and butterfat. When the latter may be sold to creamery stations and the skim milk fed to calves and pigs along with alfalfa the profits are greater than from almost any other form of agriculture. No other business tends so rapidly to build up the fertility of the farm, and, when judiciously conducted, no other branch of farming yields more satisfactory financial returns. Raising and feeding alfalfa will add from $I_{5}$ to 30 per cent to the profits of dairying over the use of any other feedstuff 
that may be raised or bought. The profit problem for the dairyman is constantly to find the feed that will decrease the cost of his production.

The diagram below, prepared by the editor of the Nebraska Farmer, is to "represent the digestible protein or milk property contained in different kinds of roughness. Points represent the decimals of a pound, and the bars are an exact representation of the superiority of one kind of food over another for the production of milk. Each bar represents Io pounds of roughness. The approximate yield is also given per acre:"

Approximate Yield Per Acre.

\begin{tabular}{|c|c|c|}
\hline Corn Stover & 6 to 8 Tons & 17 Points \\
\hline Drilled Corn Fodder & 10 to 14 Tons & 25 Points \\
\hline Timothy Hay & 2 Tons & 28 Points \\
\hline Prairie Hay & 2 Tons & 30 Points \\
\hline Millet Hay & 3 Tons & 32 Points \\
\hline Oat Hay & 3 to 4 Tons & 43 Points \\
\hline Red Top & 2 Tons & 48 Points \\
\hline Red Clover & 2 Tons & 68 Points \\
\hline Alsike & 3 Tons & 84 Points \\
\hline Alfalfa & 6 to 8 Tons & 110 Points \\
\hline
\end{tabular}

A. S. Hitchcock cites as an illustration of feeding alfalfa alone, the case of the dairy farms in the vicinity of Moneta, Cal., where the stock are ordinarily fed no other ration than alfalfa. As alfalfa is not a balanced ration, a number of local dairymen tried to replace a part of the alfalfa by sorghum, thus giving a more nearly balanced ration. The cows, however, did not give as much milk upon this combination as upon pure alfalfa. "This result 
may be assigned to the fact that the cattle were unable to consume a sufficient quantity of the mixture to produce the same results as the alfalfa alone. These dairymen find they can secure a larger yield by feeding a little grain; but the increased yield does not pay for the grain, which is high priced in this locality."

\section{AN ESSENTIAI IN MLK PRODUCTION}

Oscar Erf, professor of dairying at the Kansas experiment station, writing for this volume, says: "Alfalfa is quite indispensable in successful dairy operations, being one of the cheapest sources of protein, that most essential compound in feeds for milk production. The Kansas station found that for milk I $1 / 4$ pounds of well-leaved alfalfa hay, containing a high per cent of protein, is equal in feeding value to a pound of bran. In case the alfalfa is of a stemmy nature it requires $\mathrm{I} 3 / 4$ pounds to equal the feeding value of a pound of bran. Alfalfa hay is worth from $\$ 4$ to $\$ 7$ per ton on the farm, while bran costs from \$14 to \$20 per ton, hence it is far more economical to feed the alfalfa hay.

"Like other hays alfalfa varies in composition according to the time of cutting, the soil on which it grows, and its per cent of leaves. It has been found that three-fourths of a pound of alfalfa hay is equal in feeding value to a pound of clover hay of equal brightness and quality. A good stand of clover yields about $2 \frac{1}{2} 2$ tons per acre per year, while a good stand of alfalfa yields about 5 tons per acre per year. Hence, on an acre of land, i Ioo pounds of protein can be produced by raising alfalfa while only 340 pounds can be produced by growing clover, the pro- 
tein in the alfalfa and that in the clover being equally digestible. This comparison is chosen from the fact that clover is the next cheaper source of protein found on the farm.

"At the Kansas station the following experiment was conducted, and illustrates the low cost of a ration including alfalfa hay for roughness as compared with a ration in which prairie hay was used. The experiment was with ten cows. The first ration consisted of 2 I pounds of alfalfa hay and 9 pounds of corn. While the cows were on this ration each produced an average 26 pounds of milk per day, the milk containing 3.9 per cent of butterfat. To formulate a ration from prairie hay and bran which had the same amount of nutrients, we were obliged to feed I9 pounds of bran and I 5 of hay. Fed on this each cow produced only 24 pounds of milk per day, containing 4 per cent of butterfat. The 2 I pounds of alfalfa hay at $\$ 7$ per ton, which is rather a high estimate, and 9 pounds of corn at 70 cents per hundred weight cost I 3.6 cents per day. At this rate it cost $3 \mathrm{I}-3$ cents to produce a gallon of milk, or approximately $\mathrm{I} 3.5$ cents for a pound of butterfat. Estimating bran at $\$ 16$ per ton and prairie hay at $\$ 5$ per ton, the cost of the second ration was 18.95 cents per day, and milk approximately 7 cents per gallon, making the butterfat worth I9.7 cents per pound.

"The following two tables show the difference in cost between a ration in which alfalfa is used for part of the roughness and one which contains no alfalfa but has the same amount of digestible nutrients: 
Alfalfa hay ... I9 lbs at $\$ 7.00$ per ton...\$.066

Corn ...... 7 lbs at

.70 per cwt... .049

Bran

I 8.00 per ton... .0225

\$. I 375

Sorghum hay... Io lbs at $\$ 3.50$ per ton.\$.0I75

Prairie hay....I2 lbs at 6.00 per ton. .036

Ground wheat.. 8 lbs at .80 per bu.. . . 066

Cottonseed meal. 3 lbs at 24.00 per ton. .036

\$. I96I

"As shown by the table a gain of 5.86 cents is made by feeding the alfalfa. Being a proteinaceous feed it can to a great extent be substituted for cottonseed meal, linseed meal or gluten meal, and will entirely substitute other leguminous hays and forages, such as soy bean hay, cowpea hay, clover hay and vetch hay, any one of which is more expensive, for nutrients contained, than alfalfa hay.

"The Kansas station has found it practicable, from results obtained in the past three years, to ensile green alfalfa for dairy cows. This is superior to dry alfalfa, owing to its succulent nature. In the eastern part of the United States ensiling alfalfa has another advantage in that all cuttings can be harvested in perfect condition. As a rule the first cutting throughout this whole territory is liable to be damaged more or less by rains. By putting the green alfalfa into a well constructed silo this loss can be obviated and the full value retained. For example: a man has 40 acres of alfalfa, from which he harvests for the first crop $I \frac{I}{2}$ tons per acre. Estimating the price of 
good, clean alfalfa hay at $\$ 7$ a ton, this would be worth $\$ 420$. Should the hay be damaged by rain its value would be greatly reduced and, as has been the case for many years, such damaged hay could be purchased for $\$ 2$ or less per ton. Accordingly this damaged hay would be worth \$I20. The loss caused by rain would therefore be \$300. Put into the silo this first cutting would be equal in value to the best bright hay.

"The cost of a roo-ton silo is $\$ 250$, hence the owner could not only save the first cutting, but money besides. Furthermore, it is not infrequently the case that alfalfa of the first cutting is of a stemmy nature, and it has been estimated that fully 28 per cent of such hay is wasted when fed to cows, as they do not eat the coarse stems. This loss can be entirely eliminated by the siloing, for cows will readily eat the stems as silage.

"The value of alfalfa silage in influencing the milk flow was indicated when a ration was fed to sixteen cows, in which I 2 pounds of alfalfa hay, 20 pounds of corn silage, 5 pounds of bran and 4 pounds of corn meal were used; this ration was afterward changed by substituting alfalfa silage for the corn silage, and at the same time the bran was reduced to I pound, and the corn increased I pound. By these changes the milk was increased ro per cent.

"With butterfat worth 23 cents a pound the value of a ton of alfalfa silage has been estimated at approximately \$8. This silage solves the problem of feeding cows economically in summer, as well as in winter, under a system of intensive farming."

W. J. Fraser, chief in dairy husbandry at the University of Illinois, says: "Corn silage and alfalfa, two of 
the best feeds for dairy cows, make practically a complete or balanced ration in themselves. Several years' experience in supplying the university dairy herd with various kinds of soiling crops in midsummer has led to this high recommendation of corn silage and alfalfa.

Alfalfa hay has much the same laxative effect as June pasture. An Elgin, Ill., dairyman, with fifty cows, says : "Every month I feed alfalfa in winter gives me a month in which I have practically pasture conditions. The cows show the pasture-effect in the glossy condition of their hair and in the yield of milk, and have never before looked quite so well. 
CHAPTER XIII.

\section{Alfalfa for Swine}

HOGS WHL EAT HAY

In the preceding chapter it was stated that alfalfa is a valuable pasture or soiling crop for pigs. It is equally true that they will actually eat alfalfa hay. A hog is not usually ranked as a hay-eating animal but an exception must be made as to his eating alfalfa hay. As a pasture or soiling crop for sows and young pigs, alfalfa proves a wonderfully helpful ration for milk-making in the sow and for growth in the pigs. Experiments have shown that pigs make better growth when the dam is fed considerable alfalfa than those from sows fed the best of commercial rations, but with no alfalfa. Given two sets of pigs, one fed clover, rape and soaked corn and the other fed only alfalfa forage, the latter seemed to grow the more rapidly. For brood sows it is a most valuable food, either as hay, a soiling crop, or as pasture. The litters of such sows are generally large and vigorous and the dams have a strong flow of nutritious milk. Alfalfa meal in slop may be used with profit where the hay is not to be obtained. It is also claimed that sows fed on alfalfa during pregnancy will not devour their young, its mineral elements seeming to satisfy the appetite of the sow, while contributing to the fetal development of the pigs. 


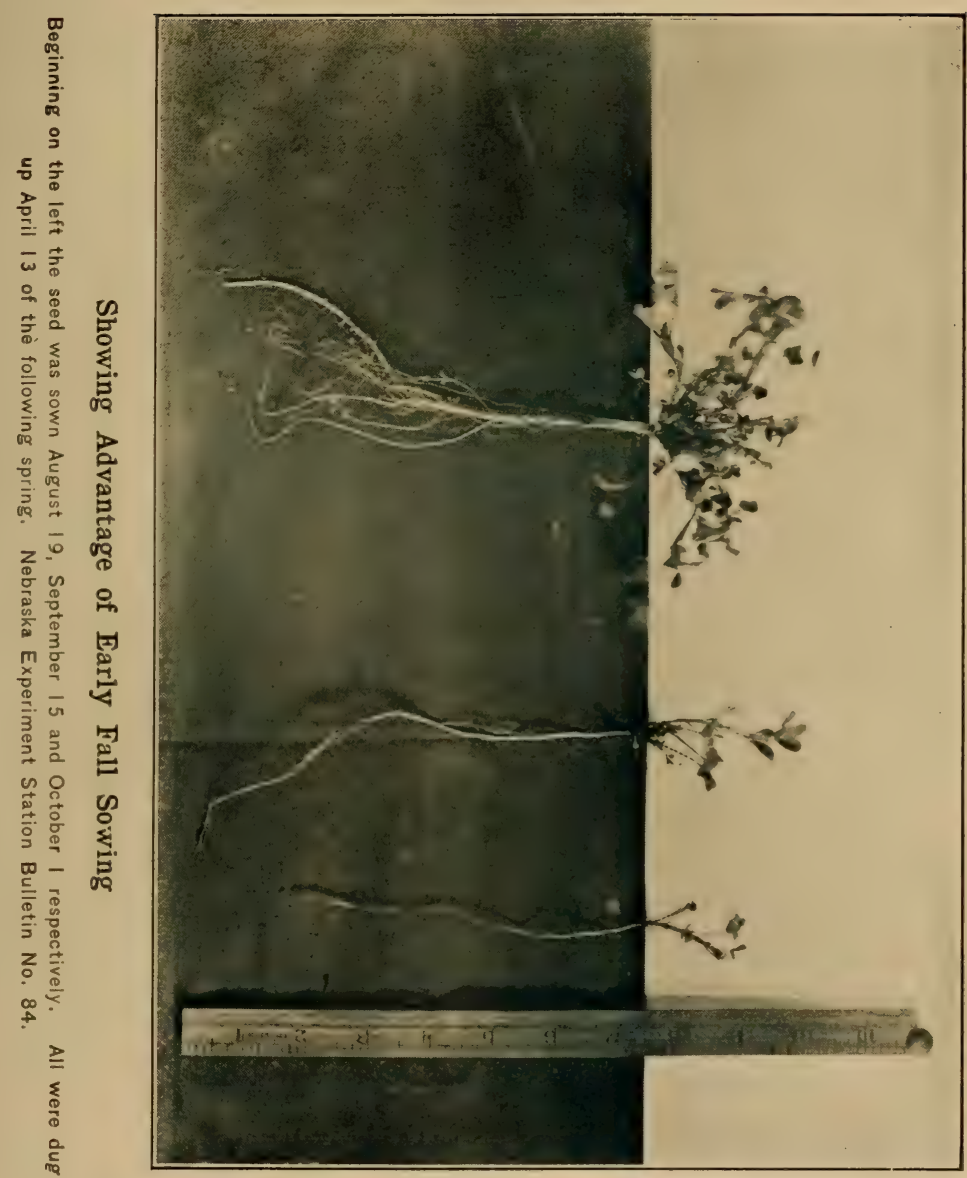




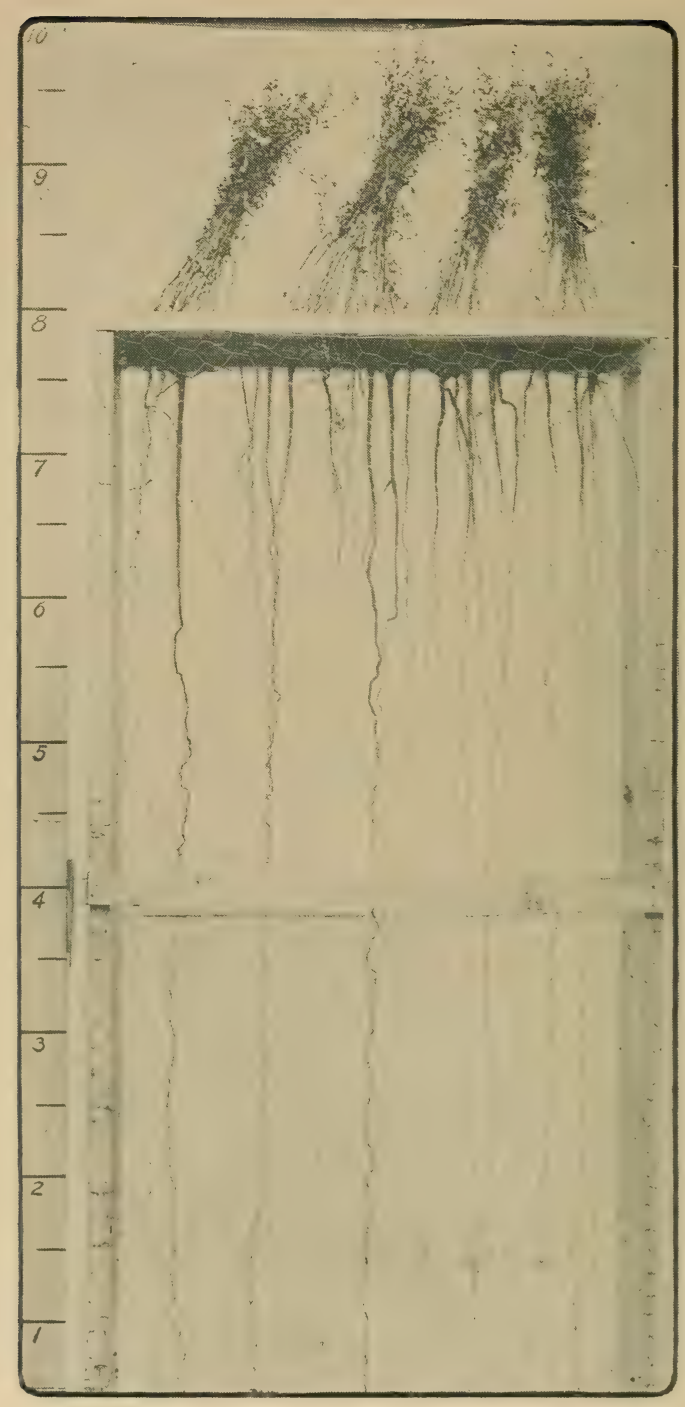

Five-year-old Alfalfa

at the time of its third cutting, September 8, and its root development. Grown at Manhattan, Kansas, on upland prairie having a heavy clay subsoil. 
On a farm of Governor Hoard, in Wisconsin, all the brood sows have for several years been wintered onalfalfa hay of the third cutting, and their drink, without any grain until the last two weeks of gestation. Mr. Hoard says the object was to give the sows a food that should keep them in a non-feverish state and furnish protein sufficient to build the bodies of the forthcoming pigs. (Their "drink" was the skim milk from the dairy.)

"It was a matter of experiment at first, our only guide being what knowledge and reason we could exercise from what we knew, or thought we knew, of the philosophy of gestation. The experiment proved to be a success from the first. The sows went through their work in fine condition, giving milk abundantly. The pigs came with splendid vitality, thus reducing our losses from early death fully 30 per cent over what they had previously been. The hay is fed dry and is thrown into the pen on the feeding floor without any cutting or chaffing whatever. We have sometimes thought we would try the experiment of cutting it into half-inch lengths and moistening it. Possibly it would take less hay in this way. The sows keep in good flesh, fully as much so as we like."

A Finney county, Kansas, farmer reports having pastured 30 pigs on one acre of alfalfa from May ist to September Ist, when they weighed Ioo pounds each and were in fine condition for fattening. Another Kansas farmer reports keeping Ioo pigs from about the middle of April to September on five acres of alfalfa pasture. A little grain during the last two months would have gained him many pounds of pork. Many alfalfa raising pig- 
growers insist that their pigs can be maintained from May to October on alfalfa for one-half what it would cost for almost any other feed.

The Utah station found that young shoats gained onethird of a pound a day on alfalfa pasture without grain. But the station found also that the gain was not so great in older hogs. A Wisconsin dairyman reported that he kept nine sows all winter and spring on alfalfa hay and skim milk, without any grain, and raised from them 75 pigs, all healthy and vigorous.

The Colorado station considers that a ration of threefourths corn and one-fourth alfalfa hay is the best for fattening hogs for market, but for young hogs not ready for fattening the proportions should be reversed. The station does not recommend grinding alfalfa hay for hogs, probably on the theory that the hog's time is not worth much at best.

\section{A VALUABLE FEEDING TEST}

The Kansas station in the fall of 1898 made a series of experiments of interest to feeders everywhere. The test was to determine the value of alfalfa hay fed to fattening hogs that were receiving all the grain they would eat. The results are related here in the language of the bulletin :

"The hogs fed in this experiment were bought of farmers, and averaged in weight I 25 pounds each. They were placed in lots of ten each, in large pens, having for shelter some sheds open to the south. The alfalfa hay used was of the best quality, carefully cured. Blackhulled White Kafir-corn was the grain used, the hogs being fed all they 
would eat without waste. The hay was fed dry in forkfuls in a large flat trough. The pigs were given more than they could eat, and they picked out the leaves and finer stems, rejecting the coarser stems. One lot of hogs was fed Kafir-corn meal dry and alfalfa hay; one lot whole Kafir-corn dry; one lot Kafir-corn meal dry, and one lot Kafir-corn meal wet.

"The experiment began on November 24 and lasted nine weeks. By that time the alfalfa-fed hogs became well fattened, and were marketed. We estimated that it would require four to five weeks additional feeding, with ordinary weather, to get the hogs that were fed grain alone into good marketable condition.

"The gain in nine weeks from the different methods of feeding were as follows:

\section{Gains per hog in pounds}

Kafir-corn meal dry and alfalfa hay..90.9 Kafir-corn whole ......... 59.4

Kafir-corn meal fed dry............. $5^{2.4}$

Kafir-corn meal fed wet.......6.63.3

"The gain from feeding alfalfa hay with Kafir-corn meal fed dry, over the meal alone fed dry, is more than 73 per cent.

"The gains per bushel of feed were as follows:

Kafir-corn meal dry and 7.83 pounds alfalfa hay............. 0.88

Kafir-corn whole .............. 8.56

Kafir-corn meal fed dry.........7.48

Kafir-corn meal fed wet........8.09 
"Ten hogs in nine weeks were fed 656 pounds of alfalfa hay; and as shown above, for each 7.83 pounds of alfalfa hay fed with the dry Kafir-corn meal, the hogs gained 3.4 pounds over those having dry Kafir-corn meal alone-a gain of 868 pounds of pork per ton of alfalfa hay. These results are not due to the feeding value of the alfalfa alone, but also to its influence in aiding the hogs to better digest the Kafir-corn. The alfalfa hay also gave a variety to the ration, making it more appetizing and inducing the hogs to eat more grain. The ten hogs having grain alone ate 3885 pounds of dry Kafir-corn meal, while the ten hogs having hay and grain ate 4679 pounds of the Kafir-corn meal and 656 pounds of alfalfa hay. The hay-fed hogs ate more grain and gained more for each bushel eaten.

"In a former experiment pigs were pastured through the summer on alfalfa with a light feeding of corn. After deducting the probable gain from the corn, the gain per acre from the alfalfa pasture was 776 pounds of pork.

"These facts indicate that to produce pork most cheaply the Kansas farmer must have alfalfa pasture in summer and alfalfa hay in winter."

The Kansas station also found in another test that one acre of alfalfa produced pork worth $\$ 20.30$, while one acre of rape produced pork worth \$I0.05.

The Iowa station director estimated that one acre of alfalfa pastured was worth at ieast three acres of bluegrass for pigs. It is claimed by Kansas farmers that an average acre of alfalfa will pasture I 5 pigs, while some report having pastured 20 or more pigs per acre. Those 
who have used alfalfa as a soiling crop for pigs admit, however, that one acre so utilized is equal to two if not three used as pasture.

It is argued by feeders that as many hogs may profitably be allowed with cattle that are being fattened on corn and alfalfa as when fed corn alone, as the feeders believe in cleaning out the feed-racks every few days and giving the left-over stems to the hogs. If necessary, a little corn is added to the hog ration.

\section{A NEBRASKA TEST}

The Nebraska experiment station, from a hog-feeding test made in 1903 reported the following:

"With the alfalfa hay worth $\$ 7$ per ton, the leaves, containing 40 per cent more protein, would be worth approximately \$IO per ton. The shorts cost \$I2.5O per ton delivered. The dairy department charged 15 cents per hundred for the skim milk used. Corn was delivered to the barns at 30 cents per bushel. Adding the usual rate of 6 cents per hundred for grinding, the corn meal cost $\$ 12$ per ton. At these prices, each hundred pounds of gain in the several lots cost as follows:

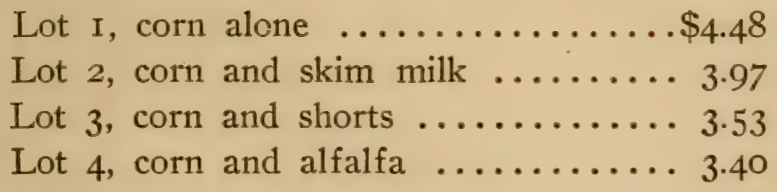

"This experiment shows that at the market prices quoted and the proportions used in the experiment, skim milk will make corn bring four cents more per bushel, wheat shorts eight cents more, and alfalfa leaves ninecents 
more. Assuming that only five per cent of the 252,520,I73 bushels of corn produced in Nebraska this year is being fed to hogs as a single food, these figures would go to show that $\$ \mathrm{I}, 000,000$ more wealth would be added to the state if wheat shorts or alfalfa were substituted for one-fifth of the corn fed."

\section{CUT ALFALFA EARLY FOR HOGS}

It is especially important that alfalfa intended to be fed to hogs should be cut early. An experiment at the Kansas station showed that a ton of early cut and wellcured alfalfa, fed with grain, produced 868 pounds of pork while a ton late cut and poorly cured, fed with grain, produced only 333 pounds. Fo: fattening hogs it is well to feed about one ton of well-cured alfalfa hay with each 250 bushels of grain.

Farmer's Bulletin No. 2I 5 of the United States Department of Agriculture declares that alfalfa is an ideal pasture plant for hogs. "There is no danger from bloat and with a limited number of hogs there is practically no injury to the alfalfa field. Vigorous alfalfa will support i 5 to 25 head of pigs per acre. It is best to limit the number of pigs to that which will be insufficient to keep down an alfalfa field. Cuttings of hay may then be made at intervals and the growth thus rejuvenated. On the average pigs weighing 30 to 60 pounds in the spring will make a gain of about Ioo pounds each during the season. Although pigs may be grown and fattened upon alfalfa alone, it is best to combine the alfalfa with some kind of a grain ration. Alfalfa by itself is too rich in protein to give a balanced ration. Where pigs are pastured upon 
alfalfa alone they may be prepared for the market by feeding for a few weeks upon corn. It is still better, however, to feed a third to a half of a ration of corn or other grain during the time of pasturing."

The great mistake made by too many who attempt to pasture swine on alfalfa is in overstocking. There is a tendency to keep within a small pasture more stock than it can comfortably support, with the result that the stand is gnawed, trampled and rooted out, while the animals fail to prosper as they would under more rational treatment.

One of the most extensive and successful swine raisers in Kansas tells the author this: "Twenty-five years of pasturing hogs of all ages on alfalfa has proven conclusively to me that with a fourth to a half grain ration, while they are on such pasture, will produce in them a greater growth per day than when in dry lots on full feeds of corn. Hogs will maintain a reasonable growth, but not fatten much, on alfalfa pasture alone; I believe it profitable to feed them some grain while running on green alfalfa. If it is desired to full-feed hogs, they will make a rapid fattening growth by increasing the grain ration while on the pasture, and with the full grain ration the meat will be nearly as firm as those of the dry lot, where grain alone has been fed. I find no distinction on the market between alfalfa-fed swine and those purely grain-fed, and they sell price and price alike. The general health of the alfalfa-fed hogs is equal to that of those maintained on any other feed, and they are prolific." 
The Kansas station realized \$I I.90 per acre from rape pasture and \$24. Io per acre from alfalfa pasture in ninety-eight days. These results were obtained from the following experiments, which were begun July 25 and concluded October 3 I.

Thirty shoats, averaging fifty-two pounds in weight, were divided as nearly equally as possible into three iots of ten each. Lot I was fed on a grain mixture of shorts one-half, corn meal one-fourth, and Kafir-corn meal onefourth, in a dry lot. The other two lots were fed the same grain ration, but one received rape pasture and the other alfalfa pasture in addition. Each lot was given what grain the hogs would eat up clean, and each had access to water and ashes.' The weights of grain consumed and gains made are as follows:

\begin{tabular}{c|c|c|c}
\hline Feed & $\begin{array}{c}\text { Grain consumed } \\
\text { in pounds }\end{array}$ & $\begin{array}{c}\text { Total gain, in } \\
\text { pounds }\end{array}$ & $\begin{array}{c}\text { Grain consumed } \\
\text { per 100 lbs. gain, } \\
\text { in pounds }\end{array}$ \\
\hline I. No pasture............... & 3,801 & 1,023 & 371 \\
II. Rape pasture......... & 3,244 & 1,076 \\
III. Alfalfa pasture......... & 3,244 & 1,078 & 301 \\
\hline
\end{tabular}

The gains of the three lots are very nearly equal. The dry lot consumed 557 pounds (or seventy pounds for every Ioo pounds of gain) more grain than the pasture lots. The lot on rape required one acre of pasture, while the alfalfa lot used a trifle less than one-half acre.

The lot without pasture required 3.7I pounds of grain to produce one pound of gain. Assigning the same value to the grain fed the hogs on rape pasture, we have 877 pounds of pork credited to the grain and I99 pounds credited to the rape. At six cents per pound, the 
price at which hogs were selling at the close of the experiment, this would be a credit of $\$ I I .90$ per acre for the rape. In a similar manner, the alfalfa is credited with 201 pounds of pork, equal to $\$ \mathrm{I} 2.05$, and as there was only a half-acre of alfalfa, this makes a rate of $\$ 24$. Io per acre.

The cost of preparing the seed bed and seeding the rape was $\$ \mathrm{I} .80$ per acre. It was seeded in the feed lots, on soil that would otherwise have remained idle or would have grown up to weeds.

The shoats on pasture enjoyed their diet and seemed satisfied. Those in dry lot seemed to be hankering after something green, and their appetites seemed unsatisfied without some kind of roughness. They would even nibble at straw, in a vain attempt to satisfy their craying.

"The experiment," says Prof. D. H. Otis, "emphasizes the superior value of alfalfa pasture. Where alfalfa is not available, or where variety is wanted, or it is desired to utilize otherwise waste land, Dwarf Essex rape, seeded at the rate of six to eight pounds per acre, any time from early spring to late summer, will furnish an excellent diet that is greatly relished by the hogs."

J. E. Woodford, of Coffey county, Kansas, April I, I905, placed ten choice pure bred Poland-China brood sows from twelve to eighteen months old that were due to farrow in the latter days of June, on a five-acre field of alfalfa. They were given no other feed than the alfalfa pasturage until they had farrowed and their pigs were a week old. After that the sows had in addition to the alfalfa some bran slop until about August 20, when new corn was fit for feeding. He says: "The sows from the 
time they were turned on the alfalfa until the last week in June made a remarkable growth, besides gaining somewhat in flesh. They did well with their pigs, reared an average of seven to each sow, and as sucklers they were a sight to see. The pigs were the most attractive bunch ever raised in Coffey county, as admitted by our breeding competitors. We weighed a gilt from this lot when six months and five days old, and her weight of two hundred and twenty-five pounds was not above the average of the whole lot. In our lifelong experience in rearing swine we have found nothing of the grass kind for them that in value approaches alfalfa.

A plat of thrifty, well-established alfalfa suitably fenced and used for pasturing swine of whatever age can scarcely fall short of being among the most profitable parts of any farm upon which swine husbandry is given attention. 
CHAPTER XIV.

\section{Alfalfa for Horses and Mules}

J. W. Robison, a Kansas breeder of Percherons, who ranks among the foremost anywhere, raises his colts to three years at an average weight of 1700 pounds and his four-year-olds at 1900 pounds, ready for the sale yard, on alfalfa, except such limited quantities of grain as will make it more nearly a properly balanced food, and incidentally expedite growth. His opinion, fortified by sixty years of experience, is that alfalfa as pasturage and hay constitutes by far the most excellent and economical frame- and muscle-forming food available to the live stock industry. His colts have alfalfa as their first green food, and, if foaled in winter, are taught in a few days to nibble the cut hay. He also says colts reared mainly on alfalfa have equal spirit and vigor and better dispositions than those given much grain. His brood mares are matle to rely on alfalfa as their main ration, and for three months before foaling it is practically, unless in midwinter, their only feed. As a result they are always in ideal condition, their colts are delivered easily, the mares give an abundance of nourishing milk, free from feverish tendencies, and the colts are robustly rugged from their beginning. The cost of rearing colts and horses by this 
method, he says, is less, quality and rapidity of their growth considered, than by any other of which he has knowledge.

The well-known J. E. Wing, of Ohio, says: "There is no one thing so good for the work horse as alfalfa. He needs less grain, and has more life and spirit than when fed upon any other hay, yet even working teams can, on account of its richness, be fed too much. This puts an undue strain upon their excretory organs to eliminate the unnecessary food substances from the tissues. The overfeeding of alfalfa hay to horses has in some localities caused the use of it to become unpopular, and to raise an outcry against it. The writer has fed no other hay to his horses-working teams, driving horses, mares and foals - for many years, and has yet to observe the first instance of evil result, save that the driving horses when not used regularly become soft and easily sweated.

\section{GOOD FOR WORK HORSES}

Until recently it was not thought in the eastern states that alfalfa was an especially good feed for horses. On the somewhat noted Watson ranch at Kearney, Nebraska, the grain supply became exhausted one summer when the prices were high. There was an abundance of alfalfa hay, and although it was in August and the horses were at heavy work, such as plowing and ditching, the entire force of eighty was kept on alfalfa hay and but little grain, without any injurious effect. They relished the hay, did the hard work every day and looked as sleek as if on pasture. Since that time alfalfa hay has been the principal ration for all of the farm's work horses, colts and driving stock. 
In western Kansas farm horses have been wintered on a daily feed of Io pounds of alfalfa hay and some corn stover, and thin horses fattened on alfalfa hay and a little corn.

\section{CRESCEUS EATS ALFALFA}

Again, the prevalent notion that it is not good for driving horses has been contradicted by hundreds of farmers who use it for such horses, and by hundreds in western towns who use it for delivery horses, dray horses, and light drivers, as well. In parts of California it is the only hay fed to horses. "Cresceus, the great race horse, is said to have been raised on it and it is said that he is fed no other hay, even while on the racing circuit." The same was said of Sysonby, the fleetest Thoroughbred in the races of 1905. Many of the city transfer companies in Denver, Kansas City and Omaha use alfalfa hay, claiming that it enables them to reduce their grain ration, while their horses seem stronger and look better than they did with the former feed of corn and timothy.

\section{TOO MUCH HAY FED}

It is no doubt true that Americans feed their horses too much hay. It is common among horse owners to let horses stand to full mangers when not at work. In London the cab horses, for example, are given hay for but two hours a day, in the evening. At the end of two hours the mangers are cleared. Careful testing in decreasing the timothy hay ration one-half has not shown that the horses required any more grain than before to keep them in equally good condition. 
Horses do not need a heavy ration of alfalfa hay. Fed with grain, probably Io or I 5 pounds of it is equal to a manger full of other hay. As they become accustomed to the alfalfa it may be increased a little, and the grain decreased. It is a rich food and should not be used as freely as hays with less protein.

Prof. L. A. Merrill of the Utah station made six tests of alfalfa hay in comparison with timothy for horses under varying conditions of work, and found that it was less difficult to maintain their weight with alfalfa. The appearance of the horses in every comparison was in favor of the alfalfa-fed horse, and no ill results were noted on their health by long-continued alfalfa feeding. Fourteen-hundred pound horses at hard work could be maintained in condition on 32.6 pounds of alfalfa hay per day, and at rest 20 pounds was sufficient for the same horses.

The quantity of hay fed on most farms could be reduced at least one-half

With all its merits alfalfa hay is by no means a properly balanced ration for all purposes, and those unacquainted with this fact are liable to feed it, exclusively or otherwise, in such quantities as are both extravagant and harmful. D. C. Smead, a veterinarian of note, in writing about using the hay in too great quantities, especially in feeding horses, says this :

"There is more danger in deranging the digestion or man or beast by an excess of protein than by overfeeding on a carbonaceous food. The proteins in food are more easily acted upon by the digestive fluids, and thus more easily digested and carried into the blood, 
where an excess means work for the kidneys to carry it off. We can founder a horse more easily on wheat than on corn for this very reason. Alfalfa has a nutritive ratio of practically I to 4. An ordinary Iooo-pound horse, if given all it will eat of it, will eat from thirty to forty pounds in twenty-four hours. As the alfalfa contains about I I per cent of easily digested proteins, you will readily see that the horse would be taking into his system nearly four and one-half pounds of protein.

"About two and one-half pounds of digestible protein is all that an ordinary horse or cow of a thousand pounds weight, when at work or in milk, can utilize. In the alfalfa hay we have nearly twice as much as is needed. If it were not for some of it being physicked off, we would soon have an animal with overworked kidneys or muscular stiffness of a rheumatic nature. In case of a mare in foal, when fed on alfalfa and nothing else, the chances are she would drop her colt prematurely, or if it went full time, the colt would be a nice, fat, little, plump fellow, with little vitality and with a tendency to rickets or bowel disease, all because the alfalfa was too narrow a ration.

"Now if we fed this mare alfalfa hay once a day or even twice a day, in moderate quantities, say fifteen pounds, and gave her one feed of straw or timothy hay or corn fodder, which are carbonaceous foods, with a quart of oats a day to impart a little nerve force, we would have her practically on right lines. Alfalfa, good as it is, is not an all-sufficient food for any animal. The danger lies in sections where it is being thrown to the animals relishing it so well and the owner having it in such abundance 
that it will come to be considered all-sufficient, and then trouble is liable to follow. But fed with judgment it is the best of all protein foods, and will enable the farmer to feed wisely and well many of the unmarketable rough foods he raises, like straw and corn stover, the one balancing the other."

Here and there are norses with digestive apparatus not suited for the best use of alfalfa, but they are rare exceptions rather than the rule.

\section{PRODUCES RAPID GROWTH}

One of the foremost horse breeders in America, who constantly maintains upwards of one hundred head of various ages, writes the author this:

"In my experience of twenty-five years in pasturing horses on alfalfa, results have convinced me that it produces more bone, muscle and blood in horses in less time than any other pasturage with which I am acquainted. But I believe it profitable in raising the best horses to also use a moderate grain ration, to stimulate rapid growth and early development; my horses, however, have shown no ill effects from pasturing on alfalfa without grain, or other feed, and I have found such pasturing conducive to health and prolificacy, maturing animals equal for service to any reared otherwise. I have raised three-year-olds grown on alfalfa and a light grain ration to exceed a ton in weight, carrying all the good qualities of the breed to which they belonged. Further, I find using alfalfa as a horse pasture a much more economical method of raising horses than any other." 


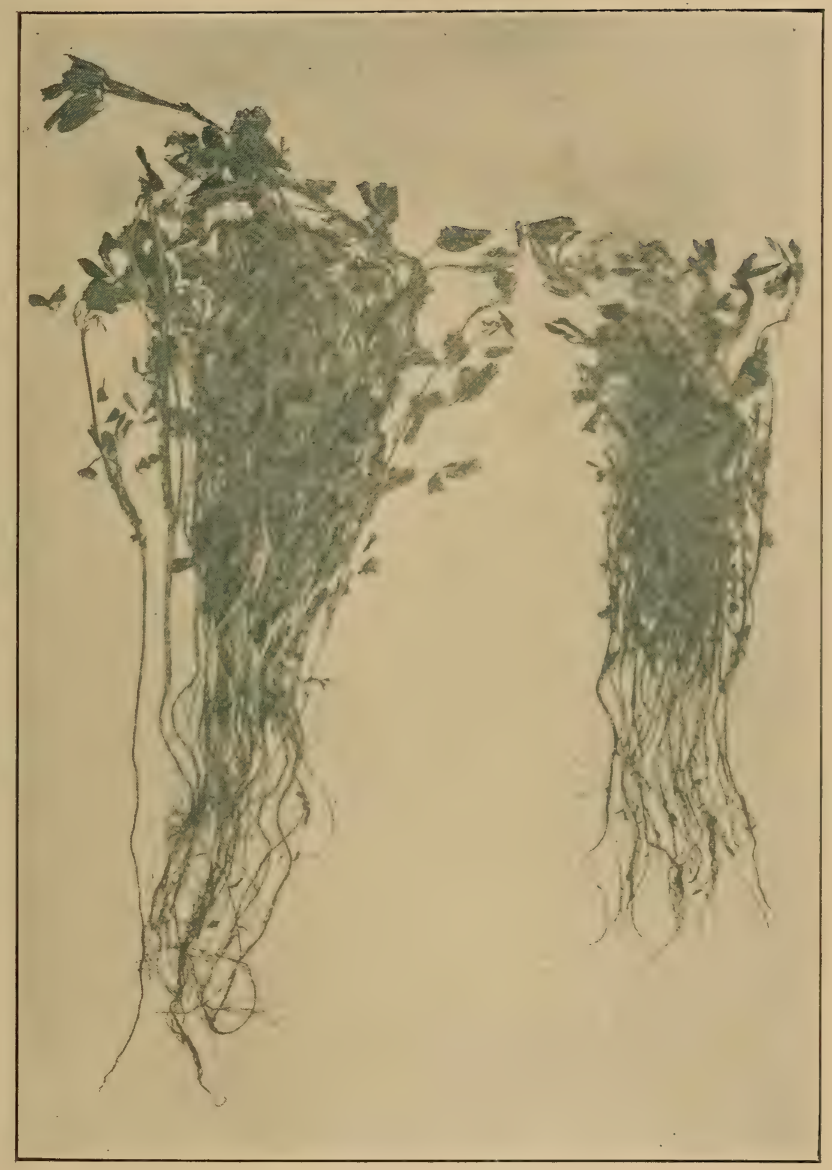

Alfalfa One Year Old Showing Effects of Inoculation

Plants on the left inoculated with "nitro-culture," those on the right not inoculated. 


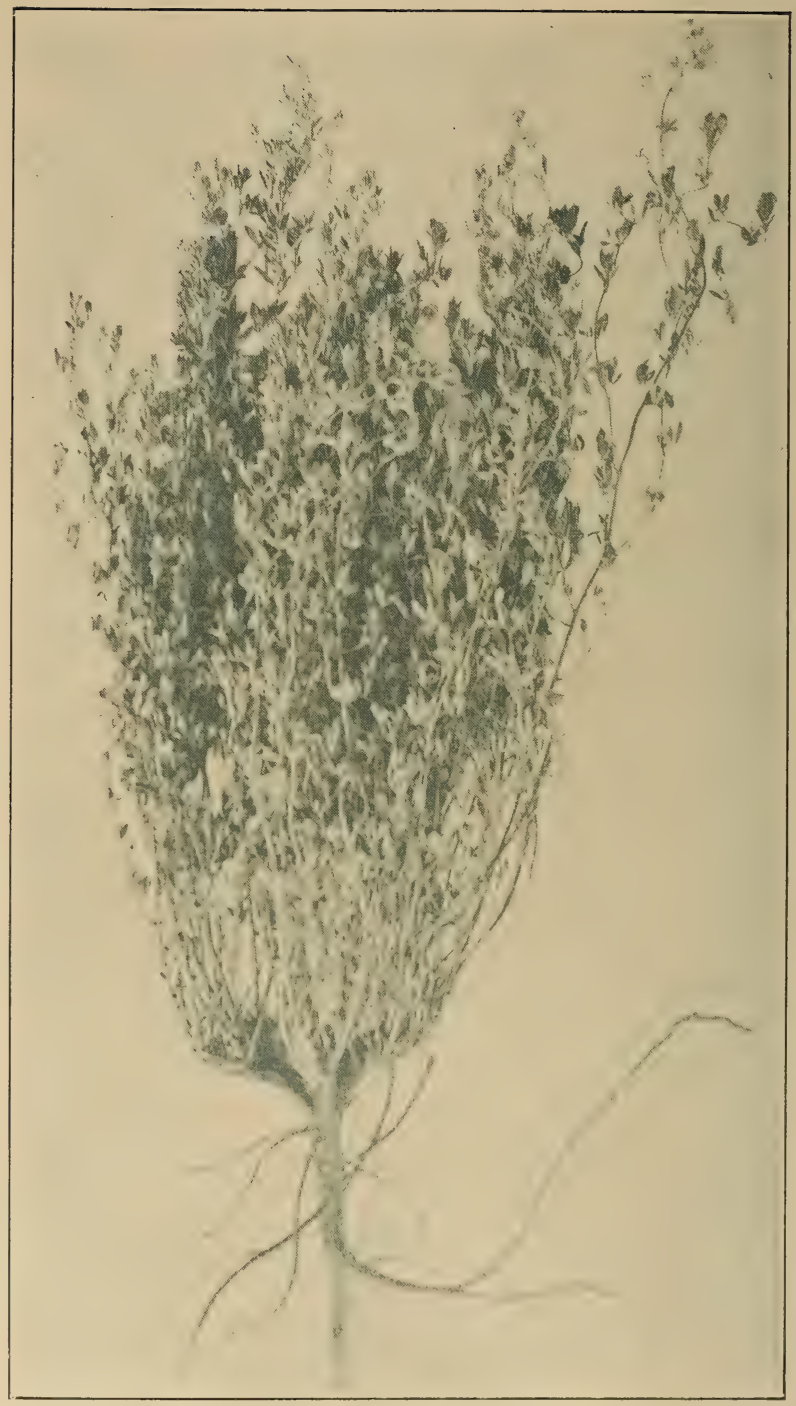

\section{A Good Type of a Four-year-old Alfalfa Plant}

grown on Kansas upland. Height, May 28, 36 inches. The crown shows the effect of splitting with a disk harrow. 
CHAPTER XV.

\section{Alfalfa and Sheep-Raising}

The day is not far distant when the free "range" will be practically eliminated from the stockman's assets. His stock must be reared on cultivated crops instead of by grazing on grasses that cost nothing. Pound for pound alfalfa is more fattening for young lambs or old sheep than clover. Lambs soiled on alfalfa cut daily make a phenomenal growth and are as a rule free from disease. They may be carried through the summer on a light feeding of green alfalfa and general pasture or farm grazing, and fattened in the fall on alfalfa hay and cowpeas or a little grain, at a generous profit.

Thousands of sheep and lambs are every year brought from Colorado and Montana to western Kansas and Nebraska and fattened for market on alfalfa hay and grain, making for these commodities a convenient market at good prices.

\section{HOW TO PREVENT BLOATING}

Pasturing sheep or lambs on alfalfa is dangerous, although there are sheep raisers who make it a main reliance. One man reports absolute freedom from loss for several years, and his method is to have his sheep pen adjoining the alfalfa field and early in April when the alfalfa is just beginning to put on its green, he arranges 
a "creep" for the lambs to go through into the field, and lets them stay there at pleasure. They soon wean themselves; the "creep" is then closed and a safe pen in the alfalfa field is used for shelter from rains and protection from dogs. When necessary to fasten them in at night to guard against dogs or wolves, he cuts green alfalfa each evening to give them with a little grain in the morning before turning them back to the field. The lambs grow rapidly and none ever bioat. Nevertheless, most sheep raisers will continue to reckon alfalfa pasture too expensive when it costs so many animals for the privilege of its use. Safety is the exception, and not the rule.

Owners of large flocks of sheep claim to be able to market lambs from alfalfa pasture, or when soiled, at one-half to one-third the cost of maintenance with any other crop. Green or cured it seems to hasten development and the lambs are in fine condition for fattening in October, or the ewes to put into the breeding pen.

The Nebraska station in a winter experiment of 98 days with one hundred 50 -pound lambs, divided into different lots and variously fed with prairie hay, alfalfa hay, shelled corn, wheat bran, oats and linseed meal figured at the prices then current, reached these results:

I. The alfalfa-fed lambs consumed I.34 pounds of alfalfa hay and one pound of grain per day as against .88 pound of prairie hay and .89 pound of grain consumed by the prairie hay fed lambs.

2. The alfalfa-fed lambs made fifty-two per cent greater gains than the lambs fed prairie hay and the same grain ration. 
3. The lambs fed prairie hay with corn and 16 per cent of oil meal made 26 per cent larger gains than the lots fed prairie hay with a grain ration of shelled corn, or shelled corn with 25 per cent of bran or oats added.

In the twenty-fifth annual report of the Ontario agricultural college are some interesting reports on feeding lambs on various foods. The feeding periods were 74 days for the first experiment and 42 for the second.

By these tests alfalfa hay was shown to be slightly better for the lambs in every way than clover hay under practically equivalent conditions.

The first and second cuttings of alfalfa were equal in value; the third cutting was slightly better than the first.

W. L. Carlyle, dean of the Colorado agricultural college declares alfalfa hay is the basis of the feeding industry in northern Colorado. "Without alfalfa our agriculture would be of very little moment. Alfalfa forms the basis of all our sugar-beet growing. It not only enriches the soil in which it grows, but prepares it for the growing of sugar-beets in a way that no other crop or system or cultivation can, and while doing this preparatory work it yields an enormous tonnage of the most valuable feed for fattening sheep and cattle. Usually lambs are given free access to the hay and are allowed to eat all of it that they will."

Lamb feeding in northern Colorado has been carried on quite extensively for a number of years, and with such success that "Fort Collins lambs" are recognized in the eastern markets as superior to anything that is shipped from any other section of the country. The name "Fort 
Collins sheep" has extended to all of northern Colorado, just as the "Greeley potato" is the term given to all potatoes grown in the northern part of the state.

In recent years many thousands of old ewes have been fed at the various sugar factories upon beet pulp, alfalfa hay and corn. The old ewes thrive much better upon the beet pulp than the lambs or younger sheep. It produces a very desirable sappiness of flesh, and when these sheep have been on this feed with alfalfa hay for two or three months and are then finished with corn, they bring the highest price on the market 


\section{Alfalfa and Bees}

\section{THE BEE FERTHLES THE ALFALFA}

It has been discovered that the honey bee is of even more importance to the alfalfa than the alfalfa is to the bee. The wonderful strength and speed of the bees take them long distances for their food and they have recourse to a great variety of plants. But the peculiar construction of the alfalfa blossom renders it unable to fertilize itself and its shape makes cross fertilization very difficult. In the marvelous "balance of good" in nature, alfalfa, like thousands of other plants, is aided in its lease on life by the insect world. It is not known just how many insects or birds assist this remarkable plant, but the honey bee is the most conspicuous, the most industrious, the most eager, and certainly the most useful.

Careful observations have been made of seed pods grown near colonies of bees, and also of those so far from any bee colonies that it was safely assumed no bees had visited the fields producing the pods. In every case it was found that those from nearby fields had from 50 to 75 per cent more seeds than the others and that they were larger and more perfectly developed. In Colorado and western Kansas, where bee culture has been greatly developed in recent years, it is found that the alfalfa seed crop in fields nearest to bee colonies is much heavier and of better quality than that of fields but a few miles away. 
At the Kansas experiment station a small plat of vigorous alfalfa was covered just before coming into bloom with mosquito netting supported on sticks. It was therefore known that no bees nor other insects could come into contact with the blossoms. Later a careful examination disclosed that the pods which had formed were entirely without seeds.

\section{HOW THE FERTHIZING IS ACCOMPLISHED}

As suggesting something of the relation of bees and like insects to the cross fertilization of alfalfa blossoms and consequent increased seed production, Prof. S. J. Hunter, entomologist of the University of Kansas, who has spent much time making critical observations of bees in the alfalfa fields of the Middle West, writes the following for this volume:

"Every farmer is familiar with the evil effects of continuous inbreeding among live stock. In plant life this same continuous fertilization of one plant by its own pollen works no less injury to its race of plants. To prevent such inbreeding among plants nature has devised several means. One of these is illustrated in the alfalfa blossom. If the reader will tear away the purple blossom exposing the true organs of fertilization, it will be seen that the central round body, the stigma, designed to receive the pollen grains, is higher than the surrounding, elongated, pollen-bearing anthers. It will become evident, then, that it will be possible and most likely for the pollen to drop to the base of the flower without coming in contact with the stigma, and the flower will thus go unfertilized. This is as nature intended it should be, namely, that the 
plant should go unfertilized if it could be fertilized only by the pollen of its own blossom. Provision, however, is made for cross fertilization, that is, fertilization from the pollen of another flower.

"The color of the flower itself, its fragrance, and finally the sip of nectar secreted at the base of the flower, are all intended to attract flower-frequenting insects. Chief among these is the honey bee. The fragrance of the flower draws the insect from afar. The color of the flower reveals its exact location to the insect and when the tongue of the bee is inserted into the flower, in quest of the coveted nectar, the stamens and pistil spring up, striking the under part of the hairy-covered head. These hairs are barbed and readily retain the pollen, so that the flower both discharges its own pollen and also takes from the head and breast of the bee pollen previously collected from other flowers. Obviously, the first flower which the insect visits is not cross-fertilized. Practical observations upon the relations existing between the honey bee and the alfalfa plant are of value in illustrating the effects of the bees upon alfalfa.

'A case in point: A hundred well matured pods were collected upon an alfalfa field less than one-half mile away from a large apiary. A similar number were taken from another field. The two fields were as nearly identical as possible in the matter of soil, culture, and conditions governing the vegetable growth of the alfalfa plant. The second field, however, was about twenty-five miles away from a colony of bees. No bees were observed in the field and since there was no timber, nor other place of shelter where bees might possibly live, it seemed reason- 
ably safe to say that there were no wild bees in the vicinity. An examination of the seed pods from each of the two localities was made and the number of seeds counted. In the field near the apiary the average number of seeds in a pod was found to be 5.58 . The seeds were plump and the pods were numerous upon a cluster. The pods themselves had several spirals. In the other field, the one remote from a known colony of bees, the average number of seeds in a pod was 3.35 . The seeds in at least onethird of the pods were small and shriveled. The pods were few in the cluster, short, and with but few spirals. The seed crop of the first field could be estimated on this basis at two-thirds greater than that of the second field.

"It is a well-known fact that the seed yield per acre for Red clover is comparatively small. Red clover belongs to the same family of plants as alfalfa and it, too, is dependent upon insects for fertilization of its flowers. The work, however, is restricted largely to the bumble bee, since but few other insects have tongues long enough to reach down to the nectar of the clover blossom and consequently do not visit the clover blossom and bring about proper formation of seed. So in proportion as the bumble bees thrive, the clover flourishes. Alfalfa, however, is not so limited in its number of insect assistants, since the flower itself is shorter and the nectar àccordingly accessible to a greater number of insects."

\section{THE HONEY PRODUCT}

Alfalfa raisers find it to their advantage to have a few stands of bees. As the original cost is slight and the bees provide their own food, go after the raw material for 
the manufacture of honey, demand but slight attention and make such bountiful returns, bee culture has come to be a valuable "side line" for the farm. As blooms are to be found in alfalfa districts every day from early May to late October, the bees have a constant opportunity for service.

Alfalfa honey is white and clear, in an extremely delicate comb, has a delicious flavor, and an aroma that is delightful. One authentic report from a western Kansas county is of a single hive that contained nearly two hundred pounds, and of another having ninety-six pounds. The owner of these had twenty-five acres of alfalfa which in one year yielded him over one hundred tons of choice hay besides the honey. The next year he increased his apiary to fifty stands.

While the average yield per hive elsewhere varies from fifteen to thirty pounds, theaverage in thealfalfa-growing territory is far higher. Thus the financial returns of alfalfa may be greatly increased and in some instances doubled by having, say, two colonies of bees for each acre. Or, if only a part of the alfalfa raisers in a neighborhood keep bees, this ratio could be doubled or trebled by those who do. Unlike other trespassers on neighbors' fields the bees do the neighbors a distinct favor, by fertilizing their alfalfa. 


\section{Alfalfa and Poultry}

\section{BETTER THAN MEDICINE}

At first it might seem that too much was claimed for alfalfa if written of as a specially valuable adjunct in poultry raising. The poultry industry of the United States is making wonderful advances, and the volume of its returns is enormous; the figures are well-nigh incredible. One of the handicaps is disease. Poultry men are a unit in saying that where alfalfa in any form can be supplied to poultry disease is almost unknown. Fowls like it green, and whether allowed the run of the field or it is given to them daily they eat it greedily and thrive. Many farmers say emphatically that the hens lay more and larger eggs when allowed alfalfa in any form. Its nitrogen contributes to the albumen of the eggs and to the growth of the young chickens.

\section{MAY INFLUENCE EGG FERTILTTY}

Scientific tests of feeding alfalfa to poultry have not been made, but, no doubt, will be in the near future. If it is found that the eggs are larger when the hens are given alfalfa, it may also be found that the percentage of fertility is greater. For years the complaint has been made by farmers and poultrymen that there are too many infertile eggs. The financial losses are great if a fourth or 
third of the eggs used for incubation prove infertile. It would seem that the same elements that contribute to the growth of the hatched chicken should also add to the vitality of the embryo, increasing the percentage of fertility and adding to the vigor of $t_{1}^{1}$.e newly hatched chick

\section{AIDS IN PREPARING FOR MARKET}

The growth of young chickens is greatly aided by alfalfa. One man reports an experiment with five hundred capons, hatched early in March, that averaged in December nearly eight pounds and sold in the city market at nineteen cents per pound. They were given the run of a patch of alfalfa for a time and ate little other feed. Later they were put in the yards and fed with alfalfa cut into short lengths, with a little grain; still later alfalfa meal was added, with a little wheat. Then, finally, alfalfa hay was cut and steamed and added to the ration. The cost of maintenance and fattening must have been small compared with the large returns.

This item is from the Harper, Kansas, Sentinel: A subscriber tells us that the mites and chicken lice were completely driven out of his barn and hen house, as soon as he had alfalfa hay put in his barn and used it in the house for nests. He says that before the hay was cut, it was impossible to keep a horse in the barn or to have a hen hatch a nest of eggs, but neither mites nor lice can be found now. This is a new use for alfalfa, but if it does the work, it will be lots cheaper than buying poisonous decoctions and spraying pumps to get rid of lice and mites, the greatest pests to poultry raisers. 


\section{Alfalfa Food Preparation}

The growing appreciation of alfalfa as a stock and dairy food and the expense of baling and shipping it as hay, the loss of leaves, and the liability to heat and mold unless well cured, have led to the manufacture from it of several food preparations. These in some cases are made by simply grinding into a meal, and in others by mixing the meal with molasses, or a variety of food products, and assumed condiments and appetizers.

The Colorado station in a feeding test concluded that the ground alfalfa was not an economical feed for fattening pigs. With cut alfalfa hay costing $\$ 8$ a ton and ground alfalfa $\$ \mathrm{I} 6$ a ton the cost of producing one hundred pounds of gain with the former was $\$ 2.62$ and with the alfalfa meal \$3.I2. With corn and cut alfalfa hay fed in equal parts by weight the cost of producing one hundred pounds of gain was $\$ 2.72$. With corn and alfalfa meal fed in equal parts by weight the cost was \$3.96. It is not improbable, however, that better results would have been obtained if a less proportion of ground or cut alfalfa had been fed. It is also probable that the hog's grinding machinery is better adapted to his digestive apparatus than is any other. 


\section{PROFESSOR COTTRELL ON ALFALFA MEAL}

It is worth while, however, to consider the arguments in favor of grinding alfalfa. Prof. H. M. Cottrell says :

"Grinding alfalfa increases its digestibility. How much has not been determined. Grinding increases the digestibility of corn and oats as much as I4 per cent, and of wheat Io per cent. It is probable that there is a greater gain in digestibility from grinding alfalfa, a coarse feed, than there is from grinding grain.

"When alfalfa is to be fed at a distance from the place where grown it must be baled for shipping. When the bales are opened and scattered in feeding a considerable part of the leaves is wasted. Over 8 per cent of the protein in alfalfa is found in the leaves, and the loss of protein from leaves wasted in feeding baled hay is frequently from one-fourth to one-half of the total amount in the original hay. With ground alfalfa there is no waste in feeding either from leaf or stem. Alfalfa ground is in the best condition for shipping and handling cheaply and without waste.

"Ground alfalfa is not only a good feed itself but when mixed with grain aids in the digestion of the other feeds, enabling the feeder to get more out of his home grown grain.

"Experiments have not been made to determine the exact value of this diluting effect of alfalfa meal in increasing the feed value of heavy grains. Tests have shown that corn-and-cob meal has the same feeding value as an equal weight of clear corn meal. Practically worthless ground cobs by their 'lightening up' the heavy corn meal add 20 per cent to the feeding value of the meal 
with which they are mixed. It is reasonable to believe that a rich feed like ground alfalfa has even a greater influence when mixed with corn meal. The more intimate the mixture the greater the benefits from alfalfa, and for this reason ground alfalfa is far superior to the wholehay.

"Grinding alfalfa hay reduces the power needed to digest and assimilate it. It takes power for an animal to chew the feed, digest it and bring about the chemical changes that convert it into flesh or milk. All this energy is taken from the actual food material in the alfalfa. Experiments show that a much larger amount of food value is used up in this way with coarse feeds than with concentrated fine feeds. In corn, a concentrated feed easily worked up in the animal's body, three-fourths of the protein actually in the hay is digested; and in straw, a still coarser feed, only one-tenth. Forty-eight per cent of all the energy in coarse hay is used up in chewing and digesting it, while only twenty per cent of the energy in oats is used in these processes. This shows the value of preparing feed in such a way as to require the least effort on the part of the animal to use it.

"In a well constructed mill it requires one horse-power ten hours to grind alfalfa sufficient for a month's ration for a dairy cow in full milk. This indicates what a saving the grinding of alfalfa makes in its effective use by an animal.

"Experiments show that good alfalfa hay and wheat bran have practically the same value in feeding for milk. In a test made of bran and alfalfa meal, two lots of cows were selected that were giving equal weights of milk. One lot was fed bran, the other lot the same weight of 
alfalfa meal. For each Ioo pounds of milk given by the cows fed bran, I4I pounds were yielded by the cows fed alfalfa meal."

As an example, "Alfamo" is the name of one of the numerous new feeds on the market, having alfalfa meal as its principal ingredient. After a year of experimenting with grinding and mixing various feeds it was determined by the manufacturers that a feed made of three parts alfalfa meal and one part beet-sugar molasses would possess a very high value. The ingredients are mixed by a special apparatus and subjected to a process which retains and preserves the high nutriment of the feed.

Prof. Samuel Avery of the Nebraska station made an analysis of "Alfamo," which showed the following composition :

\section{Per cent}

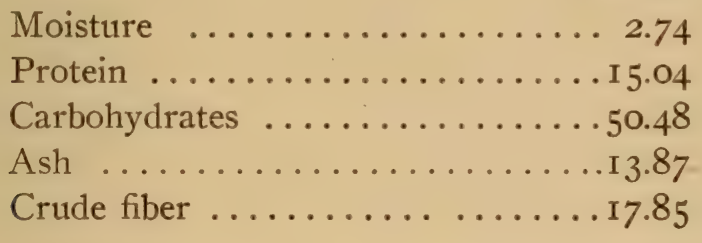

Professor Avery also states: "This feed was made by mixing molasses with alfalfa meal which contained I6. I 5 per cent protein. It will be noticed that the protein content is not greatly reduced, while a large quantity of nutritious matter has been added in the molasses. An analysis of the molasses used in this product, showed practically fifty per cent sugar, and it should be remembered that the sugar in molasses is all digestible and 
ready for the animal without extra effort on the animal's part, which is not so in corn or other foods, strong in carbohydrates from which the starch must be extracted by the digestive apparatus."

\section{SOLVING THE TRANSPORTATION PROBLEM}

Several mills for the manufacture of alfalfa foods have been and are being established, and it is reasonable to assume that the use of these foods will become quite general in cities and districts remote from the alfalfa regions. Whether or not the actual feeding value is appreciably increased, or the nutritive constituents made more thorougly available, is as yet not determined by sufficient tests, nor has it been determined by any station test that any factory food preparation is more economical than alfalfa hay, where the hay can be obtained well cured and with a reasonable proportion of its leaves. It is altogether probable, however, that alfalfa meal will be more economical in distant cities than baled hay. If these preparations of alfalfa prove to be satisfactory to consumers in distant markets, it will lead to the multiplication of mills in the alfalfa regions, thereby decreasing the cost of transportation and giving the grower a wider and probably a better market. The use of the meal or the food preparations is likely to prove most especially valuable for dairy cows and poultry. 


\section{Alfalfa for Town and City}

While the preceding chapters have dealt with almost every phase of alfalfa, it is thought well to emphasize the advantages of its more general use in cities and towns. In the minds of many there is an undefined impression that alfalfa is for farm consumption only. Often when first introduced into a community, farmers who raise more than they have stock to consume, complain that it is difficult to sell in small towns.

\section{THE TOWN COW NEEDS ALFALFA}

Milk producers who know it best concede that alfalfa is an invaluable feed in the dairy, closely akin to wheat bran in results and usually much less expensive. In the average small town or city there is about one cow for every ten or fifteen people. Therefore, in a town of one thousand population, there will probably be seventy-five to one hundred cows. If alfalfa will increase the quantity of their milk and butterfat, giving a product at a lower cost than the concentrated foods, it should be more used. But as yet it is not generally used, because it is not understood and appreciated.

The best time to secure a supply is when it is being harvested and can be taken directly from the field. If the mow is large enough for three or more tons, a ton can be stored from each of the different cuttings, and be 
cured in superior condition almost regardless of the weather. It would be found a most economical feed for the family cow and, if fowls are kept, it could constitute one-third of their ration, adding to growth and to the egg supply.

\section{A CHEAP FEED FOR HORSES}

The larger users of hay in the towns and cities are liverymen, deliverymen and teamsters. These have been unacquainted with or doubtful of the utility of alfalfa and have never given it a fair trial, or possibly any trial at all. Those who have used it and thought its effects harmful have perhaps not understood its highly nutritious character and may have fed it in too large quantities. Having such a large protein content it should not be used with the same prodigality as prairie hay. For driving horses it should be cut when more matured than for other stock, or when about half in bloom, and should be well cured. Fed then, in reasonable rations of from ten to twenty pounds a day, livery horses may be kept in vigorous thrift with a small additional quantity of grain, and thus a saving be made of twenty to thirty per cent in cost of maintenance. In the alfalfa districts there may be found many liverymen who, having had experience with alfalfa hay, feed their horses little of anything else. In the last few years there has been a growing demand for alfalfa hay for southern towns and cities.

The coat and general appearance of horses fed alfalfa are improved, as compared with those fed timothy or prairie hay and the tendency to constipation and indigestion is greatly lessened. It is rarely that an alfalfa-fed animal of any kind is constipated. 


\section{Alfalfa in Crop Rotation}

\section{MAINTAINING FERTHLITY}

It is a fundamental principle of the best agriculture that every acre should be kept constantly at its highest productive capacity. In one sense the farm is a great machine for the production of food. All prosperity must originate on and emanate from the farm; the farmer is really the only original producer. The measure of the world's material success must be the relative amount of the product of the farm. As lands decrease in fertility, the cost of living increases in direct proportion. As fertility decreases, land values decrease and rural population decreases. Already there are districts in America that are almost depopulated because of the barrenness of what was, but a short while ago, fertile land.

The fundamental principle of maintaining fertility is to restore to the land annually those chemical elements taken from it by the crops grown. A prominent importer of horses relates that he was once entertained on a great horse farm in France, whose owner told him that much of the farm had been in cultivation for over eight hundred years and was, he believed, as productive now as ever in its history.

Alfalfa ranks as the greatest fertilizing plant known to scientific agriculture. All cereal crops use large quan- 
tities of nitrogen. A field cropped for years in corn or wheat will come to have too little nitrogen for the production of a profitable crop. Alfalfa, as has already been stated, after the first few months of its life obtains its whole supply of nitrogen from the air ; in fact, more than it really needs. As a soil improver it possesses at least five valuable properties:

I. It gathers nitrogen from the air for its own maintenance and a surplus that is constantly being added to the soil.

2. It is a deep feeder and its roots penetrate the earth to extraordinary depths, drawing toward the surface and utilizing moisture and valuable mineral elements that other crops would never reach, leaving the desirable elements there for future crops, of whatever kinds.

3. By capillarity, these roots and rootlets draw up moisture from below the surface until it modifies the very top soil, changing wonderfully the nature of the field. The analysis of a cubic foot of earth of a flourishing alfalfa field shows a marvelous change in moisture content since the sowing.

4. The mere mechanical effect of the extensive root system can scarcely be over-estimated. As soon as germination begins the plant starts its tiny roots downward on the search for moisture. Roots four feet long have been found on alfalfa but four months old; roots nine feet long have been found below alfalfa but nine months old. After the taproot reaches a few inches below the surface, it sends out smaller roots that have a lateral growth of but a few inches, when they too, take a downward course for moisture and for mineral elements needed 
for the growth above. These first smaller roots decay and others start out from the taproot lower down. These decay and still others start. The decaying roots add humus to the soil, and the openings left by them form a wonderful system of channels for the penetration of air and water into the soil. The erstwhile compact earth is honeycombed and air and water penetrate the graves of the dead roots until, when the alfalfa field is ready to be used for a different crop, the soil has been wonderfully changed not only in its chemical elements but in its physical character.

5. The regular deposit of alfalfa leaves, from the cuttings, under the best care, has been estimated at onehalf ton or more per acre every year. As these leaves contain a great percentage of protein, it can readily be seen that they make a heavy contribution to the soil's fertility.

\section{VALUE OF STUBBLE AND ROOTS}

When in his system of rotation the farmer is ready to plow up his alfalfa, he has another inestimable contribution to the land's fertility in the stubble and roots. It is not recommended to plow under any considerable growth as a green manure, as the hay crop is too valuable. Its market value would buy more fertilizers than the same growth is worth for humus. After a field has stood for five or six years, the roots have added largely to the humus content. Prof. W. P. Headden of Colorado, estimated that the fertilizing value of the stubble and $6 \mathrm{~T} / 2$ inches of roots plowed under is about $\$ 20$ per acre, while the value of the stubble and entire root system is not less than $\$ 35$ per acre. 
The New Jersey station estimated that the amounts of plant food gathered by an acre of alfalfa in two years were equivalent in nitrogen to that contained in 3500 pounds of nitrate of soda ; in phosphoric acid to that contained in 600 pounds of boneblack superphosphate, and in potash to the amount contained in I 200 pounds of muriate of potash, or equal to what would have cost \$I24.

\section{EFFECTS ON SUCCEEDING CROPS}

The Wyoming station, at Laramie, under direction of Prof. B. C. Buffum (Bul. No. 44) made some tests that proved the market fertilizing value of alfalfa. A plot of ground that had been in alfalfa for five years adjoined a plot of the same size that had been in varied crops, wheat, oats, potatoes, etc. After the alfalfa sod was broken the two plots were prepared together and planted crosswise to wheat, oats and potatoes, with half of each on the broken sod and half on the other plot with the following yields and gains :

After Alfalfa After Other Crops Money Gain Wheat ...30 bu.... I8 bu....\$8 to $\$ 12$

Oats ....78 bu...37 bu.... I6

Potatoes . .8I bu...52 bu.... I6

Stating the results in another way, Prof. Buffum says:

"The value of alfalfa harvested from one-half acre of land for five years was about $\$ 50$ more than the cost of producing it.

"The value of potatoes and grain from an adjoining half-acre for five years was about $\$ 44$ more than the cost of producing, at local prices. 
"When the alfalfa half-acre was plowed and planted to wheat it produced $\$ 8$ to $\$$ I 2 more value in wheat per acre than the land which had grown potatoes and grain before.

"When the alfalfa half-acre was plowed and planted to oats it produced \$16 worth of grain more than land which had grown potatoes and grain before.

"When the alfalfa half-acre was plowed and planted to potatoes it gave $\$ \mathrm{I} 6$ worth more of potatoes per acre than was obtained from land which had grown potatoes and grain before.

"By growing alfalfa the increase of yields and values were produced with absolutely no cost for fertilizing the land."

This gain, it will be noted, cost nothing in the way of fertilization, as the alfalfa had every year been more profitable than the other crops. A Marion county, Kansas, manager of large estates reports that a field of wheat after alfalfa averaged forty bushels per acre while an adjoining field of equal original fertility averaged but fifteen bushels. These results have been duplicated in innumerable instances where alfalfa fields have been plowed and planted to other crops. A Colorado man who farms 1000 acres, with 200 acres of it in alfalfa, says he cannot afford not to plow his alfalfa after he has had from it four years' crops ; that it is necessary to maintain the general farm fertility and obtain big crops of corn, oats and potatoes. In the potato districts of Colorado alfalfa is used systematically as a rotation to maintain the yields and quality of their potatoes, both of which are so famous. 
In the corn belt, which may be said to extend from the central meridian of Kansas to Pennsylvania, alfalfa used in rotation will do much to prevent the disgrace of raising an average of but twenty or twenty-five bushels of corn to the acre. And so in what were once famous wheat belts, alfalfa will restore the crop records, if properly used in a rotation.

\section{ROTATION A NECESSITY}

Some experiment station men insist that where alfalfa is allowed to stand for many years it will cease to have a fertilizing value; that alfalfa draws heavily on the potash and phosphoric acid in the soil, and will after, say, eight or ten years begin to deplete it of these important elements. Therefore they insist that alfalfa should not be allowed to stand for over six or eight years unless it is given an annual top-dressing of manure. They favor plowing up the alfalfa after about five years and cropping to corn or cotton.

Former Governor Hoard in speaking of the value of alfalfa as compared with that of clover in a crop rotation says that, "alfalfa having a much larger root development goes deeper down, thoroughly subsoils the ground, brings up phosphorus and potash from the lower strata, and leaves much more vegetable matter to decay and furnish humus. Nothing else we have ever tried equals alfalfa for putting the soil in good tilth."

\section{SPREADS THE BACTERIA OVER THE FARM}

Men who are raising alfalfa for use in a regular rotation never leave it over six years; many prefer five, while 
others make it a rule to plow up their fields every four years; thus the bacteria becomes fixed in the soil of the whole farm. Such farmers use alfalfa as they formerly used clover, to restore fertility needed for profitable crops of grain, hay and forage.

The sod is hard to plow. It is well to do the breaking immediately after the season's cutting, if possible; disk and harrow it several times and sow to rye for winter pasture, and plant to corn or cotton or potatoes in the spring. The winter's freezing will help to put it in fine tilth. If it is desired to follow with wheat (not always advisable, however, on account of causing a too rank growth), the sod may be plowed after the year's second mowing, disked and sowed to rye to prevent the soil from leaching.

Breaking up a well set alfalfa field is no trifling matter. It may be done with three heavy horses, but it is hard work for them, and they will not be able to break more than one acre a day. An authority says the best plan is to use five heavy horses - three in the lead and two on the end of the beam. They can go right along and plow two acres a day. Alfalfa roots are very tough and strong when the plants have attained full growth, and they give a jerky motion to the plow, which is severe on horses' shoulders. A cast steel plow is the best to use and if it is tempered right a file can just cut it. It can be hammered out thin at the blacksmith's shop when it becomes too thick to file easily. "The reason for filing, rather than using the hard, thin edge as in other plowing is that the edge needs to be rough as well as thin, or the roots will slip along the sloping edge of the share and not be cut." It is 
important that the furrow turned shall not be wider than the plowshare will all the time cut clean, as any main roots that are left uncut will send up a more vigorous growth of stems than before, which, in another cultivated crop will be the same as weeds. 


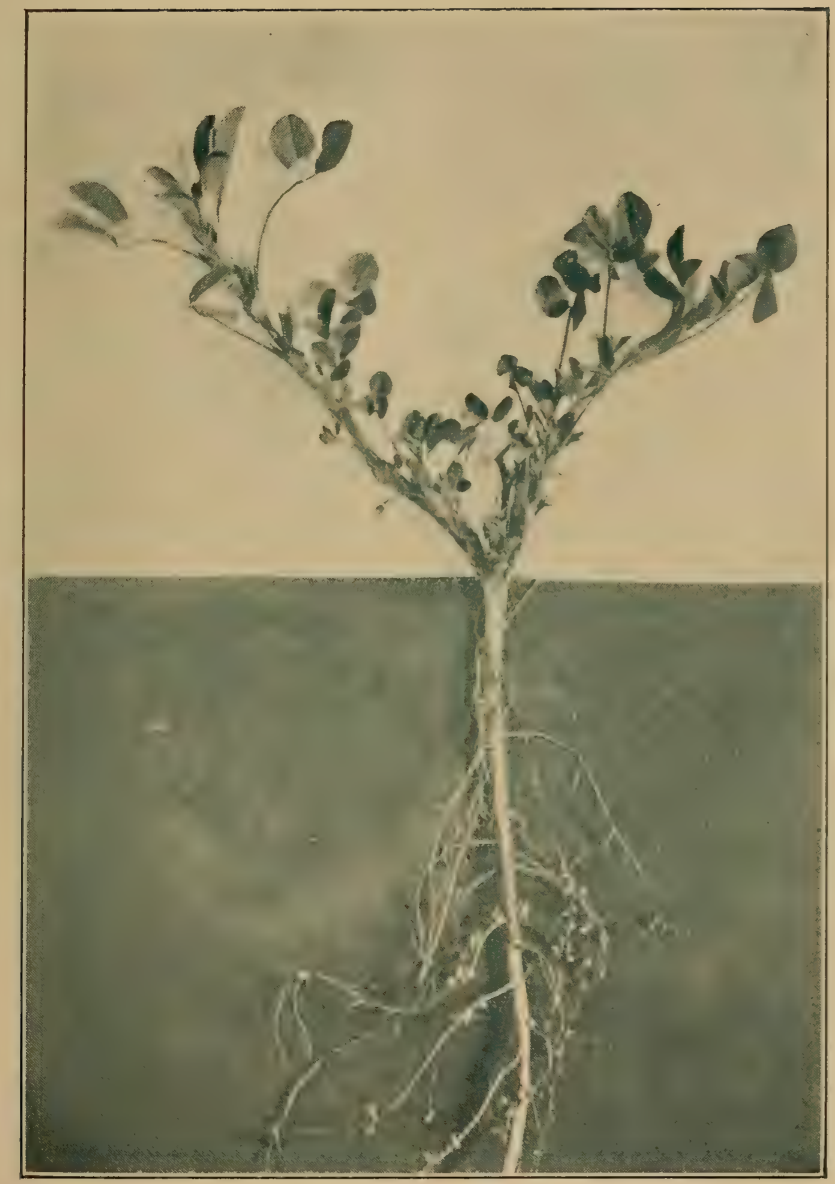

Alfalfa Plant and Roots Showing Bacteria Nodules 


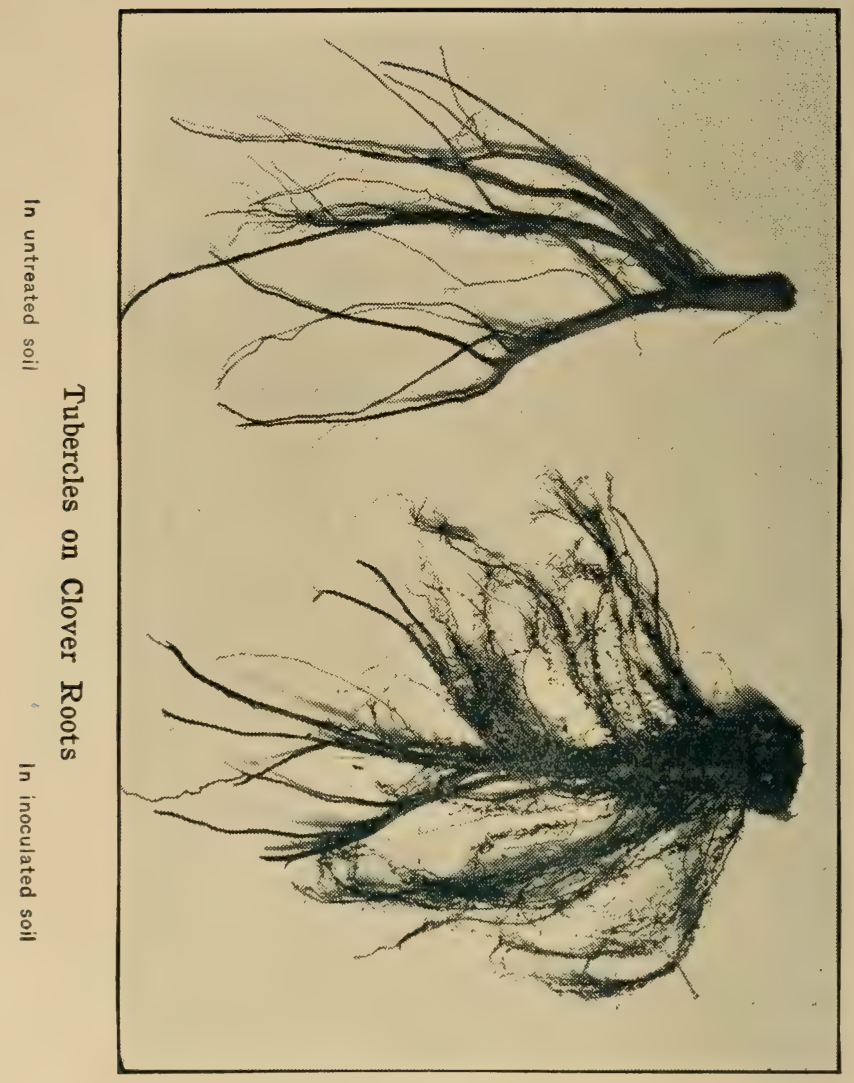




\section{Nitro-Culture}

\section{AN OLD-NEW THEORY}

The inoculation of soil, like many other lately exploited theories, has no doubt been known for hundreds of years. There are evidences that it was practiced in England at least a century ago, and it is thought to be an old custom among the Chinese. Some space was given to "soil inoculation" in a preceding chapter, attention there being devoted to the simple methods of infecting soil with bacteria.

\section{IMPORTANT DISCOVERIES}

Some twenty years ago a German scientist, Nobbe, discovered that the small nodules found on the roots of the leguminous plants contained bacteria that took nitrogen from the air and transferred it to the plant. It had been known that cultivated soils were rapidly losing their original supply of nitrogen and there seemed no practicable way of restoring it in sufficient quantity. Commercial nitrogen costs fifteen cents per pound and the expense of applying it to the land to equalize the loss from an ordinary farm crop is almost equal to the value of a crop. Hence, the discovery that the legumes were nitrogen-gathering, by means of these bacteria, was 
hailed as one of the greatest of the age. With millions of pounds of nitrogen over his land there seemed now a method whereby the farmer could utilize some needed portions of it. The bacteria live in tubercles upon the roots of various leguminous plants, such as Red clover, Sweet clover, Bur clover, alfalfa, cowpeas, garden peas, vetches and beans. These tubercles are the home of the bacteria, minute forms of vegetable life, too small to be seen with the naked eye. The legumes have no power in themselves to draw nitrogen from the air, yet these bacteria seem to have the power to absorb the free nitrogen and cause it to combine with other elements, forming nitrates or other assimilable compounds suitable for plant food. It has also been demonstrated that, as a rule, there are different species of these bacteria for different species of legumes.

After German scientists had made their discoveries, one of the existence of these bacteria on the roots of the legumes and another that in the laboratory, these organisms could be bred and multiplied, they seemed unable to develop them of sufficient vigor to survive any general distribution. At this point Dr. George T. Moore of the United States Department of Agriculture, hit upon a plan of cultivating them in a way by which they could be preserved for many months, and he also gave them a much greater power. This nitrogen-fixing power was so developed that seeds soaked in the solution, it is claimed, sprouted and produced plants in sand that possessed no nitrates. He then found that these bacteria when grown upon nitrogen-free media will retain a high activity for a long time, if carefully dried out and then revived in a 
liquid medium. He also devised a plan by which they could be mailed to any part of the world and arrive in perfect condition.

Most experiment station men have given to Dr. Moore great credit for his discoveries and have tried, with rather marked success, his method of nitro-culture; on the other hand a few have been opposed to the method from the beginning and are still opposed. It would seem that the tests made prove that nitro-culture does introduce bacteria when directions are followed.

Of course if a farmer's soil has the alfalfa bacteria, it is not necessary to use any system of inoculation. If Sweet clover or Bur clover is growing in the vicinity, or if alfalfa is thriftily growing near without the aid of inoculation, it is hardly necessary to make there further efforts for the introduction of bacteria.

\section{SUGGESTIONS FROM THE DEPARTMENT OF AGRICUL- TORE}

In a preceding chapter the opinion was expressed that in most states, and in most localities in those states, inoculation was unnecessary because bacteria were already present; yet it is true that these bacteria are present, if at all, in varying quantity. If comparatively few are present, any method of inoculation that will introduce more into the soil, to hasten the growth of the tubercles and promote the gathering of nitrogen, will be helpful. The fact is, we know as yet comparatively little of all there is to be learned about this wonderful principle. It is altogether probable that the use of nitro-culture is as practicable and as free from objections as the use of inoculated soil, espe- 
cially from distant and unknown fields. In one of its bulletins the United States Department of Agriculture has summarized its advice as to inoculation as follows:

When Inoculation is Necessary.-Inoculation is necessary-

I. On a soil low in organic matter that has not previously borne leguminous crops.

2. If the legumes previously grown on the same land were devoid of nodules, of "nitrogen knots," thus showing the need of the nodule-forming bacteria.

3. When the legume to be sown belongs to a species not closely related to one previously grown on the same soil. For instance, soil in which Red clover forms nodules will often fail to produce nodules on alfalfa when sown with the latter crop for the first time.

When Inoculation May Prove Advantageous.-Inoculation may prove advantageous-

I. When the soil produces a sickly growth of legumes, even though their roots show some nodules.

If the cultures introduced are of the highest virility, their use will often result in a more vigorous growth.

2. When a leguminous crop already sown has made a stand, but shows signs of failing, owing to the absence of root nodules.

The use of the culture liquid as a spray or by mixture with soil and top-dressing may save the stand if other conditions are favorable.

When Inoculation is Unnecessary.-On the other hand, inoculation is unnecessary and offers little prospect of gain- 
I. When the leguminous crops that are usually grown are producing up to the average, and the roots show nodules in normal abundance.

Cultures of nitrogen-fixing bacteria are not to be regarded in the light of fertilizers, or as capable of increasing the yield under average conditions. They do not contain nitrogen itself, but bacteria, which make it possible for the legumes to secure nitrogen from the air (through the formation of root nodules). Where the soil is already adequately supplied with these bacteria, it will not usually pay to practice artificial inoculation.

2. When the soil is already rich in nitrogen.

It is neither necessary nor profitable to inoculate a soil rich in nitrogen when sowing legumes. Not only does the available nitrogen in the soil render the formation of nodules less necessary, but the nitrogenous materials in the soil largely prevent the bacteria from forming nodules.

Any increased virility in nitrogen-fixing power possessed by any of the types of bacteria yet distributed, may be rapidly lost in a soil containing an abundance of nitrogen, because the bacteria are in a medium in which there is no demand for activity in securing atmospheric nitrogen.

When Failure is to be Expected-Inoculation will fail where other conditions (aside from the need of bacteria) are not taken into account, among which are the following-

I. In soil that is acid and in need of lime.

Liming to correct acidity is as important for the proper acidity of the bacteria as for the growth of the plants. 
2. In soil that is deficient in fertilizers, such as potash, phosphoric acid or lime.

The activity of the bacteria in securing nitrogen from the air and rendering it available to the legumes does not do away with the need for such fertilizing elements as potash and phosphorus.

3. It must also be remembered that inoculation does not "act like magic"; it will not overcome results due to bad seed, improper preparation and cultivation of the ground, and decidedly adverse conditions of weather and climate.

In the use of the cultures, also, failure is almost certain where the directions are not carefully studied and intelligently followed.

\section{SWEET CLOVER SOIL USED TO INOCULATE ALFALFA FIELDS}

The discovery in Illinois that inoculation of the soil for alfalfa was necessary in certain places and not in others suggested the theory that bacteria living on some other, probably native, plant were identical with the alfalfa bacteria. Investigations led to satisfactory evidence that this was the case and that the native plant was the ordinary Sweet clover (Melilotus alba). The illustration facing page 23I shows the results of a series of pot culture experiments made at the University of Illinois and reported in Bulletin No. 94 by Prof. Cyril G. Hopkins. The four photographs were made five, six, seven and eight weeks, respectively, from the time of planting. Alfalfa seed were planted in each of the five pots, in carefully prepared soil practically free of combined nitrogen, and at the same time four of the five pots were inoculated as follows: 
Pot No. I.-Not inoculated.

Pot No. 2.-Inoculated with bacteria obtained from infected alfalfa soil.

Pot No. 3.-Inoculated with bacteria obtained from alfalfa root tubercles.

Pot No. 4.-Inoculated with bacteria obtained from infected Sweet clover soil.

Pot No. 5.-Inoculated with bacteria obtained from Sweet clover root tubercles.

The results indicate that the same effect is produced upon the growth of the alfalfa by the nitrogen-gathering bacteria obtained from Sweet clover as by those from the older alfalfa, and seem to prove that infected Sweet clover soil can be used for the inoculation of alfalfa fields. Investigations have shown that Ioo pounds of thoroughly infected soil to the acre is sufficient to produce a satisfactory inoculation within one year from the time it is applied. 
CHAPTER XXII.

\section{Alfalfa as a Commercial Factor}

\section{EFFECT ON LAND VALUES}

Only a few years ago alfalfa hay was not named in the market reports. Now it is conspicuous in the lists of hays. Then there were thousands of sandy acres in Kansas and Nebraska being held at from $\$ 2$ to $\$ 5$ per acre that now, seeded to alfalfa, are selling at from $\$ 30$ to $\$ 75$ per acre. Then, cultivated farms in those districts could be rented for \$I per acre; now, seeded one-half to alfalfa, they rent for $\$ 3$ to $\$ 5$ and more per acre. In the South cotton lands rent for $\$ 5$, and alfalfa lands at $\$ 15$ per acre. Land in the Yellowstone valley was worth, wild, \$I.50 per acre; now, under irrigation and seeded half to alfalfa and half to wheat it commands $\$$ roo per acre. A few years ago labor commanded in those districts that now raise alfalfa about $\$ \mathrm{I}$ a day; since then, during alfalfa harvest, hundreds of men have been imported there and paid $\$ 2$ or $\$ 2.50$ per day. Then farmers were poor and trade was dull; now, a farmer who owns eighty acres well set in alfalfa, harvests about 300 tons of hay worth from $\$ 5$ to $\$$ I 2 per ton and has the proceeds available for added comforts, improvements and luxuries.

A few years ago it was thought that America was approaching a crisis in the matter of beef and pork and 
mutton production because of the rapid diminishing of the free public ranges by the forest reserves, irrigation projects, and the like. It was insisted that the farmers could not nearly sustain the meat supply. Possibly they cannot, but alfalfa is doing wonders in helping to solve the problem of cheap meat production. Millions of sheep and thousands of cattle are being fattened annually on the alfalfa of California, Montana, Colorado, Kansas and Nebraska, and in some portions where a few years ago the sandy prairies gave but a scant subsistence to scrawny range cattle.

\section{ENHANCES DAIRY INTERESTS}

In parts of the East since the introduction of alfalfa, the number of dairy cows in many townships has trebled and the dairy product more than quadrupled. When two acres of alfalfa will carry ten dairy cows through a summer, the day and opportunity of the small dairyman are certainly at hand. When, as is the case, alfalfa increases the rental and selling value and consequently the taxable value of land; when it increases the demand for and price of labor: when it increases the fertility of the land for other crops that may follow; when it brings enlarged profits to the entire stock-raising and stock-fattening interests, and puts more money in circulation, it is inevitably to be considered a commercial factor. 


\section{The Enemies of Alfalfa}

The most notable enemies of alfalfa are weeds, insects, parasites, and animals. More failures to raise alfalfa are caused by weeds than by all other enemies combined. The cause of weeds in a field is usually poor farming. Clipping alfalfa early in May will kill many weeds. If the weeds grow up, clip again and do the same every time they threaten to become rampant. If they are kept from seeding, and do not in a large measure crowd out the alfalfa, good crops may be had from it the second season. If sowed in the fall, disking early in April may kill most of the weeds. It is folly to sow alfalfa on a foul field, as it is far less expensive to kill out the weeds beforehand. Disking and clipping will do much to destroy them, but if they secure a strong foothold the best thing to do is to plow up the field, plant it in corn, give it clean cultivation, and sow alfalfa again when the weeds have been exterminated.

\section{DODDER}

Dodder is an annoying enemy. It is a parasite, belonging to the morning-glory family, growing from its own small seed but attaching itself very soon to the alfalfa stalk. It then separates itself from its own root and thereafter lives on the juices of the alfalfa until it ripens 


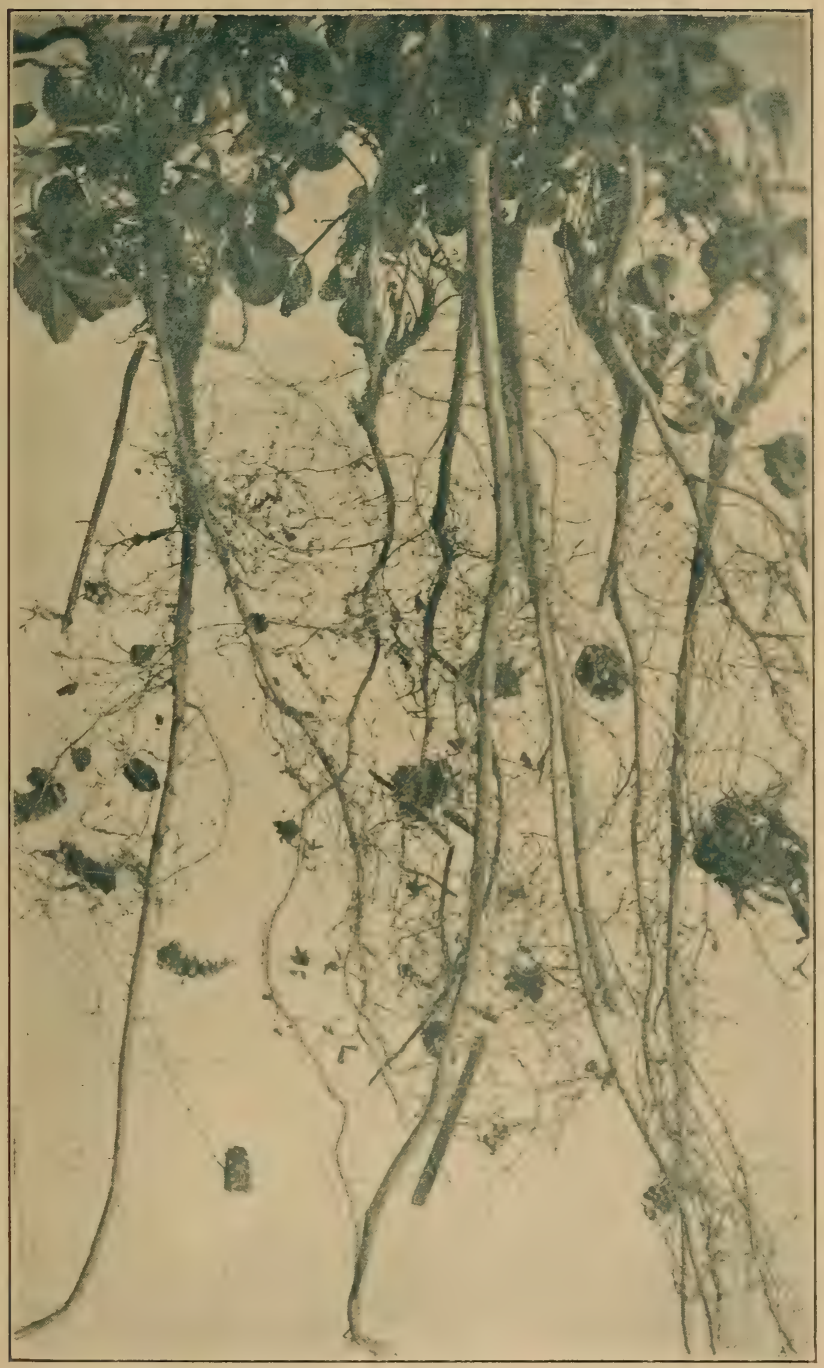

Peculiar Nodules in Groups on Small Rootlets

and distant from the large alfalfa roots. From Michigan Experiment Station Bulletin No. 225. 


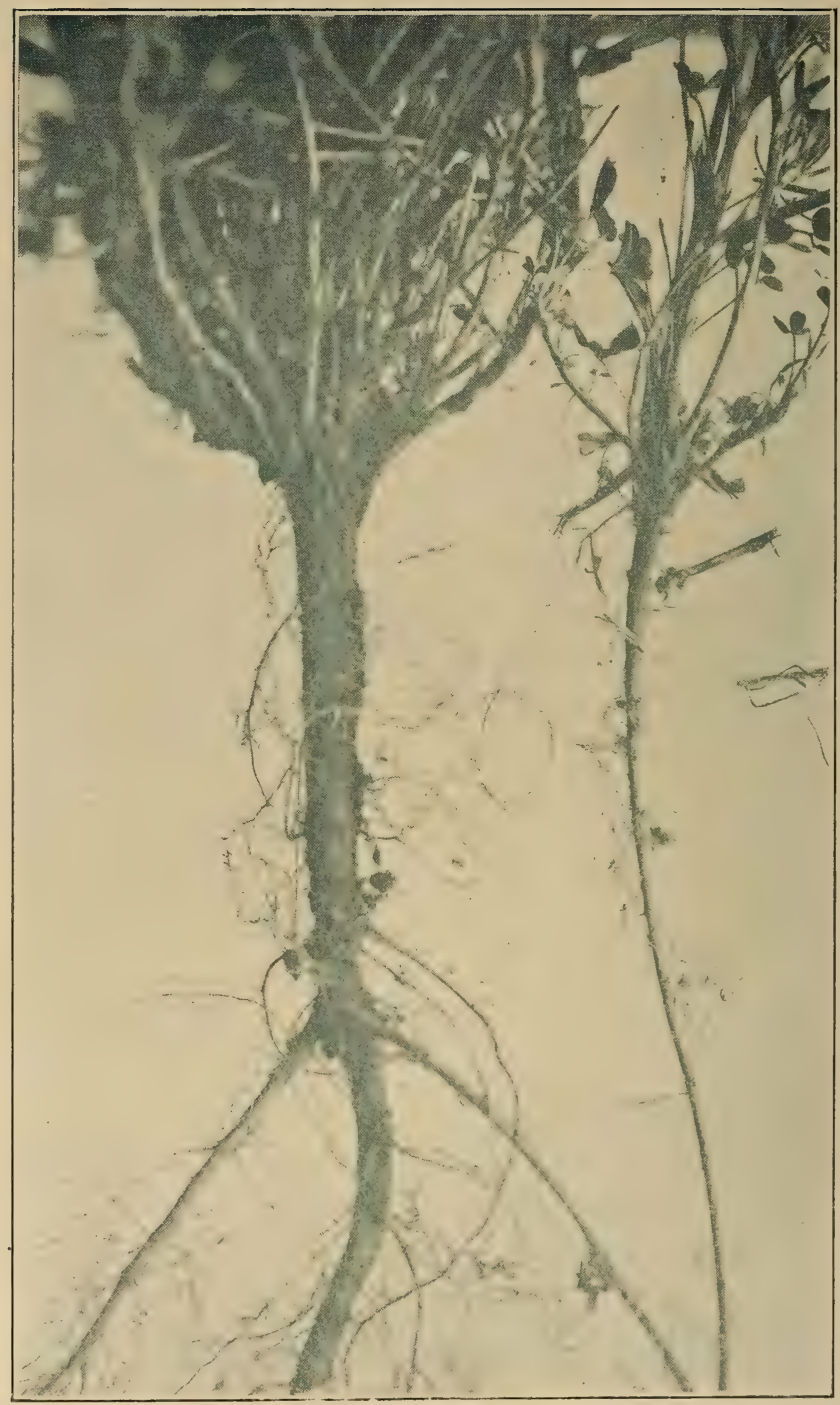

Alfalfa Roots Showing Normal Nodules

small and near the large roots. From Michigan Experiment Station Bulletin No. 225. 
its seeds or has killed the alfalfa. The wisest and safest thing to do is to sow only seed so thoroughly cleaned that there will be no dodder with it. If, later, it is found that any dodder seed escaped the cleaning operations and is growing, the grower should go through the field with a knife or sickle and a large basket or sack and cut out and burn every dodder vine and every plant to which dodder is attached. If so unfortunate as to have sown seed with a considerable mixture of dodder, clip the alfalfa early in May, let the clippings dry for two or three days or longer, and then burn on the field, watching carefully to have the fire touch every part. It will facilitate a complete burning to sprinkle parts not burning readily, with kerosene. If there is a poor stand of alfalfa, largely infested with dodder, safety lies in plowing it up and cultivating the field in corn or potatotes for two or three years.

From an excellent article on the dodder that infests alfalfa (Cuscuta epithymum) by Mr. F. E. Dawley, a New York authority on alfalfa, and printed with illustrations in the Country Gentleman, the excerpts here following are taken:

"The only sure method of keeping alfalfa fields free from dodder is through exercising greater caution in the purchase of seed. There is no reason why thoroughly recleaned alfalfa seed should have any dodder seed in it, as reference to the illustrations will show. The relative sizes and forms of the seeds of alfalfa and dodder are shown herewith. It will be seen that there is a marked difference in both the sizes and the shapes of the seeds. The alfalfa seed is shaped like a little kidney bean, and 
varies in color from light yellowish-green to a richgoldenyellow, and in some instances, because of weathering, or sweating in the cock, or perhaps standing too long, it shows a reddish-brown color. The dodder seed is darker in color than the alfalfa, all of that which I have succeeded in gathering from the plants being a rich goldenbrown. The accompanying illustrations show the form of the dodder and alfalfa seed respectively.

"The seeds, being sown, germinate in the soil, throwing up a slender, thread-like stem somewhat resembling a corn silk, which retains its connection with the ground until it comes in contact with the stem of the alfalfa plant. It twines around this tightly, sending its feeding suckers through the outside bark, and as soon as it is firmly attached to the host plant, the ground connection is severed and it is sustained by the plant juices which are taken in by the suckers. It continues to grow and spread, twining around other stalks and increasing very rapidly until a colony is established. Continuing to grow, it climbs toward the upper portion of the plants, feeding on their juices and sapping their vitality, but never goes to the extreme top, seeming to prefer the dampness and darkness of the matted alfalfa rather than sunlight. The plants first attacked begin to die, and the dodder, spreading out in all directions, forms a circle or ring.

"The rapidity with which the pest spreads makes it a serious menace to the alfalfa grower. Comparatively little work has been done by scientific men in studying the dodders and methods of eradication, and the fact that the little rootlets or suckers (haustoria) become so firmly affixed to the host plant that it must be destroyed together 
with the parasite, has made the work hard and the results obtained unsatisfactory. There are a number of methods by which dodder may be spread through a field. As soon as it becomes thoroughly established on a host plant, the many little branches, waving about like the shoot produced from the seed, attach themselves to other plants, and thus the colony is increased in size. In legumes, the host plant first attacked soon dies, but before this occurs, the parasite has become firmly established on adjoining plants and is reaching out and completing the colony. As soon as a host dies, the dodder also perishes, but before this happens it is very likely to have blossomed and seeded.

"In the operations of mowing, tedding, raking and drawing the alfalfa hay, these little colonies are spread about the fields by the machines and the workmen, and on the horses' feet. The sale of infested hay is a prolific means of dissemination. Hunters and pleasure seekers, walking through the fields, notice the peculiar corn-silklike growths and often, by picking up particles of it which are soon cast away, establish new colonies. The flower is very peculiar and attracts the attention of people passing, who are apt to pick them together with some of the maturing seed, and scatter these over the fields. In a pastured field, the animals spread the seed to some extent while moving from place to place in feeding. The most serious menace, however, is from the purchase of impure seed; farmers should always be absolutely certain that the alfalfa seed which they are buying is thoroughly recleaned and that no small weed seed is to be found in it. One should never sow clover or alfalfa from a field or even from a locality in which dodder is known to exist. 
It is probable that the seeds thoroughly ripened will retain their germinating powers for some years. The purchase of hay from dodder infested fields, or the purchase of manure from barns where infested hay has been fed, are sure sources of contamination.

"Where a newly seeded alfalfa field shows evidence of quite general dodder infection, it is useless to attempt to eradicate it, and the field should be plowed up and planted with some hoed crop for a period of years. Old fields that have been thoroughly infested will probably be more economically treated in this manner than in any other. In newly sown fields, one of the most effective methods is probably hoeing over the spots where the dodder appears, going over them once in two weeks and allowing nothing to grow on them until the dodder seed is germinated. A modification of this method has been used successfully by spading in fields where the colonies of dodder were seen, raking out all the tops, roots and branches, adding a little straw or hay and burning the mass, and then keeping the spot thoroughly hoed for a season. For fields where the colonies are small and scattered, this method of hoeing and shallow cultivation is probably the most practicable, as it helps to secure the early germination of any seeds that were left in the ground, and also kills them as soon as they are germinated. If the seed has developed, one must be careful not to spade it in too deep, as it may retain its vitality for some years if left covered in the moist soil.

"Burning has been recommended by some, raking the dodder vines and what is left of the alfalfa to the center of the colonies, putting brush or straw with it, together 
with some fine, light wood or chips and sprinkling with kerosene, so that the alfalfa plants will be burned close to the ground. This is necessary from the fact that the little coils of dodder close to the crown of the plants will retain their vitality and grow after a very severe burning, providing the alfalfa which is above the ground is not killed also. The most difficult problem to be confronted in killing out dodder where it has become established, arises from the fact that if these little coils which wind themselves closely around the plant are not killed or removed, the dodder will spread from these and make a new growth. Many experiments have been made with chemicals, but none of them have proved wholly successful, from the fact that these little rings were not destroyed. All the rest of the plant was killed and the production of flowers and seed prevented; but as these little rings were not killed, the dodder began growing again and continued to grow throughout the season."

\section{LEAF SPOT}

Leaf spot is a very peculiar disease and, fortunately, not common in this country. It has been known in France since 1832 . In 1891 it was destructive in Iowa alfalfa, the loss in the neighborhood of the experiment station being estimated at 50 per cent. In reference to this infliction the Iowa station, among other information, printed the following:

"Any time after the plant has attained a growth of four to six inches from the seed, but most commonly after the first year's growth, there appears upon the upper side of the leaves small, irregular brownish spots, which 
enlarge to about one-sixteenth of an inch in diameter and extend through the leaf to the under side, turning all parts brown. When many spots occur on the same leaf the whole leaf soon turns yellow and falls off. This falling of the leaves and the natural loss in vigor, due to the diseased condition before the falling, constitute its great damage. Frequent cutting of the crop materially prevents the disease."

In eastern states farmers report that there are frequent patches in their fields where the leaves turn red and the plant dies. The probable explanation of this trouble is "wet feet," which alfalfa will not abide. Don't expect to get a crop of alfalfa from a field in which water is near the surface. Drain it or use another field.

\section{ROOT ROT}

A disease peculiar to portions of the southern states is called "root rot," and similar to the root rot found in cotton fields. The alfalfa dies in spots, these spots widening in circular form. This is a fungus that spreads only in summer. The only means of eradicating so far (reported by the Texas station) is the application of common salt and kerosene. It has not proven a serious annoyance.

\section{GOPHERS AND PRAIRIE DOGS}

Gophers and prairie dogs are great pests in some parts of the Middle West, and about the only successful means of combating them is poison. The state of Kansas has, probably more than any other, made a systematic effort to destroy its gophers and prairie dogs, by liberal appro- 
priations and a field agent to supervise the work to be carried out under provisions of law by local officials.

The injury done by the gophers consists chiefly in throwing up mounds of soil taken from the burrows and these greatly interfere with operating the mowing machine in harvesting. In the alfalfa fields there is also a noticeable thinning out of the plants, by reason of the cutting off of the roots. These root cuttings are stored in the burrows in considerable piles, and are used in cold weather by the gophers for food. It is claimed by some alfalfa growers that this process of thinning out the plants is a benefit rather than an injury to the field, but, says Prof. D. E. Lantz, the official formerly in charge of the Kansas work, "I have known fields where this thinning has continued until the crop did not half cover the ground at cutting time, and the fields were plowed up for the planting of other crops. The loss from gopher depredations to the alfalfa growers of Kansas during I90 I was probably fully one-tenth of the entire product, and had a money value of at least $\$ 500,000 . "$

According to Professor Lantz, carbon bisulphide and other poisonous gases have frequently been recommended for the destruction of the pocket-gopher, but the great length of the burrows and their irregularities in depth prevent the gases from flowing into every part, and the animals often escape. Trapping, if properly done, is a sure method of killing the gopher; but it is attended with considerable labor and is very slow. An excellent trap for general use is the No. O ordinary steel trap. Sink it in loose soil to the level of the runway, nearly conceal it by sprinkling fine earth over it, and leave the hole open. 
Gophers are easily poisoned. They are fond of potatoes, sweet potatoes, apples, raisins and prunes. The presence of strychnine, arsenic or other poisons does not seem to deter them from eating the food; but if the poison is sweetened they seem to eat it more readily. In summer it may be desirable to sweeten the poison, but in the fall and early spring it does not seem worth while. The poisoned food being introduced to the burrows below the surface, there is no danger of poisoning stock. It might be well, however, not to let swine run in the fields for a time after the poison has been put out.

The following method of introducing poison is recommended: Cut the potatoes or other food into pieces not more than three-fourths of an inch in diameter. Cut a slit in each piece and with a point of the knife blade insert a little sulphate of strychnine; as much as half the bulk of a grain of wheat. Having prepared the bait in sufficient quantity, go to the field armed with a round, sharp-pointed implement an inch or an inch and a half in diameter and of sufficient length. The tool here illustrated was made by a blacksmith.

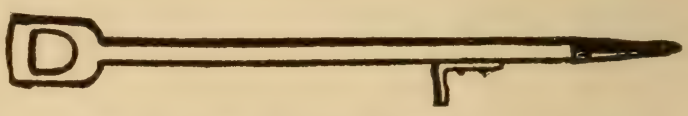

It is a spade handle shod with an iron point. A bar is attached about fifteen inches from the point to enable the operator to use his foot in pressing it into the soil. With this tool it is only necessary to find the runway of the gopher. The handle is sufficiently thick to make a hole large enough to permit one to drop the poisoned potato directly into the burrow. The operator then passes 
on to another place, leaving the hole open. No digging with a spade or other hard labor is necessary. An experienced person can distribute poison to many acres of alfalfa in a day; and if proper care is taken to rightly distribute the bait, it will not be necessary to go over the ground a second time. Some experience is required to find the burrows quickly. It is best to insert the food as near as possible to the freshest mounds of earth. Two or three pieces of potato at that place are worth many scattered in other parts of the runway. The operator should avoid the larger mounds and those that are not freshly made.

For destroying prairie dogs, Professor Lantz says that out of thousands of suggestions nothing has been found more effective than strychnine poison and carbon bisulphide. Following are directions for preparing and using the strychnine:

"Dissolve one and a half ounces of strychnine sulphate in a quart of hot water. Add a quart of syrup-molasses, sorghum, or thick sugar and water-and a teaspoonful of oil of anise. Thoroughly heat and mix the liquid. While hot pour it over a bushel of clean wheat and mix completely. Then stir in two or more pounds of fine corn meal. The quantity of corn meal needed will depend upon the amount of extra moisture present. There should be enough to wet every grain of the wheat and no more. Care should be taken that there is no leakage from the vessel in which the wheat is mixed. Let the poisoned grain stand over night, and distribute it in the early morning of a bright day. Use a tablespoonful of the wheat to each hole occupied by prairie 
dogs, putting it near the mouth of the burrow in two or three little bunches. Do not put out the poison in cold or stormy weather. It will keep for a considerable time, and is much more effective after a cold period, as the animals are then hungry and eat the grain readily. A bushel of wheat should poison Iooo to I 200 holes. An excellent substitute for the oil of anise in this formula can be made by soaking two ounces of green coffee berries in the whites of three eggs. Let this stand for about twelve hours, and use the liquid instead of anise oil."

A tablespoonful of carbon bisulphide, upon some such absorbent material as cotton, dry horse manure, or a piece of corn-cob, and rolled into the burrows, is effective. It is best immediately to cover the hole with a sod and stamp down firmly.

\section{GRASSHOPPERS}

Grasshoppers are a source of no little loss to alfalfa growers in some parts of the West. They usually do their greatest damage to the season's second crop, the young not being very destructive to the first. The best remedy, or rather prevention, is deep disking in April and then harrowing to destroy the eggs.

Where the pests attack or are about to attack a field of alfalfa, Prof. L. Bruner, of the Nebraska station recommends the use of a "hopper dozer," which is "simply a long, shallow pan of stove-pipe iron or galvanized iron mounted on runners and backed by a light frame covered with cloth. The pan is about four inches deep, from eighteen inches to two feet wide, and from ten to sixteen fcet long. It is partly filled with water and a little kerosene. A horse drags the machine across the field over 
the stubble of the first crop and the half-grown hoppers jump into the pan where the oil coats them over and kills every one that it touches. The hopper dozer works best on level land. On sloping ground the oil and water run to one end and slop over. To prevent this the pan is usually divided into sections by a number of partitions. The runners should stick out in front of the pan about a foot and one-half, and a piece of chain or heavy rope should be stretched loosely between them to drag ahead of the machine and make the hoppers jump. On level fields there are no great difficulties in the use of the hopper dozer. Careless driving may spill oil on some alfalfa and kill it. If these machines are to be really effective, they must be used before the grasshoppers get their wings. The first crop of alfalfa should be cut as early as possible, and the hopper dozers should follow the rakes as closely as may be. On the whole, they should be used only where plowing and harrowing have not been done or have failed to keep the grasshoppers in check."

Of the use of this implement or machine Prof. S. J. Hunter has this to say:

"The height of the runners depends upon the height of crop to be protected. It is important that there be no timbers in front of the pan, so that its front line may come in contact with the grain passed over. The insects then fall directly into the fluid. When ready for use place two buckets of water and one-half gallon of coaloil in a pan, and then drive back and forth across the end of the field where the grasshoppers are entering until you have filled the pans; remove the insects, replenish with oil and water, and continue until the field is rid of the pest. 
"Many grasshoppers will be seen strike the sheetiron back, drop into the pans and immediately jump out again. Those farmers who observed the experiments were at first of the opinion that the locusts that jumped out had jumped away 'to live another day.' The writer asked those interested to watch the insects and note the actions of grasshoppers that had jumped out. In every case the report was that the insects became sick and soon died. In fact, persons going over fields where a day or so before the hopper dozer had been at work, were impressed with the number of dead grasshoppers on the ground. An examination showed the presence of coal-oil upon the body. This kerosene and water is an external irritant, and my observations have been that the mixture is more effective than the oil alone.

"The use of the machine may be best shown by examples. In Ford county, Kansas, a large tract of alfalfa was cut, and the locusts at once began moving into a large field of Kafir corn which had been sown broadcast. The hopper dozer was drawn back and forth across the end of the corn field nearest the alfalfa land until a portion of the field about twenty rods deep had been gone over. Here it was apparent that there were very few grasshoppers; or, in other words, the advance line of the locusts' march only extended twenty rods into the field. Two days later the same area of ground was covered, but not as many insects were taken. Grasshoppers no longer entered this corn and the hopper dozer was no longer used at this point.

"It has been my experience with this machine that after it has passed over vegetation it does not injure the 
plants, but in some way renders the vegetation distasteful to the grasshoppers, so that they turn their course and seek food elsewhere. I have observed that these native grasshoppers enter a field from one corner or side, and that they are not as a rule scattered over the whole field, but occur in great numbers in patches. This being the case, it is evident that with very little labor with this machine the products of a field can be given full opportunity to mature."

\section{ARMY WORMS}

In Nebraska the fall army worm has caused considerable damage. It is distinct from the true army worm, having small hairs growing out from small black spots; it has a whitish " $Y$ " shaped mark upon the head. The parent of the worms is a moth of a yellowish, ash-gray color. The female moth deposits her eggs in clusters upon the leaves and stems. With the approach of cold weather the worms pass into the ground and enter the chrysalis stage about one or two inches below the surface. When very numerous the only effective treatment is to disk thoroughly in the spring.

\section{BIND WEED}

Bindweed, belonging to the morning-glory family, is one of the meanest weeds that annoy alfalfa raisers. It spreads from the root, and is more than liable to smother out alfalfa or any other crop which tries to occupy its ground. If infested fields could be grazed closely with hogs or sheep, they might keep the bindweed down and finally eradicate it. If this cannot be done, the only remedy is to plow and use the land for some other crop. 


\section{Difficulties and Discouragements}

Notwithstanding the fact that alfalfa is now grown successfully in all parts of the United States, in almost all kinds of soils and under many dissimilar conditions of climate, there are grouped here as a summary from preceding chapters the several difficulties and discouragements that may confront the one who would grow it.

I. Securing a Good Stand. Theoretically, the farmer should secure a good stand every year with every crop, but he does not. He obtains, however, poor stands of wheat and corn and potatoes oftener than a poor stand of alfalfa. Why does he fail with alfalfa? The following, at least in part, suggests why:

a He neglects to prepare sufficiently in advance. He should select his alfalfa field one or two years before he intends sowing. If he raises wheat, he should sow a little alfalfa seed with wheat, one or even two years before ready for alfalfa. This will leave a few roots and the proper bacteria will have been introduced into the soil. For two years there should be a vigorous fight against weeds, the fewest possible being permitted to ripen seed.

$b$ He neglects to prepare properly for the preceding crop, and sometimes plants the wrong crop, although sorghum and Kafir corn are about the only very objectionable planting to precede alfalfa. These have usually 


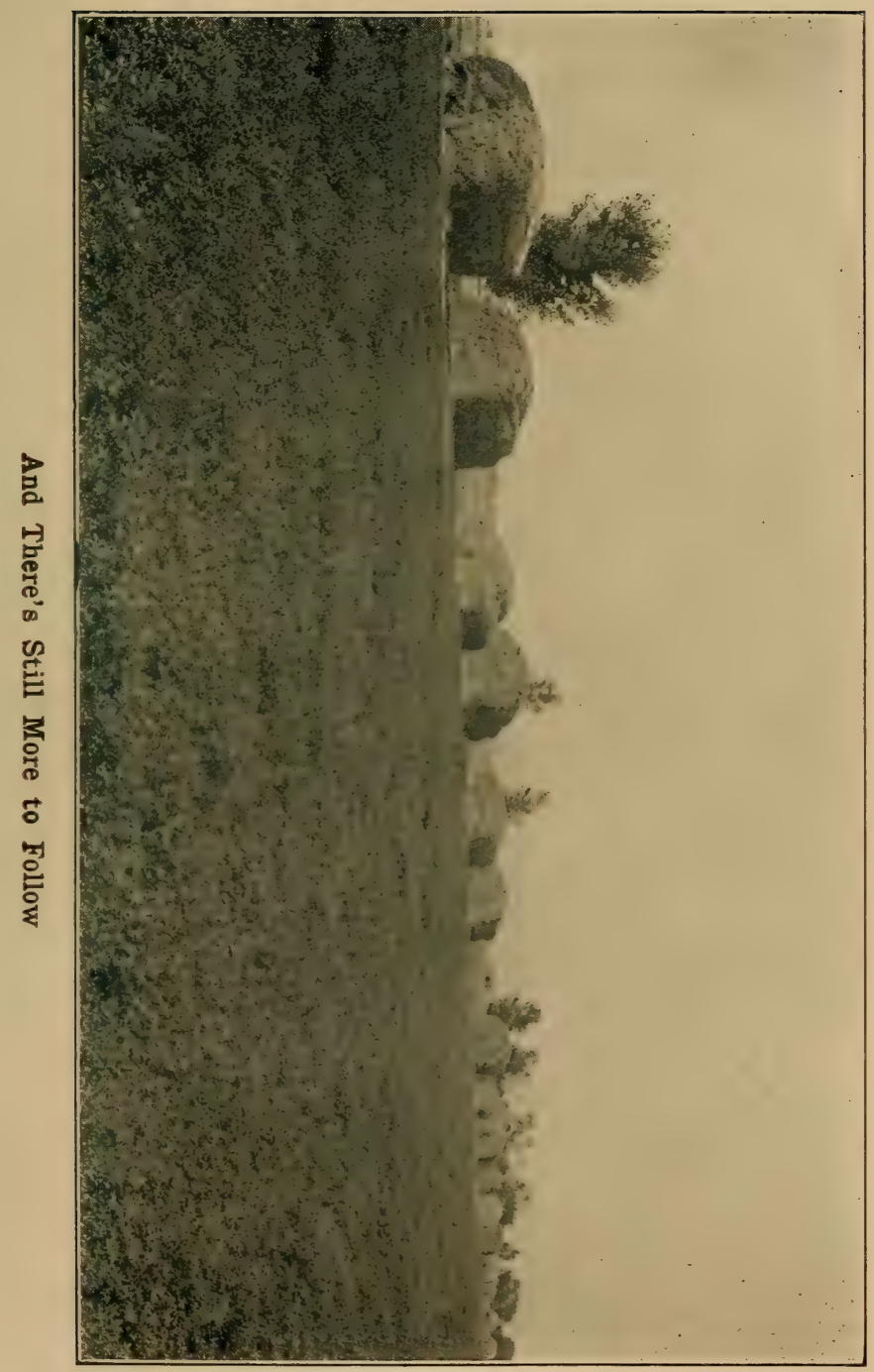



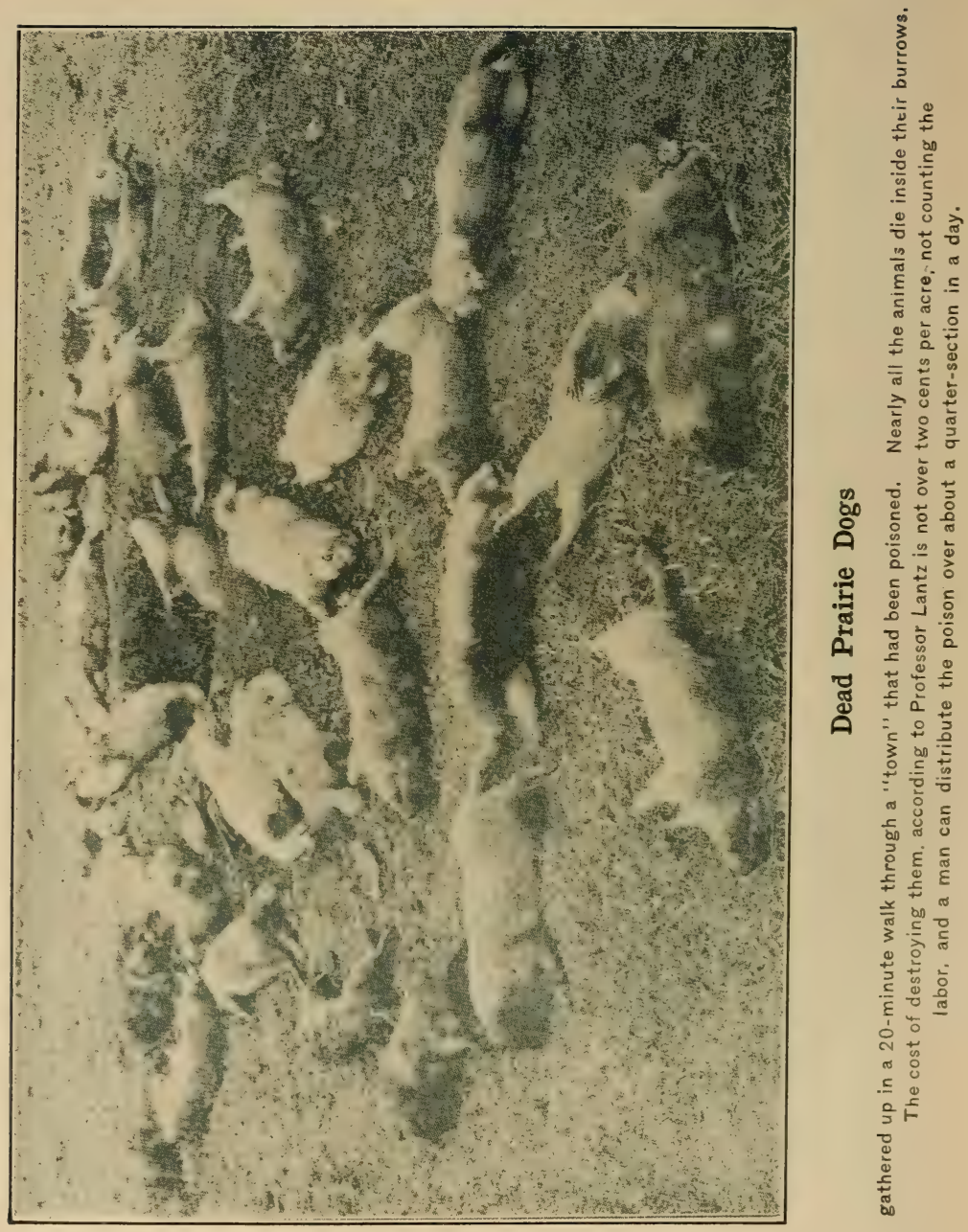
taken too much of the land's moisture, especially if the season has been somewhat dry, to permit a prosperous beginning of the plants from fall sown seed. Millet, oats or cowpeas are the best crops to precede, i. e. for the first trial. The plowing for this preceding crop should be deep. In clay land a subsoil plow (the kind which loosens but does not throw the subsoil to the surface) should follow. It is extremely important that a dressing of stable manure be plowed under for this preceding crop. The seed bed should be carefully prepared, and under favorable conditions. Working the ground when too wet would make it impossible to secure a proper seed bed later when preparing for alfalfa.

c He neglects to prepare the alfalfa seed bed properly. He should begin disking and harrowing as soon as the preparatory crop is off the ground, and continue this at intervals of ten or fifteen days until time for sowing, when the soil should be as fine as for an onion bed.

$d$ He uses poor seed; seed that is infertile, or adulterated with weed seeds-undesirable and unreliable in every way.

2. Dying out the second year, which in most instances is due to one of two causes, viz. : neglect to plow under stable manure for the preceding crop, or pasturing alfalfa in its first year. Not an animal should be turned on an alfalfa field for pasture until the second or, preferably, the third year. Another cause is disturbance of the soil and plants by severe freezing. This may often be prevented in a degree by a light top-dressing of manure in December. 
3. Failure through harvesting and stacking.

4. Injury from insects or disease.

These are practically all the things that need occasion serious vexation. Of course alfalfa calls for more work in harvesting than corn, or clover, or timothy; but one acre of prosperous alfalfa is worth two or three of corn, or clover or timothy, even for market, while for feeding purposes the difference is even greater. The "poor" farmer, the lazy farmer, the "corner grocery" farmer should not sow alfalfa. 


\section{CHAPTER XXV.}

\section{Miscellaneous}

\section{ALFALFA IN THE ORCHARD}

Probably nine-tenths of those who have written on this subject have condemned the practice of sowing alfalfa in the orchard. They have said that the alfalfa demanded so much moisture that the trees would be dwarfed if not destroyed. In going through an immense amount of material in the preparation of this book only two instances have been found of men who claim that the alfalfa is a benefit to orchards. One of these was from Texas and the newspaper quoting him did not give his name. He was reported to have used his orchard for hog pasture, keeping on five acres from ten to fifteen sows with their pigs from early April to September. $\mathrm{He}$ claimed that the alfalfa instead of robbing the orchard of moisture actually contributed to the surface moisture and benefited the trees.

Prof. F. L. Watrous, of the Colorado station, is an earnest advocate of the use of alfalfa in the orchard and from an article of his this is quoted:

"Whatever may have been believed or imagined as to the uncongeniality of trees and alfalfa the theory is destined to an early downfall. The evidence is at hand now 
to show that not only is alfalfa not a detriment when grown among fruit trees, but in many ways it is a positive benefit, lending itself and its properties to the advantage of the trees.

"On land where moisture can be found at from six to ten feet from the surface, the congeniality of the alfalfa plant and the apple tree becomes apparent. Both need plenty of water the first year, a little less the second, and very little or none thereafter.

"After trees become old enough to bear and need all the land between them, and that fertilized and renovated, alfalfa may be used as a food gatherer and distributer. It pushes down into the lower strata, bringing up mineral elements, captures nitrogen from the air through its root processes, and brings all together near the surface, thus giving to the trees the food they need to fill up and mature fruit. Nor is this all. The alfalfa falling on the ground makes a soft cover upon which windfalls may drop with little bruising; it so occupies the soil as to allow no foul growth to creep in; it does away with the work of weeding or cultivating, and keeps the surface cool and porous, furnishing excellent pasture for hogs if the trees are protected. It would be possible, of course, in this system of co-operation between fruit trees and alfalfa to secure a crop of hay or seed during the off years for fruit, but whether this would prove profitable may be questioned. Orchards growing under the conditions described have produced magnificent crops of fruit which, for size, quality and coloring, is seldom equaled." 


\section{SOME ALFALFA "MUSTS" AND "DON"TS"}

A Knox county, Ohio, man, in expressing himself as to some of the requisites for success with alfalfa, as observed from his viewpoint has this to say:

"I have known about alfalfa from boyhood; been familiar with it for thirty years, and have grown it successfully on many soils, from a stiff clay, upwards. The failures which I have seen have been accounted for by the non-performance of some of the essentials. There are certain 'musts', not 'shoulds,' to be observed to secure success. Here they are from my experience:

"First of all the seed must be pure, of high germinating power, and of the highest possible vitality. If I doubted my own proficiency in these determinations, I would consult the nearest experiment station. I have had occasion to consult experiment stations, from New Jersey to Wisconsin, on various subjects, and in every instance have met with prompt and valuable-and sympathetic-assistance.

"The soil must have lime; either as one of its natural constituents, or lime must be added. If the soil is deficient, then the lime must be incorporated with the soil some months before seeding.

"The land must have efficient drainage, either natural, or, as in the case of clay and heavy clay loams, artificial.

"The land must be fertile to a depth of at least nine inches. Beyond that depth the taproot in its search for water will take care of itself."

Another writer, impressed by practices he regards as reprehensible, enumerates them as follows: 
"Don't sow any nurse crop.

"Don't sow on freshly plowed land, no matter how carefully prepared.

"Don't let weeds or grass grow over six inches high without clipping.

“Don't clip or mow when wet with rain or dew.

"Don't let alfalfa stand if turning yellow; cut it.

"Don't sow old seed.

"Don't sow less than twenty-five pounds per acre, onehalf each way.

"Don't sow on land that will not raise 250 bushels of potatoes per ac

"Don't sow twenty-five acres at first, sow fiv

“Don't pasture it.

"Don't put any of the rotten manure anywhere but on your alfalfa plot.

“Don't depend on 'culture cakes' or soil from some distant field.

"Don't let water ever stand on it.

"Don't let it go if a thin stand, but disk in more seed; don't be afraid you will kill it.

"Don't replow the land; disk it.

"Don't wait for it to stool; it never does.

"Don't try to cut for hay until the alfalfa takes the field.

"Don't sow on any land not well underdrained.

"Don't leave your land rough; use a roller or a plank float to level and smooth :-

"Don't give up." 


\section{ALFILERILLA OR "ALFTLARIA"}

(Erodium citcutarium.)

On account of the similarity of its name to that of alfalfa and the possibility of the two plants being confused in the minds of those not acquainted with them, it is proper to make mention here of the plant referred to in the caption above. It is not generally known nor widely distributed, and has as yet its principal habitat in semi-arid parts of the southwestern United States. The Century Dictionary calls it Pin-clover or Pin-grass, and classifies it with the Geranium family. Webster's Dictionary speaks of it as a weed in California. It is an annual and seeds profusely; a few seeds scattered over quite a large area result in a thorough seeding the second year. A stockman in Arizona writes that it will grow on any kind of soil except alkali; that it was introcitced from Australia by sheep carrying it in their wool. It is a southern plant and should not be seeded largely north of the northern line of Oklahoma until tested by the experiment stations. It should not be confused with alfalfa, as it is entirely dissimilar and not related.

In discussing this plant an Arizona editor writes the following :

"It is by no means a new or experimental crop, for it was the main reliance of Arizona stockmen during ten years of drouth. We suppose that the experiment stations in the West have given it little attention because it is as well known as alfalfa here, and millions of acres are covered with it in various portions of the Territory. 
"We know from many years experience that alfilaria will thrive and keep stock in good condition where no grass roots would live through one of the dry seasons. It is peculiarly adapted to the poorer soils in western Kansas, Nebraska, the Texas Panhandle, New Mexico, and portions of the northern section of Mexico.

"Its merits are that it will grow in seasons so dry that other forage fails and that it will keep cattle in better health and condition as to flesh and growth than anything else we can grow in Arizona, not excepting alfalfa. In the spring cattle and horses will go miles to find it and it is better than 'condition powders' to put them in condition for summer growth.

"What it will do on other classes of soil, under excess of moisture, is a matter of experiment; but where it is needed most-as above outlined, there is nothing that has ever been tested under these adverse conditions which can compare with alfilaria. This will be certified to by every ranchman and cattleman in this section of Arizona."

\section{MEASURING HAY IN THE STACK}

Some method of arriving at the quantity in a stack, rick, or mow without weighing it, is, at one time and another, found desirable by everyone who has to do with loose hay. There can be no absolute rule laid down for this because of the varying compactness the hay attains under differing conditions of coarseness or fineness, moisture, length of time stacked or stored and the weight which has rested upon it.

For prairie hay stacked not less than thirty days a cube seven feet square (343 cubic feet) is not uncom- 
monly bought or sold as a ton; yet seven-and-a-half feet square, or 422 cubic feet, are often made the basis of estimating. The author is advised that in the alfalfa growing districts of the Yellowstone valley it is the general custom to accept as a ton 422 cubic feet of alfalfa hay if it has settled thirty days or more. Also that haymen find there is a noticeable variation between the different cuttings. The first cutting will fall short of actual weight more than the second, while the third cutting will hold up in weight, and sometimes overrun. Prof. E. A. Burnett, of the Nebraska experiment station, thinks an eight-foot cube, or 512 cubic feet, a fair figure.

Professor Ten Eyck says:

"The rules for measuring hay in the stack will vary according to the length of time the hay has been stacked and the kind and quality of the hay, and also according to the character of the stack. With alfalfa or prairie hay which has been stacked for thirty days it is usual to compute an eight-foot cube or 512 cubic feet as a ton. When the hay has been stacked five or six months, usually a seven-and-a-half-foot cube or 422 cubic feet is calculated for a ton. In old stacks which have been stacked a year or more a seven-foot cube or 343 cubic feet is allowed for a ton.

"There are different methods of measuring a stack, depending upon its shape and also its size. For a long stack or rick the usual method is to throw a line over the stack measuring the distance (in two or three places, and use the average) from the bottom on one side to the bottom on the other; add to this the average width of the stack, divide this sum by four (which equals one side 
of the square) and multiply the quotient by itself and this product by the length of the stack; this will give the number of cubic feet in the stack, which may be divided by 5 I 2,422 , or 343 in order to find the number of tons. For small, low ricks the rule is to subtract the width from the 'over,' divide by 2 , multiply by the width and multiply the product by the length, dividing the result by the number of cubic feet in a ton.

"There is no established rule for measuring round stacks, but this one will approximate the contents of one of the ordinary conical form: Find the circumference at or above the base or 'bulge' at a height that will average the base from there to the ground, find the vertical height of the measured circumference from the ground and the slant height from the circumference to the top of the stack. Multiply the circumference by itself and divide by 100 and multiply by 8 , then multiply the result by the height of the base plus one-third of the slant height of top. The hay in a round is necessarily less compact than in a rectangular stack, hence a greater number of feet should be allowed for a ton; with well settled hay, probably 5 I2 feet.

"The rules given may also be used in measuring any kind of hay, sorghum or Kafir-fodder in the stack. However, for sorghum or Kafir-fodder only approximate results can be procured by stack measurements because the fodder is apt to vary greatly in weight, according to the moisture it contains." 


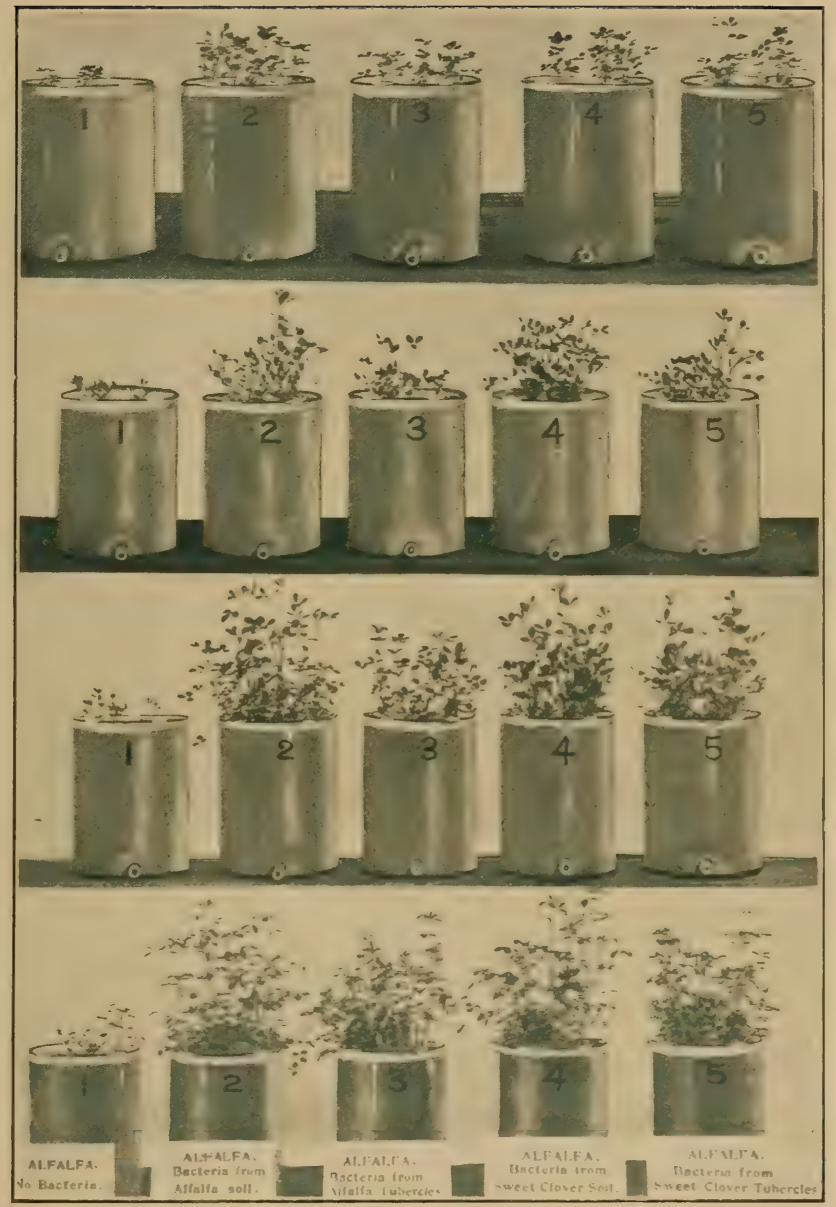

Pot Culture Experiments at University of Illinois

showing effect produced upon growth of alfalfa by nitrogen-gathering bacteria obtained from older alfalfa and sweet clover. Reading from top to bottom the four photographs were made five, six, seven and eight weeks, respectively, from time of planting. 


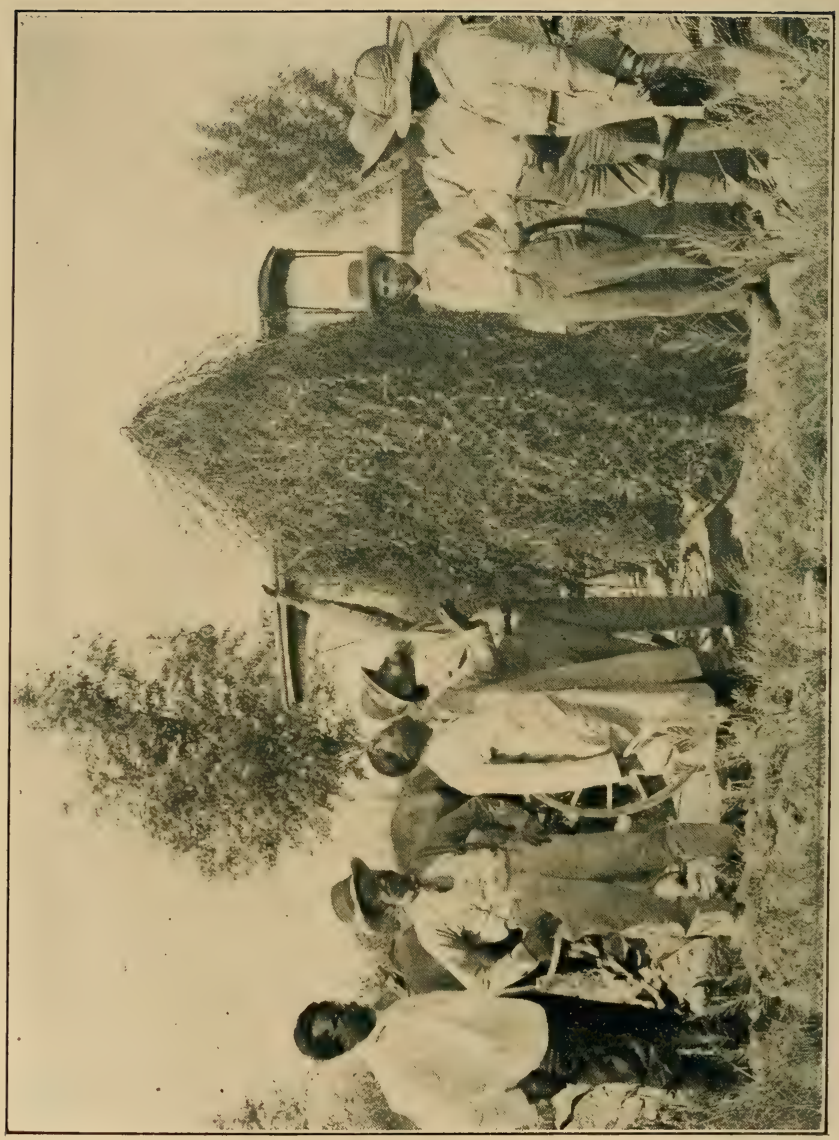

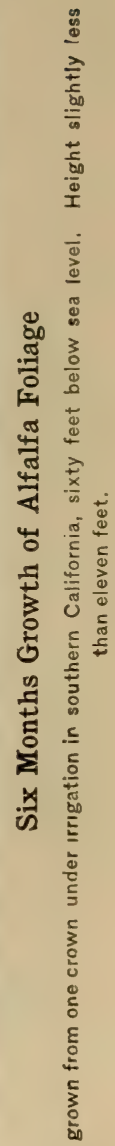


CHAPTER XXVI.

\section{Practical Experiences of Alfalfa Growers in the United States of America}

\section{ALABAMA}

Prof. J. F. Duggar, Director Alabama experiment station.-Alfalfa is grown in Alabama with entire success on the lime soil of the central prairie region of the state. This is a strip of land from Io to 20 miles wide, extending southeast and northwest almost across the state and into Mississippi. Beginning near Union Springs, this prairie passes near Montgomery, Selma, Demopolis, Greensboro and northwestward towards Columbus, Miss. On the prairie lands in this area alfalfa affords from three to six cuttings per year, usually four, and the yield is from three to six tons per acre. Irrigation is not practiced. The seed is sown either in September or in the early part of March, usually from 20 to 24 pounds per acre. Almost a full crop is secured the first year from fall seeding, but only from one-third to twothirds of a full crop is secured the first year from sowing seed in March. It is not customary on this soil to use fertilizer on alfalfa, but an application of even a light coat of stable manure immensely increases the yield on the poor spots. Failure has generally attended attempts to 
grow alfalfa on non-calcareous or sandy soils, though under favorable conditions, with liberal manuring and constant warfare against crab-grass, it occasionally succeeds. In Bulletin No. I27 of the Alabama experiment station the results in alfalfa growing are summarized as follows: Usually the best crop to precede spring sown alfalfa is cotton, especially if cotton follows melilotus (Sweet clover). The best crop to prepare the land for fall sown alfalfa is cowpeas, sown very thickly. Farmers have found that alfalfa thrives when sown on Johnson grass meadows, holding its own, at least for the first few years, against this aggressive grass. Dodder, a yellow threadlike growth, is a serious enemy of alfalfa. One of the remedies consists in mowing and burning. Seed merchants often pass alfalfa seed through a machine which is claimed to remove the dodder seed. On sandy upland soils at Auburn, alfalfa has not afforded very profitable yields. On such soils it requires heavy applications of lime or barnyard manure, and it is believed that more profitable use can be made of manure. At Auburn neither nitrate of soda nor cottonseed meal very greatly increased the yield of alfalfa that was properly stocked with root tubercles. Acid phosphate and potash fertilizers are considered indispensable here, and generally advisable on sandy or other soils not rich in lime. Inoculation with soil from old fields of either alfalfa or Bur clover greatly increases the yields of alfalfa growing on sandy land. The germ that causes tubercles to develop on Sweet clover also causes tubercles to develop on the roots of alfalfa. Hence artificial inoculation of alfalfa is not necessary when it is grown on prairie land that has recently 
borne a crop of melilotus. Artificiai inoculation of $\mathrm{a}_{1-}$ falfa is probably advisable even for prairie soils when it is uncertain whether either the melilotus or alfalfa germs are present in great numbers. In regions in Alabama where neither alfalfa, melilotus, nor Bur clover is extensively grown, inoculation of alfalfa is advisable. For this purpose one may use soil from old fields of either of these plants or inoculating material prepared in the laboratory.

\section{ARIZONA}

John Blake, Graham county.-Alfalfa is the king of forage plants here. It will stand considerable dry weather and live, but it will not yield profitably unless irrigated, or on naturally damp ground. It does not do well here on clay soil, and if clay subsoil is near the surface it is likely to dry out, unless watered. I have grown alfalfa for eight years on I75 acres, first and second bottom, and upland, with sandy and loam soils, with small patches of clay and various subsoils; the alluvial bottoms are usually loam of different depths, underlaid with sand and gravel; the next bottom more clayey, with quicksand about I3 feet deep and gravel about 30 feet below the surface. On first bottoms, well water is reached at a depth of 3 to 8 feet, the soil being dry on the surface only; on the upland, the soil is dry for 20 to 30 feet, or until water is reached. Land intended for alfalfa had best be cultivated in other crops for two or three years, thus insuring the killing off of native brush and grass, and their roots; then it must be laid off in "lands" of various widths, according to the slope, each land being leveled uniformly and bordered to hold water. Seed may be sown in August, September, 
and October; in fact, all the year, except from the middle of April to the first of August, when it is so hot and dry here. The quantity of seed used varies with the preparation, from 12 to 20 pounds per acre. Sow with a "Cahoon" seeder, and cover with a brush or light harrow. It is generally sown here with barley, wheat, or oats. The grain is cut early for hay, or ripened and headed, in which case the stubble and alfalfa are cut immediately afterward and hauled off. The ground is then irrigated, and if it has previously been foul, there will be plenty of weeds. Another cutting in good time will usually eradicate these. The plant will not winterkill here if old enough to have four leaves before frost. We irrigate abundantly, from the Gila river, in winter and spring, filling up the soil and thus making less need for water during the hot, dry period. Irrigate after each crop is taken off, and some land is benefited by two irrigations for each cutting. The quantity of water needed depends on the character of the soil and subsoil; some on the bottoms needs but little after the first year, and it is a good plan, if the subsoil is open, to let the plant go without artificial water after it has a good start, as it sends its roots down to moisture or water, if at a reasonable depth below; it will then thrive on much less water, and the crop will be more nutritious. If one is raising hay for quantity, of course this does not apply. The four crops per season yield on an average: First, $I \frac{1}{2}$ to 2 tons; second and third, $\mathrm{I} / 4$ to 4 ; fourth, three-fourths to one ton. If cutting for quantity, mow when fairly in bloom; if for feeding, when the seed has formed. I have raised no seed, but the crop used for that purpose is usually the sec- 
ond, and it is not irrigated. The time required for curing depends on the stage at which the hay is cut, the dryness of the ground, etc.; a good rule is to rake as soon as the rake will take it up clean, and let it cure in windrows or cocks. I use a "Landen" single pole stacker, with slings, which puts the hay, just as it laid on the wagon, in the center of the stack. The seed, threshed on an ordinary thresher, contains straw and chaff, which are easily taken out by running through ordinary wire screen-door netting, and then it is suitable for the "Cahoon" seeder. On land worth $\$ 40$ per acre, the hay in the stack costs $\$ 3$ per ton. Baling costs $\$ 2$ per ton, the best size being Ioo or I 50 pounds in weight. Size does not affect the keeping quality of the hay. The hay has sold here for $\$ 6$ to $\$ 12$, averaging about $\$ 7.50$, and the seed sold here last year for 9 cents per pound. I do not think the straw is of much value. Alfalfa will yield abundantly the second year, and, if harrowed with a good harrow, digging up the soil, it will yield for a very long period. Mine, which is Io years old, looks as well as it did when two years old. To rid land of it, it would be well to plow when dry, then cross plow later on. On naturally damp bottom it is hard to kill. Cattle pastured on rank alfalfa in the spring are liable to bloat.

Thomas C. Graham, Pinal county.-Though I have been familiar with alfalfa growing for Io years, my first experience on a large scale was five years ago, when I seeded the Kenilworth farms, containing 900 acres. I was successful in securing a good stand on the entire tract. Some of the land is upland, with sandy loam soil, washed from the mountains, and various subsoils, hard- 
pan being, in places, only ro inches below the surface; the remainder of the land is low, or bottom, with adobe soil. Well water is found at a depth of 95 feet, and the soil is dry from the surface to within a few feet of the water stratum. Before sowing, the surface soil is plowed and harrowed thoroughly; 20 pounds of seed is used to the acre, and covered not more than one-half inch deep. In our section, the best time for seeding is in September and October, and there is nodanger from the winter frost. During the first season we cut twice or three times, to destroy all weeds, and obtain $2 \frac{1}{2}$ or 3 tons of hay per acre, but have never been able to get a paying crop of seed from the first season's cutting. For irrigation, we obtain water from the Gila and Salt rivers, but in some sections of our country water is pumped from wells by steam pumps. It has not been found practicable to lift the water from a greater depth than 50 feet for this purpose. The first year, as the land is very dry, it requires twice the quantity of water that is needed the second year and after. We flood the alfalfa five or six times a yearonce in the fall, in the spring, and after each cutting, using water enough to cover the land to a depth of about one inch. We have no rain to amount to anything here, and depend entirely on irrigation. I think the ground should be prepared in the fall, and seeded in February or March as, if seeded in the fall, the young plants might be liable to injury from frost. In all cases, the soil should be thoroughly prepared, and the seed not covered more than one-half inch deep. It is not uncommon to harvest six crops of alfalfa in a single season, and its feeding qualities are unequaled for cattle, horses, or swine. It is 
found, by careful tests, that alfalfa is 45 per cent better than clover and 65 per cent better than timothy for feeding farm animals. In my opinion, there is no other hay that will equal properly cured alfalfa. That grown without irrigation is much better, as it contains less sap and is not so stalky. The threshed hay is splendid feed for milch cows, and is sold here for the same price brought by the hay cut earlier. Last season I pastured 65 head of hogs on Io acres of alfalfa, and they did well. In my experience, it is far better than clover, from the fact that it cannot be dislodged, the roots penetrating to a depth of Io to 20 feet. The pasturage is profitable and satisfactory for sheep and horses, and 45 per cent better for cattle than clover. They will bloat sometimes, but if properly handled there is little danger. The best preventive is to not allow the cattle to become too hungry. We get, on an average, three cuttings a year, averaging I to $I / 2$ tons per acre each, and have pasture for five or six months. For hay, we mow when in full bloom, rake as soon as possible, and let stand in windrows until the stems are about half dry; then put in the cock for two days, and stack in large ricks of about 80 to Ioo tons each. If put up damp or green, it will mold. The seed is harvested, usually, from the second crop, when the pods turn black and can be shelled out by rubbing in the hand. It is cut, raked in windrows, and allowed to stand until thoroughly dry. I used, this season, a J. I. Case separator, and threshed and cleaned 6000 pounds of seed in three days. An ordinary yield is Ioo pounds to the acre, and the cost of cutting and threshing is 3 cents a pound. The total cost of the hay in the stack is about 
$\$ 3$ a ton on $\$ 50$ land, with I 5 cents an acre for irrigation. The average selling price for hay is $\$ 4$ a ton, and for seed, Io cents a pound. With proper care, alfalfa will last time without end, and improve each year, and it is difficult to kill it out, as it makes more or less seed every crop. An open soil. free from hardpan, is best for it.

\section{CALIFORNIA}

Henry Miller, San Mateo county.-Since I871, we have gradually increased our acreage of alfalfa, until we now have about 20,000 acres. This is on reclaimed swamp and upland, under a complete system of irrigation, with the exception of a little light, loamy soil, with water near the surface and no irrigation. On the latter ground the plant is short-lived, on account of the gophers. The depth at which well water is found varies from Io to 40 feet, and, with irrigation, it is immaterial whether the soil is naturally moist or dry. The preparation for seeding consists of deep plowing and cross plowing, and the depth for planting. is not over two or three inches. For light, loamy soils, I 2 pounds of seed to the acre is ample, while for hard, rough, new land, from I6 to 20 pounds is required to insure a good stand. Seeding may be done here after the cold season, and when danger of heavy frost is past, but in time to take advantage of the spring rains, which are very essential. During the first season, the weeds should be mowed as they require it, without regard to returns of alfalfa, and after they are subdued it is well to let the first year's growth go to seed and allow it to be trampled into the soil by young stock, but if there is a full stand this is not necessary. We irri- 
gate from streams, applying water as soon as the spring opens and every time a crop is cut, the quantity of water needed depending on the quality of the soil. Drainage is very necessary, especially when irrigation is done in warm weather. After the first irrigation, less water is needed at an application than at first. Winterkilling seems to be effectually prevented by watering in the fall. Alfalfa will attain its best state in three or four years, and its condition after that will depend upon its treatment. We put stock on our land generally after the first and second growth is cut, and the only rest the land receives is when it is being irrigated. After hay has been cut for several years, we harrow in the spring with a heavy harrow or disk cutter, and take the opportunity to reseed that which shows lack of vigor. The more sun and the less shade there is, the better the growth and the more satisfactory the yield. We find it more difficult to get a stand than to get rid of it; but, in some instances, where we have wanted the land for orchard, vegetables, or root crops, we found several plowings would destroy it. Without irrigation, we have not found the crop very profitable, but there are a few favored spots in the state where it can be grown without water; but when we plant we usually select such land as can be put under a perfect system of irrigation before using. Longevity of the plant depends on treatment and on the nature of the soil. On heavy adobe soil it will not live and thrive as long as on loamy soil, and on sandy, light soil it will be of short duration without constant and judicious irrigation. After the first season, we make two cuttings a year, and consider two tons to the acre each time a good yield. For 
hay, we cut when the first crop is moderately ripe-say nearly in full bloom; the second crop and any later ones are cut when the bloom first shows; otherwise the lower leaves will drop off. The first crop is generally preferable for seed, provided bitterflies and other insects have not injured the bloom, as they often do. If the second crop is used for seed, it should ripen longer than the first. The crop for seed is mowed, windrowed as soon as possible, allowed to dry in that state, gathered with a hand fork, loaded on hay wagons, and put in stack as gently as possible. We find a good crop of seed a rare thing, but use the ordinary threshing outfit, and turn out 800 to IOoo pounds a day, in rare instances double that quantity, with a cost for threshing and cleaning of about 5 cents a pound. The hay we never put in barns, but stack in small, narrow ricks, to a void danger of heating, endeavoring to get it in the rick as dry as possible, gathering in the forenoons to avoid shelling. When we use our own press and men, the cost of baling does not exceed \$I per ton. The weight of the bale depends on the kind of press used. An average, handy bale weighs about I5O to I75 pounds, and we never have any trouble about the hay keeping perfectly in bales of that size. The average price per ton for hay in our San Francisco market is about $\$ 8$ to $\$$ IO; of seed, by the ton, 8 to $12 \mathrm{I} / 2$ cents a pound, Io cents a pound being about the usual average price. For feeding farm animals, good, well-cured alfalfa hay is better than clover. For milch stock, especially, we consider it fully as good as any other hay. We find but little difference between the straw and the hay, and while all stock like the straw better, there is no doubt that the hay 
contains the more nutriment. Like all rank growths, alfalfa will produce double under irrigation, and the quantity will greatly overbalance any possible improvement in quality without irrigation, for I have found little difference between that grown by irrigation and under natural moisture. For horses, there is no pasture better than the alfalfa; for sheep and cattle, it sometimes works injury by way of bloat, caused by too rapid grazing, especially when there is dew, thin cattle and young stock being most liable. Cattle in high condition and cows suckling or well forward in calf do not bloat. As preventive of the bloat, hay should be kept in the pasture where the stock can run to it, and a good supply of salt in troughs to which they have constant access. The plant will not stand trampling by stock unless the surface of the ground be entirely dry, and we do not allow sheep or cattle on the fields during certain stages of growth nor during certain states of the weather. We consider this pasture better than clover for swine, especially when the ground has a smooth surface, but if the soil is of a sandy nature, and allowed to dry, it is not so good. The capacity per acre depends on the nature of the soil, and the gain in weight made by the hogs depends on the breed and on the comfort they have. We can raise hogs on alfalfa, and by feeding them two months on grain (say barley, wheat, or Egyptian corn) they will average, when Io months old, $25^{\circ}$ pounds, gross.

J. B. De Jarnette, Colusa county.-I have had I I years' experience with alfalfa, and have about Ioo acres bordering on the Sacramento river. The soil ranges in depth from Io to 20 feet, and rests on a clay subsoil, while 
water is reached at a depth of from 12 to 20 feet. In sinking two wells on my place, the soil was found as follows: First 12 feet, decomposed vegetable matter; 4 feet of quicksand; 4 feet of clay loam; 4 feet of hardpan; I6 feet of yellow clay; 6 feet of hardpan; 2 feet of black sand, and at 48 feet, coarse gravel. The ground should be thoroughly pulverized-the finer the better-after plowing at least 12 inches deep, and then seeded with not less than 25 pounds of seed to the acre. I have had the best results from sowing in the early fall, immediately after the first rains, using the "Gem" seeder, harrowing in with very light harrow, and rolling the ground well. The first crop is usually quite weedy, and of little value, but the second is better, producing about $\mathrm{I} / 2$ tons of hay to the acre, if the stand is good. Stock of all kinds should be kept off the first year. There is no danger here of winterkilling, and by the second year the full yield is realized. The length of time the plant continues vigorous depends on the treatment. If pastured extensively, it will require to be reseeded in from five to eight years; but otherwise it may go considerably longer. I invariably obtain three crops a year, averaging per acre for the first $2 \mathrm{I} / 2$, and for the others $I / 2$ to 2 tons. I irrigate only in the winter, when the river is bank full and I can turn in water from it. Alfalfa produces the best results with irrigation after each cutting, and in that case there are five to seven cuttings obtainable, where with winter flooding I can secure the three only. I mow for hay as soon as the bloom begins to develop, raking in the afternoon following the morning cutting, commence hauling about the third day after, and then put in the barn with plenty of 
salt. The third crop is given the preference for seed, ana is harvested when the plant is well matured. I let it cure in the windrows and haul to the thresher, handling as little as possible. The common yield of seed is from Ioo pounds up, according to the stand. The cost of my hay, on land worth \$IOo to \$1 50 per acre, does not exceed \$2 per ton, and it sells for from $\$ 5$ to $\$ 8$, while seed brings from 8 to 16 cents per pound. The hay after threshing is of but little value. The pasture is unquestionably the most profitable I have ever had any experience with, supporting more stock of any kind to the acre than any other forage plant. In early spring, cattle are liable to bloat on the rank alfalfa, but after the first of June I have had no trouble. There is no special difficulty in ridding land of the plant, and it is undoubtedly as good for fertilizing as Red clover.

\section{COLORADO}

Jacob Downing, Arapahoe county.-I introduced alfalfa into Colorado in 1862 , and have between 500 and 700 acres. It is on upland, clay, sandy and loam soil, with some adobe subsoil, but mostly sandy loam; it is generally dry to sand rock, and then it is necessary to drill 50 to 100 feet to get water. The plant will not thrive where there is hardpan, but will grow in any soil that is dry. Unlike most other forage plants it derives considerable nourishment from the air and water, though too much moisture will kill it. After deep plowing and thorough pulverizing of the soil, the land should be scraped thoroughly smooth, as this cannot be done after sowing, and is needed to make the mower work smoothly. I sow about 25 pounds to the acre, 
drilling in about two inches deep, $12 \frac{1}{2}$ pounds one way, and the other $121 / 2$ pounds across it, thus making an even stand. Prefer to sow in the spring, early. After the plant is eight inches high, it may be cut and used for feed, but is not very good. After this there will be no weeds. It matures in three years, and after that is good for seed. I have seen, near the city of Mexico, fields of alfalfa 300 years old that had been constantly cropped and never reseeded. It will last Iooo years, and possibly forever. Irrigate from streams, as is required; when there is a great deal of heat and wind, probably three times. The water must not run too long, or the plant will be killed, and the land should be kept as dry as possible during the winter, particularly in cold climates, as on wet soil alfalfa winterkills. Well water is better than the stream, provided it is pumped into a reservoir and allowed to get warm. Water is brought from the streams by ditches. Less water can be used the first year than after the plant is matured. I am five miles west of Denver, and 500 feet above the city, in warm valleys. With plenty of water, I can obtain three cuttings a year. Have raised as much as $3 \frac{1}{2}$ tons to the acre at one cutting, and my highest yield of seed per acre has been nine bushels. Hay is cut when the plant is in bloom, cured until it is dry to the touch of the hand. Stacking by hand makes the best hay, as machinery is likely to pack it in bunches, causing it to heat and become dusty. Hay in the stack costs about $\$ 1.50$ per ton. Baling costs $\$ 2$ per ton; Ioo-pound bales are well esteemed, but it is probable that large bales keep better than small, if properly cured. The seed pod assumes the form of a cornucopia, and, when the seed is 
ripe, it is of a rich prown or mahogany color. The first crop is preferable for seed, and should be cut and stacked as the hay is. It can be left and threshed when most convenient, but the longer it remains in the stack the more easily its threshes. The ordinary threshing machine does for the alfalfa, but the seed must be fanned to be marketable. Six bushels is a common yield, and the cost of threshing and cleaning is probably 25 cents per bushel. The price of hay has ranged from $\$ 5$ to $\$ I_{5}$ per ton, and of seed, from 8 to 20 cents per pound. The straw has almost no value, as it is cut up very fine, and can be used only where it is threshed; if fed there, it is very fattening. For feeding horses for slow work, the hay is better than clover or timothy. For fattening purposes, it is the best in the world, for, while the animal lays on fat, it is never feverish, but always healthy. For pasturing cattle and swine, alfalfa is superior to anything else, and, after it is mown, it makes very excellent feed for horses and sheep. If the alfalfa is wet, ruminants pastured on it bloat and die very quickly. It is not properly a pasture plant, and such animals should be kept away from it, but the hay, properly cured, is superior to any other food raised for fattening purposes. There is no difficulty in ridding land of the plant, as a good team and sharp plow will cut it out without any trouble. I have plowed fields of alfalfa under and put in oats, obtaining three or four times the usual yield, and have known of 50 bushels of wheat to the acre on broken alfalfa land.

L. W. Markham, Prowers county.-I have had four years' experience with alfalfa. Have under my charge 500 acres. It is on both second bottom and upland; part 
has clay subsoil, other dark loam, and all has more or less sand. Water is reached at from Io to 40 feet, and on land not irrigated the soil is dry all the way down to the water veins. The preferred time for sowing is either April I or August I. Have as good success right on the sod as on old land. If to raise seed only, Io pounds is sufficient to the acre; for hay, 20 pounds is not too much. Seed not more than two inches deep. About June I 5 cut weeds and tops of young alfalfa, and then irrigate well, and you get one-half to one ton of hay in September. It is best to not try for seed the first year, but give all the strength to the roots. It does not winterkill here. We irrigate from the Arkansas river, and the number of irrigations depends on the soil. The first year requires twice as much water as later ones. Usually three applications are needed: in early spring, mid-summer, and late fall. $I$ have $I 60$ acres not irrigated for three years. We have three cuttings, yielding $\mathrm{I} / 2$ to 2 tons per acre each. Cut for hay just when coming into full bloom, and stack in the field-never in barn-in long ricks, I2 feet wide by 80 to 120 feet long. It will not heat in the stack. Let all pods become dark brown or black before cutting for seed. The second crop is preferable, unless there is a large acreage, when I take one-half the first crop and onehalf the second, in order to help the farmer out with work. Have men follow the machine closely, and cock up, to remain four or five days before stacking. Never cut for seed with a mowing machine, as you will lose onethird of the crop in trying to gather it. The cost of alfalfa in the stack is not over $\$ 2$ at the outside. To bale - preferably in 8o-pound bales-costs $\$ 1.50$ per ton. An 
ordinary yield of seed is five bushels per acre. The cost for threshing is 60 cents per bushel. There is a special alfalfa huller, as even the ordinary clover huller is not a success. For a number of years the average price paid the farmer for alfalfa seed has been $\$ 4.50$ per bushel, and hay in the stack has sold for $\$ 3.50$ to $\$ 5$. For feeding farm animals, alfalfa hay is far more valuable than timothy or clover. Horses will work and do well the year round on the first cutting of alfalfa, and no grain whatever. The pasturage for hogs and cattle is far better than clover, and is profitable and satisfactory for horses and sheep. I have 250 hogs now, and raise them to weigh 200 pounds on green alfalfa alone; turn the sows in the lot in early spring; they raise their young, and I never bother them for eight months at a time, as they have plenty of alfalfa and water. Put cattle on the pasture in early spring and let them run, and few, if any, will bloat; but when they are not used to it, they eat too fast, or too much, and bloat. The hay is not so good after it is threshed as that cut earlier for hay alone, but the straw sells readily at $\$ 1.50$ in the stack. The stand gets better every year for hay, and I know of fields in old Mexico 6o years old that have never been reseeded. There is no difficulty in ridding land of the plant if it is plowed under eight inches deep while green. It makes far better green manure than does red clover. On the same quarter section, wheat grown on old wheat land produced 20 bushels per acre, and that on broken alfalfa land 50 bushels per acre.

\section{CONNECTICUT}

Dr. E. H. Jenkins, Director Connecticut experiment station.-Alfalfa has been tried in a haphazard way in 
Connecticut for many years and scattered plants and colonies may often be seen in fence cornersand headlands. Within five years, however, some farmers under direction of the agricultural station at New Haven, or on their own initiative, have made more careful experiments and while failures are numerous, there are at present a number of small areas well establisined, yielding three or four cuttings yearly and highly valued by their owners. On the farm of C. W. Beach of West Hartford, F. H. Stadmueller had for seven years a considerable field of alfalfa which yielded well and was used as a soiling crop. Mr. Barnard of North Haven, after repeated failures, has a fine field and feeds it to both cows and poultry. The Gaylord Farm sanatorium at Wallingford, John Matthies of New Milford and others might be cited as successful growers of alfalfa. It does well on a variety of soils with us. Liming heavily, I 500 to 2000 pounds per acre, is a necessity. Some form of inoculation of the soil is generally required and clean, well-tilled land. Weeds are the worst enemy of the newly seeded alfalfa and easily smother the crop. For that reason we prefer August seeding, using at least 30 pounds of clean, fresh seed. It will pay to fallow the land, in order to kill the weeds before seeding down. Thin spots cannot be successfully patched by seeding later. Great care in preparing the land pays with a permanent crop like alfalfa.

\section{DELAWARE}

Dr. Arthur T. Neale, Director Delaware experiment station.-Twenty years ago, I drilled alfalfa in rows $\mathrm{I} 8$ inches apart, and cultivated at intervals of ten days until the crop occupied the ground, seeding late in March, say 
the 28th. The first cutting of nearly 8 tons of green forage per acre was made nine weeks later. Thereafter four additional cuttings were made that season, resulting in a total yield of $2 \mathrm{I}$ tons of green forage per acre. This plot remained in good profit, all told, for five years. An adjoining plot seeded broadcast, grew into a weed crop the first year, but during four succeeding years was in every respect the equal of its neighbor, the drilled plot. Twenty similar experiments made during that year in as many other sections of the state failed utterly. The dates of seeding were in every instance subsequent to March 28, but followed each other as rapidly as men could travel from point to point, drilling the seed on well and previously prepared soil. Two years later nine similar failures resulted from spring seedings. Late summer is now the time most frequently selected for alfalfa seedings, but success is by no means invariably attained even then. Liming has been of service in one five-acre test conducted in Kent county, by W. H. Dickson in co-operation with this station. The third trial within four consecutive years appears at present to be a complete success. The first seeding gave a satisfactory stand, but the plants died late in the following spring. The ground was limed that summer, after thorough preparation of the seedbed. Nitro-cultures from federal sources were used upon portions of the seed, and Iooo pounds of soil per acre from a successful alfalfa plantation were applied to the other areas. This second seeding also failed. The five-acre plot was then plowed, wheat was drilled and a fair crop resulted. The wheat was harvested, lime was again used after the seedbed had been prepared, and alfalfa seed sown 
as usual. The crop this year has exceeded anticipations. The check strip, to which no lime whatever has been applied, but upon which nitro-cultures were used, carries no crop. It will be disked after the third cutting of alfalfa this year, well limed and again seeded.

\section{GEORGIA}

Prof. R. J. Redding, Director Georgia experiment station. - This station has successfully cultivated alfalfa for 12 years, and we have never found it necessary to inoculate when we have sown the seed on rich, well prepared land. The plants at once became supplied with nitrogen tubercles and grew as luxuriantly as might be expected from the quality of the land. Our practice is to fertilize annually in January or February by sowing from 800 to Iooo pounds of acid phosphate and one-fourth as much muriate of potash per acre. We run a cutaway harrow over the alfalfa two or three times in different directions. We then use a smoothing harrow and finally a heavy roller. This puts the land in good shape for the mowing machine and at the same time destroys weeds that come up during the fall and early winter. I believe that it is not desirable to continue land in alfalfa more than six or eight years, because of the impossibility of preventing infestation of weeds to such extent as to very greatly diminish the yield of alfalfa. We have a plot growing, that was sown about April Io, which seems to be as favorable a time as any, provided there shall be one or two good rains to give the young plants a start. The main factors in success are: First, a deep, well-prepared and well-drained soil, made very rich; and second, good seed, carefully sown and repeated mowings at the proper time. 


\section{ФАННО}

H. W. Kiefer, Bingham county.-I have grown alfalfa in Idaho, under irrigation, for I2 years. Have 40 acres on second bottom, heavy clay soil for 12 feet. This subsoil pulverizes by the action of the air, and will produce a good crop of small grain. Water 1 s reached at Ioo feet. The $\mathrm{I} 2$ feet of clay is dry; the gravel and sand below are more or less moist till water is reached. Land having produced two successive crops of small grain is preferred for alfalfa. Sow 20 pounds, in the spring, and cover lightly with harrow, brush, or drag, or roll. The plants should be vigorous enough to choke out weeds. Amount of hay obtained the first year is governed by conditions and treatment. When sudden freezing and thawing occur, it is liable to winterkill. The frequency of our irrigation is governed by the rainfall, but is usually done when the ground is dry, without regard to stage of growth, allowing the water to run until the soil is wet the depth of a spade; usually average two irrigations to each cutting. Our supply of water comes from Snake river and tributaries, which furnish sufficient for the Snake river valley. Have noticed no difference in amount of water required during first or later years, except as affected by the amount of rainfall. We get three cuttings, averaging about five tons for the season, cutting for hay when in bloom, and for seed when seed is matured, which generally requires the entire season to mature in this locality. The seed crop should be handled as little as possible, to avoid loss of seed. Alfalfa should cure at least two days, and, if dry, will not mold in stack. The cost of alfalfa hay, if irrigated, is about \$2 per ton. 
Cost of baling, $\$ 1.75$ per ton, in bales weighing 75 to Ioo pounds, the keeping being governed more by the solidity than size of bale. During the past six years, hay has averaged about $\$ 4$ per ton, in the stack, and seed about 8 cents per pound. Alfalfa makes satisfactory pasturage for sheep and horses. Cattle are liable to bloat, but, if taken in time, may be relieved with a gag, and by exercise which will cause the gases to escape; the knife is used as a last resort. The straw from which seed has been threshed has about the same value as green oat straw. The various soils here appear equally favorable to longevity Usually the third year gives about the best yield. If not damaged by freezing, it will not need reseeding for Io or 15 years. We have no trouble in ridding land of alfalfa. We cut a hay crop, and plow under, for spring wheat, with good results. Our best alfalfa land is clay, which requires moisture, artificial or natural. Our best yields have been six tons per acre for the season. The feeding qualities of the hay have been well established.

James Otterson, Logan county.-Have had I2 years' experience growing alfalfa on sagebrush land, that will grow nothing but sagebrush without irrigation. It is fine, sandy loam, extending down 6 to Io feet, where lava is encountered, which is from I to Ioo feet deep. The soil is dry until water is struck, which is at a depth of from Ioo to 200 feet. There is no water in the soil. When preparing for alfalfa, we plow well, level the ground, and sow $I_{5}$ to 20 pounds of seed per acre, and harrow lightly, or brush it in. Sow as early as the ground can be worked-about March I. The first crop, if properly handled, will yield from three to five tons per acre; 
it will have more or less sunflowers, which are a protection while the plant is getting a start. It seldom winterkills. We irrigate by flooding the ground twice each season from a stream. After the first year, three cuttings are had; $2 \mathrm{I} / 2$ tons per acre the first; $I \frac{\mathrm{T} / 2}{2}$ to 2 the second; and one ton per acre the third. Cut for hay as soon as well blossomed. It grows too rank here for seed. Hay should cure in from one to two days, and, if properly cured, stack as other hay. Alfalfa costs, in stack, \$3 per ton. The size of bales is immaterial, except in fitting cars. Prices for hay have ranged from $\$ 5$ to $\$$ Io per ton; for seed, from 7 to 15 cents per pound. It is the best hay in use for farm animals. Horses will thrive on it without grain, if properly handled. For swine pasture it is far ahead of clover. It is satisfactory for sheep. In some localities it will cause cattie to bloat; as a preventive, feed well with dry hay before turning them on the pasture. Deep soil is the best for the long life of the plant. The second year it is at its best, and, if properly handled, and does not winterkill, will last for all time. It is much better than Red clover for green manure.

\section{ILLINOIS}

'Prof. C. G. Hopkins, Agronomist Illinois experiment station.-Alfalfa is being introduced into Illinois to a considerable extent. Very careful and somewhat extensive investigations conducted by the experiment station, beginning in I9OI, have positively established the fact that alfalfa can be grown in this state on several of our most abundant types of soil. As a rule, it is markedly advantageous to thoroughly inoculate the soil with alfalfa bac- 
teria, preferably by taking infected soil trom a well-established alfalfa field, where root tubercles are found in abundance or from land where Sweet clover (melilotus), has been growing successfully for several years. Infected Sweet clover soil serves just as well as infected alfalfa soil for the inoculation of alfalfa fields. As a rule, the best results are secured from summer seeding. The land should be thoroughly prepared and made as free from weeds and foul grass as possible and then seeded between June ${ }_{5} 5$ and August I5, if the conditions are favorable. Under exceptional conditions good results are obtained from earlier and later seeding. Three cuttings are usually obtained in the northern part of the state and four in the southern part. The average yield is five or six tons per acre. A liberal use of farm manure in getting the alfalfa started is advantageous and on some soils the application of lime is necessary in order to correct the acidity of the soil. As a rule, the yield is increased by adding to the soil some form of phosphorous. A yield of $8 \mathrm{r} / 2$ tons of thoroughly air-dry hay has been obtained where a special effort has been made to make the conditions favorable.

\section{INDIANA}

C. M. Ginther, Wayne county writes in Orange Judd Farmer, July 8, I905:- "Up to last year there had not been half a dozen attempts to grow alfalfa in Wayne county, not because there was no desire on the part of the farmers to raise the crop, but because the farmers knew absolutely nothing about the methods to pursue in order to get a fair stand. Last year, however, a number of agriculturists in the county determined to try the crop. 
A mile west of Richmond lies the farm of J. H. Hollingsworth, a well-known farmer, whose practical ideas about farming have given him a local reputation. $\mathrm{He}$ is an advocate of intensive farming and cultivates his crops in the most thorough manner. He keeps a herd of dairy cattle and in his search for more economical food than mill stuffs and clover hay, he decided to try alfalfa and feed it with a ration of corn meal. He had a tract of five acres. This land was a clay loam with a good mixture of sand. It was not underdrained, and Mr. Hollingsworth believes the result would have been better had there been a thorough system of underdrainage. The soil is what is known here as sugar tree land. About May I of last year, the tract was plowed moderately and then rolled. During the previous winter a heavy top-dressing of barnyard manure had been applied to two acres for the purpose of comparison. One week later the roller was run over it again. After this the ground was thoroughly torn up with a two-horse cultivator. This was for the purpose of killing the weeds, which had been given time to take a start. After the cultivator had thoroughly torn up the ground, the field was harrowed twice both ways. It was then rolled, and pronounced in first-class condition. The weeds had succumbed to these repeated attacks and but very few appeared in the crop later. This thorough preparation of the ground is absolutely necessary for the successful starting of alfalfa. It is a fastidious plant, requiring the most favorable surroundings in its early life, but gradually grows quite robust and strong. Its early weeks seem to be the critical time in its life, and if it can 
once be started well its thrifty nature will assert itself and it will grow with amazing rapidity. On June I I the seed was planted. It was sown broadcast and harrowed in lightly. One hundred pounds pure alfalfa seed were sown, which was 20 pounds to the acre. The experience of many others is that I 5 pounds per acre is better. The seed was first treated with bacteria, procured from the department of agriculture at Washington, and when the seeds were thoroughly dry, they were planted. Exactly five weeks after the seed was planted, the crop was I foot high and covered the ground everywhere. On that day it was clipped first and later given two more clippings during the season. The effect of the clipping was to cause the crop to become more stalky, and spread out more over the ground. None of the crop was removed from the soil last year, the three clippings being allowed to remain about the roots as a mulch. This was regarded as highly important and its effect was noticeable in the perfect manner in which the crop passed through the winter. Early this spring it started to grow and on April i8 the plants averaged $\mathrm{I} 2$ inches high all over the tract. Mr. Hollingsworth is a firm believer in the efficacy of the bacterial treatment of the seed before planting. He attributes the wonderful growth of this crop to the effect of the organisms produced by inoculation. It is interesting to note the effect of the top-dressing which was applied to two acres of the tract. The crop on that part of the ground is larger and more luxuriant than the part that received no dressing. The crop all over the tract appears vigorous and healthy, but the two acres show a decided improvement and superiority." 

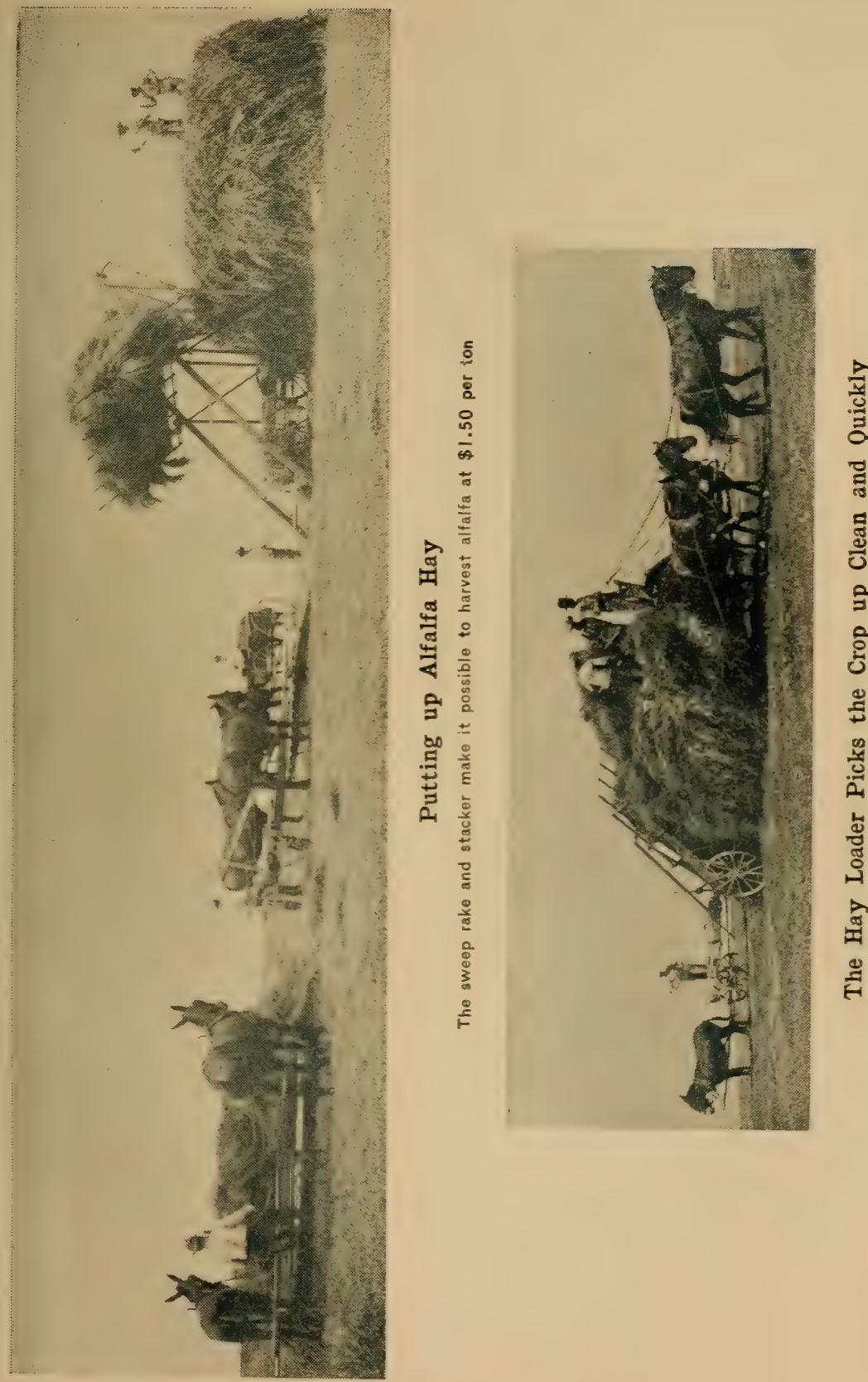


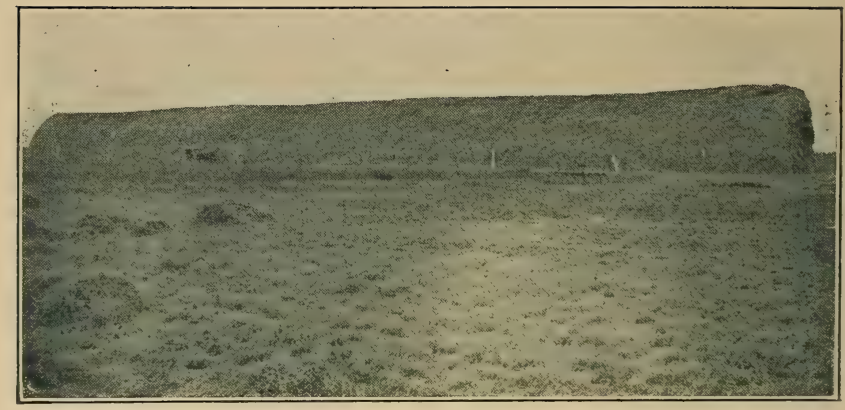

A 400-ton Rick of Alfalfa

in Malheur County, southeastern Oregon. Dimensions, $400 \times 30 \times 26$ feet.

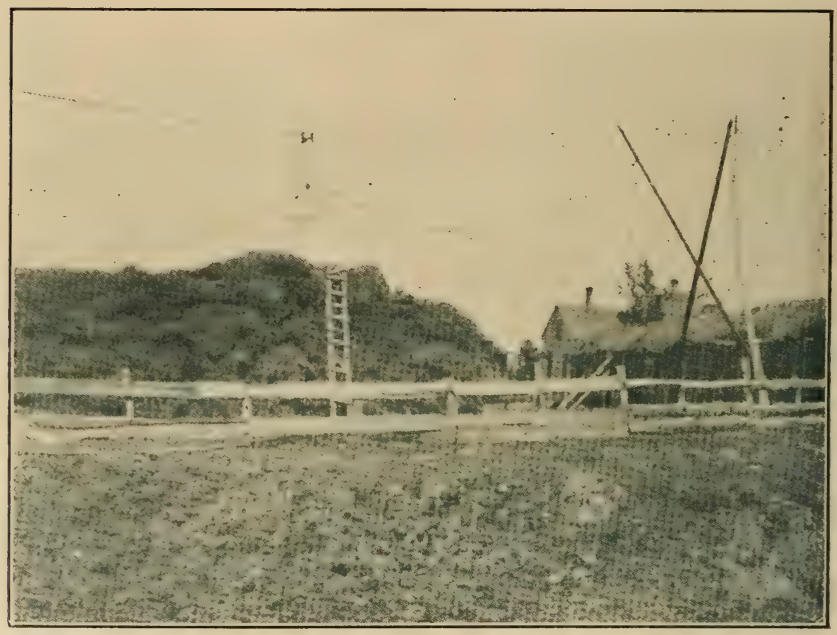

A Cable Derrick, Provided with a Grapple Fork

The cable is supported by poles at the ends, and these in turn by guy ropes. 
Farmers Guide says:-With alfalfa more generally grown throughout Indiana we are hearing less complaint regarding hay crop failures. In fact, some farmers who have taken our advice and tried the crop are now saying that they are having all they can do to take care of their crops of hay. Think of cutting four or even three crops of good hay from the same area each season. Isn't it worth being busy and not going fishing when a farmer can do that? It means an enormous saving in highpriced land when ten acres will produce as much hay as thirty or more formerly did, and hay better in quality also. And then, think of keeping a field in meadow thirty, forty, or more years and having it growing better each year. There is not much necessity for crop rotation under those conditions, is there? especially when every season means three or four crops of good hay. But that is the way with alfalfa and the more farmers get of it the more they usually want. We are glad so many Indiana farmers are getting busy with this crop, and there is no question of its keeping them busy if they will only give it a trial.

IOWA.

Prof M. L. Bowman, Department Farm Crops, Iowa experiment station.-We are receiving very good results from the alfalfa which is being grown at this station, making from three to four cuttings each season with the yield ranging from 4 to 7 tons to the acre. From one field, seeded in August, I905, the first cutting was taken June I I, I906, and yielded 2.I 7 tons per acre. Two other cuttings were made. We believe alfalfa is sure to become 
one of Iowa's great crops as desirable results are being obtained in many parts of the state where land is properly seeded. We take great pains to see that the ground is in good physical condition and that the seed is sown in late summer, some time between August 5 and I 5, so that the young plants will make sufficient growth to withstand the winter. If the seeding takes place in the fall, the alfalfa plants will not make sufficient growth to withstand the winter. Alfalfa should not be pastured the first season. The growth from seeding time until winter sets in should be 6 to 8 inches and should be left on the ground for winter protection. A nurse crop should not be used. Alfalfa will not do well on low, wet ground, but must have land that is well drained. In the northern parts of the state it may be sown in the spring, and in this case desirable results have been secured by using a nurse crop. If oats are used at all, they should be an early variety. Wheat or barley is much better. They are not so likely to lodge. If the nurse crop is heavy, a poor stand of alfalfa is almost sure to follow. Not more than one-half the usual amount of grain should be sown to the acre. Better results may be expected if no nurse crop is used. In this case, it will be necessary for the weeds to be mowed down two or three times during the summer, so that the alfalfa will not be choked out. It is better to sow in the spring than late in the fall. Late summer seeding is the best. The following year it will be freer from weeds 'and have a better stand than that which was sown the spring before. Cornstalk ground which was well manured the year before for corn is generally used for spring seeding. The stalks should first be removed. The 
field may then be thoroughly disked and harrowed. The seed should be sown about the middle of April.

\section{KANSAs.}

C. D. Perry, Clark county.-In I887, I sowed 200 acres of alfalfa, and now have 270 acres. This is nearly all on second bottom land, with black, sandy loam, black sand, and gumbo. The land is largely "madẹe" land, about 6 to 12 feet of good soil, with gumbo only on top for 12 or 14 inches. On the heavy land the dry soil begins at the top, and, at the breaking of the sod, extended down eight or nine feet. Water is found at a depth of 12 to 2 I feet. We irrigate most of our crop from the Cimarron river. The first time the land is watered it takes from two to five times as much water as is required later, and now we find the best results are obtained by watering about Io days before cutting, using three or four inches of water. There is no damage by frost, except on low, wet land. Without irrigation, I should double plow the ground before seeding, having one plow follow the other in the same furrow, and going as deep as possible. Seed by drilling one-half to one inch deep, Io pounds to the acre for seed, 20 pounds for hay, and 30 pounds for pasture, usually about March I 5 here. We mow the weeds the first year before they seed, leaving them on the ground. After this, there will be a yield of three-fourths to two tons of hay, or one to six bushels of seed to the acre, depending on the season. In two or three years the plant is at its best, and does not seem to need reseeding after that. We have from three to five crops a year 
depending on promptness in watering and cutting. Any later cutting is better than the first for seed, and, before cutting, two-thirds of the seed pods should be black. We mow, then rake and cock at once, stacking as soon as well cured. Hay should be cut when it is coming into bloom. To make good hay, let it lie for half a day (if dry weather), then rake and cock, and let cure thoroughly. We stack in long ricks, and it keeps well. The alfalfa land is valued at $\$ 50$ an acre, and the four irrigations cost 25 cents each; the estimated cost of the alfalfa in the stack is $\$ 2.15$ a ton. An average yield of seed is three bushels to the acre, and the cost of threshing and cleaning it is 80 cents a bushel. Hay has sold for $\$ 5$ a ton, and seed for 6,8 and Io cents a pound. The threshed hay is not so good as that cut earlier, but cattle eat it all clean. The pasture is excellent for horses, hogs, and cattle. If the alfalfa is wet, it is liable to cause bloating with sheep; for cattle, there is not much danger, except for the first few days they are turned on. If the animal is seen in time, it may be relieved by driving around, but if too bad to be helped in that way, it needs the trocar. I have had 50 hogs on six acres of pasture this summer, and have 50 pigs, 3 to I 2 weeks old; used two bushels of ground wheat and barley each day, and think I could have had as many more hogs on the pasture. The sod is very hard to plow, but it can be killed. On a piece of hog pasture plowed under, I raised 70 bushels of barley to the acre. My alfalfa seems to do the best on black, sandy land and on gumbo, with sand or open subsoil below.

J. R. Blackshere, Chase county.-I began with alfalfa in 1875 , by sowing $1 / 2$ bushels of seed bought in San 
Francisco, at the rate of $\$ 2 \mathrm{I}$ per bushel. As the germ1nation was defective, or the seed grown so far away was not adapted to our soil or climatic conditions, a good stand was not at first obtained, but I now have 700 acres on Cottonwood river bottom land, having a clay subsoil underlaid by a layer of sand 20 feet below, and with a good portion of gumbo, where the best alfalfa grows. The soil is not especially moist until water, 20 to 30 feet below, is reached. My best results have been obtained on corn land, cutting across the rows with a disk harrow, leveling with a plank drag, and sowing, after danger of freezing is past, 20 pounds of seed per acre with a disk having seeder attachment, being sure to have all the seed covered. I cut the weeds off with a mower, and leave them on the ground. After the first year my average product annually for Io or I2 years has been about five tons per acre. That permitted to ripen seed yields three to five bushels per acre. I do not irrigate. The plant will thrive on upland having a clay subsoil without a stratum of hardpan. Grazed closely late in the fall, it is liable to die out in a dry winter.

Benj. Brown, Osborne county.-I have had four years' experience with alfalfa growing in this country, and have also grown it in England, without any irrigation, and now have 45 acres. The land is bottom rising to second bottom, with vegetable loam and some gumbo in the upper portion, and loam subsoil, similar to surface, but somewhat paler, for I 5 feet down. Well water is found by digging I I to 22 feet through the soil, which is usually moist except in dry weather, when the upper two or three feet are not. It has been found best to plow six 
inches deep, in August or September; to roll or level with a heavy float about April I5, then harrow, and broadcast 25 pounds (or drill 20 pounds) of seed to the acre. I broadcast all of mine, and harrow and roll or level. The best time for sowing here is April I4 to 30, as it almost invariably rains here about April 20, and frosts have never hurt my crop, nor does it winterkill. Mow first when the weeds are six to nine inches high, and, if worth hauling, stack; if not, let lie; generally mow again about July 4 to 20 , and stack; there may be one-fourth to onehalf ton of hay per acre. The second season we cut three times, unless we ripen seed, and obtain from onefourth to one ton each cutting; after this it grows about a foot high by October. For hay, mow as soon as about half full of flowers, rake the same morning, and haul in one or two days, as the leaves fall if dry. It does not heat nor mold here if the sap is half out and the straw long; I use the "Acme" hay harvester, making stacks with rounded ends, nine steps long by five wide, and top out with straw or hay, taking care to keep the middle well filled. The total cost of hay in stack is about $\$ 1.50$ per ton, the land being valued at $\$$ I 5 per acre, or $\$ 60$ with a good stand of alfalfa. The hay has sold for $\$ 4$ to $\$ 6$ per ton during the past four years. The best crop for seed depends on the weather; sometimes the first flowers set best, and again the later ones do better; on my bottom land the plant grows too large for seed, unless in a dry time. If seed is ripe, cut only while damp or in the early morning, rake into rows immediately or early the next morning, haul with a "Monarch" rake, and use a stacker. Last year and year 
before I obtained four bushels of seed to the acre, and it cost me 60 cents per bushel for cleaning. Used ordinary threshing outfit, and set hind end of thresher ro inches lower than front. The seed has sold here during four years for $\$ 5$ to $\$ 8$ per bushel. Horses and sheep should not be pastured on the alfalfa, as it pays to mow and haul it to them, either green or dry. It makes good pasturage for cattle, but they must notbe turned on when the ground is frozen, nor when they are hungry, as it is necessary to start them gradually to avoid bloating. Mine never have bloated, and I feed milch cows in the early spring and on the fourth crop in the fall. Alfalfa ripened and threshed has little value, as it breaks up into dust and chaff. My stand improved every year; was about at its best the sixth year, and continues about the same for an indefinite time. If it gets a fair start, and is cut three times, a good stand can be kept; but if it is pastured, and the weeds are not eaten, it is apt to thin itself. A neighbor plowed under alfalfa for green manure, but the next year it grew up as thick and strong as if not plowed. We do not need manure here. I have seen several pieces of fairly good alfalfa on high prairie, with some gumbo in the soil, but it grows best where the subsoil is fairly open. Upland is generally best for seed, as the plants should grow only one to two feet high, and mine on the bottom grows 2 to $3 \frac{1}{2}$ after the second year. I think there is no other crop here to compare with alfalfa. My third year's crop cleared me over $\$ 20$ per acre. I have known of nine bushels of seed on one acre, and have heard of $\mathrm{I}_{5}$ in this county. My bottom lands will grow three good crops of hay almost without rain, and kill out all the weeds. 


\section{KENTUCKY}

Prof. H. Garman, Botanist Kentucky experiment station.-We have grown alfalfa on the experiment farm for a good many years and have been impressed with its many good qualities, although we have not found it as well adapted to our soil and climate as it appears to be in the western states. In our small experimental plots, on good soil, it has recently done remarkably well. This is partly the result of understanding it better than formerly, and partly due to the care which these plots receive. Last year we harvested, from some of them, hay at the rate of from 6.32 to 10.03 tons per acre. The same plots are yielding very well this season, but I think will not produce quite as much hay as last year, though they look very well at present. Farmers in this state are becoming interested in alfalfa, stimulated by the reports made to them at farmers' institutes, and urged by failure to grow Red clover successfully in some parts of the state. But thus far they have not met with uniform success. Part of this is due to a lack of acquaintance with the plant and part may be attributed to our climate. A few men have been growing alfalfa successfully for eight or Io years, and I can see no reason why many others should not succeed with it. The chief difficulty appears to come in getting a start. Alfalfa, thoroughly started, holds its own better than Red clover and yields much more forage. The value of the forage is recognized by everybody, and I expect to see in the course of the next quarter of a century a much larger acreage sown in Kentucky. 


\section{LOUISIANA.}

Prof. W. R. Dodson, Director Louisiana experiment station.-Alfalfa has been grown by the Louisiana stations since 1887 . At the time the stations were established there was little or no alfalfa grown in the state. From the very first experiments conducted by Dr. W. C. Stubbs, it was apparent that the plant was well suited to the alluvial lands of the Mississippi and Red rivers. Dr. Stubbs never lost an opportunity to advocate its culture, and the great progress made in securing its extensive cultivation is largely due to his efforts. Alfalfa is now extensively grown in the Red river bottoms, and a very large percentage of the sugar planters grow it for soiling and for hay for the plantation mules. We get from four to seven cuttings per year. The average is about $\mathrm{I} / 2$ tons for the first three cuttings, but less for the last cuttings. The station one year secured a harvest of I2 tons of cured hay per acre; six tons in a season is a good yield. Were it not that one or more of these cuttings will fall due during a rainy season, when it is difficult to cure hay, we would go into the business very extensively in this state. As to the quality of the hay or forage, there is no question about its place at the head of the list of desirable forage crops. The sugar planters find it especially desirable to mix with their cheap molasses, as the former is rich in protein and the latter rich in carbohydrates. In the southern portion of the state best results are secured by planting in the fall. In the northern portion good results are secured from early spring planting. We use from 25 to 30 pounds of seed to the acre. Some planters use more than this. Land 
that is least suited for growing corn in Louisiana, because of its stiffness, is the very best land for alfalfa. Where the crop has once been used and the local supply runs short, it is shipped in from Colorado to supply the demand. It is selling now for $\$ \mathrm{I}_{5}$ a ton. No better testimonial need be given of the people's estimate of its value.

\section{MASSACHUSETTS.}

Prof. William P. Brooks, Director Hatch experiment station.-Our experiments with alfalfa have been continued both upon our own grounds and those of a few selected farms in different parts of the state. We are bringing to bear upon these experiments information in regard to successful methods from every possible source. We find in all cases a distinct benefit from a heavy initial application of lime. We have used from 2,000 to 3,000 pounds per acre. We are enriching soils already naturally good by heavy applications both of manures and fertilizers, using materials which experience has proved best. We are also giving the soil a most thorough preparatory tillage. It has usually been fall-plowed, and in addition it is plowed in the spring, and repeatedly harrowed to destroy weeds which start in the early part of the season. We have tried inoculating the soil, both with earth obtained from a field in New York, where alfalfa is successfully grown and with the cultures sent out by the department of agriculture and prepared by private firms. $\mathrm{W}^{\top} \mathrm{e}$ have not attained such degree of success as justifies us in recommending the crop. We have occasionally got a fair stand of alfalfa, but in all cases the winters prove 
more or less injurious. In the course of a few years the alfalfa is mostly crowded out by grasses and clovers. The alfalfa almost every year suffers from leaf spot, which tends to cut down the yield. We have found a very distinct benefit from the inoculation with earth from the New York alfalfa field. We have not found an equally distinct benefit to follow inoculation with any of the cultures; and, although we are not as yet ready to make a final report, it should be here remarked that the most careful experiments on the use of these cultures in sterilized soils, under conditions calculated to give accurate results, indicate that they have little, if any, value. In our various experiments alfalfa has been tried on a wide variety of soils. We have had a quarter of an acre field upon a coarse-textured soil upon a farm in this neighborhood where there is never any standing water within 50 to 60 feet of the surface. Even on this soil the alfalfa, although it did fairly well for a year, has been injured by successive winters, until it is at the present time almost ruined. In this connection I call attention further to the fact that D. S. Bliss of the department of agriculture, who has been making special efforts to promote the introduction of alfalfa into New England, and who has traveled extensively for the purpose of studying the results obtained, now speaks very discouragingly as to the outlook in general. In conclusion, while we are not inclined to discourage experiments with alfalfa, we do wish most emphatically to caution against engaging in these experiments upon an extended scale, for we feel that disappointment is almost inevitable. 


\section{MICHIGAN}

Prof. C. D. Smith, Director Michigan experiment station.-Alfalfa has had and is having a checkered career. Under favorable conditions it makes a good stand. Some fields have produced crops for many years, the ground being occasionally fertilized by manurial salts. The difficulties that environ the crop are: (I) The severe winters, which sometimes kill off whole fields, leaving scarcely a root alive; this has happened to fields two, three, or four years old. (2) The Blue grass crowds it out badly; (3) the ignorance of the farmers in regard to the requirements of the crop and the consequent imperfect preparation of the soil in the matter of tillage or fertilization, has made it difficult to introduce it in a broad way. Notwithstanding these difficulties and the farther consideration that alfalfa does not easily lend itself to a short rotation, the crop is advancing in the state by leaps and bounds. Hundreds of farmers are experimenting with it and are learning how to prepare the ground, sow it and care for the crop afterwards. Statistics are not at hand to show how many acres of alfalfa there are in the state, nor can definite figures be given as to the growth of interest in the crop and its actual acreage. When proper strains have been developed, it seems fair to presume that alfalfa will be one of the staple crops in Michigan. On the station grounds at the agricultural college fields of alfalfa have been continuously maintained from 1897 to 1904 . There are fields here sown in 1903 bearing their three crops each year, yielding from 5 to 7 tons of dry hay annually per acre. There has been some difficulty in getting pure and vigorous seed. 


\section{MINNESOTA}

Prof. W. M. Liggett, Director Minnesota experiment station.-Our experience with alfalfa has extended over I 2 or I 5 years. In the early days of this station, it was not very successfully grown. During the past eight or ten years, however, the changes in soil due to manures and cultivation and the discovery of several varieties of alfalfa which appear to be hardy, have made it possible to grow it successfully in nearly every part of the state. For the past five years we have cut three crops of alfalfa hay, yielding from 4 to $5 \frac{1}{2}$ tons per acre each year. With the land properly prepared and some attention given to seeding at the right time, there is no difficulty in growing it on the state farm. Occasionally it will winterkill. We were unfortunate enough to have a heavy, driving rain during March of the present year which froze as it fell and smothered the alfalfa crop. We are not discouraged, however, as the clover crop in southeastern Minnesota was killed at the same time and from the same cause. We regard alfalfa just as sure as Red clover. It is sometimes a little difficult to get a stand under careless methods of farming. With the land nicely prepared and with a good supply of humus in such condition that the plant food is readily available, strong, vigorous growth and a good stand can be secured during any normal year. We have alfalfa growing at the northwest sub-station at Crookston, and in several localities in the northwestern part of the state, where even clover is not supposed to grow. The outlook at the present time for this crop is very bright. Dairymen, swine raisers and sheep men unite in praising its merits as stock food. 


\section{MISSOURI}

Prof. M. F. Miller, Agronomist, Missouri experiment station.-Alfalfa is being grown with success on various types of soil, although many soils are not well adapted to its growth. A knowledge of the peculiarities of the plant will ultimately make it possible to extend its culture to most soil types of the state. Liberal manuring is the key to successful culture on upland soils. The manure may be applied before plowing and also as frequent topdressings. The value of the crop as a feed and its high yield, where favorable conditions are supplied, make it a particularly desirable one to grow, at least in small areas, on farms where mixed farming or dairy farming is practiced. While alfalfa makes a most nutritious pasture crop, it does not lend itself well to pasturing unless certain precautions are taken. Where it is grown for hay, difficulty is often experienced in harvesting the first, and sometimes other cuttings, on account of wet weather. The silo may be used in such cases. The stiff subsoils of the state are responsible for most failures reported, because it requires some knowledge of the methods of handling the crop to make it succeed under such conditions. Alfalfa is not adapted to our soils, liming, manuring or drainage being necessary to prepare such for the crop. If sown on upland soils that have never grown alfalfa or Sweet clover, it is benefited by inoculation. On bottom lands or lands that are very fertile, inoculation has little or no effect. The surest and often the simplest means of inoculation is by means of inoculated soil. The cultures prepared for seed inoculation have in many cases given excellent results, but they are still in the experimental stage 
and some skill is required to handle them properly. The best preparation of the seedbed is that which allows of an early plowing and the use of a harrow every time a crust forms or weeds start before time to sow the seed. The seedbed should be much like that for wheat-loose above but firm below. The best time to sow in this state is between the middle of August and the middle of September, the last week in August usually giving best results. The amount of seed to sow is between 15 and 20 pounds, depending upon the quality and the character of the soil. It is best sown without a nurse crop. It must be clipped frequently the first and sometimes the second season, especially on soils to which it is not well adapted. It should usually be cut when the lower leaves begin to turn yellow.

\section{MONTANA}

Alfred Rasicot, Deer Lodge county.-Alfalfa is the most valuable crop that is raised in Idaho or Utah for hay, growing on any kind of land but that which is low and wet, yielding five to seven tons of hay to the acre, and providing excellent feed for all kinds of farm animals. For about 20 years I have grown from 20 to 50 acres on second bottom and upland of heavy clay soil, with gravel below and water at a depth varying from I6 to Ioo feet on different localities. We irrigate from streams, flooding the land and turning the water off as soon as the land has been all covered, applying once for the first cutting and twice for each succeeding cutting, whenever the ground is dry. The first year on new land requires fully one-third more water than is needed afterward. Before seeding, the ground should be mellow, . 
then harrowed with the back part of the harrow or brushed, and seeded with I 5 to 20 pounds to the acre, between the first and middle of April. The plant will usually run out the weeds, and on that account no special treatment is needed. The first season will produce a small crop of hay, but no good seed. Unless water is allowed to freeze on the land, alfalfa does not winterkill here, and at two or three years of age it is at its best, continuing vigorous for 10,20 or 30 years without seeding. The first cutting of the season yields about $2^{\mathrm{T}} / 2$ to 3 tons to the acre, the second about 2 to $2 \frac{1}{2}$, and the third I to $\mathrm{I} / 2$ tons. The hay is cut when the plant has been in bloom 8 or Io days, allowed to lie for 24 to 36 hours, and treated as Red clover is. The second crop is always the best for seed here. The cost in the stack, on \$25 land, irrigation costing 50 to 75 cents an acre, is $\$ 2$ a ton. To put this into Ioo-pound bales costs $\$ 2.50$ a ton. On the ground it sells for $\$ 3$ to $\$ 5$ a ton, while the seed brings $\$ 3, \$ 4$ and $\$ 5$ a bushel. An ordinary yield of seed is 300 pounds to the acre, and this is threshed with the same machine used for grain, at a cost of about onefourth of the seed. The straw is worth about one-fourth as much as the hay. We consider alfalfa hay, for cattle, sheep, and hogs, far superior to clover, but for horses timothy is best. It will keep steers and sheep fat all winter, providing they are under shelter, and is excellent for milch cows. The pasture for swine and cattle is far better than clover, and for work horses and sheep it is good, but not the best for horses that are driven fast. Cattle will bloat about as they do on Red clover when turned onto it after rain, dew, or frost. To rid land of a stand 
of alfalfa is very difficult, requiring four stout horses with a very sharp plow to turn it over, but as a green manure it has about the same effect as Red clover, produeing two or three extra crops afterwards.

\section{NEBRASKA}

Olmstead \& Olmstead, Furnas county._Alfalfa, while excellent for all other stock, is preeminently the feed for hogs. Its early appearance, its wonderfully rapid growth, its nutritious properties, its perennial nature (keeping green until about December), its resistance to drouth, its wonderful fecundity, and, lastly, its adaptability as a dry feed, make it, in our opinion, the most profitable crop that can be grown. Ten acres of alfalfa will pasture I5O head of hogs, and give them abundance. From the I $5^{\text {th }}$ of March, or at most not later than the I 5 th of April, hogs and cattle can be turned on pasture, and kept there until snow flies. On first bottoms, six tons per acre can be depended upon as a fair, average yield, while many fields this year have made as high as eight. On divide, or high land, where it has been tested for three years, it averages about two to four tons per acre, but this land gives the best returns for seed, not growing too rank. Since we have been investigating and gathering information on this subject, we have had reported to us a yield as high as eight bushels of seed per acre, and quite a number as high as nine, and some eleven. Six bushels an acre on a good stand is an average yield, while some will fall below that. The seed has never sold here below $\$ 4$ per bushel. Last year and this, all seed grown in this part of the country sold readily at 
$\$ 5$ per bushel, and for the next five years will probably not go lower than $\$ 3$. One crop of seed and two of hay are the average on low land, and one crop less of hay on high land. The threshed hay is nearly as good for feed as the unthreshed. There is no waste in feeding this hay, and horses are especially fond of the coarse stems. It stands our winters remarkably well, so far, coming through in excellent condition. There is no stock but eats alfalfa hay as well or better than clover or timothy. Young colts and calves will winter in fine condition on this hay, with little or no grain. If the last cutting is allowed to stand, with a growth from six to eight inches, horses and cattle will graze on it through the winter, the same as on Red clover, doing equally as well. Now, as to the other side. Will this clover grow in all latitudes and longitudes as well as Red clover? We think it doubtful. It requires a dry, porous soil, in which there is no hardpan nor too much clay, and it does not like too much water. It does well where the soil is somewhat sandy, its roots penetrating to a depth of from I $_{5}$ to 25 feet, thus drawing its nutrition from various strata of soil. What else against it? If cattle are turned on after a rain, when it is wet, or dew is on, they often bloat and die; but if turned on in the spring, and kept on continuously, have little danger of gorging themselves or bloating. No other stock is adversely affected by it. This is all that can be honestly said against alfalfa, and this is obviated by a little care by the farmer, while the many good things said about it must certainly recommend it to the intelligent husbandman. Thus we can enumerate: First, its certainty as a crop; second, its enormous yield; 
third, its excellent pasturage qualities; fourth, its nutritious qualities, being equally good green or dry; fifth, its yield and price of seed, which is threshed with an ordinary grain separator; sixth, its tremendously rapid growth during the summer season. There are many more attributes that can be credited to alfalfa.

W. O. Thompson, Lincoln county.-I have had 20 years' experience with alfalfa, on second bottom and upland. The upland has a clay subsoil; the second bottom soil is three feet deep, underlaid with a bed of sand and gravel. Abundant water is found from 8 to 23 feet from the surface. If dry soil is found, it is the first three feet below the surface. Land should be tilled several years before seeding, in order to perfectly subdue the sod. Use about 16 pounds of seed per acre, and prepare the ground the same as for wheat, sowing in the spring. The first crop will be nearly all weeds; cut and haul these off the ground. The second crop will produce about one ton of hay per acre. Alfalfa is liable to winterkill if the winter is warm and dry. I irrigate from a stream two or three times during the season, with sufficient water to flood all the ground. The first year the ground is soft and porous, and twice the water is required as in the following years. From three to four crops are raised during the season, yielding from $\mathrm{I}^{\mathrm{I}} / 2$ to 2 tons each cutting, or from five to six tons per acre in one season. Cut when in bloom for hay, and let the seed ripen before cutting for seed, using either the first or second crop for this seed. When cutting for seed, it should be pitched out of the way of the mower after each round; then let it dry before stacking, but not enough for the 
leaves to fall off when handled. Stack in the ordinary way, but be sure the hay is thoroughly dry in the shock before stacking. It is more liable to get moldy in the barn than in the stack. About $\$ 2$ per ton will cover all expenses of raising, on land worth $\$ 50$ per acre. The expense of baling is about $\$ 1.50$ per ton, Ioo-pound bales being preferred. It should not be baled until perfectly dry in the stack. About six bushels per acre is the average yield of seed, and it costs about 75 cents per bushel to thresh and clean. A clover huller is the most satisfactory for threshing alfalfa. The hay has sold here at $\$ 3$ to $\$$ Io per ton, averaging $\$ 6$. The seed has brought from \$3 to \$Io per bushel averaging \$5. One acre of alfalfa will raise 35 hogs, with the aid of a little grain. Horses thrive on it, but it is unsafe for sheep and cattle. Animals which chew the cud will bloat if pastured on alfalfa. The only way to prevent it is to keep them from the pasture. The best way to cure it is to insert a tube into the paunch, to allow the gas to escape. As to the longevity of the plant, I call to mind a patch sown in I873, on upland, and it is still growing. Alfalfa attains its best growth in about two years. I do not think it can be profitably raised on high, arid ground, without irrigation. Hogs can be wintered on alfalfa hay and a very. little grain, and cattle can be fattened for the home market, but it produces softer flesh, and they could not be shipped a great distance in the best condition.

Richard Stolley, Hall county.--In reading the farm papers I see many articles about seeding alfalfa, but have failed to see anything in the line of advice regarding a sure way to kill it, if it has to be done. We have had 
alfalfa on our place as long as I can remember-nearly thirty years. At first it was a small piece, just for experiment's sake. Finally we sowed about nine acres on good soil and had it well manured before sowing. The result was immense crops, as high as four cuttings; and, really, the worst feature was to harvest the crop so often, since it came just as regularly as clock-work. It actually stood in the way of alfalfa, for I asked one of our neighbors, who had very little hay, why he did not sow alfalfa, and all he could answer was: "Well, I have to harvest it too often and I haven't the time to do it."

We did not sow more of it until we got more improved methods of handling it, and we have had as high as fifty to sixty acres on a I6o-acre farm here at home. Some fields run out in about ten years. Our plan is to then plow it up. The first thing you learn is to have a very sharp plow, and it must have a strong cutter bolted to the share, being long enough to reach well through the sod. Then if you have three good horses you are fixed out. A riding plow that we tried was thrown out too easily or pulled too hard. Others had the same experience, and the old reliable fourteen or sixteen-inch walking plow fills the bill best. We plowed some of it quite early in the spring and after harvesting the oats we had a wonderful stand on the field in the fall. All the inconvenience the clover had was to take a little time to start work at the crown and start sprout at the other end; that is the root end.

I do not know of any other plant that is not a weed that has this peculiarity. Planting corn on alfalfa sod cannot work well, because the roots are so tough that no 
cultivator will be able to cut them, and since burning does not make any difference, it only has a tendency to start roots and sprouts at both ends at the same time. This is, of course, only possible in a wet year. Now, we tried late plowing in the spring; that is, let the clover get up to about six or eight inches. We had a chain on the plow and disked and harrowed it well, and to kill it sure, put in millet to smother it. We intended to raise seed from the millet, but the crop got too heavy and we cut it for hay. After putting it up I saw very little alfalfa signs and went home contented that all was dead.

Some nice rains came on and soon I noticed from our house, since I did not go to that corner of the farm in between, that all of it was green again, and sure enough, there was a comparatively good stand and the sprouts showed quite a bit of vigor. This surprised me. I had no time to plow right away and having a large harvest of bottom hay, I did not go to the field for three weeks, and when I saw it again it was just about ready to cut. I actually did cut and harvest it and it was well worth the time it took us to do the work. The next plowing and disking, of course, thinned it out, and especially as dry weather came just right to assist in killing it.

All this made it clear to my mind that we did not find the right time to plow alfalfa, so the next time I tried it still later; in fact, it was almost in bloom, and, being a wet year, there was little difference in the result. This year I waited the second time for the alfalfa to come up a foot high before plowing it back and drilled in sweet corn, and now I can hardly see any difference on parts of the field. 


\section{NEW HAMTSHIRE}

Prof. Frederick W. Taylor, Agriculturist New Hampshire experiment station.-We have tried to secure a stand of alfalfa for four consecutive seasons, but so far our efforts have been unsuccessful. Various types of soil, from a heavy boulder clay to a light sandy loam, have been tried, and, contrary to our expectations, the most promising crop was on the heavy clay soil. Our chief difficulty has been in having the alfalfa keep ahead of the weeds and in getting a uniform catch that would withstand our winters. From one-fourth to one-half of the plants have usually wintered over in good condition and made a vigorous growth the next season, but there has not been enough of them to say that we have made a success with alfalfa. We have largely eliminated the seed question by plowing the ground early and keeping it harrowed until about the middle of July, when it is sown. Our experience seems to indicate that an application of lime is beneficial, if not absolutely necessary, in this section and we have accordingly been using it at the rate of a ton to the acre. We have also tried inoculation with the various cultures, but in no case have any benefits been observed. So far as we know, there have been no successful attempts to grow alfalfa on a medium or large scale in this state, although several farmers in the Connecticut river valley have reported success on some areas of an acre or less. When we more thoroughly understand the plant, and the conditions necessary for its growth, we believe it can be grown upon some of our soils. 


\section{NEW JERSEY}

Dr. E. B. Voorhees, Director New Jersey experiment station.-The farmers of the state have manifested much interest in the growing of alfalfa, and many experimental plots have been seeded in the past two or three years. In order to obtain accurate information as to the methods employed, and the results obtained, a circular letter was sent out during the past summer to I40 growers. Detailed replies were obtained from IOI growers. Of these there were 57 distributed over I 5 counties, which showed the successful establishment of the crop. The soils upon which these successful crops are growing vary widely, both in their physical and chemical character, ranging from a light, sandy loam, with sandy subsoil, to a medium heavy clay, with compact clay subsoil, which indicates clearly that success does not depend so much upon the character of the soil as upon the methods of seeding, fertilization and after-treatment, though the most successful stands were, as a rule, obtained upon sandy soils, overlying a reasonably open subsoil. Twenty-seven growers had a more or less satisfactory experience, while I7 were absolute failures. A study of the reports of failures shows that in most instances they were due to lack of observation of the methods recommended for the seeding and care of the crop, which experience at the station showed to be essential for success. In most cases the land was imperfectly prepared; in many an insufficient amount of fertilizer or manure was applied. In many cases, too little seed was used; in others the date of seeding was contrary to all recommendations, or the crop was not clipped often, and thus choked out by weeds. 
In many instances, where lime had not been used for many years, none was applied at the time of seeding. In the case of those having more or less success, the recommendations were not fully observed or soil conditions were imperfect.

D. C. Lewis of Middlesex county, in the summer of I903 seeded about I I $/ 4$ acres with alfalfa, observing closely all of the recommendations of the experiment station in reference to seeding, but did not inoculate the soil. The seed germinated well, and the crop grew nicely during the fall, but entirely disappeared later. In 1904, the same area, after an oat crop was grown, was seeded again, on August Io. The soil is a clay loam, with a clay subsoil, and in a good state of fertility. The land had been previously in grass and corn. The corn was manured and the alfalfa area well limed previous to seeding in 1903. The seed was at the rate of about 25 pounds, and at time of seeding 800 pounds of Mapes' fertilizer and an extra bag of high-grade sulphate of potash were applied, and the field was inoculated with about 300 pounds of soil, taken from the old alfalfa patch at the experiment station. The seed germinated well, and made a rapid. and large fall growth and passed the winter successfully. The yield per acre was about three tons of hay for the first cutting. This experiment is strikingly suggestive in showing the importance of soil inoculation, for while inoculation is not apparently essential in all cases, it would seem that where soils have not been heavily manured that this point should be carefully observed. 
J. P. Nelson of Monmouth county has had a very successful experience in the growth of alfalfa, since he has observed all of the recommendations made as to methods of seeding and after-treatment. The following is a description of his method and the results obtained from a seeding made August IO, I904. The surface soil is a medium clay loam, underlaid with a gravelly clay subsoil. The crops preceding were grass and corn, and the manures used were barnyard manure and 600 pounds per acre of ground bone. The corn preceding the alfalfa was limed at the rate of $\mathrm{I}, 000$ pounds per acre, and I,400 pounds per acre were applied just previous to the seeding of alfalfa. Thirty pounds of seed were used per acre, and lightly harrowed in and the land rolled. The germination and early growth were good, and the first crop was harvested June I, 1905. The yield was two big, two-horse loads of cured hay per acre.

E. T. Gill of Camden county has a sandy loam, underlaid by a subsoil varying from sand to clay. He has an area of 24 acres, ranging from two to six years in age. The first seeding of about two acres is still growing profitable crops, though not uniform in stand. The later seedings show an excellent stand and large and profitable crops are annually harvested. Ustually four cuts are made each year, which are used both for soiling and for lay, with splendid results. The practice on this farm is to top-dress with manure during the winter at the rate of about eight tons per acre. Mr. Gill's experience leads him to believe that the stand is often injured, particularly during the first year, by allowing the crop to reach tou great maturity and then cutting when the plants 
are just beginning to bloom, and leaving a stubble of at least three inches. Mr. Gill did not inoculate the seed or soil at his first seeding, but did follow this practice with recent seedings, and believes it to be a wise precaution, especially on soils that have not been previously heavily manured.

\section{NEW MEXICO}

Thomas J. Clark, Grant county.-I have had I 5 years' experience with alfalfa on first and second bottom land with gravel soil, dry to within four feet of water, which is reached at a depth of I 5 feet. I irrigate from the Gila river, and my alfalfa, which is I4 years old, is as good to-day as at any time since it was sown. The seed is sown as turnip seed is. I plow the land thoroughly, harrow it over smoothly, then sow the seed in March, and harrow lightly once. Then the water is turned on, and the ground will remain moist until the seeds sprout. After the alfalfa is six inches high, I cut it to make it spread and destroy all the large weeds; and there may be two cuttings of hay that same season. Water will not injure the plant unless it stands on it in low places. Stagnant water standing on the plant, or mineral water so near the surface that the roots reach it, will kill the plant, but it is not liable to injury from winter frost. After the first season there are three or four crops, the first being usually chosen for seed and not irrigated. For hay it is cut when in full bloom, and, if the sun is shining, should cure 24 hours if in June, or 20 in July or August, before raking, and then 30 hours in the cock. It must be thoroughly cured before stacking, and then will not 
mold. The most convenient bales weigh 90 to Ioo pounds, and the cost of preparing them is $\$ 2$ a ton. The total cost of hay in the stack is about $\$ 3$ a ton, and the average yield about three tons to the acre each year. When the burs turn brown the seed is harvested, and when well cured should be stacked in a dry place. An average yield is 500 to 600 pounds to the acre, and it sells for $\$ 4$ a bushel. The hay makes excellent feed for farm animals, keeping them in good condition the year around without grain. The alfalfa pasturage is better for swine and cattle than clover, and yields more largely; sheep may be kept on it to advantage also. A good acre will keep five grown hogs in excellent condition, but will not make them fat. If they are taken up in October and fed about 40 days on grain, they will be marketable. Cattle on the pasture sometimes bloat, but I have had Ioo head of cows and calves on mine for two months, and have had no trouble. The irrigated alfalfa is better than that grown on land that requires no water. The straw is about equal to oat straw, but not half so good as the alfalfa hay. To rid land of the plant requires a strong team and a sharp Io-inch plow. The roots rot at once after plowing, and the land is well fertilized for other crops. In my opinion, alfalfa is the best forage plant known in this western country. It is most easily raised, produces the largest yield, commands the best price, and can be planted at any time from March to September. Land seeded to it is the most valuable, and the farmer who has plenty of it is the most prosperous. Farming here cannot be a success without it, and I take pleasure in recommending it to my brother farmers. It 
will lie dormant all summer if it is dry, and with fall rains revive and make good pasture. It is the earliest plant up in the spring, and the last to stay green in the fall. In other words, it is the best of all.

Hartman \& Weil, San Miguel county.-We have been dealers in alfalfa hay for eight years, and have some small fields of our own. This is on both bottom and upland. In the bottom, the subsoil is sand and bowlders; on the upland, stiff bluish clay, and in some places blue limestone. Well water is reached on the bottom land at a depth of 8 to Io feet, through soil moist all the way; on the upland, it is necessary to dig 60 to roo feet, and, beginning two or four feet from the surface, the ground is dry. When seed is planted in the spring, the soil should be well pulverized, moist, and warm, that the seed may germinate quickly. It should not be put in deeper than $I \frac{1}{2}$ inches, and may be planted in May or June, or any time in the spring after the soil becomes warm. In our climate, it is best to sow about 30 pounds of good seed to the acre, besides just enough oats to shade the ground and protect the young alfalfa from the hot sun. Once well started, it will kill out all weeds, and does not winterkill here. We irrigate from streams. Alfalfa should not be irrigated when quite young, for, if the small plant is covered with soil, when watered, it will not come up again, but, after it gets a good start, it is not easily killed. There should be about two irrigations to each crop harvested, or ordinarily, six in a season. The heavier the stand the more water is needed. We have three cuttings, yielding about 3,000 pounds of cured hay per acre per cutting. When the plant is fairly well 
in bloom, it is cut, and is best when cured under large sheds or in the shade. If left until dry where cut, the foliage will fall off and pulverize. It is best to stack in narrow ricks, as it is liable to heat if put in large stacks, and it should be salted liberally when stacked. The last cutting is preferred for seed, which is mowed when most of the pods are well matured; in this case only two crops should be cut during the year. The straw makes good feed for stock in winter, having about half the value of the hay. Each irrigation costs about 50 cents per acre, and the total cost of hay in the stack is about $\$ 3.50$ per ton. Baling costs $\$ \mathrm{I} .25$ per ton, with 50 cents additional for wire. The common yield of seed is 6 to ro bushels from the acre. "Reeves" clover huller will thresh about I.2 bushels per hour. The price of hay, baled, in New Mexico has averaged about $\$ 8$ per ton for the past eight years and seed for the same time about $\$ 5$ per bushel. Our experience indicates that alfalfa hay is a more nutritious food for farm animals than either clover or timothy. We have found nothing better to feed cattle for market; it makes good, solid beef, and they take on fat very fast. The pasturage is excellent for swine, horses, aid cattle. If overfed, animals will sometimes bloat on rank alfalfa, especially if unaccustomed to it. About the tizircl year from seeding, the plant has acquired its best yield. It is difficult to rid land of it, as plowing under is sometimes beneficial, making it come up thicker than before. Success with it on high prairies depends upon the precipitation during the growing season. We think four inches of rainfall cluring the time of its growth 
would make a fair crop of hay; or 8 to I 2 inches from May to September, for two or three cuttings.

\section{NEW YORK}

Isaac Zoller, Montgomery county, writes in a recent article in American Agriculturist:- "In the spring of I889, I sowed my first ten acres of alfalfa. The field was reseeded for the second time in April, I905. I now have 25 acres. The land was plowed in the fall after being manured. In the spring, generally during the last two weeks of April, the surface for five or six inches is made extra fine and 25 to 30 pounds of the best seed are sown with three pecks of oats as a nurse crop. By June I the oats are cut three inches above ground and again every four weeks during the first season. The following June during the third week the first crop is cut, usually yielding about three tons. The second cutting generally comes during the last week in July when $\mathrm{I} / 2$ tons is an average. By September, the third cutting is made, but I generally let sheep browse it, but not very close or after it is frozen. The season of 1905 it was cut and allowed to wilt, raked with a side delivery rake, allowed to lie a couple of hours, then rolled over with the rake and drawn to the barn. Formerly I used to shock it and allow it to sweat, but this is too much work. I feed it to sheep and find it equal, if not superior to Red clover. To be at its best it must be cut when about one-tenth of the blossoms are out. The soil in which my alfalfa grows is a heavy, clay loam and rolling, but is underdrained. The soil here is apt to heave three or four inches during winter and injure clover. But where properly drained, this does 
not occur on alfalfa fields. I am certain alfalfa can be more extensively and economically grown here."

H. B. Fullerton, Long Island.-As an experiment, an acre of scrub-oak, waste land was cleared and the brush and stumps burned in November, 1905. About 2,000 pounds of wood ashes were applied and turned under at once. In April about ten tons of manure was applied so that each quarter acre would have about 2,500 pounds. Three weeks later 400 pounds of kainit were applied and ten days later 200 pounds of Canada wood ashes. Since the soil, when tested, still showed acidity, about 400 pounds more of ashes were spread, chiefly because of its high percentage of vegetable lime, 40 per cent. The lime of ashes on Long Island soils is considered superior to that of stone or shells. Early in June the test acre, being considered ready, was finally prepared and sown to alfalfa in two directions crosswise over each quarter acre. In less than a week the plants appeared evenly on all four plots. Showery weather continued from before seeding until well into June. One of the quarter acre plots sown with a dressing of I 50 pounds of soil from an old alfalfa field at Fayetteville, N. Y., early took the lead in color and vigor and about six weeks from sowing could be readily distinguished at a distance by the richness of its foliage. It was also in flower before the other plots, one of which was uninoculated, the other two sown with inoculated seed. Unfavorable weather prevented cutting until mid-August when all four plots were cut, the few large weeds were removed and the alfalfa weighed. The plot inoculated with alfalfa soil yielded 1673 green poundis which cured to 701 dry; the 


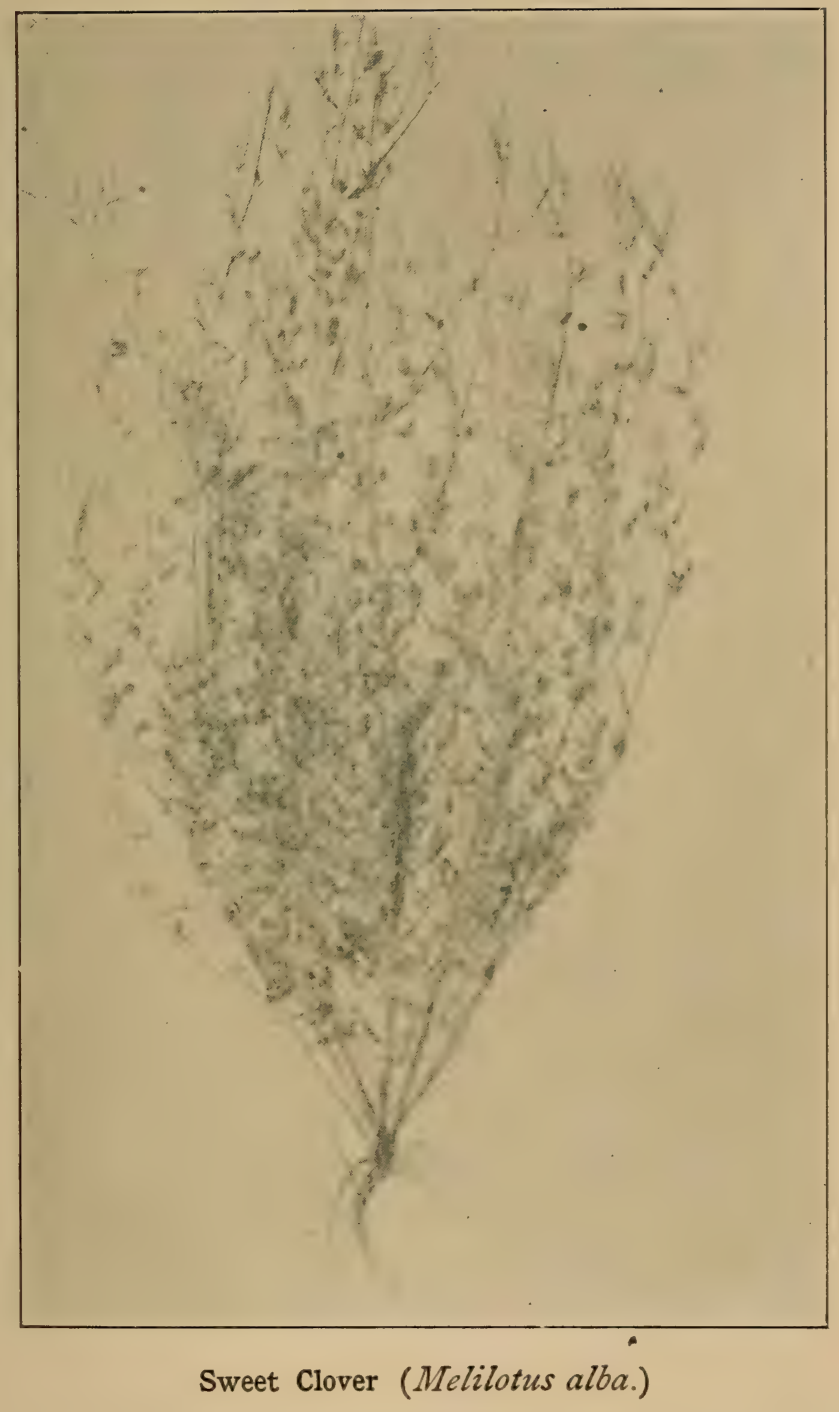

The seed of Sweet clover is an occasional adulterant of alfalfa. The plant is much taller than any of the species of Medicago. The flowers are white and borne in rows on elongated flower stems. 


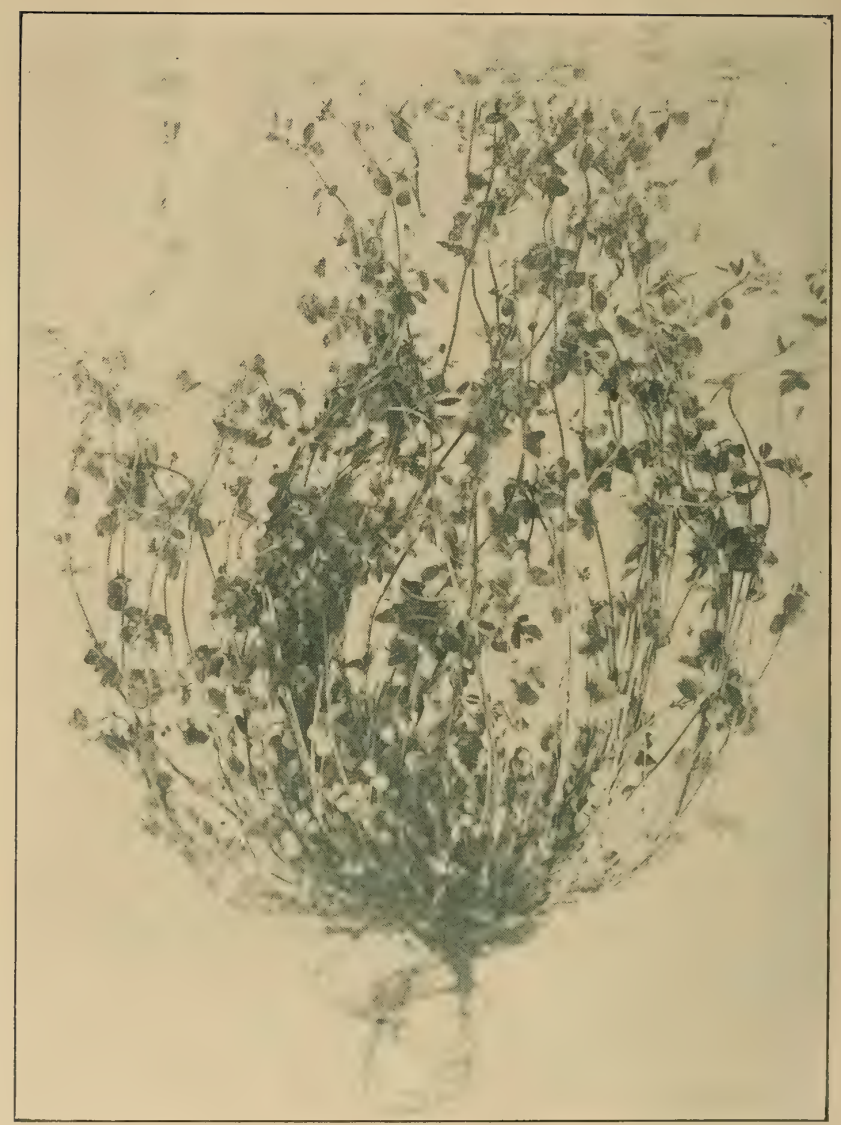

Yellow Trefoil (Medicago Iupulina)

A common adulterant of alfalfa. The leaflets are broader and more clover-like than alfalfa. The flowers are yellow and sparsely scattered in small, hop-like clusters at tips of long flower-stems. 
uninoculated plot yielded 726 green and 3 I 3 dry, the other two plots sown with inoculated seed 416 and 377 pounds green or 189 and 168 pounds dry respectively. These results point favorably to inoculating the soil from old alfalfa fields

\section{NORTH CAROLINA}

Dr. B. W. Kilgore, Director North Carolina experiment station.-Alfalfa has been grown in a small way in this state, particularly in the section around Hillsboro, for 75 to 100 years. The soil there has become well inoculated and there are some small areas of good alfalfa grown there. There has been for a number of years past considerable interest in the production of this crop, but its cultivation has not been very successful. On our experiment farms in different sections of the state it has done reasonably well, and there have been put out quite a large number of small areas during the last few years, which give hopes of success with the crop. When some further details regarding the time and method for seeding and treatment, especially to prevent crab grass and weeds from getting the upper hand of the crop during the summer have been worked out, we believe that alfalfa will be grown to quite a large extent and be a most valuable addition to our present forage crops.

\section{NORTH DAKOTA}

Prof. J. H. Shepperd, Dcan of the North Dakota Agricultural college.-Alfalfa has not been given a thorough trial by the people of North Dakota, but the results secured by the experiment station indicate that it is 
capable of producing paying crops here. It will yield two or more tons of hay per acre annually and will, when sown on well drained land, continue to live from year to year as it does in old alfalfa districts. A little growth should be allowed to stand through the winter season to protect the roots by catching a covering of snow over the entire field. Our people are thoroughly awakened and encouraged by the results secured at the experiment station, and its growth is likely to soon be a common practice in the state.

\section{ОНIO}

Prof. Charles E. Thorne; Director Ohio experiment station.-Numerous attempts were made during the latter half of the nineteenth century to grow alfalfa in Ohio, but so far as the knowledge of the writer goes, that of Joseph E. Wing of Mechanicsburg was the first that could be pronounced a decided success. Mr. Wing had seen the plant growing in the arid region of the West, and was fortunately able to make his initial experiments on the soil formed from the decomposing limestone gravels of Champaign county, a soil possessing three of the indispensable requisites for alfalfa culture. Plenty of lime, plenty of humus and good drainage. Other farmers curing recent years have attempted the culture of this plant, and where experiments have been conducted upon suitable soils and carried out with sufficient care and persistence, they have been successful. Thus far the most promising alfalfa fields in the state are to be found either in such localities as those of Mr. Wing, namely upon the soils underlaid with limestone gravel which are found 
over the western half of the state, or upon such of the river bottom lands of the state as are above overflow and are underlaid with gravel, giving natural drainage. The experience of Ohio growers of alfalfa has demonstrated the following points: (I) Alfalfa must have lime. If the soil is naturally deficient in this substance it must be added artificially. (2) Alfalfa must have humus. It is idle to attempt to grow it upon a soil which has been worn so thin that it will not grow a good crop of corn. Such soils must be manured before they will successfully produce alfalfa. In this respect it is very different from the plant which it so closely resembles in habit of growth, Sweet clover. (3) Alfalfa will not grow with wet feet, yet it is a great consumer of water, and the soil must be of such a character as to hold large stores of water without being water logged. Hence the value of bottom lands naturally underdrained by strata of gravel a few feet below the surface. (4) IVhen lime, humus and drainage are supplied, the bacterial organisms through which atmospheric nitrogen is assimilated will gradually appear upon the alfalfa roots, but their growth may be hastened by inoculating the land with soil from a field in which alfalfa or Sweet clover has previously grown. The experiment station has been most successful in getting a stand of alfalfa where the land was thoroughly prepared in the spring and then harrowed every week or ten days until July or August. The seed was then sown and harrowed in. By this means the weed seeds were germinated and destroyed before the alfalfa was sown. 


\section{OKLAHOMA}

Agricultural experiment station: Bul. 7 I, by Prof. F. C. Burtis and L. A. Moorhouse.-This crop is being grown in every county in Oklahoma and in some sections, a fair acreage is present. From many fields as large yields are obtained as are produced any place else in the United States without irrigation. On the uplands in Oklahoma, as elsewhere, the returns vary. Where the subsoil is hard and impervious, the yields are quite meager under unfavorable climatic conditions and the crop needs considerable nursing such as disking and harrowing, to keep the crab grass from taking the field in a few years. On these upland soils with the hardpan subsoils which grow cowpeas to perfection, the farmer who is not willing to inform himself about proper methods and to give his alfalfa fields much attention and care, should grow cowpeas instead. But as has been indicated before, alfalfa is being grown on such soil successfully and profitably, but only in small areas.

The soil of the experiment station farm at Stillwater, on which the following yields of alfalfa were obtained is a clay loam underlaid by a verv stiff, impervious subsoil of a hardpan nature.

Yields of Field F, containing about four acres; cured hay for the season.

I902-I.76 tons hay per acre in 5 cuttings. I904-I.23 tons hay per acre in 5 cuttings. I904-3.I 3 tons hay per acre in 4 cuttings. I905-3. I 3 tons hay per acre in 5 cuttings. Average for four years, 2.3 I tons of hay per acre. In the spring of 1904 the field received an applica- 
tion of barnyard manure at the rate of 15 tons per acre. Every season, the field was disked from three to four times and harrowed. During I903 and I904, web worms damaged the crop.

Yields of Plats I, 2, 3, and 4, Field E. The plats are on similar soil to that of Field $F$ and have been handled about the same as that field. The yield is given for all the plats together.

I902-2.67 tons hay per acre.

I903-3.27 tons hay per acre.

I904-3.3I tons hay per acre.

Average for three years, 3.08 tons of hay per acre.

Yield of Field $\mathrm{H}$, containing about five acres :

1902-4.20 tons hay per acre in 5 cuttings.

I903-2.88 tons hay per acre in 5 cuttings.

1904-2.12 tons hay per acre in 5 cuttings.

1905-2.27 tons hay per acre in 5 cuttings.

Average for four years 2.69 tons per acre.

Barnyard manure was applied to this field in Igoo-'or, and it was given the same treatment as was received by the fields previously mentioned. Other results will be given in a later bulletin, but those cited give a fair idea of what may be expected on upland where the subsoil is a hardpan. The hay from all the fields mentioned above, obtained in the last two or three cuttings, contained varying amounts of crab grass, so the yields given are not all alfalfa. Since the above results were obtained, some good bottom land has been acquired by the experiment station and alfalfa has already been seeded on some of it. In a few years, yields that will look better when compared with those of our best alfalfa growers can 
probably be reported. The following summary will be helpful.

I. Alfalfa is a great and valuable crop for Oklahoma, where there are as good alfalfa soils as are found in the world and as good yields are produced as anywhere.

2. The acreage of alfalfa should be greatly increased in Oklahoma. There are but few farms here that do not contain a few acres at least that will grow the crop profitably.

3. Select the best soil on the farm for the first trial, and try only a few acres at first.

4. Decide a year or two in advance of seeding time what field is to be seeded to alfalfa, and follow the best methods of cropping and preparation known.

5. Buy only the very best seed. Get a sample and test it before buying and purchase your seed a year before you expect to sow it unless you are sure you can get good seed just when you want it.

6. Twenty pounds of good seed to the acre is plenty and as low as twelve pounds is all that is used by many.

7. Seed either with the drill or by broadcasting. Conditions must be right for either to succeed.

8. Fall seeding and spring seeding are both followed in Oklahoma with good success. If the conditions are not right at seeding time, or turn out unfavorable after seeding, or while the plants are small, either may fail.

9. As a rule fall seeding is preferable in Oklahoma, particularly on the less adapted soils.

Io. Take due care in harvesting the hay that half its value is not lost at that time. 
I I. Don't give up trying to raise the crop because you fail in your first attempt or even if the failure continues to the second and third attempts. Successful alfalfa raisers have stated that in instances they have failed as many as five times in getting certain fields started to alfalfa, and after they did get the field seeded, the returns from it would justify reseeding ten times if necessary.

\section{OREGON}

George W. Dunn, Jackson county.-For eight years I have grown 60 acres of alfalfa on bottom land with granite loam soil, gravelly and sandy. The plant does not grow well unless the soil is deep and well drained, and will not grow where there is a clay subsoil or stagnant water. Well water is reached at a depth of Io to I 2 feet, and the soil, unless cultivated or irrigated, becomes dry and hard in the summer. As soon as the heavy frosts in the spring are over, seed may be put in, after thorough, deep plowing and pulverizing. I always sow broadcast, 20 to 25 pounds to the acre, then harrow in and clod-mash or roll. Water for irrigation is obtained from streams, and it should be applied as quickly as possible, the best way being to flood the whole field for a few days, and then take all the water off, as standing water will kill the plant quicker than anything else. The quantity of water needed the first and later years does not seem to differ materially. As soon as the young alfalfa is high enough, it should be mowed. This kills the weeds, and gives better chance for growth. Then I cut for hay, but it does not pay much the first year. If land is well drained, the plant lives through the winter easily, and by 
the second or third year is at its best. In ground adapted to its growth, it is almost everlasting, unless killed by gophers or hogs. After the first season, there are three or four cuttings, averaging each from one to three tons to the acre. For hay, I cut as soon as it begins to bloom freely, ordinarily raking the next day, and cocking the third, in this dry atmosphere. The stack does not shed water well, and the best plan is to put in a good barn. The hay bales well, and the size of bale is simply a matter of opinion or convenience, there being no difference in the keeping quality. The second crop is the one for seed, as the first always contains more or less foul stuff, and the third will not mature seed. I dispose of hay at from $\$ 4$ to $\$$ Io a ton-the same price as other hay in the same market-and it is in great demand for milch cows. The seed costs me from Io to I 6 cents a pound. The straw makes good feed, but of course is not so good as the hay. For feeding farm animals, alfalfa is superior to clover or timothy. We produce as fine beef here, by feeding alfalfa alone, as can be done in Kansas or elsewhere by feeding ordinary hay and corn. The pasturage is profitable and satisfactory for horses and sheep, and for hogs it is unsurpassed-they will grow and fatten on it without other food. Cattle on the pasture sometimes bloat, but not when they are used to it, or when it is dry. I keep about I5O head, and in eight years have lost but two. The roots will grow to, but not into, water, and thrive in deep gravelly or sandy soil. The plant sends down a large, straight taproot, which, as it approaches water, branches and spreads out into numerous small rootlets. 


\section{PENNSYLVANIA}

Prof. George C. Watson, Pennsylvania experiment station.-The experiment station has received many letters requesting information pertaining to the growth and cultivation of alfalfa. From these communications it has been learned that many farmers have attempted to grow alfalfa on land that is not at all well suited for this purpose, and consequently, many failures have resulted. The first attempts to grow alfalfa were made wholly by spring seeding, which, in most instances, has proved quite unsatisfactory. As alfalfa starts slowly and exists as a small plant for a considerable length of time, the weeds have an abundant opportunity to germinate and outgrow the more delicate alfalfa plants. Whatever conditions favor the growth of weeds, particularly in the early part of the growing season, materially increase the risk of failure with alfalfa. Largely on account of the weeds and grass, late in summer or fall seeding has been most satisfactory. While a drouth at this time may seriously interfere with germination, yet the injury from insufficient moisture is not likely to be so great as that from a rank growth of weeds earlier in the season. Land that has been cultivated for a few weeks during the summer may be sown to alfalfa in August or September with comparatively little danger from annual weeds, which are so troublesome in spring seeding. Land that is infested with noxious perennial weeds and grass would not, of course, be in suitable condition for seeding after a few weeks of cultivation, no matter how thorough it may be. The most tenacious grasses and weeds, like Canada thistles and quack grass, should be given at least 
a few months of thorough cultivation before seeding. Experiments indicate that alfalfa will not survive continued alternate freezing and thawing if the soil contains very much moisture. Land that is at all inclined to "heave" is not suited for the growth of this crop. The soil of the station farm, upon which most of these experiments have been made, is a porous limestone clay underlaid with limestone rocks which afford abundant drainage through the fissures. Notwithstanding the fact that the soil is naturally well drained, in some places it seems to hold too much water to afford a most congenial home for alfalfa. This crop will endure severe freezing, provided the soil is sufficiently dry so that it has no tendency to "heave." Land upon "which clover will "heave" undoubtedly contains too much moisture for alfalfa. It seems to be able to endure the rigors of winter better than clover, provided the moisture conditions are favorable.

\section{RHODE ISLAND}

Dr. H. J. Wheeler, Director Rhode Island experiment station.-Alfalfa culture in Rhode Island is a very uncertain undertaking. A few persons have occasionally met with some success, but the majority of experiments have been failures because: (I) Most of the soil in this state is too deficient in carbonate of lime to enable alfalfa to succeed even if other conditions are favorable. (2) It is occasionally almost destroyed by clover leaf spot. (3) The general culture of alfalfa in this state cannot be made successful even if all of the conditions aside from the climate are made favorable. Farther 
north where the snow falls before the ground freezes and remains until the opening of spring, this plant can be grown successfully. Farther south where the changes are less severe, the same is true. In Colorado and other places where irrigation is practiced, if it is desired to get rid of a field of alfalfa, the ground is flooded after it is frozen and the freezing of water over the surface accomplishes what is desired. In Rhode Island it not infrequently happens that we have in winter a considerable fall of snow. A warm southeasterly rain may fall which transforms it very shortly to slush. In a few hours the temperature may drop to zero or below. Sometimes rain which falls freezes over the surface, forming a solid coating. These conditions in this state destroy the alfalfa just as the flooding does it in the West, and while alfalfa may be carried successfully through the winter, if the season is favorable, I believe the chances are too great to make it a promising crop. Last winter we carried some through successfully and have done so once or twice before, but my advice to Rhode Island farmers is to grow the clovers, soy beans, and possibly cowpeas rather than attempt to embark in growing alfalfa until it has been definitely shown by experiment that the climate and other conditions can be successfully combated.

\section{SOUTH CAROLINA}

Prof. C. L. Nerwman, Agriculturist South Carolina experiment station.-We have, to some extent, had remarkable success with alfalfa. On the old exposition grounds at Charleston, over six tons of cured hay were cut last year on one acre. This year one cutting afforded 
4. I 5 pounds of cured hay. In the upper portion of the state, alfalfa is grown with considerably greater difficulty. At Anderson, the county seat of Anderson county, there is an alfalfa field that was sown 65 years ago and it still affords some return.

\section{SOUTH DAKOTA}

Prof. James W. Wilson, Director South Dakota experiment station.-Experience shows that a good stand of alfalfa can be secured, if ordinary care be exercised in preparing the seedbed. It is not a plant that does well when sowed on the native prairie sod after disking. On the college farm during the spring of 1904 a small area of native sod was disked five times; part was sowed to alfalfa and part to clover. The next spring only a few scattering plants of alfalfa could be found, while a fair stand of clover was secured. Good results have been obtained with both the Turkestan and the American varie. ties. Neither has winterkilled during the time, and the yield per acre in each case has been good. A field sowed to Turkestan alfalfa in 1899 at Highmore Forge testing station still produces good yields. The quantity of seed to sow per acre depends largely on the way it is sowed, requiring more if broadcast than when drilled. We suggest 20 pounds when drilled and 25 pounds when sown broadcast. The time to sow depends upon the condition of tilth. Contrary to what is sometimes supposed, alfalfa does not require a wet soil, but one that is wel! drained, with a loose subsoil. The plants will stand cutting several times during the first year. This method should be resorted to when sown on a field badly infested 
with weeds, in order to secure a stand of alfalfa. In 1902 a field rented by the college farm, which had been cropped for several years and become foul with mustard, was sowed to alfalfa. It was cut three times during the growing season, and the result was that in 1903 there was practically no mustard to be seen, but a first class stand of alfalfa was obtained.

George E. McEathron of Beadle county writes: "I consider alfalfa and clover culture practicable in this locality. I do not think it necessary to inoculate soil for these crops in South Dakota. After the first year I cut my alfalfa fields three times and secured an average yield of five tons to the acre. I have never allowed seed to mature, always cutting for hay. No trouble from winterkilling has been noticed."

O. S. Jones of Lake county writes: "I began raising alfalfa on my place two miles west of Madison five years ago. The soil is a dark loam with some sand in it, lays level and has a sand and gravel subsoil. Water is obtained at a depth of eight to ten feet. I have used both the Turkestan and the common alfalfa, and I consider the latter the better for my land, as it grows ranker, with more leaf and better color than the former. I have had the best success in sowing about the first of May, without a nurse crop. On one four-acre piece seeded three years ago, I pastured I 50 to I 75 head of hogs and spring pigs for two months this year and also cut between 15 and $\mathrm{I} 6$ tons of hay in two cuttings. I sowed 12 acres this year in two six-acre fields, that have been pastured, continually, with I75 head of hogs and pigs and ten head of young cattle since early in July, and a great deal of it ma- 
tured seed. I could have cut these pieces in August with profit had I so desired, and then had plenty of growth to have kept the stock in pasture, changing pastures each week."

N. O. P. Synoground of Brown county writes: "I consider alfalfa and clover culture practicable in this locality. I also consider the Turkestan variety superior to the home-grown varieties. Cut the field twice the first year and received four tons per acre. I have never cut any for seed. These crops have not winterkilled here."

\section{TENNESSEE}

Prof. H. A. Morgan, Director Tennessee experiment station.-Alfalfa has been known in Tennessee for many years, but not until the general failure of Red clover, due to one or more species of Colletotrichum, and the search for substitutes for Red clover, were any serious efforts made to grow alfalfa in this state. On alluvial land along the Mississippi river in west Tennessee, in what is known as the Central Basin section of middle Tennessee, and on the richer lands of east Tennessee, alfalfa has been grown very successfully, and each year large areas are being sown to this clover. Mr. L. Donaldson, of Lake county, gives the following relative to the preparation of soil, etc., for alfaifa in the alluvial area of west Tennessee: "The land is plowed deep with large moldboard breaking plows in September or about the first of March. It is then harrowed until thoroughly pulverized, and either about October Io or April I, two gallons of seed are sown, by machine or by hand. The harrow is used for covering the seed. We have no more trouble with 
the crop after seeding. The plants germinate and take root rapidly. I have known alfalfa roots to reach a length of two feet from the last of March to June 25 We frequently cut the crop five times per year." George Campbell Brown of Maury county states that he has sown alfalfa in March using spring bariey as nurse crop, and in September with success. Land sown to alfalfa in I90 I yielded four cuttings per year in 1902, I903, and I904, averaging from 16 to 18 tons per acre in the three years. Mr. Brown uses soil for inoculating, and believes he has gotten well-defined results from nitro-culture sent out by United States department of agriculture. At the experiment station at Knoxville, alfalfa has been successfully grown for many years. Heavy applications of farmyard manure and the use of 300 pounds of acid phosphate and 25 bushels of lime per acre invariably insures large yields of alfalfa. Crab grass, Panicum sanguinale, in summer and chickweed, Stellaria media, in winter are cnemies to alfalfa in this latitude. These pests should be gotten rid of by the use of clean culture crops preparatory to the sowing of alfalfa. With plenty of stable manure, lime, and phosphorous, artificial inoculation seems unnecessary. Any soil of over a few feet deep may be prepared so as to grow profitable crops of alfalfa. This preparation is much more expensive on some soils than others.

\section{TEXAS}

Prof. B. C. Pittuck, Agriculturist of the Texas cxperiment station.-Alfalfa sliould receive the attention of farmers in every section of Texas where conditions are in 
any way favorable to its growth. At present prices, after it is once established, a yield of one ton of hay per acre will afford a good profit, while yields of four and six tons, which are not unusual on favorable soils, make the investment exceedingly profitable. The present demand is much greater than the supply and bids fair to increase in greater proportion during the coming year. Its increasing popularity with the farmer is based upon sound Dusiness principles, as its value does not consist solely in its market price, but in its value as food for his stock and food for his soil. It will furnish green pasturage and hay of the best quality without materially impoverishing the soil. Many farmers refrain from planting alfalfa because some neighbor, far or near, planted on land apparently similar to theirs, and it died of the disease commonly known as cotton root rot. It would be far better for each farmer to test his own land, for alfalfa may be affected by this fungus at one place and entirely unaffected on ground only a few rods away. The value of an alfalfa meadow is such as to warrant a farmer in giving considerable time, labor and study to the plant, before deciding that natural conditions prohibit him from successfully growing it.

\section{UTAH}

Aaron F. Farr, Jr., Cache county.-Fifteen years ago, when I began raising alfalfa, I had 40 acres, and for the past eight years I have had about I 35 acres, all on heavy clay soil, containing considerable salt, and underlaid with very stiff, white clay. The soil is dry on top, but below a depth of $2 \mathrm{~T} / 2$ feet is damp, and salty water is found at 
a depth of eight feet. Small grain was raised on the new land for one or two years, after which the ground was plowed in the fall, and again in the spring, harrowed, and well pulverized. Seed was put in, I 2 pounds to the acre, two inches deep, with a press drill. The time for sowing is about the same as for corn, in April or May. If there is plenty of water, it is well to sow the alfalfa with oats, and then cut for hay the first season. Some of my land is irrigated, by flooding, three times in the season, by means of a large canal from the river. The more water is used, the more alfalfa there will be, but the hay from unirrigated land is less sappy than that which has been watered. The plant is not liable to winterkill here, and on sandy loam and gravel soils the full yield is attained the second year, while, on heavy soils, it requires three or four years. I have some that is 20 years old, and cannot say how long it will yet continue vigorous. There is difficulty in ridding land of the plant, unless it is flooded in the winter time. We have usually two cuttings each season, with an average yield for each of about two tons to the acre, although some parts of the land yield four tons at each cutting. I have found it more profitable to raise seed than hay, and for this purpose I prefer the second cutting, using the self-rake, allowing the alfalfa to lie in small piles until dry, then hauling, stacking, and threshing, the same as wheat. The hay lies about 22 hours in the swath, 24 hours in the windrow, and one or two days in the cock, after which it is stacked in large ricks with a horse fork. If properly cured, it will not mold or heat, as it will if damp. On land valued at $\$ 30$ an acre, the cost of the alfalfa, in the stack, is 
about $\$ 1.50$ a ton. The cost of baling is about $\$ 2$ a ton, the popular weight for bales being about Ioo pounds. An average yield of seed is from 300 to 500 pounds to the acre. Threshers take one-sixth toll, and can thresh about Ioo bushels in a day. The common machinery saves only about two-thircis of the seed. A bushel of seed weighs more than 60 pounds, and we put I75 pounds in a two-bushel seamless sack. The average selling price of the seed is about $\$ 3.50$ a bushel. I have one piece of land, containing 60 acres, not irrigated, valued at \$30 an acre, from which, for ten years, I have cut one crop of hay, and one of seed, and realized an annual net profit of \$Iooo cash. As compared with clover and timothy for feeding farm animals, my opinion is that alfalfa will fatten quicker, but will not go so far. The pasturage is profitable and satisfactory for horses and sheep; for hogs, one acre of it is as good as $21 / 2$ of Red clover, and for cattle, one acre is as good as two of clover, provided the land is dry. On wet land, the clover is better for cattle, and, as to bloating, the danger is just the same from the two plants. In my opinion, the plant will do well on sidehills, where the drainage is good, if the land is plowed deep, and the seed drilled in two inches deep and rolled with a heavy roller. Once started, the plant lives almost forever, on any soil, unless the wrong kind of a winter strikes it. I have an alfalfa root, taken up in digging a well, that is $2 \mathrm{I}$ feet long. The roots of alfalfa are sure to find the water, if anywhere at all within reasonable reach.

John Jones, Utah county. - I have rased alfalfa 20 years, and now have 250 acres, mostly on sandy loam upland; have some on bottom land, where it grows too 
rank for seed. The subsoil is light clay, with water from I 5 to 20 feet from the surface. On land with hardpan subsoil, it declines after a few years, unless irrigated often. In digging for water, we find the subsoil begins to get dry at about I 8 inches, and continues quite dry for 8 or Io feet; then moisture increases until water is reached. We prepare ground by plowing in the fall, drag very fine in the spring, and sow as early as the season will permit, in order to catch the spring rains, using 20 to 25 pounds of seed per acre. Our first cutting is made about June 20, and is a little weedy, but there are fewer weeds in later cuttings. We get about two tons the first cutting, if the stand is good, and about the same the other cuttings that year; have no trouble here about winterkilling; standing water is injurious to the plant. Here alfalfa on uplands is watered three or four times each season; some land needs only one or two floodings, while other lower lands have no irrigation. After getting a good start from the seed, we begin watering about May I, from small mountain streams. The first year requires water about every week; after that, once a month is sufficient. For hay, we begin cutting with the first bloom, obtaining 2 to $2 \frac{1}{2}$ tons from the first cutting, about 2 the second, and from I to I $1 / 4$ the third cutting; let 1 lie about two days before hauling to stack, being careful not to stack too green. For seed, begin cutting when seed is ripe, the second crop being considered best. The grasshoppers have been troubling the second crop to some extent, and we have on that account been cutting the first crop for seed, using a reaper and separating with a threshing machine. On a basis of 7 per cent interest on $\$ 30$ 
per acre with five tons of hay per acre each year, it has cost about $\$ I .55$ per ton to raise alfalfa. We estimate \$I per ton for cutting and stacking, and 60 cents per acre for water tax. It costs $\$ 2.25$ per ton for baling, roo to I25-pound bale, the size having no effect as to the keeping of properly cured hay. From 8 to Io bushels is a fair average seed yield, the cost of threshing and cleaning being about 40 cents per bushel. Baled hay is worth (free on board) about $\$ 6.50$, and loose, about $\$ 4$ per ton; seed sells for about 7 cents per pound. Alfalfa hay is preferable to timothy or clover, ton for ton, for feeding without grain; with grain, our liverymen prefer timothy. We find alfalfa with grain equal to timothy for draft horses, but for drivers, timothy is preferred. Alfalfa is considered better than clover by our hog raisers; it makes good pasturage for horses, and is better than Red clover for cattle. If cattle are kept continually on the alfalfa, they are not very likely to bloat; the trouble arises from turning hungry animals on it. We use a gag, made of a stick about three inches in diameter, to force the mouth open, but sometimes have to make an opening in the paunch with a knife. Irrigation seems to improve the quantity without increasing the quality. The early cut hay has at least 20 per cent more value than the straw from the seed crop; we have had very good results from feeding the straw, as it always contains more or less seed. Alfalfa sown on clay soil, with hardpan subsoil, gradually dies out after two or three years; also when water is near the surface; when the roots reach water too near by, the plant dies. Sown on good sandy loam, it reaches its best yield about the 
second year; on heavier soils, about the third year. We have alfalfa 20 years old, as vigorous and good to yięld as when started. It is preferable to clover for turning under, as the large roots make more manure, and the tops are much heavier. IVe grow alfalfa on our uplands without irrigation, but it requires two or three years to get a start; the first year, it makes a growth of 8 or Io inches, and wilts; second year, it grows a little taller, thickens up somewhat, and then, apparently, dies; the third year, it gains in height and strength, and yields a good crop, or even two crops, according to the subsoil. If the subsoil is hardpan, I would not predict the result as worth the effort. I do not see how Utah would get along without alfalfa. I have Ioo acres, from which are cut from 2 to $2 \frac{1}{2}$ tons oi hay per acre, and from 800 to I300 bushels of seed each year, and it has not been irrigated for 15 years. Last year the seed yield was 968 bushels, and the grasshoppers damaged it considerably; the seed brought Io cents per pound on the track here. We make good beef from the hay alone, and have done so on the threshed straw.

\section{VERMONT}

Prof. J. L. Hill, Director Vermont experiment station, in Bulletin No II4 says that popular interest in the question of alfalfa culture was never so great in Vermont as it is today. The result of $5^{6}$ trials at as many Vermont points are summarized: as, permanent successes, I2; temporary successes, ten; success at outset, eight; seeming success, five; questionable, seven; failure, I4. Thirty-six per cent of the trials may fairly be said to 
have been a success, and 68 per cent of these were located in the Champlain valley. Only ro of the $5^{6}$ alfalfa growers appear to have sown more than an acre. It should be noted that success with a fraction of an acre does not of necessity imply that an equal degree of success would be attained with plantings on larger areas. The preeminence of the Champlain valley in alfalfa growing seems to be due to the character of the farming in that section and to the nature of its soil. Failures may generally be ascribed to one or more of several unfavorable soil or weather conditions, to weeds, to disease, or to seed which either is inferior or from an unsuitable source. There seems to be a sufficient proportion of successes in the state to justify the encouragement of further trials. It is equally clear, however, that anyone planting alfalfa for the first time should not only give careful heed to the needs of the plant and to the methods of culture outlined later, but should begin by experimenting in a small way. The most significant thing developed by the analysis of the returns to date is that the crop seems to succeed best in the Champlain valley. Why is this? Probably one factor, not apparent on the surface, is that the men who have succeeded in Addison county are largely sheep breeders who value the crop so highly in their special industry that they are willing to give more attention to its culture than are the dairy farmers. It should be recalled in this connection, however, that the evidence reviewed indicates practical success with alfalfa at Plattsburgh and in adjacent Canadian territory. Without prassing the matter to a definite conclusion, we consider two things to be at least strongly suggested and 
worthy to be borne in mind in connection with further experiments in alfalfa culture: (I) The chances of permanent success with it are probably better in Vermont than they are farther south and east in New England. This may be in part attributable to soil conditions and in part to climate, the latter being associated with greater remoteness from the seashore. (2) In Vermont the chance of success in its culture seem to be greater in the Champlain valley than elsewhere. The reasons suggested in the above may apply in explanation of this. The nature of the geological formations is also worthy of consideration. It seems not unlikely that the relative richness of the soil of this region in lime and potash and its other chemical and physical characters make it especially favorable to alfalfa growing.

\section{VIRGINIA}

Prof. Andrew M. Soule, Director Virginia experment station.-In Bulletin No. I 54 from this station we summarize as follows: Alfalfa is being grown with success in various parts of Virginia and the indications are that it will do well in humid climates, providing the soil is brought into suitable condition for its growth. Alfalfa has many useful qualities. It yields from three to five tons of cured hay in a year, and remains on the land for a long period of time when once well established. It grows best on deep, open, porous soils well supplied with vegetable matter. The roots of alfalfa are from five to I 5 feet in length, enabling it to draw much of its food from the subsoil. It thus enriches the land for succeeding crops and opens it up to the action of air and water. 
Land intended for alfalfa should be made very rich by plowing under legumes or applying farmyard manure. In addition, from 200 to 400 pounds of acid phosphate, Thomas slag or bone meal, with 100 pounds of muriate of potash, should be applied per acre. If the land is acid, which may be determined by testing with blue litmus paper, an application of 25 bushels of lime should be made. It is generally best to use the unslaked lime, which may be applied with a manure spreader, a grain drill or broadcasted over the land and covered with a harrow. Land intended for alfalfa should be carefully cultivated in hoed crops or summer fallowwed so as to destroy weeds, the worst enemy of alfalfa during the early stages of its growth. Alfalfa may be seeded either fall or spring. When fall sown it can be cut for hay the next summer, whereas, the spring sown crop should be clipped several times during the first season and left to mulch the ground. Alfalfa seed is sometimes infested with dodder, which grows as a parasite on the plant. The orangeyellow threadlike appearance of dodder gives warning of its presence, and it can be easily destroyed by cutting and burning if taken at the outset. Alfalfa is frequently attacked by leaf spot in the eastern states. The disease is easily recognized as its name indicates, and persistent clipping will generally eradicate it. The amount of seed to sow varies, but 20 pounds will answer as a rule. Alfalfa should be cut for hay when coming into bloom, as it yields more nutrients per acre at that time, and succeeding crops yield better. Alfalfa is not more difficult to make into hay than is Red clover. It may also be pastured to advantage, though there is some danger of bloat, and, 
owing to the high feeding vaiue of the hay, it is doubtful whether it would be good practice to graze it in the East, except with hogs. Alfalfa being a legume has the power of assimilating atmospheric nitrogen under certain conditions. It is thus a soil improver. Farmers cannot afford to purchase nitrogen when they can gather it from the air through the action of leguminous plants. Alfalfa often fails, even though all the physical conditions seem favorable, because the bacteria which live in the nodules on its roots are not present in the soil. This deficiency may be supplied by getting soil from an old alfalfa field or from fields where Sweet clover or Bur clover pre-viously grew with success, or by means of artificial cultures. The Virginia experiment station, realizing the importance of alfalfa to Virginia farmers and the difficulty of securing inoculated soil at a reasonable cost, has undertaken the preparation of pure cultures which it is distributing at a cost of 25 cents per acre. Soil inoculation through artificial cultures is still in its experimental stages, but it seems wise that Virginia farmers should be given an opportunity to test these cultures at a moderate cost and determine once for all their real value under field conditions. The high feeding value of alfalfa has long been recognized. It is admirabiy adapted to the needs of all classes of live stock. It has been fed with profit to horses, cattle, sheep and swine. It can be so utilized as to largely take the place of wheat bran and other expensive concentrates. The plats of alfalfa seeded in the spring of 1904 , both on the station farm and on Brush mountain, show the importance of soil inoculation and the advantages of using lime and phosphates on land 
intended for this crop. From a general review of the situation it appears that there is no reason why alfalfa, under good management, should not succeed in many parts of Virginia.

\section{WASHINGTON}

F. M. Lowden, Walla Walla county.-In 22 years I have had experience with from I to 400 acres of alfalfa, on bottom, second bottom, and upland, with clay, sand and loam soils, with subsoil of hardpan and strong alkali from 18 to 20 inches below the surface, and water at depth of 18 to 20 feet. The soil is seldom moist all the way down, the dry soil beginning five to eight feet below the surface and ending within two or three feet of the water. After plowing deep and harrowing well, I sow in the spring, late enough to miss frost, 25 to 30 pounds to the acre; then cover, in light soil from one to two inches, and in clay soil less. During the first season it should be mowed so that the weeds cannot choke it out, and then there will be about a ton of hay to the acre to be cut in August. I irrigate with water from streams thoroughly in the spring and after each cutting, using enough water to soak the ground for a few days. New land requires more water than old, but the quantity needed is about the same every year. At three years the plant attains its best yields, and with proper care will not need reseeding. There are usually three cuttings each season, with an average of $\mathrm{I} / 2$ tons to the acre, and $I$ have known five cuttings. It is mowed for hay when it commences to bloom, and for seed any time before the frost comes, the second crop being best for the latter use. 
The seed is mowed, threshed and dried as any other clover is. The hay should lie before raking until it is thoroughly wilted, then cure in cock two or three days. We stack in ricks 16 to 18 feet wide and any desired height or length. The hay will not heat if well cured before stacking. On land valued at $\$ 40$ an acre, the cost of hay in the stack is about $\$ 1.50$, and to bale this costs $\$ 2$ a ton. The yield of seed is 5 to Io bushels to the acre, and it sells for $\$ 4.50$ to $\$ 7.50$ a bushel, while hay brings $\$ 4$, formerly $\$ 8$. For threshing, a clover huller is better than the common machine. The alfalfa straw is of double the value of any other straw for feeding. The hay grown without irrigation is not so rank as that which is watered, and is consequently more valuable as a feed; any is better than timothy, and equal to clover for cattle, but the seed must form in it to make it valuable for working horses. After cutting three crops in a season, I usually use the field in the fall for pasturing cattle, and it furnishes nearly double the feed that Red clover will, acre for acre. For hogs the pasturage is much better than clover, and I sow with blue grass and clover, on rich ground. For horses and sheep the pasturage is better than clover, but causes bloat in the same way. It is difficult to plow up alfalfa, but continued cultivation will rid land of it when desired.

Oscar Drumheller, Walia Walla county.-Have grown alfalfa for six years, and now have I 50 acres, part on bottom, some on clay, and a part on slightly sandy soil ; subsoil is a thin layer of hardpan; below that a sort of gumbo, and underneath that a white clay. Abundant water is found at Io to 8 feet, moist soil reaching to the water. Our land requires no special preparation for 
alfalfa; manure is spread on weak spots; we sow 20 pounds of seed broadcast, about May Ist, and harrow once to cover. Some cut it the first year; some years the crop is not worth touching for either hay or seed; there is no trouble here from winterkilling. We never irrigate. The first cutting yields about three tons, the second, about two and one-half tons, the third, about two tons, and the fourth, one ton. For hay, cutting should begin when in full bloom; we never cut for seed, but the first crop is best. The season must govern the time for curing, whether two days or Io; it will heat and mold if not dry before stacking; no choice in size of stacks. On land worth $\$ 40$ per acre, it costs about $\$ I .50$ per ton to grow and put alfalfa in the stack; baling costs $\$ 1.50$ to $\$ 2$ per ton, the bales weighing I 50 pounds. Alfalfa hay sold for $\$ 12$ per ton in 1890 , and is now selling for $\$ 2.50$; seed sells for Io to 12 cents per pound. For cattle, alfalfa hay leads all others; for work animals, it is a little "washy," but we use nothing else; for pasturing hogs, one acre of alfalfa is worth two of clover, and it is found satisfactory for horses and sheep; alfalfa will pasture more cattle than clover, but is more productive of bloat, especially on windy days. The best remedy for bloat is to get the foreparts of the animal on high ground and splash cold water on its back; when all else fails, apply the knife to the left side. We prefer unirrigated hay, which seems firmer and less "washy." Alfalfa reaches its best yields about the third year, and will last 20 years; it is not difficult to kill; it is similar to Red clover for turning under for green manure. All cattle here are fed on alfalfa hay alone. I have fed cattle in 
open yards in December, January, and February, and made them gain 160 pounds per steer in three months. If beef on the Pacific coast would bring 3 cents, there would be no better investment than alfalfa. In I892, we sold hay for $\$ 60$ per acre; to-day it will not sell for a third of that

\section{WEST VIRGINIA}

Prof. J. H. Stewart, Director West Virginia experiment station.-Very little alfalfa is grown in West Virginia. Within the past four or five years some stimulus has been given it by current publications, etc., but extensive growth has not obtained as yet. The attempts to grow it on our small farm at the experiment station have in fact been failures. However, there are a few small tracts that have done well in portions of the state. Hon. T. B. Davis of Mineral county and E. W. McNeil of Hardy county are persons who have been successful. I am frank to say, however, that the experiences and practice thus far in this state have not proven it to be a dependable crop.

\section{WISCONSIN}

Prof. R. A. More, Agronomist Wisconsin expermuent station.-Alfalfa is receiving greatattention in Wisconsin and dairymen have been quick to perceive its value. Through the efforts of the experiment station, alfalfa seed has been disseminated in every county in the state and crops have been grown which were highly satisfactory. Experiments at the station show that as much protein can be secured from one acre of alfalfa as from 
three acres of clover, nine acres of timothy or I2 of Brome grass. In this experiment four cuttings of alfalfa were secured, two cuttings of clover and one cutting each of timothy and Brome grass. Alfalfa seed should have its viability tested before the seed is purchased. Seed that does not give a germination test of 90 per cent or above should be rejected. We advise selecting high, welldrained land inclined to be rolling. A clay loam on a gravelly subsoil is best suited for growths of alfalfa. Sow in spring as soon as ground works well, putting on about twice the cultivation necessary for cereal crops. Where land is inclined to be weedy, sow three pecks of barley per acre as a nurse crop. If ground is free from weeds, sow alfalfa seed without nurse crop, using at least 20 pounds of seed per acre. Several hundred members of the Wisconsin experiment association have been carrying on tests with alfalfa since I903, and practically all have succeeded in getting good fields started. Bacteria-laden soil has been shipped to members of the experiment association, who are making tests, with directions for scattering on a small plot, in order to get the proper bacteria established in the soil. The sowing of some alfalfa seed with clover for the purpose of getting a few alfalfa plants established as bacteria distributers has been followed with good success. These lands when later sown to alfalfa result in good catches. Alfalfa should be cut when onetenth is in blossom, and not later than the first week in September. We look for greatly increased acreage from year to year as our farmers learn the value of this great forage plant. 
W. D. Hoard, Editor Hoard's Dairyman.-It is now twelve years since the editor of the Dairyman commenced the practical study of alfalfa. A good deal of experience as well as observation of the practices of others has come to him in that time. He does not feel that he has exhausted the subject by any means, but there are a few things which he believes to be well settled principles. They may be enumerated as follows :

I. The richer the soil the better.

2. A carefully prepared seed bed. Too much pains cannot be had here.

3. Good seed; every farmer should test the seed he expects to sow. A great amount of failure has come from weak, infertile seed.

4. Side hills where the rain or melted snow in March will readily run off and thus prevent an ice cap from sudden freezing is much the preferable location.

5. Cutting it each time as soon as the first blossoms appear will always bring a stronger succeeding growth for the next crop.

6. Never pasture it unless you wish to weaken it so it will break up more easily the next spring.

7. Always cure it in the cock with hay caps if possible. The quality of the hay is greatly superior to that which is cured in the sun or windrow.

The nutritive quality and value of alfalfa as well as clover may be greatly lessened and the owner not be aware of it, by allowing too much sunshine on the hay. To throw away the feeding value of any food by unwise methods of handling or curing is very poor economy. For this reason farmers should make a closer study 
than they do as to the right time of cutting alfalfa and clover and the right way of curing it. Too many farmers look only at the labor involved. They want to do it quick. Hence they wait before cutting till the stalks are overripe so they will dry quickly and then they use hay loaders that will take up the hay in the swath overdried and the goodness evaporated out of it by the action of the sun. All this time they are never giving a moment's thought to the great question: "What kind of food is this going to make for my cows next winter?" The best of study and care should be given to this matter of curing alfalfa and clover. Nicely cured clover is worth half as much as bran as a milk producing food, and alfalfa is worth fully as much. We have demonstrated in our own stables that with 35 pounds of corn ensilage and Io pounds of nice alfalfa hay a day, we can save half of the grain ration that would be necessary if we fed other hay.

8. As a renewer and renovator of fertility we know of nothing that will equal alfalfa. The present year is proving that in Wisconsin most convincingly. Nearly all of the old alfalfa, as well as clover seeding, was killed by an ice storm in March. That compelled the farmers to plow up these old fields and plant them to corn, potatoes or some sowed crop. The greater growth of crops on these old alfalfa fields is universally noticed. The farmers of the country have not half begun to know the wonderful value of the alfalfa plant. For just this reason they should not be discouraged in trying to grow it.

Dr. A. S. Alexander, Wisconsin experiment station.After all that has been written and said in favor of the more general cultivation of alfalfa, it seems strange to 
find much prejudice and ignorance still existing among farmers relative to the merits of this magnificent forage plant. When we ask a farmer why he has not seeded an area of land to alfalfa he almost invariably answers by another question; viz., "Do you think I can make it catch?" And it is this doubt so generally existent that keeps down the area of alfalfa, and hence the profits of many a man who could make it a wonderful success.

To our mind there has been too much alleged scientific talk relative to "nitrification," "root nodules" and "soil inoculation" for alfalfa; so much of it, in fact, as a fad, that the average farmer has become possessed of the erroneous idea that it requires a deeply scientific knowledge of the subject and much trouble of various sorts to secure a stand of alfalfa. For this reason many a man has dismissed the subject from his mind and deemed it best to think most of the simple things within his ken, but in so doing he has missed some of the greatest boons and blessings possible in his business. Alfalfa will grow on most any good land that will produce clover and that is in no way waterlogged. There is little mystery in its successful cultivation, and the "tricks" of the business are easily learned from the literature mentioned. We believe it to be one of the very finest of forage plants and a grand adjunct in the feeding of hogs; a crop in fact that is bound to become common and that should at once be given far more general attention than is now the case. It is neither difficult to obtain a catch nor make the crop a success if the farmer will but try and in starting follow the simple instructions now published by many of the agricultural experiment siations. 


\section{WYOMING}

Asil T. Wilson, Fremont county.-For six years I have been raising alfalfa on first-bench upland, a gravelly loam, with a cement subsoil of a lime nature. Water is found at 40 feet; moist soil is encountered at a depth of I2 feet from the surface, and continues until water is reached. A depth of one inch for seeding is best. Sow in early spring. If alfalfa and timothy are sown together, sow 20 pounds of the former to 6 of the latter; if alone, 20 pounds of alfalfa. No weeds will trouble; cut either crop for hay; the first crop for seed. Watering after the last cutting will cause alfalfa to winterkill. Irrigate as early as possible, if dry, and whenever getting dry, also about five days before cutting; the soil being moist after cutting, the next crop will start up quickly. The larger the quantity of water used the better if it runs off quickly. We obtain water from a stream. After the first year I cut twice, obtaining two tons each cutting. I cut for hay just as it comes into bloom, as it is not so woody and more leaves are saved. The first cutting is preferable for seed. When cutting for seed, wait until the curls get well filled and black; put it into cocks and thresh when dry. Alfalfa hay should be cut one day and raked the next; then cock, and let it stand two or three days before stacking; by so doing all the leaves are saved, and it cures in the cock so there is no danger of molding in the stack. My alfalfa in stack costs \$I per ton, from land valued at $\$ 5$ per acre. Irrigation rosts 20 cents per acre. Baling costs $\$ 3$ per ton, I50 pounds in bale. Seed yields six bushels per acre; threshing costs \$I per bushel. Prices for hay have ranged from $\$ 5$ to $\$$ Io per ton, and $\$ 7$ per 
bushel for seed. Alfalfa hay is equal to clover or timothy for farm animals. For swine pasturage it is better than clover; one acre will pasture Io head of swine, gaining one pound per head each day. For horses and sheep it is good, and as good for cattle as clover, but dangerous, as they bloat and die. The best yrelds on upland are from three to five years after seeding; and, if watered at proper intervals, it will last 20 years. There is no difficulty in ridding land of alfalfa; plow it late in the fall, level it down and mark it, then water, and let it freeze up in winter. Alfalfa for green manure is as good or better than Red clover. Without plenty of rain, I would not recommend growing alfalfa in any locality. Seed raised from alfalfa thin on the ground is best.

John H. Gordon, Laramic county.-During the past Io years, I have had from Io to 200 acres of alfalfa on second bottom and upland, with sandy loam from two inches to six feet deep, and below this soft rock, water being found at depths of 20 to 200 feet. I plow or break the soil the first year, and raise a crop of wheat or oats; the second year plow deep, sow about half a crop of oats, and when this is well harrowed, sow 20 pounds of alfalfa seed and cover it about two inches deep. To get the best results, this seeding is done about April Ist, and there is no trouble here with weeds. In cutting the grain, the alfalfa is cut off too, but it does not grow tall enough for hay the first year. The plant does not winterkill, and reaches its full yields by the third or fourth year; I have found no necessity for reseeding any of my land. We irrigate from streams, the quantity of water used depending on the season. There are generally three applications 
of water, about six inches each time. After the first two or three years, only about half the quantity used at first will be needed. After the first year I cut twice, and obtain about $I \frac{I}{2}$ tons to the acre each time. The first crop is best for seed, and is harvested when the top bolls are dead ripe, raked the day after cutting, bunched for two days and then stacked, to be threshed with the common threshing machinery, putting through twice. Five bushels to the acre is a ccmmon yield of seed, and the cleaning and threshing cost 50 to 75 cents a bushel. The hay is cut when the greater part is in bloom, allowed to lie about a day before raking, cured about three days, and then stacked, I4 to I6 feet wide, 60 feet long, and 20 feet high. It does not seem to heat or mold here. The total cost in the stack is about $\$ \mathrm{I} .5 \mathrm{O}$ a ton, and baling, in Ioo-pound bales, costs $\$ 2$ a ton. Selling price of loose hay in this section is $\$ 5$ a ton, and the seed, Io to I 2 cents per pound in the market. The straw is worth about as much as the hay for feed. I am well satisfied with the general results of growing alfalfa here, and am now preparing 200 acres for seeding. Where it will grow well, it is the best forage plant ever discovered, being good feed for cattle, hogs, sheep, fowls, and, in fact, all animals on the farm, while as a fertilizer it cannot be surpassed. But one cannot do anything with it if there is not sufficient moisture to raise wheat or oats. 


\section{INDEX.}

PAGE

Albama, alfalfa in..... 16 Experiments ............231

Acclimation .........

Acid soil, test for......... 45

Unfavorable ........44, 201

Acreage, too great......... 87

Address, Professor Spill-

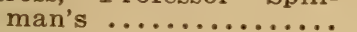

Adulterants $\ldots \ldots \ldots \ldots \ldots$ ...... $\ddot{3} \dot{3}, \ddot{3} 6, \ddot{3} \ddot{3}, \ddot{3} 9,40$

Africa, alfalfa introduced.. 2 South, alfalfa in....... 15

Agricultural Department bulletin ............. 33

Agriculture, Stover's; haycaps ............. 85

Agrostologist's opinion .... 9

Air shaft in mow........ 95

Alaska, hay for ..........104

Albuminoids ............. 22

Alfalfa fields 200 years old. 5

Alfalfa, fails "here"...... 51

Description ........... 5

Below sea level ......... 15

Improves land values....204

Origin of name ....... 2

Objection to ..................... 18

Preparations ......................

Is "queen"..............141

Replaces other legumes.151

Synonyms ............ 4

Alfalmo ................ 185

Alfilaria, merits of....227, 228

Alsike and alfalfa compared ...........21, 148

Analyses, corn ........... 22

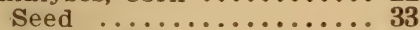

Soll, free .............. 64

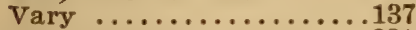

Animals, keep off field...221

Annual manuring ........ 70

Appetizer, alfalfa as an...125

Apples and alfalfa together .............224

Arabian seed, imported.... 8

Arapahoe County, Colorado ..............243

Argentine Republic, alfalfa in $\ldots \ldots \ldots \ldots \ldots \ldots \ldots 15$
PAGE

Arizona, alfilaria in......227

Experiments ........ 8, 233

Army worm ..............219

Asiatic seed introduced.... 7

Assimilative restrictions ..134

Avery, Prof. S., on alfalmo ..............185

Bacteria, cowpeas increase ............ 48

Humus helps .........6 61

In some soils ......... 6]

In nodules ..........60, 198

Introducing $\ldots \ldots .46,50,51$

Introducing unnecessary.199

Lacking, failure result... 66

Need nitrogen.........660

Not fertilizers ........201

On cowpeas ........... 49

Spread on farm........ 194

Bale, hollow ...........105

Bales, heating............104

Loading . . . . . . . . . 10. 10

Poor prices for.............. 104

Round $\ldots . . \ldots \ldots \ldots \ldots \ldots 104$

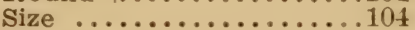

Shipping .............. 104

Baling ...............102

New Mexico ...........283

Machine new .........105

Space saved ..................

Barley as inurse crop....... 58

Leaves weeds ......... 59

Bare spots restored....... 71

Barn, storing .......... 95

Beach, C. W.............248

Beadle County, South Da-

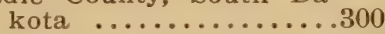

Beak on trefoil seed...... 39

Beef, balanced ration for..135

Cheap western.........142

Making .................138

Yield to acre............... 131

Bees land alfalfa.......12, 175

Belgium, alfalfa introduced. 2

Berry, J. W., storing......96 96

Bindweed .............219

Blackshere, J. R., report..260 Blake, John, experiments..233 
PAGE

Bliss, D S., report......267

Bloat, lambs do not.......172

Preventing ....110, 113, 171

Preventing in Kansas...111

Professor Mayo on......116

Remedy .....115, 121, 316

Rules to prevent........115

Tapping for ...........119

Not due to food.........117

On lalfalfa pasture......109

Bloom, cutting in....... 80

Cut in .............. 88

Blossoming, cut before... 80

Blue grass or alfalfa for pigs ................158

Blue-grass, yields.........21

With alfalfa ...........111

Botany of alfalfa......... 4

Bowman, Prof. M. L., report .............257

Bran analysis ...........127

And alfalfa compared...

.........10, 79, 85, 144

And alfalfa meal for cows ...............184

Food value .............132

Sown with seed........ 56

Brandon, Manitoba, yield.. 14

Breaking sod hard work...195

Breeders' Gazette on sheep pasture ............114

Brewers' grains and alfalfa compared ............114

British Columbia, alfalfa in ................. 14

Broadcast seeding ....... 55

Brome grass and alfalfa compared ...........21

Brooks, Prof. William P., report ............266

Brown, Benjamin, report..261

Brown County, South Dakota ...............302

Brown, George Campbell, report .............303

Bruner, Prof. L., on hopper dozer ...........216

Buckhorn in alfalfa seed.. 41

Buckwheat bran, food value ..............132

Buffum, Prof. B. C., on fertilizing value ........192

Bulletin, Alabama........2232

Farmers', baled alfalfa..104 Farmers', irrigation ....77
Bulletin, Continued

PAGE

Farmers', alfalfa for hogs ..............160

Kansas, hog raising.....156

Nebraska, soiling and pasture ............123

Nebraska, feed test......139

New Jersey, feed values,

.................. 132

New York, fodder crops.126

Ohio, impure seed....... 33

Texas, feedstuffs........127

Utah, cuttings............128

Utah, tirrigation........ 74

Vermont ...............309

Virginia .....................

W y o $\mathrm{m}$ in $\mathrm{g}$, fertilizing value ...............192

Bulletins, various hay composition ............. 75

Buncher ............... 87

Burnett, Prof. E. A., dimensions of ton.....229

Burning weeds..........69 69

Bushel weight ............ 31

Butter fat, cost..............150

Butter, the marketable product .............147

Buyer to blame............ 41

Buying soil, necessity of.. 61

Dangers of..........6. 62

Not necessary..........6. 61

Cache County, Utah.......304

California, alfalfa introduced .............. 2

Cutting in............ 89

Eleven cuttings........... 10

Experiments ......... 238

Feeding alfalfa alone....148

Sheep fattening........205

Camden County, New Jersey ..............282

Canada, alfalfa in.......... 14

Time to sow .........47

Canadian Northwest yield.. 14

Cannula for bloat ........119

Cape Colony, alfalfa in.... 15

Capons on alfalfa ........187

Carbohydrates and fats interchangeable ........135

Function of ............135

Not replace protein......136

In excess.............136

In hay $\ldots \ldots \ldots \ldots \ldots \ldots \ldots .76$

Lacking $\ldots \ldots \ldots \ldots \ldots \ldots \ldots \ldots$ 
Carbonaceous foods needed.125

Carlyle, Prof. W. L., hay...173

Cattle, dangers in pasture..109 Experiences with.......110 Growing, balanced ration. 135 Young, balanced ration..135 Pasturing ...........235 Utab, fed............... 25

Chase County, Kansas.....260

Champlain Valley ........310

Characteristics, seed...... 37

Chickweed, destroying.....303

City use of alfalfa.........187

Clark County, Kansas......258

Clark, Thomas J., report...283 Clay, alfalfa on.....15, 19, 17 Climates adapted to....... 15 Affects irrigation....... 77 Curing in dry......... 87 Arid, effect on hay.76, 88, 94 Arid, irrigation in...... 73 Humid, curing difficulties 88 Humid, difficulties ...... 81 Humid, effect on hay.... 76 Humid, harvesting ...... 82 Humid, hay-caps ....85, 89 Humid, haying in...... 94 Humid, seed raising.....992

Clipping before bloom..... 67 Invigorates ......... 67

Clothier praises alfalfa..... 10

Clover, alfalfa following... 50 And alfalfa compared.20, 21, $127,143,146,148,149,222$ Beaten on thin soil..... 19 Bur, adulterant ...32, 33, 40 Bur, bacteria on........199 Bur, everywhere ......61 Bur, seed recognized .... 39 Bur, seed in alfalfa..... 32 Feed value....126, 132, 145 Hay making .......... 83 Hop, an adulterant...... 35 Huller for threshing.....91 Pin ...............227 Plowed for alfalfa ..... 49 Protein value ..........133 Sweet, adulterants....... .........32, 33, 40 Sweet, bacteria ....... 60 Sweet, everywhere ...... 61 Sweet, stock reject..... 40 Sweet, seed described.... 40 With alfalfa .......51, 112
Clover soil, Sweet, for inoculating .........60, 202

Cocking at night........ 84 Colorado, alfalfa precedes sugar beet ...........173 Alfalfa in orchards.....223 Bees in ............. 175 Corn and alfalfa com-

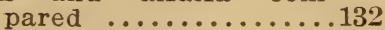

Cutting in ............ 73

Experiments ..............243

Fall sowing in......... 53

Feeding in................

Ground alfalfa for pigs..182

Harvesting in......... 84

Hay composition........ 76

Hog rations............. 156

Lamb feeding ...........173

Losses from stacking....998

Losses in curing........ 82

Pasturing sheep..........113

Plowing alfalfa for other

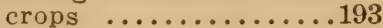

Seed ............... 29

Sheep fattening ........ 205

Siloing ..............102

Value of stubble.........191

Wetted hay ........... 81

Colusca County, California.241

Combustion, spontaneous, See Fire

Composition, irrigation influences .......... 74 Prof. Ten Eyck quoted... 75

Varies ..............149

Compression, double.......104

Connecticut, experiments..247

Cooke, Prof. W. W., corn and alfalfa .........132

Co-operative irrigation experiments .......... 76

Corn analysis..............127 And alfalfa compared... $\ldots \ldots \ldots \ldots \ldots 22,132,222$

Before reseeding...... 72

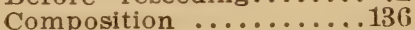

Fails $\ldots \ldots \ldots \ldots \ldots 16,17,23$

Fed with alfalfa........125

Feed value ............132

Fodder and alfalfa compared .............148

Fodder, feed composition .......................

Fodder, feed value.....145

Fodder, analyses ......127 
Corn, Continued PAGE

Fodder, protein value...133

Fodder, value ..........126

Following alfalfa........ 193

Increasing yield with alfalfa ............... 194

Lands, Illinois, alfalfa on .............. 16

Meal sown with seed....56

Precedes alfalfa ....... 46

Money from acre....... 25

Silage and alfalfa for cows commended......152

Stover and alfalfa compared .............148

Unprofitable fattening food ............126

Cortes brings alfalfa to

America ............ 2

Cottonseed, analysis.......127 Meal replaced by alfalfa. 151 Hulls, analysis.........127

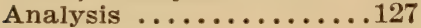

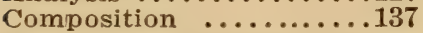

Cotton soils, depleted, for alfalfa ........... 16

Cottonwood river bottom lands .............260

Cottrell, Prof. H. M., alfalfa meal ...........183

Early cutting ......... 80

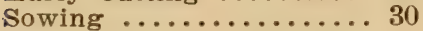

Spontaneous combustion

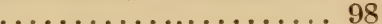

Country Gentleman, dodder ..............207

Cover crop, winter before alfalfa ............ 48

Cowpea analysis .........127

Cowpeas, bacteria ....... 49

Before fall seeding ..... 49

Feed value .......132, 145 Increase bacteria ...... 48 Increase fertility ...... 48 Preceding alfalfa ..... 46 Prepare soil for alfalfa.. 46 Winter cover .........4 48

Cows, number to acre....205 Scrub fed in Kansas.... 143 Sell farm produce......147

Crab grass, destroying....303 In seed ....................... Keeping down ........112 Persistent enemy ......6.
Craters in center, prevent-

ing .............. 97 Creep, in pasturing lambs.172

Cresceus eats alfalfa......167 Critical time with alfalfa.. 73

Crops, small ........... 65

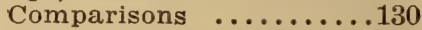
First season .........65 To introduce bacteria... 50 Crop-worn land improved.. 16 Cultivation, perfect, essential ............. 44

Curing, Arizona ......... . 235 Case in ................. 93 Difficult after rain..... 82 Dry climates .......... 87 Hay-caps for ........ 84 Important agent in..... 93 Improper .......... 83 Kansas .............259

Losses in .......... 82, 93 New Mexico ...........283 Pennsylvania bulletin.... 83 Poor method ......... 87 Proper .............. 83 Rules ............... 89 Stack .............. 90

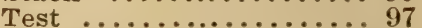

Utah ........................

Washington ............314

Windrow ............ 87

Cuscuta arvensis ......... 42

Cuscuta epithymum ....42, 207

Cut for cows ...........144

Cutting after rain....... 82 Before or after irrigation .............. 73

Colorado .............246

Dates, Utah .......... 78

Difficulties in humid climate ............ 81

Early ................ 21

Early, objections ...... 89

Early, Professor Cottrell quoted ................ 80

Ensilage first..........101

First, not for seed..... 89

For silo ................... 102

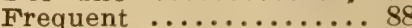

In bloom ........... 88

Kansas ..............261

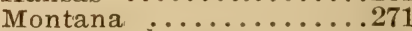

Number of times....... 99

Rules ............... 89

Seed time............ 89 
Cutting, Continued

PAGE

Second, for seed......... 92

Third, for seed......... 91

Time .........80,82, 89

Utah ....................304

Clover and alfalfa compared .............20

Early, most protein in.. 81

Nine a year .......... 10

Number in Alabama....2231

Number in California...242

Relative values.........127

Six or more under irrigation ................. 72

Time between ..........24

Two preferred ......... 88

Dactylis glomerata with alfalfa ..............111

Damp hay, storing....... 97

Dampness in mow ....... 97

Dangers in irrigation...... 73

Danger from dampness.... 97

Dairy cow, balanced ration .................135

Interests enhanced ....20.

Products in South....... 14

Dairies, alfalfa ......... 26

Dairying, alfalfa in......... 143

Davis, Hon. T. B., alfalfa

in West Virginia......317

Dawley, F. E., dodder......207

De Jarnette, J. B. experiments ...........241

Deer Lodge County, Montana .............271

Defective alfalfa seed...... 33

Delaware, experiments.....248

Seed for ............. 29

Department of Agriculture experiments ..........

Buying soil ...........6 62

Imports Asiatic seed.... 7

Hog raising ...........160

Depth roots go ......... 6

Description of alfalfa .... 5

Desert, alfalfa in Nevada, ................16, 17

Dew on hay, effects..... 85

Dextrine losses in hay..... 81

Dickson, W. H., experiments ..............240

Difficulties of growing in 1793
PAGE

Reduced by fall sowing. 49 Digestible matter to acre..125

Digestive restrictions......134

Dimensions to ton.......229

Diseased soil for inoculation ............. 62

Diskin $\ldots \ldots \ldots \ldots \ldots \ldots \ldots . \ldots . \ldots . \ldots . \ldots 70$

After freshets ........ 44

After turning .........6 69

Benefits of .......... 71

Each spring .......... 70

Fields after cutting..... 24

Overcomes failure...... 71

Splits crowns ......... 57

To kill weeds.......... 59

District of Columbia, yield

in .............. 14

Distribution of alfalfa..13, 14

Dodder, annoying enemy..206

Cut with scythe........91

Destroying, Alabama . . . 232

Eradicating .........210

Fighting .............207

In alfalfa seed........32, 35

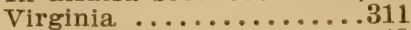

Most dreaded.......... 42

Objectionable impurity.. 42

Seed described .........4 41

Seed not adulterant.....42

Seed removing ....42, 91

Spreading ...........209

To get rid of......... 42

Dodson, Prof. W. R., alfal-

fa for Louisiana...... 14

Report .............264

Donaldson, L., report......302

"Don'ts" .............225

Double compression ......104

Downing, Jacob, experi-

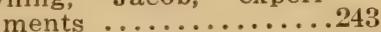

Drainage necessary....... 18

Drenching animals .......122

Drill seeding .......... 55

Favored by spurrier....67

Drumheller, Oscar, report.315

"Dry land" alfalfa....... 29

Dry matter in corn....... 22

Drying out, danger of soil. 50

Duggar, Prof. J. F., Ala-

bama .............231

Dunn, George W., report..295

Dyeing with alfalfa seed.. 32

Dying out ...........221

Earthworms encouraging.. 46 
PAGE

Economy of alfalfa......151 Of alfalfa in dairying...149

Of balanced ration......134

Of labor ...........21, 2 5

Of root growth ....... 6

Eight cuttings in Louisiana .............. 14

Eighty feet to water.......44

Elements specially needed. 65

Eleven cuttings a year..... 10 Elgin dairyman praises alfalfa ..............153

Enemies .............206

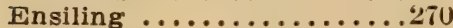

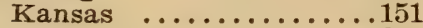

England, growing in.....261 Alfalfa introduced ..... 2

Examination of soil........64

Example of success....... 17

Exhibition stalk, large.... 6

Experiment stations disfavor nurse ........ 59

Favor inoculation .... 60

玉xport alfalfa hay........104

Exports, seeds ......... 31

Erf, Prof. Oscar, alfalfa for cows ........................

Erodium citcutarium ......227

Essentials of growing....444 Of preparing soil .......46

Evaporation in curing.... 83 In mow ............. 97

Failures, because not cut. 69 Causes of............220 Due to weeds .......... 48

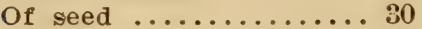
Overcome by disking.... 71 Redeeming ...........65 To be expected ......201

Fairchild, D. G., Arabian

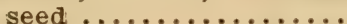

Fall sowing........49, 52, 53

Fanning mill ........... 91

Fanning removes dodder.. 42

Farr, Aaron F. Jr., report ..............304

Fat and carbohydrates interchangeable .......135

In corn ............. 21

In hay $\ldots \ldots \ldots \ldots \ldots \ldots \ldots 76$

Not replaceable by pro-

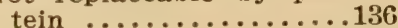

Fats in excess..........136 Lacking in alfalfa......125
PAGE

attening with corn unprofitable ...........126

Farming, character altered. 17

Farmers" Assistant mentions alfalfa ....... 3

Farms, fruit, alfalfa on... 17

Feed, quality ............145

Value, fodder crops......126

Values, various ..........145

Feeding alfalfa alone.....148

Before pasturing .......110

Colorado .............141

Cows economically .....152

Economical western ....142

Experiments for milk...184

Hogs, Nebraska ........159

Tests ..............138

Tests, hog ............156

Tests, Kansas .....138, 142

Tests, Nebraska ........139

Tests, various cuttings.. 81

Tests, Utah ............138

Waste in ................ 144

Value, Arizona ......................

Value, California ......241

Value, Colorado .......247

Value, Idaho .......... 253

Value, Kansas ... . . . . . 259

Value, Utah .......305, 306

Value, various cuttings . 88

Value, various crops ....132

Feedstuffs, analysis........126

Fertility, best means of improving ............ 147

Increased by cowpeas .. 48

Robbed by nurse crops.. 58

Fertilization by bees......177

Fertilizers, Alabama..231, 232

Specially needed .......65

Fertilizing, Georgia ...... 250

Virginia .......................

Long Island ...........288

Fescue, meadow yields.... 21

Festuca elatior with alfalfa .............111

Fiber in corn $\ldots \ldots \ldots \ldots \ldots 22$

Fields disked after cutting ............. 24 Of alfalfa 200 years old.. 5 Oid, in South Carolina.. 9 Oid in West .......... 9

Fire for weeds......... 69 Preventing ............. 96

Fires caused by wet hay..997 Occur, when ..........98 
Fires, Continued PAGE

Professor Cottrell discusses .............99

Rare............... 96

Flesh forming ...........11

Flooding at critical time.. 73

Effects ............. 44

For second crup ....... 72

Floor, loose preferred for storing ............. 95

Florida, alfalfa in....... 15

Fodder corn, feed value...145

Crops, feed value of....126

Fodders, values of various .................. 145

Fort Collins lambs.........173

Foster, Prof. L., cuttings..128

Foxtail, keeping down.....112

France, alfalfa introduced

Oldest fields in ........

Seed from ............ 32

Fraser, W. J., feed for cows ...............152

Fraud in alfalfa seed..... 36

Freshet, disking after..... 44

Freshets, effect .........44

Freezing effect on soll.....195

Harm from .......... 50

Soil for seeding ....... 52

Fruit farms, alfalfa on.... 17

Raising, alfalfa in.....223

Fullerton, H. B., report..288

Furnas County, Nebraska.273

Garman, Prof. H., report..264

Gaylord Farm Sanatorium

..................248

Georgia, experiments......250

Germ killed............ 27

Germany, seed from...... 32

Germinability, storing impairs ............ 30

Germination, conditions influencing ............57

Test seed for............ 28

Gila River irrigation.234, 283

Ginther, C M., report....254

Gill, E. T., report........282

Gluten meal, feed composi-

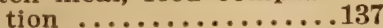

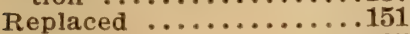

Ga-devil ...........87, 95

Gophers injure alfalfa...2212

Grades and grading hay...105
Graham, Thomas C PAGE periments ..........235

Grain and alfalfa compared ..............161

Encourages weeds ..... 59

Grange meeting at $\mathrm{Mr}$. Worker's ........... 18

Grant County, New Mexico ..................283

Grasses and alfalfa compared ..............21

Grass, destroying by fire.. 69

Pin ................227

Preceding alfalfa ..... 50

Protein value .................. 133

Grasses in pastures.......116

With alfalfa ............ 113

Grasshoppers .............216

Gravel, alfalfa on ....... 15

Greece, alfalfa taken to... 1

Grinding, time and power required ............184

Growth after cutting...... 21 Delayed by cold water.. 73

From imported seed..... 30

Gumbo, soil, alfalfa succeeds .............. 17

Habitat of alfalfa ........ 1

Influence ............. 28

Habits altered by locality... 28

Farm, changed by alfalfa ...............181

Handling hay ............ 89

Little advisable ........... 94

Hanna, S. C., bloat........111

Hansen, Prof. N. E. in Asia $\ldots \ldots \ldots \ldots \ldots \ldots$. 7

Harrow, common not disk ................. 70

Harrowing after cutting.. 24

To kill weeds .......... 59

Harrows ............ 70

Hartman and $\mathrm{W}$ eil, report

..................285

Early for hogs..................

Harvester, Acme .......262

Harvesting $\ldots . . \ldots \ldots \ldots \ldots . .79$

By stock ............... 107

Few and many ........... 88

Humid climates ........ 82

Like grain ............ . 88

Loss of leaves......... 80

Operations, time between ............ 87 
Harvesting, Continued PAGE

Seed ............... 89

Time ............. 80

Time to begin ......... 82

Hawail, hay for...........104

Hay and silage compared.102

Association, National, grades .............106

Association, Spillman's address ............. 9

Baling, California ......240

Composition depends on water ..............75

Feed value ............ 145

First season ........6. 65

Grades .................

In mow, watch ....... 97

In windrows ........84

Lying in swath ........ 84

Making, Arizona .......237

Making, losses in....... 82

Meal cheaper than baled ..................186

Measuring in stack.....228

Money in ..........22, 23

Poorly cured, value..... 87

Preserved, color........ 94

Prairie and alfalfa compared $\ldots 140,141,148,150$

Prairie, composition ....136

Prairie, dimensions of

ton ..............229

Prairie, feed value.....145

Value of.............91

Values, Arizona ........235

Various, and alfalfa compared ..............148

Field to acre, Utah..... 78

Hay-caps advantages...... 85

Described ............8 80

Favor baling ...........103

Humid regions ......... 84

Size of ............. 86

Use of ...........85, 86,89

Haying, time between operations ............. 84

Hay-loader, belt ......... 88

Headden, Prof. W. P., stubble value ...........191

Long roots .......... 6

Curing ................. 82

Seed storing .......... 31

Heating, prevent in transit .................105

seed $\ldots \ldots \ldots \ldots \ldots \ldots \ldots 31$
Heating, Continued

PAGE

Seed stack ........... 90

Stack ................ 90

Heaving, danger of...... 50

Height, normal ........ 6

Highmore forage testing station .............300

Hill, Prof. J. L., report...309

Hillman, Prof. F. H., dodder ............. 42

Hitchcock, A. S., baled alfalfa ..............104

Feeding alfalfa alone...148 Quoted on irrigation.....77

Hoard, Gov., brood sows..155 Yield ...............23

Rotation ..............194

Hoard's Dairyman, economical butter ...........144

Hogs, alfalfa or blue grass for ..............158

Balanced ration for.....136

Cut early for ..........160

Food for fattening ...... 46

Kansas ................155

Like alfalfa....23, 154,237

Over stocking 'with......161

Pastured on surplus acres .............. 87

Pasture for........48, 108

Hollingsworth, J. H. ....255

Honey from alfalfa....12, 178 Hoove, See Bloat.

Hopper dozer ..........216

Kansas .............219

Prof. S. J. Hunter.....217

Hopkins, Prof. C. G., pot cultures ...........202

Report .............253

Hog raising, Kansas.......161

Horse raising, Ohio.......166 Raising .........165, 166

Horses, alfalfa for work...166

Alfaifa for driving.....167

Cheap feed for..........188

Injure pasture .........109

On pasture ............170

Overfed ...............160

Thrive on pasture.......109

Humus favors bacteria....61 61

Hunter, Prof. S. J., hopper dozer ..............217

Bees ....................

Idaho, experiments .....251

Italy, alfalfa introduced... 1 
PAGE

Illinois, alfalfa in....... 16

Experiments ..........253

Feeding cows in......... 152

Pot culture experiments

Seed for ................ . . 29

Imported seed ........30, 31

Impurities in seed......32, 33

Income, alfalfa..22, $23,25,26$

Indiana, experiments......254

Yield in............. 23

Infected soil...........6 60

Injuries from lime....... 66

Inoculation, Alabama ....232

Any method helpful ...199

Dangers of...........6 62

Seed not needed .......6. 64

Failures expected.......201

Illinois .........................

Long Island ...........2SS

Massachusetts ........266

Methods various .......663

Necessary ...........200

Not like magic .........202

Old theory ...................

Soil, not needed........64

Soil, Sweet clover .......202

Unnecessary .........200

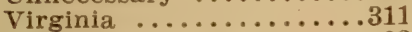

With diseased soil......662

Insects carried by soil....663

In seeds ............ 31

Introducing on farm ...... 28

Iowa, experiments ......257

Leaf spot in.........211

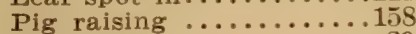

Seed for ............. 29

Spring sowing .......54, 55

Irish, C. W., depth of root growth ........... 6

Irrigation after cutting.... 73 Alfalfa under ........ 72 Before cutting ......... 73 California ............238

Colorado ............244 Co-operative experiments ...................... 76

Effect on hay ....... 76

Excessive ........... 72

Gila River ........... 234

Harrow ............ 24

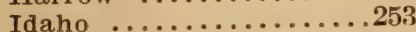

Influence on composition 74
Irrigation, Continued PAGE

Influence on seed ..... 28

Increases protein ...... 75

Necessary to saturate soil ................ 78

New Mexico ...........283

Oregon ...............295

Salt River ...........236

Spring ............ 73

Utah bulletin .......... 74

Water to acre, Utah.... 77 Irrigation Farming quoted.. 73 Irrigated land, yield....10, 23 Irrigations, number of... 77

Italy, seed from ......... 32 Jefferson, book dedicated to ............... 3

Jenkins, Dr. E. H., report. 247

Jones, John, report......306

Jones, O. S., report.......301

Jordan, Dr. W. H., opinion of feed .............141

Kafir corn preceding alfalfa ............ 49

Fed with alfalfa........125

Feed composition........136

Kansas, alfalfa flowers....176

Alfalfa for dairyman....149

Alfilaria for ..........228

Annual top dressing..... 70

Bees ..........175, 176

Bulletin, balanced ration .................135

Broadcasting at experiment station ........ 56

Cows on small area.....144

Curing in ........... 87

Early cut hay for hogs. .160

Ensiling ........................

Crab grass ........... 68

Eighty feet to water....45

Experiments .........259

Fall sowing .......... 53

Feeding cows ..........14t

Feeding tests ......138, 142

Grass in alfalfa fields...112

Gopher injuries .......213

Hay, composition of.... 76

Hog raising ...155, 161, 163

Hopper dozer .........218

Horses raised .........165

Lands, values increased.204

Low cost ration........150

Prairie dogs ...........212 


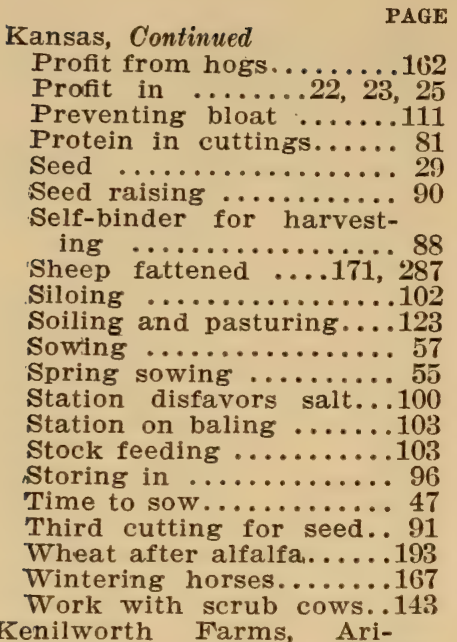
zona ..............235

Kent County, Delaware...249 Kentucky experiments....264 Kiefer, H. W., report.....251 Kilgore, Dr. B. W., report .................289

Kirk, F. S., pasturing.....113 Yield ...............24

Labor prices ...........204 Saved ............. 25

Lake County, South Dakota ...............301

Lamb-feeding, Nebraska...172

Lambs, fattening ........ 46 Fort Collins ...........173 On pasture ............114 Never bloat ...........172 Pasturage for .........48 Quarter in seed ........ 35

Land, alfalfa on bottom... 24 Foul, unfit for alfalfa... 59 Values improved.......204 Worthless made valuable ..................25

Langston, Alva, yield..... 24 Lantz, Prof. D. E., gopher injuries ...........213

Large alfalfa roots....... 18 Latitude influence on seed PAC

Leaching, winter prevented 48

Leaf spot $\ldots \ldots \ldots \ldots \ldots 63,211$

Legumes, bacteria on...... 60

Prepare soil........... 49

Leaves and stems, feed value compared ...... 82

Broken by tedder........ 84 Lost in curing...80, 82,183 Help in curing.........83 Proportion to stems ....128 Saved by slings.........94 Pay for floor........... 99 Value ................. 79 Lewis, D C., report ......281 Light discolors seed......... 31 Liggett, Prof. W. M., report ............269

Lime, air slaked..........66 Injuries $\ldots \ldots \ldots \ldots \ldots \ldots 66$ Must be applied........64 Needed ..........45, 201 Prevents mold .........100 Small dressings advisable ..............66 66 Soil for ..................

Liming ..................... 249 Connecticut ..........248 Massachusetts ........266 Ohio ..............290

Lincoln County, Nebraska.275 Linseed meal and alfalfa compared ............127 Feed composition.........137 Replaced by alfalfa......151

Listing waxy ground......52

Litmus for testing soil.... 45

Loader, disadvantages..... 95 Loading, slings ......... 94 Localities influence seed... 28 Logan County, Idaho.....252 Long Island, experiments..288 Loss from impure seed.... 32 Losses due to wetting......8 81 In curing ........... 82

Louisiana, alfalfa in...... 14 Cutting in ........... 89

Experiments ..........265

Lowden, F. M., report....314

Lucerne, book dedicated to Jefferson ............ 3

Intermediate $\ldots \ldots \ldots \ldots 76$

Origin of name ....... 4

Yellow ............ 7

Lumps, soil, bad........ 50 
Mangels, feed value..126. 145

Protein value .........133

Manitoba, alfalfa in....14, 15

Mammoth clover yields.... 21

Manure before seeding.... 64

Manuring ...........46, 70

Wheat land for alfalfa.. 48

Mare, ration for brood... ...................... 169

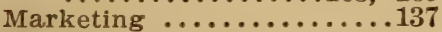

Markham, L. W., experiments .............245

Maryland, alfalfa in...... 16

Seed for ............ 29

Massachusetts, analyses, clover .............20

Experiments ...........................

Matthies, John .........248

Maximum yield, irrigation .............. 77

Maury County, Tennessee..303

Mayo, Prof. N. S., bloat....116

MeEathron, George E., report ................301

McNeil, E. W., succeeds in West Virginia .........317

Meadow fescue and alfalfa compared ..........21

Fescue and alfalfa yields ............. 21

Meal, Prof. Cottrell's opinion .................183

Superior to hay..........184

Sown with seed ......... 56

Meat production in South. 14

Medicago denticulata, bac-

teria ............. 60

ss

"

foliata ....... 7

media .........7 76

sativa ........ 4

Medicine Hat, yield...... 14

Medick, black, an adulterant ................. 35

Medicks, fifty species...... 36

Meeting at Mr. Worker's.. 18

Melilotus, bacteria on.... 60

Merrill, Prof. L. A., fed horses .............168

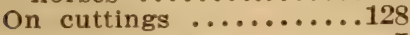

Mexican flelds, old ....... 万

Mexico, alfalfa introduced

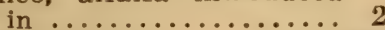

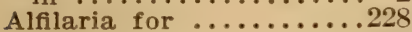

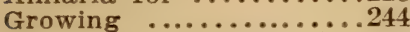

Michigan, experiments.....268 Jersey ............2s1

Middlings, food value ..... 132

Milk, alfalfa in making...143

Balanced ration ..........135

Cost of gallon .........150

Flow increased ........ 152

Tests .................143

The marketable product ...................147

Value an acre..........144

Yield increased .........146

Yield, pasture and soil-

ing ..............123

Miller, Henry, experiments

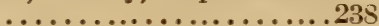

Miller, Prof. M. F., report.270

Millet, alfalfa sown with.. 51

And alfalfa compared...

..............146, 148

As preparatory crop... 52

Before reseeding........ 72

Best to precede alfalfa.. 49

Between potatoes and al-

falfa .............. 48

Fed with alfalfa.........125

Feed value .......132, 145

Good to precede........ 50

Protein value ..........133

Minimum water to apply.. 77

Minnesota, experiments....269

Field, old ........... 9 9

Seed for ............ 29

Spring sowing ........ 55

Time to sow.......... 47

Yield in ............ 14

Missouri, alfalfa in ....... 16

Experiments ..........270

Fall sowing .......... 53

Moisture absorbed by straw

.................... 97

Conserve before seed-

ing ............. 47

Robbed by nurse crop.. 58

Molasses, adulterated with

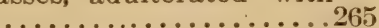

With alfalfa ........... . . 185

Mold, prevent in stacks...990

Moldy seed ............ 27

Monmouth County, New

Jersey ..........282

Montana, experiments.....271

Pasturing sheep .......111

Seed ............... 29

Sheep fattening ......205 

G. T., breeds bacteria ..............19s

Moore, Prof. R. A., report.311

Morgan, Prof. H. A., re-

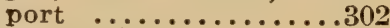

Mortgage lifter ............... 11

Mow, fires ............. 95

Storing .............. 95

Mower not favored for seed harvest ........................

Mowing, early ........... 21

For yellow leaf........ 67

Improves stand .......66 67

In wet season.........6. 68

May be wrong......... 68

Mulch not needed ....... 68

"Musts" ...............225

National Hay Association grades ...........106

Neale, Dr. Arthur F., report .............248

Nebraska, alfalmo ........ 185

Alfilaria for...........22s Comparative yields...... 21 Curing ............. 87 Experiments .........273 Fall sowing .......... 53 Feed tests ............139 Hog feeding test. . . . . . 159 Hopper dozer .........216 Lamb feeding .........172 Lands, values increased.204 Profit ..........22, 23, 25 Sand hills ........... 15, 17 Seed ............... 29 Sheep fattened......171, 205

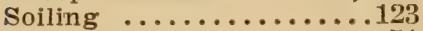
Spring sowing ........ 54 Stock feeding ..........103 Work horses fed .........166

Nebraska Farmer, on cutting ............69

Nebraska Farmer, various

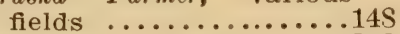

Nelson, J. P., report..... . 282

Nematodes in soil.......62

Nevada, alfalfa in........ 14 Alfalfa, on sagebrush land ............. 15

Deserts, alfalfa succeeds in $\ldots \ldots \ldots \ldots \ldots . \ldots 17$

New Brunswick, alfalfa unknown in ..........15

New England, cutting.... 8? Seed for............ 29
New England, Continued

Soiling ...............124

Success $\ldots \ldots \ldots \ldots \ldots \ldots \ldots \ldots \ldots \ldots 11$

New Hampshire, experi-

ments .............279

New Jersey, experiments...280

Hay composition.......76

Milk test...............143

Feed values ...........132

Plant food to acre ......192

Seed for .............. 29

Yields of clover ........ 20

New Mexico, alfilaria for..228

Experiments .........283

New Milford, Connecticut..248

Seed, new preferred ..... 30

New York, alfalfa introduced ............... 3 Alfalfa success ........ 17 Dairymen claim profits..144 Experiments ..........287 Lands improved ........ 26 Old field ............ 9

Seed for ............. 29

Soiling advisable.........124

New York Station fodder crops ..............126

Newman, Prof. C. L., report ................299

Nitro-cultures .........249

Nitrogen from roots...... 10

From soil .......... 52

Gathered ........190, 192

Gathered by cowpeas... 49

Not needed ........... 10

Old plants need none.... 60

Robbed by nurse crop... 58

Specially needed .......65

Sustains bacteria......6 60

Nobbe, discovery of bacteria ..............197

Nodules formed........... 59

North Carolina, experiments ............289

North Dakota, experiments

.................286

Turkestan alfalfa....... 8

Nova Scotia, alfalfa unknown ............. 15

Nurse crop, effects of cutting alfalfa ......... 59

Iowa $\ldots \ldots \ldots \ldots \ldots \ldots \ldots 257$

Or not? ............ 58

Nutrient values, various...145

Oat grass yields ........21 
Oat hay, analysis And aifalfa comi........127 Feed value ...........145 Oat straw feed value......145 Protein value .........133 Oats, sown with alfalfa.... 51 And peas, feed value... ............126, 132 As nurse crop ......... 58 Before reseeding......... 72 Frollowing alfalfa.......193 Feed value ............132 Foster weeds ......... 59

Ohio bulletin, seed....33, 34 Experiments .........290 Fall sowing ......... 53 Farmer sows thickly.... 58 Horse raising..........166 Pasturing lambs.........114 Preliminary seeding..... 51 Requisites in growing...225 seed for .............29 Oil meal and alfalfa compared .............140

Oklahoma, cutting ....... 89 Experiments ..........292 Pasturing ................113 Seed ................ 29 Field ............... 24 olmstead and Olmstead. report .............273

Ontario, lamb feeding.....173 Yield ............... 14

Orchard, alfalfa in.......223

Orchard-grass, yields .....2 21 Feed value ...........145 Protein value ...........133 With alfalfa ...........111 Oregon, experiments......295

Osborne County, Kansas...260

Otterson, James, report....252

Otis, Prof. D. H., feeding caws ..............144

Pasture for hogs.......163

Overfeeding horses........166

Over stocking with hogs...161

Panicum capillare, a weed... 69

Panicum sanguinale, a weed.. 68 Destroyinz ...........303

Parasites in purchased isoil ................6 62

Pasture, alfalfa in grass... 51 And soiling compared...123 And soiling compared...263 Grasses, feed value.......145

\section{Pasture, Continued}

PAGE

Horses ..............263

Lamb ............... 48

Only when established..108

Pig .................48

Poultry .............180

Sheep ...............263

Stock ..............24

Uplands ...............116

Pasturing ...............107

Cattle ................113

Horses ...............170

Previous to seeding....447

Rules for ............116

When to stop .........108

Pennsylvania, alfalfa introduced .............. 3

Bulletin, curing ....... 83

Experiments ..........297

Seed for ............. 29

Soiling advisable ........124

Perry, C. D., report......259

Physical effects, root growth ............ 6

Effects on soil .........21

Phosphoric acid needed... 65 Pig, See Hog.

Pigs, death rate reduced..155 Pigweed in seed ......... 35 Pinal County, Arizona....235 Pin-clover ...........227 Pittuck, Prof. B. C., report ...................297

Plantain in seed.........41 Plants smother in wet land ................ 44 Smothered under windrows .............. 84 Weak with nurse crops.. 58 Pliny praised alfalfa...... 1 Plow, character of tool....195 Plowing, deep, necessary...46

Difficult ............195 For other crops ........193

Importance of careful...195 Proper ..............221 Recent not good........ 50 Sod, rate of ..........195 Stand renewed by...... 72 Plowings saved .......... 21 Pods poorly filled .......89 89 Pork, producing cheap....158 Potash specially needed...65 Potatoes following alfaifa.193 Precede alfalfa .....48, 50 
Poultry thrive PAGE

Prairie

Injure alfalfa

Preparation, proper.......220

Soil ................4 46

Preparatory crops......49, 50

Presses for baling.........104

Press drills favored........ 56

Prices received $\ldots \ldots \ldots 22,23$

Profit reduced in feeding cows ............ 146

Profits ...22, 23, 25, 144, 147

Protection, winter ........108

From sun not needed... 58

Protein, abundance in alfalfa ..............125

And carbohydrates not interchangeable ......136

Digestible ............126

Excess in ration ........137

Function of..........134

Highest in first cutting..129

In clover ..........20, 21

Increased by irrigation.. 75

In early cuttings ......8 81

In hay ............. 76

Percentage in leaves..... 79

Values, various feeds....145

Provence, seed from...... 32

Prowers County, Colorado

$$
\text { ....................245 }
$$

Purgatives for bloat......122

Quebec, alfalfa in......... 15

Quicklime very caustic.... 66

Rain, cutting after....... 82

Hay-caps .............. 89

Rain-fall effect on hay... 75

Influence on seed.......28

Raiscot, Alfred, report.....271

Rake, Monarch .........262

Side delivery .........87

Time to start.......... 84

Range of soils ........16, 17

Rape, analysis ........127

And alfalfa for hogs compared ...............162

Ration, balanced .........134

Balanced, explained......135

Cost of .........150, 151

Money value ..........138

Unbalanced ............134

Receipts .......22, 23, 25

Recleaning seed, importance ................ 32
Recleaning to remove dodder ................. 42 Redding, Prof. R. J., report ..............250

Redtop and alfalfa compared ..............148

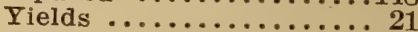

Renewing growth......... 71

Rentals of land ........... 26

Reseeding $\ldots \ldots 65,66,71,72$ Rhode Island, experiments

...................298

Rib grass in alfalfa seed. 41

Rice meal, food value.....132

Richmond, Indiana ......255

Rick, measuring for tonnage .............229

Preferred $\ldots \ldots \ldots \ldots \ldots \ldots . \ldots \ldots$

Roberts, Prof. H. F., adulterants ............. 35

Robinson, J. W., raises horses .............165

Rome, alfalfa taken to.... 1

Roofing for hay sheds..... 99

Root growth ...........190

Growth, physical effect.. 6

System ............. 6

Roots, deep ............ 6

Nitrogen in soil from.... 10

Spindling, with nurse crop .............. 58

Thumb-sized ......... 18

Value of $\ldots \ldots \ldots \ldots \ldots 21,191$

Rot, root .............212

Rotation necessary ........194

Roughness supplied by alfalfa ............. 18

Various kinds to feed.....145

Rural New-Yorker, article quoted ............ 17

Rutabagas, fodder value...126

Rye bran, food value.....132

Grass yields ..........21

Winter cover .........48, 49

Sacramento River, growth.241

Sagebrush land for ......252

Land, new alfalfa on.... 15

Sales .............22, 23

Salt River, irrigation....2236

Salt in storing hay.......100

San Mateo County, Califor-

nia ..............238

San Miguel County, New Mexico ............285 
Sand hills, Nebra falfa succeeds ......15, 17

Scott Bros., yield.......22, 23 Screened alfalfa seed recommended .......... 36

Scrub-oak land for........288

Seed, adulterated ........ 33 Analysis ............ 33

Bed, securing a fine..... 48

Bees insure fertile.......175

Best costly ...........4 41

Best from Provence..... 32 Buckhorn in........... 41

Bur clover in.......... 39

Bushel weight ......... 31

Characteristics ........ 37

Cheap ...........27, 41

'Conditions influencing germination ........ 57

Cutting time .......... 89

Damp ............... 27

Dodder described .......44

Dodder in ............ 32

Exports and imports.... 31

Fallures, imported..... 30

Farmer to blame for poor bought ........4 41

First cutting not for.....

For Illinois ......... 29

For Iowa ............ 2!

For Ohio ............ 29

For Pennsylvania ...... 29

Formation, bees help in. 176

Good costly .......... 29

Good, essential ....... 27

Harvesting ........... 89

Importance of pure...... 35

Impurities ........... 32

Imported, Department of Agriculture .........

Increased by bees ......175

Influences affecting ..... 28

Injuries by storing...... 30

Inoculation not needed.. 64

Insects in ........... 31

Introduced from Europe

K.................. 8

Kept several years...... 30

Kind to buy ........... 29

Large and small....... 38

Losses in stored........ 30

Moldy ............... 27

Nebraska ............ 29

Necessity of drying..... 9()
Seed, Continued

PAGE

New preferred ......... 30

Northern grown ....... 28

Noxious ................... 34

Oklahoma .......... 29

Old ................... 27

Plantain in ..................... 41

Pods, poorly filled....... 89

Poor, cause failures.....221

Precautions in buying... 29

Pure ................ 28

Purest in third cutting... 91

Quality of .................. 27

Quantity sowed.......24, 56

Raising, dry climate..... 28

Raising: humid climates

..............28, 92

Raising, Kansas ....... 90

Removing infertile...... 01

Removing weed .......99 91

Returns ..........22, 23

Rib grass in..........4 41

Roberts on pure........ 35

Selection .........27, 28

Sifting to remove dodder 42

Size of Bur clover ...... 39

Size of $\ldots \ldots \ldots \ldots \ldots \ldots 38$

Storing ..................... 31

Substitution of trefoil.... 39

Test before buying...... 29

Third crop self sown.... 72

Third cutting for .......99

Types of ............. 37

Utah vs. imported...... 30

Value in Arizona........2. 235

Vitality injured in stack. 90

Weed in alfalfa......... 34

Yield ............... 91

Yield, Arizona .........237

Seeding .............. 44

After disking unneces-

sary .............. 71

Alabama .............231

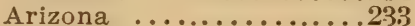

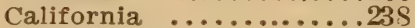

Colorado .............244

Drill or broadcast....... 55

Fall ............... 49

Importance of ........ 79

July ............... 66

Kansas ..............258

Manure before ........ 64

Pennsylvania .........297

Preliminary ......... 51 
Seeding, Continued

Soaking soil before......73

Seeder, Cahoon ........234

Gem .................242

Seeders, various..$\ldots \ldots \ldots 56$

Seeds dead ............. 27

Fertile few .......... 89

Seedsmen to blame for bad seed ............. 41

Selection of seed.........27, 28

Self sowing third crop..... 72

Self-binder, harvesting with

In seed harvest ................ 88

Selling inoculated soil.....61

Separator, J. I. Case.......237

Separators in threshing seed $\ldots \ldots \ldots \ldots \ldots \ldots 91$

Shed, hay .............. 99

Sheep, dangers to, from pasturing ........109, 113

Eat bindweed .........219

Fort Collins ..........174

Losses from bloat.......113

Old, kept off pasture....114

Shepperd, Prof. J. H., report ..............289

Sifting out dodder .......442

Silage for cows..........152

Storing as ..............101

Superior to hay.........151

Silo, advantages of using...151

Cost of ..............152

For alfalfa ..........101

Siloing suggestions.......102

Slings in stacking........994

Smead, Dr. D. C., horse feeding .............168

Smith, Prof. C. D., report..268

Smith, Prof. H. R., feed test ................139

Smothering under windrows .............. 84

In wet land ..........44

Snake River irrigation...25

Soaking soil before seeding ............... 73

Sod, breaking, for alfalfa.. 50 Hard to plow .........195

Soil acid, unfavorable..... 44

Acidity determined...... 45

Adobe ..............239

And seeding .......... 44

Baked, avoid .......... 46
Soil, Continued

PAGE

Bur clover for inoculating...$\ldots \ldots \ldots \ldots .60$ Buying inoculated ....60, 61 Buying not necessary....61 Buying infected .......6 60 Buying, objections to....61

Character affects irrigation ............ 77

Conditions demanded.... 52 Conditions essential......46

Depleted, improved ..... 16

Diseased, for inoculation. 62

For alfalfa ......... 15

Gumbo ..............261

Hardpan .............. 16, 18

Improved by alfalfa..16, 190

Improvement due to alfalfa ............. 16

Inoculated for sale.....6 61

Inoculated, quantity to acre .............6 61

Inoculation .......59, 197

Inoculation, dangers of. . 62

Inoculation, meal or hay for .............63 63

Inoculation, not necessary $\ldots \ldots \ldots \ldots \ldots 63,64$

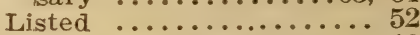

Never work wet....... 46

Not exhausted by alfalfa ................. 10

Preparation .......46, 297

Preparing, Arizona.233, 236

Preparing, Colorado.....243

Preparation, Washington ....................314

Restrictions, obsolete..... 44

Robbed of lime.........44

Rocky ............. 19

Sugar tree land..........25.

Waxy .............. 52

Wet makes failures..... 44

Soiling ...........107, 122 Advised in East..........124

And pasturing compared

...................123

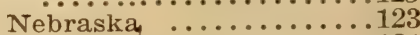

Pigs ................124

Sorghum analysis ..........127

Bad to precede alfalfa.. 49

Consumes moisture...... 49

Fails to increase milk

flow ...............148

Fed with alfalfa.........125 
Sorghum, Continued

Feed value ...........145

Hay, feed composition...136

Protein value .........133

Soule, Prof. Andrew M., report .................311

South Africa, alfalfa in.... 15

South Carolina, experiments in...........299

Old field .............. 9

South Dakota, experiments

..................300

South favors spring sow-

ing $\ldots \ldots \ldots \ldots \ldots \ldots 52$

Land values increased..205

Sowing time .........47

Southern farms, self supplied ............. 14

Southern seed .......... 28

Sowing dates ............ 47 Fall ...........49, 53

Foul land ............. 59

Spring disadvantages.... 5.3

Spring or fall?........52

Spring, on wheat ground

Points to remember.....48 48

Points to remember...... 47

Time, South ........4 47

Time, Central States.....47

Sows, brood, Mississippi...155

Like alfalfa .........154

Soy beans, feed value.....145

Feed composition........137

Spain, alfalfa introduced.1, 2

Takes alfalfa to America

................... 2

Spillman, Prof. W. J., opinion ............ 9

Spontaneous combustion, See Fire.

Spot, leaf .211

Spots, bare, in lodged nurse crop ............. 59

Restoring bare........ 71 Spotted leaf, mowing for.. 67

Spring or fall sowing?... 52

Spring sowing, disadvantages ............... 53

Sowing favored ........ 53

Sowing, importance of early .............. 58

Spurrier on alfalfa........

Favors drills ........67

Stack, curing in.........90

Elevate bottom of.......100
Stack, Continued

PAGE

Fires in ............ 95

Protect top .............100

Sweating in .......... 90

Stacks, condemned ....... 99

Covering seed .........990

Preventing mold in...... 90

Stacker, Landen .........235

Stacking, conditions......100

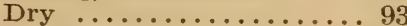

In ricks ........... 259

Losses from ..........98

Operations in ........ 87

Precautions .......... 90

Seed crop .......... 89

Slings recommended..... 94

Stadmueller, F. H........248

Stand, ideal ........... 57

Improving . .........667

Increasing ........... 51

Plowing to renew....... 72

Poor .........27, 30, 54

Securing good ........220

Thickening .......... 72

With nurse crop ....... 5s

Starch in corn........... 22

Needed by bacteria.....6 60

Steers pick up on alfalfa...125

Stellaria media, destroying..297

Stems and leaves, food value compared ..... 82

Stewart, Prof. J. H., report ..............310

Stock, best way to market alfalfa ............137

Fed, Utah ............ 25

Injure alfalfa .........107

Keep off field ........221

Stodder, J. F., bloat.......112

Storer, Prof. F. H., haycaps ............85, 86

Storing ............... 93

As silage .............101

In barn ............ 95

In evening.......... 97

seed ................ 31

Stover and alfalfa com-

pared .........140, 148

Fed, with alfalfa...125, 144

Protein value ..........133

Straw, feed value..........145

Feeding value, Colorado

.................245

For stack feed........... 91 
Straw, Continued

PAGE

Money in ..........22, 23

On damp hay .........99 97

Protein value ..........133

Value of...........91, 240

Stubble, value of......21, 191

Stubbs, Dr. W. C., experi-

ments .............265

Subsoil, tough, roots in... 18

Subsoiling effects of alfalfa

$\ldots \ldots \ldots \ldots \ldots \ldots$......... 194

Substitute for alfalfa...... 36

Substitutes, recognizing ...4 40

Substitution of trefoil for alfalfa ........... 39

Success depends on cultivation ...............44

Typical in New York.... 17

Sugar and alfalfa..........185

Sugar beet dependent on alfalfa ...........173

Sugar beets, feed value....

$$
\text { ...............126, } 145
$$

Protein value .........133

Sugar, losses in hay...... 81

Sun not greatest curing agent ............. 83

Swath, alfalfa lying in.... 84

Sweating before baling....103

In stack ............ 90

Sweet clover in alfalfa seed ................. 32

Clover soil for inoculation ...............60, 202

Swine, See Hogs.

Swing seeder ...........56

Synoground, N. O. P., re-

port ...............302

Syracuse, alfalfa near.... 17

Sysonby eats alfalfa......167

Taliaferro, Prof. W: T. L. opinion ........... 16

Tapping for bloat ........119

Taproot ............... 6

Taylor, Prof. Frederick W., report ............279

Tedder, loss from using... 84

Starting ............ 84

Ten Eyck, Prof. A. M., burning weeds .......6 69

Dimensions of ton.......229

Hay ................ 76

Hay composition........ 75

Silo composition................ 102

Tennessee, experiments....302
PAGE

Testing soil for acidity.... 45

Texas, alfalfa cut nine times ............... 10

Alfilaria for ...........228

Bulletin, feed stuff......127

Curing ............. 87

Cutting ............... 89

Experiments ............303

Yields ............. 9

Thawing, harm from..... 50

Thickening stand........ 72

Thompson, W. O., report..275

Thorne, Prof. Charles E., report ............290

Threshing made easy......99

Time between cuttings..... 24

To cut ..............89

To sow .............. 47

Timothy and alfalfa compared..21, 79, 127, 148, 222

Alfalfa sown with..... 51

Before alfalfa ......... 50

Fodder value..126, 132,145

Protein value ..........133

Ton, cubic feet in.......229

Top-dressing annual......70 70

Benefit of............74

Trampling, effects of..... 59

Transportation, s o l vi n g problems ............186

Trefoil seed in alfalfa..... 32

Yellow, adulterant ...... 33

Yellow, in alfalfa...... 36

Yellow, beak on seed.... 39

Yellow, chief adulterant. 35

Yẻllow, distinguished ... 39

Yellow, size of seed .... 38

Yellow, to distinguish seed .............. 37

Yellow, recognizing seed. 39

Trocar for bloat ........ 119

Tubercles formed ....... 59

Office of .............197

Turkestan, alfalfa ..... 7, 29 Alfalfa, North Dakota.. 8

Alfalfa, South Dakota...300

Turnips, feed value .......145

Utah bulletin, nutrients ...131

Bulletin, various cut-

tings .............128

Bulletin, irrigation .... 74

Bulletin, Utah County,

Utah ..............306

Co-operative wark ...... 76 
Utah, Continued

Dates of cutting ..... 78

Experiments .............304

Experiments, early cutting ............... 81

Fall sowing ......... 53

Feeding test ..........138

Hardy seed ..........992

Hay, composition ......76 76

Horsefeeding ..........168

Reports profits .......25

Seed ............... 29

Seed not favored ......92

Seed sown by Cottrell ... 30

Shoat raising ........156

Water applied in ...... 77

Value, leaves ........... 79

Straw ..............91

Poorly cured hay ..... 87

Values received ......... 25

Feed, various .........145

Varieties .............. 6

Alleged ............. 28

Ventilation in hay shed ...999

Vermont, experiments..15, 309

Virginia, experiment ......311

Vitality, injured in stack.. 90

Voorhees, Dr. E. B., report ............280

Wallace, Henry, spring sowing ............. 54

Wallaces' Farmer, spring sowing ............. 54

Walla Walla County, Washington .....307, 314, 315

Wallingford, Connecticut..248

Washing, soil, prevented... 48

Washington, yield ......10, 23

Experiments .........314

Waste, feeding cows .... ...........144, 146, 152

Water, effect on hay composition ........... 76

Cold, delays growth ....73

Too much irrigation .... 72

Effects on composition of hay ............74, 75

Quantity to acre, Utah.. 77

Eighty feet below surface ..............44 44

Amount required, Arizona .............234

Watrous, Prof. F. L., alfalfa in orchards ....223
Watson, Prof. George PAGE report ...........297

Watson ranch, horses fed alfalfa ............166

Wayne County, Indiana....254

Weed seeds in alfalfa...... $\ldots \ldots \ldots \ldots 32,27,34,41$ Seeds, removing ........ 91

Weeds, burning .........69 69

Carried by soil .......663

Chief enemies ...........206

Failures due to ........48

Fewer in third cutting.. 91

In hors pasture .......110

Keeping down .........4 47

Kill, before seeding ...206

Not prevented by nurse crop ..............59

Poor farming causes ...206

Preventing .............47

Repressed ...........4 46

Retarded by clipping ... 68

Subduing in July.......66 66 Weevils in seed ............ 31

Weight of bushel ......... 31

West Virginia, experiments,

Wet feet, alfalfa can't stand.........18, 44, 212

Wetting delays curing .... 81

Wheat and alfalfa compared ............19, 25

Following alfalfa .......193

Increasing yield ........194

Straw, protein value ....133

With alfalfa ..........51

Wheelbarrow seeder ...... 56

Wheeler, Dr. H. J., report..298

Widtsoe, Prof. J. A., nutrients ............131

Wilcox, Lute, quoted ...... 73

Williams, C. H., pasturing sheep .............114

Wilson, Prof. James W., report .............300

Wing, Joseph E. .......290

Curing ............... 83

Horse raising ..........166

Pasturing lambs ........114

Preliminary seeding ....5 51

Windrows, curing in ..... 87

Leaving hay in ........ 84

Smothering under ..... 84

Wisconsin, brood sows ....155 
Wisconsin, Continued

Report .............317

Time to sow ........47

Wintering sows .......156

Yield ...........9, 23

Witch-grass less bad than crab grass ........6 69

Woodford, J. E., hog raising .................163

Work animals, alfalfa for.. 14

Worker's, grange meeting at Mr. ............ 18

Worm, army ..........219

Worn-out soils restored ... 16

Wyoming, fertilizing value of alfalfa .........192

Experiments ...........322

Seed ...............29

Xerxes carried alfalfa to Greece ............. 1

Yield, acre ...........126 Affected by irrigation ... 77 Alfalfa and grass compared .............21 Arabian alfalfa ....... 8 Arizona ..............234

Below sea level ....... 15 Best when no nurse crop. 59 Butter, pasture and soiling ..............123 Compared with clover... 20 Corn and alfalfa ....... 22 District of Columbia .... 14 1815 ............... 3 Fodders, various .........148
PAGE

Increased by irrigation .. $\mathbf{7 4}$

Indiana ............ 24

Irrigations affect $\ldots \ldots \ldots 77$

Irrigated land .......10, 23

Largest annual .........128

Louisiana ..............14

Manitoba ........... 14

Maximum under irrigation ............. 78

Medicine Hat ......... 14

Milk increased ........146

Minnesota ............ 14

New Jersey ..........20

Not impaired by hogs...108

Oklahoma ............24

Ontario ............. 14

Reduced by wrong cutting ............... 80

seed $\ldots \ldots \ldots \ldots \ldots \ldots .91$

South Africa .......... 15

Turkestan, North Dakota .............. 8

Twelve tons under irrigation .............. 72

Washington .......... 10

Wisconsin ............. 23

Yields, big, poor land ...6 65

Irrigation, Utah ...... 78 Profitable ...........22, 23

Texas ............... 9

Wisconsin ........... 23

Zoller, Isaac, report .....287 
JUL. 3.1907 

LIBRARY OF CONGRESS

|||||||||||||||||||||||||||||||||||||||||||||

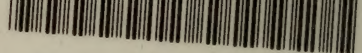

00009304113 